\title{
STUDY ON HYDRODYNAMICALLY INDUCED DRYOUT AND POST DRYOUT IMPORTANT TO HEAVY WATER REACTORS
}

by

Mamoru Ishii, Shripad T. Revankar, Sidhartha Nair, Sandeep Lele, Cris S. Eberle and Ibhrahim Babelli.

\section{DISCLAIMER}

This report was prepared as an account of work sponsored by an agency of the United States Government. Neither the United States Government nor any agency thereof, nor any of their employees, makes any warranty, express or implied, or assumes any legal liability or responsibility for the accuracy, completeness, or usefulness of any information, apparatus, product, or process disclosed, or represents that its use would not infringe privately owned rights. Reference herein to any specific commercial product, process, or service by trade name, trademark, manufacturer, or otherwise does not necessarily constitute or imply its endorsement, recommendation, or favoring by the United States Government or any agency thereof. The views and opinions of authors expressed herein do not necessarily state or reflect those of the United States Government or any agency thereof.

PURDUE UNIVERSITY

SCHOOL OF NUCLEAR ENGINEERING 


\section{DISCLAIMER}

Portions of this document may be illegible in electronic image products. Images are produced from the best available original document. 
PURDUE UNIVERSITY

SCHOOL OF NUCLEAR ENGINEERING

Study on Hydrodynamically induced dryout and post dryout important to heavy water reactors.

by

M.Ishii, S.T. Revankar, S. Nair, S. Lele, C.S. Eberle and I. Babelli

Thermal Hydraulics and Reactor Safety Laboratory

January 1995

Work supported by

U.S. Department of Energy

Office of Energy Research

1290 Nuclear Engineering Building, West Lafayette, IN 47907, U.S.A. 


\section{TABLE OF CONTENTS}

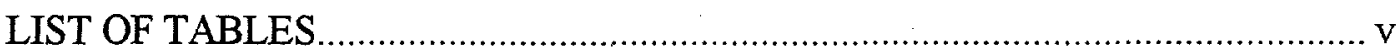

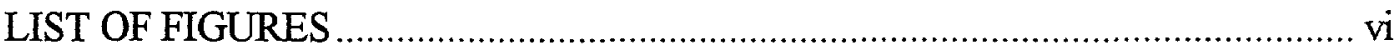

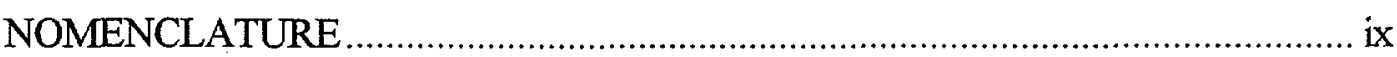

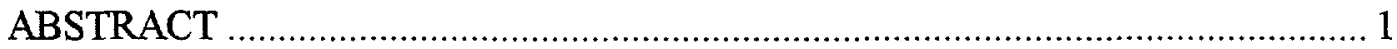

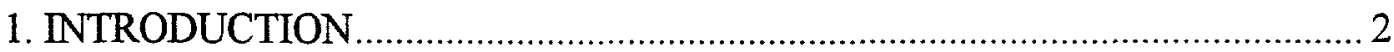

2. CHF UNDER LOW FLOW AND LOW PRESSURE CONDITION ................... 4

2.1 State of the Arts Review ................................................................................. 4

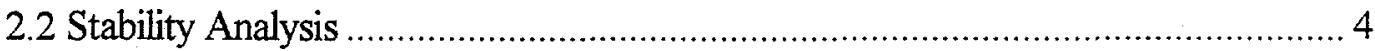

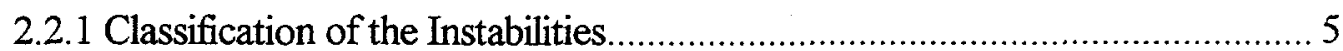

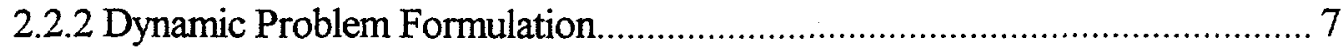

2.2.3 Method of Solution ............................................................................... 10

2.2.4 Important Non-Dimensional Parameters ............................................ 13

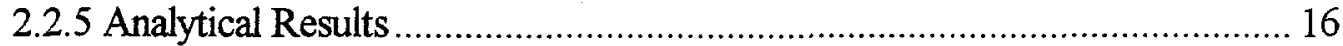

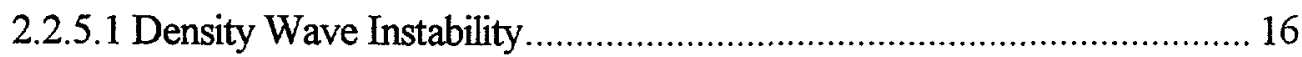

2.2.5.2 Flow Excursion Instability ......................................................... 17

2.2.5.3 Flooding and Flow Regime Transition .......................................... 18

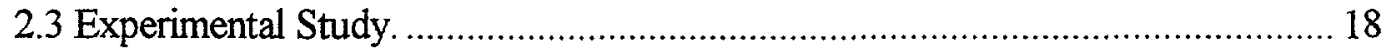

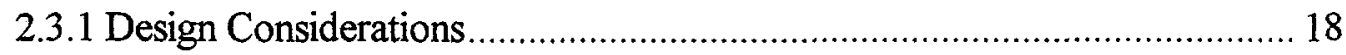

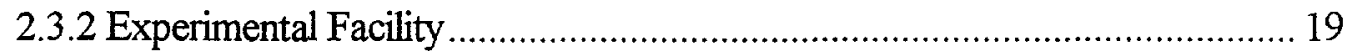

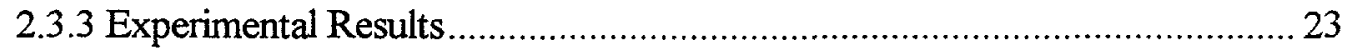

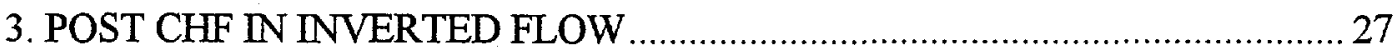

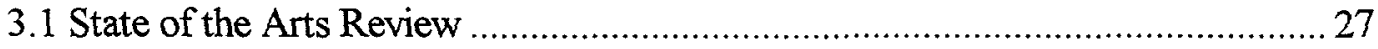

3.2 Experimental Apparatus and Procedures..................................................... 29

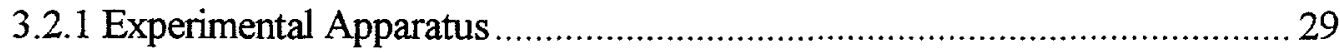

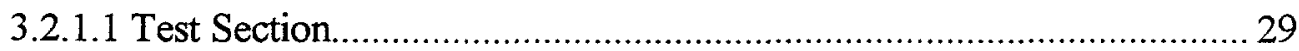


3.2.1.2 Heat Transfer Delivery System.............................................................. 30

3.2.1.3 Freon Delivery and Recovery System …………................................. 30

3.2.1.4 Pressure Measurement ..................................................................... 31

3.2.1.5 Liquid Velocity Measurement ………………..................................... 31

3.2.1.6 Temperature Measurement ................................................................ 31

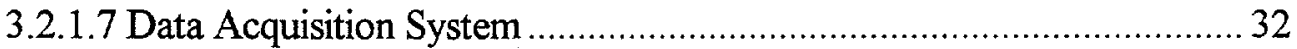

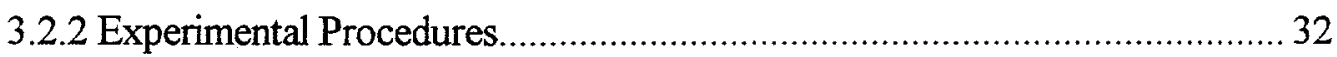

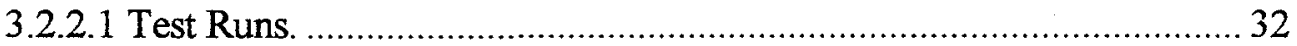

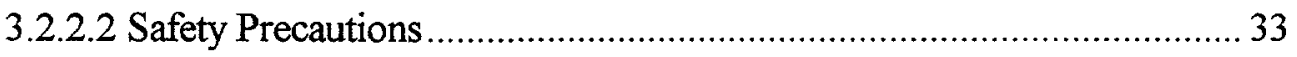

3.2.2.3 Closed Loop Operation ....................................................................... 34

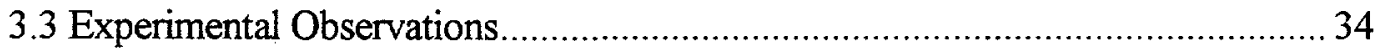

3.3.1 Rewetting Front Experimental Results................................................... 34

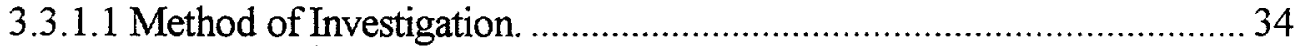

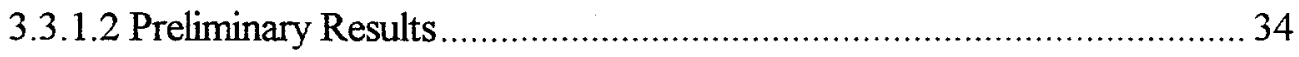

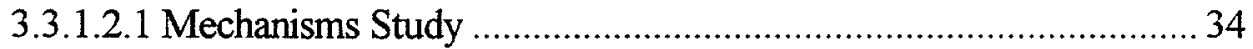

3.3.1.2.2 Quench Front Propagation Analysis ........................................... 37

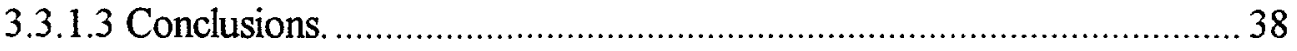

3.3.2 Inverted Annular Experimental Results ...................................................... 38

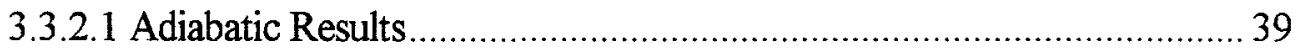

3.3.2.1.1 Experimental Test Matrix......................................................... 39

3.3.2.1.2 Adiabatic Flow Regime Criteria Modifications............................ 40

3.3.2.1.3 Analysis of Adiabatic Break-up Length Results ........................... 41

3.3.2.1.4 Mechanistic Model Development ................................................. 44

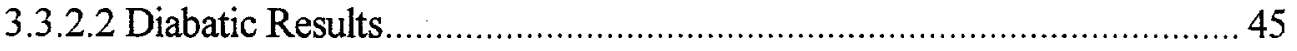

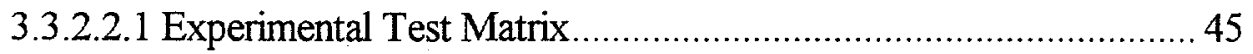

3.3.2.2.2 Analysis of Diabatic Break-up Length........................................... 46 
3.3.2.2.3 Diabatic Dimensionless Break-up Length Results ......................... 48

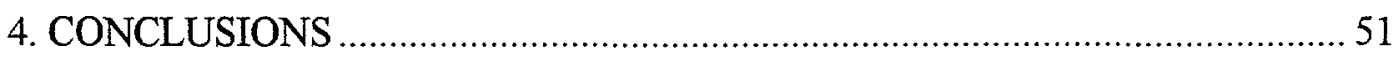

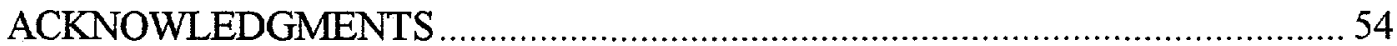

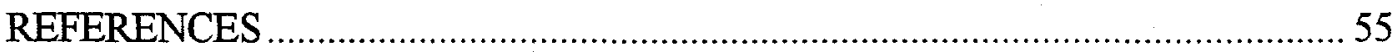




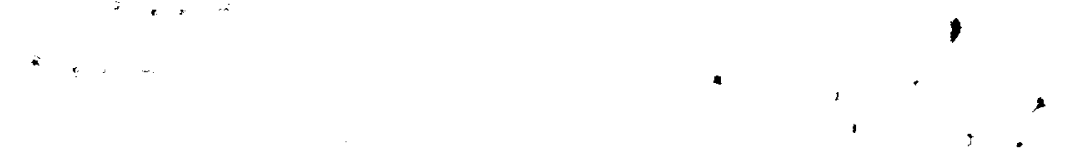

\section{LIST OF TABLES}

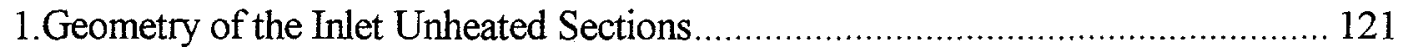

2.Parameters for prototype (Fuel-Target) and model. ........................................ 122

3.Parameters for prototype (Fuel-Fuel) and model.............................................. 123

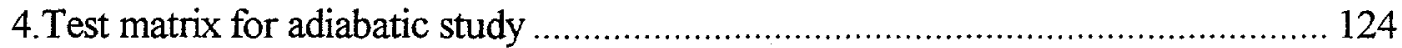

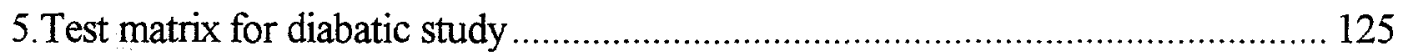

6.Statistical analysis of a large break-up maximum deviation case ........................... 126

7.Break-up length estimates of the large fluctuation visualization data ................... 127 


\section{LIST OF FIGURES}

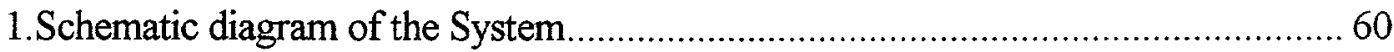

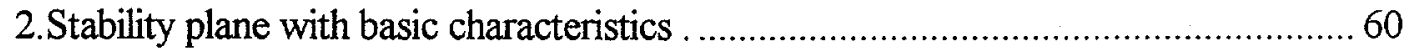

3.Stability boundary (a) for flow excursions, (b) for density wave oscillations, (c) both instabilities together

4.Effect of inlet velocity on the stability boundary (a) for flow excursions, (b) for density wave oscillations. 63

5.Effect of inlet throttling on the stability boundary (a) for flow excursions, (b) for density wave oscillations. 64

6.Effect of exit throttling on the stability boundary (a) for flow excursions, (b) for density wave oscillations.

7.(a) Effect of system pressure on system stability, (b) simple stability criterion and stability boundary for density wave oscillation. 66

8.Internal pressure drop as a function of inlet flow. 67

9.Inlet flow as a function of heat flux : (a) $\Delta p_{\text {ext }}=1.2 \times$ hydrostatic head, (b) $\Delta p_{\text {ext }}=$ $1.1 \mathrm{x}$ hydrostatic head. 68

10.Hypothetical operation curve: (a) with flow excursion stability boundary, (b) with density wave oscillation stability boundary. 69

11.Hypothetical operation curve: (a) churn-turbulent to annular flow regime transition based CHF criterion, (b) flooding based CHF criterion 70

12.CHF correlation's for prototype system 71

13.CHF correlation's for model system. 71

14.The similarity scaling of velocity between prototype and model. 72

15.The CHF scaling between the prototype and the model. 72

16.Schematic diagram of Purdue CHF experimental facility 73 
17.Test section and location of the heater thermocouples

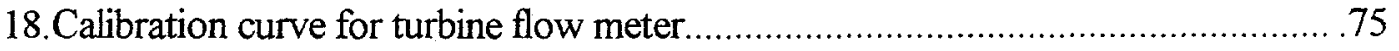

19. Calibration curves for the differential pressure transducers ............................. 76

20.Photograph of Purdue CHF Experimental Facility ....................................... 77

21. Test section flow rate vs. time for different heater powers ............................... 78

22. Test section mean flow rate vs. heater powers ............................................ 78

23. Inlet fluid temperature for different heater powers ......................................... 79

24.Outlet temperature of the fluid for different heater powers ............................... 79

25.Pressure drop across the test section for different heater powers ......................... 80

26.Photograph of the test section at liquid velocity of $35 \mathrm{~cm} / \mathrm{s}$, heater power of $1.5 \mathrm{~kW}$

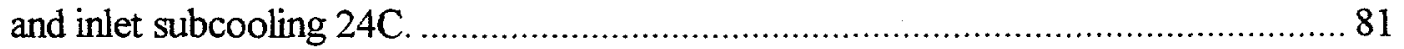

27.Photograph of the test section at liquid velocity of $25 \mathrm{~cm} / \mathrm{s}$, heater power of $2.5 \mathrm{~kW}$

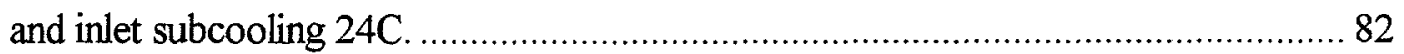

28.Photograph of the test section at liquid velocity of $20 \mathrm{~cm} / \mathrm{s}$, heater power of $3.5 \mathrm{~kW}$

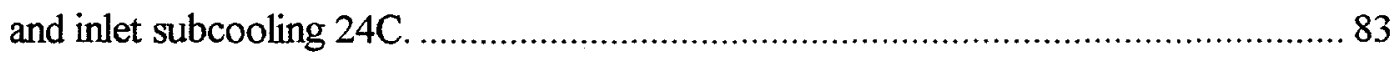

29.Heater surface temperature at inlet and exit : (a) for Run\#9 and (b) for Run\#46... 84

30.Main and Bypass flow rates : (a) for Run\#9 and (b) for Run\#46........................ 85

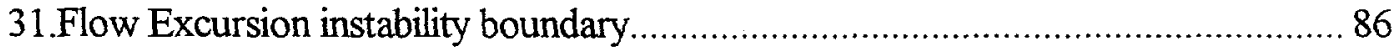

32. Illustration of flow regimes in the post dryout region.................................... 87

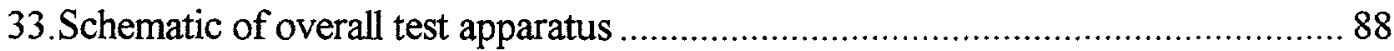

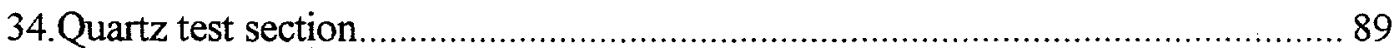

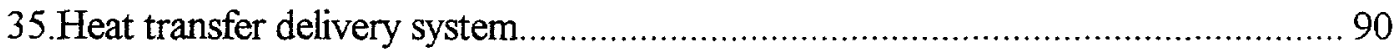

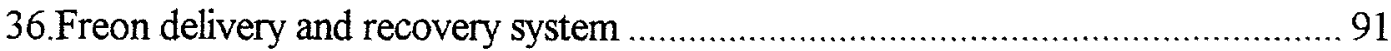

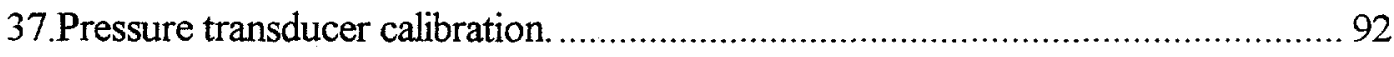

38. Temperature measurement during oscillation phenomena................................ 93

39.Pressure measurement during oscillation phenomena...................................... 94 
40. Temperature measurement during oscillation phenomena. 95

41.Pressure measurement during oscillation phenomena....................................... 96

42. Quench front propagation data, $23 \mathrm{C}$ subcooling ........................................ 97

43. Quench front propagation data, $28 \mathrm{C}$ subcooling ......................................... 98

44. Vertical up-flow quench front propagation data.......................................... 99

45.Quench front Average Propagation speed (a) up-flow (b) down-flow ................ 100

46.Example of an inhibited or stalled quench front.......................................... 101

47.Example of an accelerated quench front................................................. 102

48.An example of a typical time series for the break-up length ........................... 103

49.Break-up length data for time series F7.1 .............................................. 104

50.Average break-up length versus sample size for F7.1 data ............................ 105

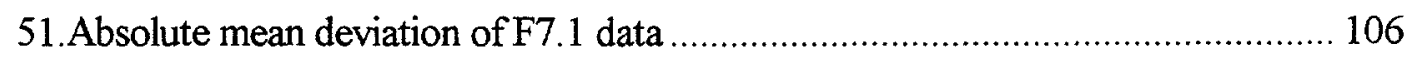

52.Comparison of break-up data for various gas velocities ................................ 107

53.Comparison of average break-up data for various gas velocities ...................... 108

54.Comparison of absolute mean deviations for various gas velocities .................. 109

55.Adiabatic results of $\mathrm{L}_{\mathrm{b}}$ versus $\mathrm{v}_{\mathrm{g}}$ data including mean and standard error ........... 110

56.Comparison of Eberle and De Jarlais Adiabatic data .................................... 111

57.Comparison of adiabatic differential pressure time series ............................ 112

58.Dimensionless break-up length for Adiabatic data.......................................... 113

59.Two break-up filming view windows for H69 data series. ............................. 114

60.Comparison of diabatic differential pressure time series ................................ 115

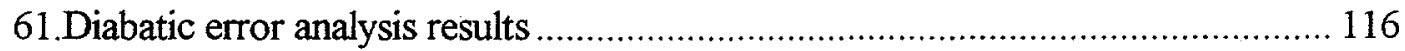

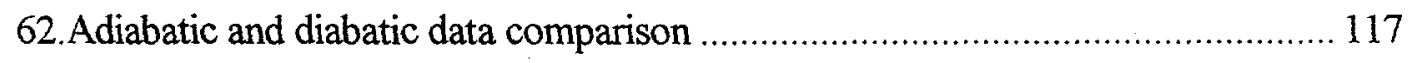

63.Denten et. al. axial extent data for upflow [23] .......................................... 118

64.Diabatic break-up length as a function of subcooling ..................................... 119

65.Dimensionless break-up length versus modified gas Weber number .................. 120 


\section{NOMENCLATURE}

\begin{tabular}{|c|c|}
\hline A & channel cross sectional area \\
\hline a & amplitude of oscillation \\
\hline $\mathrm{b}$ & growth rate of disturbance \\
\hline $\mathrm{C}$ & friction factor multiplier \\
\hline $\mathrm{Ca}$ & capillary number \\
\hline $\mathrm{C}_{\mathrm{o}}$ & distribution parameter \\
\hline $\mathrm{Cr}^{*}$ & ratio of $c_{k}$ at $z=\lambda$ and 1 \\
\hline$c_{\mathrm{k}}$ & kinematic wave velocity \\
\hline $\mathrm{D}$ & hydraulic diameter, jet nozzle diameter \\
\hline $\mathrm{f}$ & friction factor \\
\hline$f$ & sample frequency \\
\hline $\mathrm{g}$ & gravitational acceleration \\
\hline $\mathrm{I}$ & inertia \\
\hline $\mathrm{i}$ & enthalpy \\
\hline $\mathbf{i}_{1}$ & heated section inlet liquid enthalpy \\
\hline $\mathbf{i}_{\text {sub. }}$ & subcooling $\left(\mathrm{i}_{\mathrm{fs}}-\mathrm{i}_{1)}\right)$ \\
\hline$i_{f g}$ & latent heat \\
\hline $\mathrm{j}$ & volumetric flux \\
\hline $\mathrm{K}$ & wave number \\
\hline $\mathrm{k}$ & loss coefficient \\
\hline $\mathrm{L}$ & distance, axial extent of flow regime \\
\hline $\mathrm{L}_{\mathrm{B}}$ & number of break-up-events \\
\hline 1 & distance \\
\hline $\mathrm{N}$ & number \\
\hline $\mathrm{N}_{\text {pch }}$ & Phase change number \\
\hline $\mathrm{N}_{\mathrm{d}}$ & Drift number \\
\hline$N_{\rho}$ & Density number \\
\hline $\mathrm{N}_{\mathrm{G}}$ & Geometry number \\
\hline $\mathrm{N}_{\mathrm{Fr}}$ & Froude number \\
\hline $\mathrm{N}_{\text {sub. }}$ & Subcooling number \\
\hline$N_{\text {Res }}$ & Reynolds number based on inlet velocity \\
\hline$P_{\text {system }}$ & system pressure \\
\hline $\mathrm{p}$ & probability \\
\hline $\mathrm{Q}(\mathrm{s})$ & characteristic transfer function \\
\hline $\mathrm{q}_{0}^{\prime \prime}$ & heat flux \\
\hline $\mathrm{s}$ & perturbation parameter \\
\hline$t$ & time \\
\hline
\end{tabular}


V

$\mathrm{v}_{\mathrm{gj}}$

We

w

$\mathrm{x}$

$\mathrm{Z}(\mathrm{s})$

Z

\section{Greek Symbols}

$\alpha$

$\Gamma_{\mathrm{k}}$

$\delta_{\mathrm{o}}$

$\delta(\mathrm{x})$

$\Delta \mathrm{p}$

$\Delta \mathrm{i}_{\mathrm{fg}}$

$\varepsilon$

$\Lambda$

$\lambda$

$\mu$

$\xi$

$\rho$

$\Delta \rho$

$\sigma$

$\tau$

$\omega$

$\Omega$

\section{Subscripts}

c

e

f

fi

fs

$\mathrm{g}$

gs

i

J velocity

drift velocity

Weber number

mass flux

quality

shifted characteristic equation

streamwise coordinate

void fraction of gas phase

mass generation for $\mathrm{k}$ phase

initial disturbance

perturbation on $x$

pressure drop

latent heat of evaporation

surface roughness

transfer function

length at boiling point

viscosity

heated perimeter

density

density differences between the phases

surface tension

resident time

frequency of oscillation

reaction frequency

value at orifice throat

at exit

liquid phase

at the inlet of heated section

saturated liquid

gas phase

saturated vapor

value at inlet section

jet nozzle 


$\begin{array}{ll}\mathrm{m} & \text { mixture } \\ \mathrm{me} & \text { mixture in the unheated exit section } \\ 01 & \text { inlet unheated region [A] } \\ 12 & \text { heated liquid region [B] } \\ 23 & \text { heated mixture region }[\mathrm{C}] \\ 34 & \text { exit unheated region [D] } \\ \mathrm{pch} & \text { phase change } \\ \mathrm{Re} & \text { Reynolds } \\ \mathrm{S} & \text { at saturation } \\ \mathrm{Sub} & \text { subcooling }\end{array}$

Superscripts

$-$

mean or averaged value

non-dimensionalized quantity 


\title{
HYDRODYNAMICALLY INDUCED DRYOUT AND POST DRYOUT IMPORTANT TO HEAVY WATER REACTORS
}

\author{
by \\ M. Ishii, S. T. Revankar, S. Nair, S. Lele, C.S. Eberle and I. Babelli.
}

\begin{abstract}
Recently, the safety of low pressure liquid cooled nuclear reactors has become a very important issue with reference to the operation of the heavy water reactors at Savannah River Plant. Under accident conditions such as loss-of-flow or loss-of-coolant, these reactors typically encounter unstable two-phase flow which may lead to the occurrence of dryout and subsequent fuel failure. An analytical study using the one-dimensional drift flux model was carried out to investigate the two-phase flow instability for Westinghouse Savannah River Site reactor. The analysis indicates that the first and higher order instabilities exist in the possible transient operational conditions. The instabilities are encountered at higher heat fluxes or lower flow rates. The subcooling has a stabilizing effect except at very low subcooling. An experimental loop has been designed and constructed. A study was conducted on the CHF induced by various flow instabilities. Details of this test loop are presented.

The two-phase flow regimes and hydrodynamic behaviors in the post dryout region have been studied under propagating rewetting conditions. The overall experimental portion of this research was divided into two parts which included a quench front propagation data series and an inverted annular break-up length data series. The quench front research was used to investigate post dryout mechanism. Visualization and flow field data were taken simultaneously. The result provide a mechanistic means for evaluating heat transfer influences on the break-up length as a function of fluid subcooling. The most significant result for the diabatic break-up length was that global system changes, such as pressure fluctuation, cause severe decreases in the break-up length. This causes transition from inverted annular to inverted slug flow sooner than previous studies predicted. The effect of subcooling and inlet velocity on flow transition as well as on the quench front propagation was investigated. The test liquid was Freon 113 which was introduced into the bottom of the quartz test section whose walls were maintained well above the film boiling temperature of the test liquid, via a transparent heat transfer fluid.
\end{abstract}




\section{INTRODUCTION}

The phenomena of critical heat flux (CHF) results in a build up of an insulating vapor layer on the surface of the heater. This leads to abrupt reduction in heat transfer rate and rise in the heater surface temperature, that may lead to material failure of the heater. Generally the CHF mechanism under flow boiling conditions can be classified in to two categories depending on the vapor quality. At low vapor quality, the CHF is noted by a transition from nucleate boiling to film boiling. This is also called departure from nucleate boiling (DNB). This typically occurs at high pressure and/or high coolant mass velocities. On the other extreme at high vapor quality the CHF occurs mainly by dryout process where prior to reaching CHF the heater surface is covered by thin layer of liquid, while the bulk of the coolant flow consists of mixture of vapor and entrained liquid droplets. As the heat flux increases the thickness of the liquid layer decreases due to evaporation. With enough heat flux the surface dries out causing abrupt rise in heater surface temperature. Typically this dryout CHF occurs in constrained geometries and at saturated or near saturated flow conditions. The values of dryout CHF are lower than the DNB type CHF which occur at low vapor qualities. The dryout CHF is very important at low pressure and low flow conditions. Because at these conditions various flow instabilities due to boiling occur and lead to premature CHF situations [1,2].

Recently, the safety of low pressure liquid cooled nuclear reactors has become a very important issue as demonstrated by the heavy water reactors at Savannah River Plant (SRP). Because the design of the SRP reactors differs significantly from commercial reactors, the safety analysis methodology developed for the commercial reactors can not be applied directly to the SRP reactors. Under accident conditions such as loss-of-flow or loss-ofcoolant, these reactors typically encounter unstable two-phase flow which may lead to the occurrence of dryout and subsequent fuel failures. These hydrodynamically induced CHF phenomena under forced convection at low pressure (large density ratio) and low flow conditions are quite different from those well understood CHF phenomena [3-5].

There are many diverse areas in both engineering design and basic research in which post-dryout can occur and knowledge about the phenomena is essential in order to provide an accurate analysis of the system. Beyond CHF, the direct liquid/solid contact can not be sustained and this leads to much higher temperatures for the heaters/fuel assemblies. However, the ultimate failure of the fuel assemblies depends on the post dryout heat transfer and duration of dryout. There are recent experimental indications that the post dryout heat transfer can be relatively high at low qualities [6-8]. This may delay the timing of the burnout or mitigate the fuel failure under certain conditions. It should be noted that the hydrodynamically induced CHF are not limited to the downward flow systems.

In spite of the importance of the coolability limit imposed by the CHF and post CHF heat transfer under low flow and low pressure conditions, the main emphases of reactor safety 
analyses both for water and liquid-metal cooled reactors have been directed to more drastic accident conditions where natural convection boiling or low flow hydrodynamically induced CHF are of little importance. It can be recognized that the low flow CHF phenomena is important in several key areas:

1) Safety analysis of existing and new production reactors or research reactors

2) Safety analysis of liquid metal cooled reactors

3) Safety analysis of decay heat removal by natural convection boiling in conventional light water reactors.

Only recently, the importance of the CHF phenomena at low flow and low pressure has been recognized. However, the state-of-the-art indicates that a clear understanding of these phenomena has not been attained yet. Well designed experimental studies to generate benchmark data as well as careful mechanistic modeling are needed to develop reliable predictive method for those phenomena. In relation to isotope production reactors, the post dryout heat transfer and two-phase flow are very important due to occurrences of the premature dryout caused by the hydrodynamic instabilities.

The report is aimed at developing a clear understandings and reliable predictive methods for the low flow CHF phenomena and post dryout heat transfer at low pressures. A particular focus is on the hydrodynamically induced dryout and subsequent post dryout phenomena at down flow conditions. 


\section{CHF UNDER LOW FLOW AND LOW PRESSURE CONDITIONS}

\subsection{State-of-the-Art Review}

Barnard et al. [9] investigated dryout flow rate for an upward flow of Freon-113 in a vertical tube. They classified the burnout mechanisms into five types. When the flow passages are substantially filled with liquid, the burnout will occur due to the vapor production by boiling which prevents liquid from reaching the heated surface. This is the well-known pool boiling burnout. Flooding limited burnout occurs at zero net flow through the flow passage when the vapor flow prevents a sufficient downward flow of liquid [10]. When the flow rate through the flow passage is not zero, but very low, all liquid entering into the passage from the bottom will be evaporated and the vapor flow will prevent liquid flowing down from the top. In this case, the dryout occurs when the vapor quality approaches $100 \%$. This is called a circulation limited burnout. For higher flow rates, a substantial amount of the liquid will be entrained by the vapor flow, which causes dryout at vapor qualities less than $100 \%$. This is so called entrainment burnout. The last two types have often been referred to as a basic mechanism of burnout in annular two-phase flow [11]. However, the observations by Mishima and Ishii $[3,4]$ indicated the possibility of burnout caused by the flow regime transition from churn-turbulent to annular flow. This type of burnout occurred over the same range of mass velocity as circulation limited burnout. At present boundary between these different types of burnout cannot be predicted with high accuracy.

The effects of the flow instabilities $[12,13]$, flow regime transition and counter current flow limitations on the CHF are not fully understood. This is particularly true for an initially downward flow system. Ishii and Fauske[14] analyzed a loss-of-piping integrity accident for a loop type LMFBR. The result showed that the rapid flow decay toward a flow reversal lead to the two-phase excursion and subsequent premature dryout. Furthermore it was pointed out that the effect of the hysteresis for the flow excursion was significant. Thus the system could only recover from the dryout condition at a heat flux which was much lower than the $\mathrm{CHF}$ point.

\subsection{Stability Analysis}

Here the stability analysis for Westinghouse Savannah River Site Reactor has been carried out. The problem formulation was based on time and area averaged one dimensional drift flux model, with the necessary constitutive equations. A characteristic equation was obtained by analytically integrating the set of conservative equations for transient conditions using the small perturbation method. The characteristic equation was solved for the stability in terms of the operating conditions. Using this characteristic equation stability boundary will be obtained and represented in the stability plane of the phase change number and subcooling number. 


\subsubsection{Classification of Instabilities}

Two phase flow instabilities can be conveniently classified (Boure" et al [12]) into those instability mechanisms which can be explained in terms of steady state laws (static instabilities), and those which can be explained in terms of transient conservation equations (dynamic instabilities). Several examples of each type of instability mode are given below.

a) Static Instabilities :

1. Excursive (Ledinegg) instabilities

2. Flow regime relaxation instabilities

3. Nucleation instabilities

b) Dynamic Instabilities :

1. Density wave oscillations

2. Pressure drop oscillations

3. Flow regime excited instabilities

4. Acoustic instabilities

5. Condensation induced instabilities

The most important instability modes of practical concern are the excursive and density wave modes. Flow regime relaxation instability is caused by the different pressure drop characteristics of different flow regimes. Flow fluctuations can result in flow regime transition, causing pressure drop fluctuations which cause flow fluctuations : this shows that the instability can be cyclic. Nucleation instabilities include bumping and geysering phenomena, and are characterized by periodic relaxation of the metastable condition that builds up due to insufficient nucleation sites. Liquid superheat can build up until the existing nucleation sites are activated, then rapid boiling and expulsion of two phase mixture may occur.

If a system with a compressible volume has a pressure drop curve with a negative slope, periodic flow excursions may occur, resulting into pressure drop fluctuations. The reason for periodic flow excursion is that the compressible volume causes the flow to divert in such a way as to compensate the pressure drop fluctuations caused by flow perturbation. The liquid inertia causes the flow to fluctuate back and forth, giving rise to pressure drop oscillations. Flow regime excited instabilities can occur when a particular flow pattern, normally slug flow, induces a periodic disturbance in the system operating state. If the frequency of the disturbance is close to the natural frequency of the two phase system, a resonance can occur.

Acoustic instabilities may occur due to the proper combination of system geometry and sonic speed. Similar to single phase compressible fluid flow, organ pipe type standing waves can be set up by a pressure pulse propagating at the local speed of sound through two phase mixtures flowing in a conduit. Condensation induced instabilities can lead to large water 
hammer type loads. A typical example is the so called chugging phenomena observed in the vent pipes of steam relief valves submerged into a liquid pool. High velocity steam in the form of a jet within the pool collapses due to condensation, causing a liquid slug to surge up in the discharge line. Steam can heat up its interface to saturation, allowing the discharging steam pressure to increase, such that the slug is blown back into the pool. A cyclic process of this kind is associated with large inertial loads transmitted to the walls of the vessel containing the liquid pool

\section{Excursive Instabilities}

Excursive instabilities are nonperiodic flow excursions. Instabilities of this type often caused problems in the early low pressure fossil boilers, since flow excursions can lead to burnout of the boiler tubes. Ledinegg [15] was the first to analyze the instability successfully, and hence the instability is also referred as Ledinegg instability. To understand the instability, consider the transient momentum equation for a boiling loop written in the form

$$
\mathrm{I} \frac{\mathrm{dw}}{\mathrm{dt}}=\left[\Delta \mathrm{p}_{\text {pump }}-\Delta \mathrm{p}_{\text {loop }}\right]
$$

where $\delta p_{\text {loop }}$ is the loop pressure drop, $\delta p_{\text {pump }}$ is the pressure rise due to the pump, and the loop inertia I, is given by

$$
I=\sum_{i=1}^{N} \frac{L_{i}}{A_{i}}
$$

where $L_{i}$ and $A_{i}$ are the duct length and flow area in section $i$.

Consider a small flow perturbation about the steady state

$$
w(t)=w_{0}+\delta w(t)
$$

Equations (1) and (3) imply

$$
\mathrm{I} \frac{\mathrm{d} \delta \mathrm{w}}{\mathrm{dt}}+\left[\left.\frac{\partial\left(\Delta \mathrm{p}_{\text {loop }}\right)}{\partial \mathrm{w}}\right|_{\mathrm{w}_{0}}-\left.\frac{\partial\left(\Delta \mathrm{p}_{\mathrm{pump}}\right)}{\partial \mathrm{w}}\right|_{\mathrm{w}_{0}}\right] \delta \mathrm{w}=0
$$

The solution of equation (4) is

$$
\delta w(t)=\delta w(0)\left[\operatorname{Exp}\left(-\left[\left.\frac{\partial\left(\Delta p_{\text {loop }}\right)}{\partial w}\right|_{w_{0}}-\left.\frac{\partial\left(\Delta p_{\text {pump }}\right)}{\partial w}\right|_{w_{0}}\right] \frac{t}{I}\right)\right]
$$

Now, the system is said to be stable if $\lim \delta w(t)=0$. Thus, equation (5) implies stability to flow excursions if

$$
\left.\frac{\partial\left(\Delta \mathrm{p}_{\text {loop }}\right)}{\partial \mathrm{w}}\right|_{\mathrm{w}_{0}}>\left.\frac{\partial\left(\Delta \mathrm{p}_{\text {pump }}\right)}{\partial \mathrm{w}}\right|_{\mathrm{w}_{0}}
$$


Thus excursive instabilities can be predicted through the use of the steady state head versus flow curve of the loop and the pump.

Most often for low system pressure and low inlet loss coefficients, there is a negative slope region of operation of the loop for which $\partial\left(\Delta \mathrm{p}_{\text {loop }}\right) /\left.\partial \mathrm{w}\right|_{\mathrm{w}_{0}}<0$. It can be seen that equation (6) implies that in this region, the system will be unstable unless the slope of the head versus flow curve for the pump is even more negative. Thus Ledinegg flow instability is an important concern in setting SRS reactor power limits because it can lead to fuel dryout followed by rapid fuel temperature excursion and damage.

\section{Density Wave Oscillations}

The physical mechanism associated with density wave oscillations is fairly well understood. Basically, density waves oscillations are caused by the lag introduced in the system by the finite speed of propagation of density perturbations. Consider a boiling channel with a subcooled inlet subjected to a constant, parallel channel type pressure drop boundary condition. A perturbation in the inlet velocity, will create a propagating enthalpy perturbation, in the single phase region. The point at which boiling begins will then be perturbed by the arrival of this enthalpy wave. This will result into a propagating void fraction perturbation, and thus, a density wave in the two phase region.

Due to the change in flow rate and nonboiling length, there will be a perturbation in the two phase pressure drop. Since the pressure drop across the channel is externally imposed, there will be a feedback perturbation in the single phase pressure drop. Because of the lags associated with the finite speed of propagation of the enthalpy and void fraction perturbations, the resultant pressure drop perturbation in the two phase region and the corresponding feedback perturbation in the single phase region will normally be out of phase with the inlet velocity perturbation. Depending on the lag, the resultant pressure drop perturbation in the single phase region may either reinforce or attenuate the subsequent inlet velocity perturbation.

\subsubsection{Dynamic Problem Formulation a) System Description}

The system shown in figure 1 represents a coolant channel of the Westinghouse Savannah River Site reactor. It consists of a channel having flow with heat addition between two volume capacitances which can insulate any systematic propagation of disturbances. The volume capacitances are the riser and downcomer. The system does not include the riser and the down comer, also it does not include components like pump and turbine. The system is divided into four regions, namely, the upstream unheated region $[\mathrm{A}]$, the heated liquid region $[B]$, the heated mixture region $[C]$, and the downstream unheated region [D]. 
The thermodynamic process begins with the subcooled liquid of enthalpy $i_{1}$, entering the heated duct $[B]$, with velocity $v_{f i}$. The heat flux imposed on region $[B]$ is assumed to be constant. The liquid temperature and enthalpy increases as it moves through the heated duct, so assuming thermal equilibrium, the boiling boundary is taken to be the point at which the bulk liquid enthalpy reaches the saturation value $i_{\mathrm{fs}}$. From here onwards, phase change takes place, and the mixture enthalpy and the void fraction increases as the two phase mixture moves through the heated mixture region [C]. This process can be assumed to take place at constant pressure, if the channel pressure drop is assumed to be relatively small compared to the absolute system pressure.

\section{b) Governing Equations}

Region[A]: In this region the flow is assumed to be incompressible and the process is taken as isenthalpic. The velocity field is obtained with the continuity equation. Using the velocity field the acceleration, friction, and gravity presure drops are obtained, including the pressure drop across the valve or the orifice at the entrance to the region [B], from the momentum equation.

$$
\begin{gathered}
v_{f 0}=\frac{A_{c}}{A_{0}} v_{f i}(t) \quad \text { continuity eq. } \\
-\frac{\partial p}{\partial z}=\rho_{f}\left(\frac{\partial v_{f 0}}{\partial t}+v_{f 0} \frac{\partial v_{f 0}}{\partial z}+g_{0}+\frac{f_{0}}{2 D_{0}} v_{f 0}{ }^{2}\right) \quad \text { momentum eq. }
\end{gathered}
$$

For an orifice or a valve at the entrance of region $[B], \Delta p_{i}=k_{i} \rho_{f} v_{f i}{ }^{2}$.

The friction factor $f_{0}=f_{0}\left(P_{\text {system }}, v_{f 0}, \mu_{f}, \varepsilon_{0}, D_{0}\right)$.

Region[B]: In this region pressure and dissipation effects on liquid enthalpy are neglected. The thermal equilibrium between the phases is assumed. The boundary between region [B] and $[C]$ is taken to be at $z=\lambda$ where $i_{f}=i_{f s}$ (sat). Heat source is assumed to generate steady flux. The wall heat capacity is assumed to be small compared with to the fluid heat capacity. Using the continuity equation, the velocity field is obtained. The boundary between regions [A] and [B] is obtained from the energy equations, under the assumption of thermal equilibrium.

$$
\frac{\partial \rho_{f}}{\partial t}+\frac{\partial \rho_{f} v_{f}}{\partial z} \quad \text { continuity eq. }
$$




$$
\begin{gathered}
\frac{\partial i_{f}}{\partial t}+v_{f} \frac{\partial i_{f}}{\partial z}=\frac{q^{\prime \prime} 0 \xi}{\rho_{f} A_{c}} \quad \text { energy eq. } \\
-\frac{\partial p}{\partial z}=\rho_{f}\left(\frac{\partial v_{f}}{\partial t}+v_{f} \frac{\partial v_{f}}{\partial z}+g+\frac{f_{s}}{2 D} v_{f}{ }^{2}\right) \quad \text { momentum eq. }
\end{gathered}
$$

The equation of state is $\rho_{\mathrm{f}}=\rho_{\mathrm{f}}\left(\mathrm{P}_{\text {system }}\right)=$ constant.

The friction factor $f_{s}=f_{s}\left(P_{s y s t e m}, v_{f}, \mu_{f}, \varepsilon_{s}, D\right)$.

Region[C]: In this region the thermodynamic processes are assumed to take place at constant pressure, so that $\rho=\rho(i)$ only. With this assumption the momentum equation is decoupled from the continuity and energy equations. The continuity and energy equations can are solved to get the kinematic variables. Using the values of kinematic variables, the momentum equation is used to calculate the pressure drop. Here one dimensional time and area averaged drift flux model is used. calculate the pressure drop. The surface tension effects, axial conduction and normal stresses are neglected.

$$
\begin{array}{cc}
\frac{\partial \rho_{\mathrm{m}}}{\partial \mathrm{t}}+\frac{\partial \rho_{\mathrm{m}} \mathrm{v}_{\mathrm{m}}}{\partial \mathrm{z}} & \text { mixture continuity eq. } \\
\rho_{\mathrm{m}}\left(\frac{\partial \mathrm{i}_{\mathrm{f}}}{\partial \mathrm{t}}+\mathrm{v}_{\mathrm{m}} \frac{\partial \mathrm{i}_{\mathrm{m}}}{\partial \mathrm{z}}\right)=\frac{\mathrm{q}^{\prime \prime}{ }_{0}}{\mathrm{~A}_{\mathrm{c}}}-\frac{\partial}{\partial \mathrm{z}}\left(\frac{\alpha \rho_{\mathrm{g}} \rho_{\mathrm{f}}}{\rho_{\mathrm{m}}} \overline{\mathrm{v}}_{\mathrm{gj}} \Delta \mathrm{i}_{\mathrm{fg}}\right) & \text { mixture energy eq. } \\
-\frac{\partial \mathrm{p}}{\partial \mathrm{z}}=\rho_{\mathrm{m}}\left(\frac{\partial \mathrm{v}_{\mathrm{m}}}{\partial \mathrm{t}}+\mathrm{v}_{\mathrm{m}} \frac{\partial \mathrm{v}_{\mathrm{m}}}{\partial \mathrm{z}}+\mathrm{g}+\frac{\mathrm{f}_{\mathrm{m}}}{2 \mathrm{D}} \mathrm{v}_{\mathrm{m}}{ }^{2}\right)+ & \\
\frac{\partial}{\partial \mathrm{z}}\left(\frac{\rho_{\mathrm{f}}-\rho_{\mathrm{m}}}{\rho_{\mathrm{m}}-\rho_{\mathrm{g}}} \frac{\rho_{\mathrm{g}} \rho_{\mathrm{f}}}{\rho_{\mathrm{m}}} \overline{\mathrm{v}}_{\mathrm{gj}}{ }^{2}\right) & \text { mixture momentum eq. }
\end{array}
$$

Here the mixture enthalpy is $\mathrm{i}_{\mathrm{m}}=\left(\alpha \rho_{\mathrm{g}} \mathrm{i}_{\mathrm{g}}+(1-\alpha) \rho_{\mathrm{f}} \mathrm{i}_{\mathrm{f}}\right) / \rho_{\mathrm{m}}$. The mixture density is $\rho_{\mathrm{m}}=\alpha \rho_{\mathrm{g}}+(1-\alpha) \rho_{\mathrm{f}}$. For closure of the equations appropriate constitutive equations are used for drift velocity $\bar{v}_{\mathrm{g} j}$, mixture friction factor $\mathrm{f}_{\mathrm{m}}$, and imposed heat flux $\mathrm{q}^{\prime \prime} 0$.

Region[D]: In this region the pressure drop effects on mixture properties are neglected and the process is assumed to be isenthalpic. The kinematics of fluid is described by the continuity equation. The pressure drop calculations are similar to the region $[\mathrm{C}]$, and the pressure drop across the valve or orifice located at the exit of the heated section [C] is obtained trough the loss coefficient.

From continuity equation at $z=1$, the boundary between region [C] and [D]

$$
v_{m e}=\frac{A_{c}}{A_{e}} v_{m}(1, t) \text {. }
$$




$$
\begin{aligned}
&-\frac{\partial p}{\partial z}=\rho_{m e}\left(\frac{\partial v_{m e}}{\partial t}+v_{m e}\right.\left.\frac{\partial v_{m e}}{\partial z}+g+\frac{f_{m e}}{2 D_{e}} v_{m e}{ }^{2}\right)+ \\
& \frac{\partial}{\partial z}\left(\frac{\rho_{f}-\rho_{m e}}{\rho_{m e}-\rho_{g}} \frac{\rho_{g} \rho_{f}}{\rho_{m e}} \bar{v}_{g j}{ }^{2}\right) \quad \text { momentum eq. }
\end{aligned}
$$

Isenthalpic condition represents the energy equation.

\subsubsection{Method of Solution}

The objective is to obtain the transient response of the system, and determine the stability criteria for the system. The origin of axial co-ordinate is chosen to be the boundary between regions $[A]$ and $[B]$, i.e. $z=0$ at the boundary of $[A]$ and $[B]$.

The initial and the boundary conditions are: At $\mathrm{z}=0, \mathrm{t} \geq 0$,

$\rho_{\mathrm{f}}=\rho_{\mathrm{f}}\left(\mathrm{P}_{\text {system }}\right), \mathrm{P}=\mathrm{P}_{\text {system }}=$ constant.

$\mathrm{i}_{\mathrm{f}}=\mathrm{i}_{1}=$ constant, $\mathrm{i}_{\mathrm{f}}=\mathrm{i}_{\mathrm{fs}}\left(\mathrm{P}_{\text {system }}\right), \mathrm{v}_{\mathrm{f}}=\mathrm{v}_{\mathrm{f}}(\mathrm{t})=\mathrm{v}_{\mathrm{f}}+\delta \mathrm{v}(\mathrm{t})$.

The velocity perturbation is modeled using frequency response: $\delta v(t)=\varepsilon e^{\text {st }}$, where $s=a+j w$. Here, $a$ is the amplification coefficient of a particular oscillation mode and $w$ is the angular frequency. The perturbation analysis is assumed to be linear, in the sense that is assumed to be infinitesimal, compared to finite $\mathrm{v}_{\mathrm{f}}$. Thus, only the first order terms in are retained, higher order terms are neglected. The steps in the solution procedure are listed.

1. Use kinematics with boundary conditions to get steady state and perturbed solutions for kinematic variables.

2. Use dynamics to get steady state and perturbed solution for pressure drop.

3. Along with the response of pressure perturbation, use heat flux boundary condition $\mathrm{q}_{0} 0$ and rheological constitutive relation for friction factor $f_{m}$ to get the characteristic equation: $\delta(\Delta \mathrm{p})=\mathrm{Q}(\mathrm{s}) \delta(\mathrm{v})$ or $\delta(\mathrm{v})=\delta(\Delta \mathrm{p}) / \mathrm{Q}(\mathrm{s})$.

The asymptotic stability of the system is determined by the nature of roots of the characteristic equation $Q(s)=0$.

The boiling boundary and the steady state residence time in region $[B]$ is obtained from the energy equation, and is given by

$$
\bar{\lambda}=\frac{\left(\mathrm{i}_{\mathrm{fs}}-\mathrm{i}_{1}\right) \mathrm{A}_{\mathrm{c}} \rho_{\mathrm{f}} \overline{\mathrm{v}}_{\mathrm{fi}}}{\mathrm{q}_{0}{ }^{\prime \xi} \xi} ; \rightarrow \tau_{12}=\frac{\bar{\lambda}}{\overline{\mathrm{v}}_{\mathrm{fi}}} .
$$

The enthalpy response in region $[\mathrm{B}]$ is given by 


$$
i_{f}(z, t)-i_{1}=\frac{q^{\prime \prime} \xi}{\rho_{f} A_{c} \bar{v}_{f i}}\left\{z+\varepsilon e^{s t}\left[\frac{-1}{s}\left(1-e^{\frac{-s z}{\bar{v}_{f i}}}\right)\right]\right\} .
$$

In the heated mixture region [C], assuming the condition of constant properties for the liquid and vapor phases, and using a correlation for the vapor drift velocity is given as:

$$
\bar{v}_{g j}=f(j, \alpha)=\left(C_{0}-1\right) j+\ll v_{g j} \gg .
$$

Under these conditions, the mixture and the vapor continuity equations can be transformed into the volumetric flux equation and the density propagation equation as

$$
\frac{\partial j}{\partial z}=\frac{\Gamma_{g} \Delta \rho}{\rho_{g} \rho_{f}}
$$

which is the volumetric flux equation. Defining the kinematic wave velocity $c_{k}$ as

$$
c_{k}=j+\bar{v}_{g j}+\alpha \frac{\partial \ll v_{g j} \gg}{\partial \alpha},
$$

the density propagation equation is given as

$$
\frac{\partial \rho_{\mathrm{m}}}{\partial \mathrm{t}}+c_{\mathrm{k}} \frac{\partial \rho_{\mathrm{m}}}{\partial \mathrm{z}}=\frac{-\Gamma_{\mathrm{g}} \mathrm{C}_{0} \rho_{\mathrm{m}} \Delta \rho}{\rho_{\mathrm{g}} \rho_{\mathrm{f}}}+\frac{\Gamma_{\mathrm{g}}\left(\mathrm{C}_{0}-1\right) \Delta \rho}{\rho_{\mathrm{g}}}
$$

On the other hand, the thermal equilibrium condition gives the relation between vapor generation $\Gamma_{\mathrm{g}}$, the heat input and the latent heat.

$$
\Gamma_{\mathrm{g}}=\frac{\mathrm{q}^{\prime \prime}{ }_{0} \xi}{\mathrm{A}_{\mathrm{c}} \Delta \mathrm{i}_{\mathrm{fg}}} .
$$

Define a characteristic frequency of phase change as

$$
\Omega=\frac{\mathrm{q}^{\prime \prime}{ }_{0} \xi \Delta \rho}{\mathrm{A}_{\mathrm{c}} \Delta \mathrm{i}_{\mathrm{fg}} \rho_{\mathrm{g}} \rho_{\mathrm{f}}}=\frac{\Gamma_{\mathrm{g}} \Delta \rho}{\rho_{\mathrm{g}} \rho_{\mathrm{f}}} .
$$

Then the solution for the total volumetric flux is given by

$$
j(z, t)=v_{6}(t)+\Omega(z-\lambda(t)) .
$$

Assuming the fluctuations in $\ll v_{\mathrm{gj}} \gg$ and $\alpha \partial \ll v_{\mathrm{gj}} \gg / \partial \alpha$ to be negligible compared to the fluctuations in $\mathrm{j}$, the kinematic wave velocity can be written as

$$
c_{k}(z, t)=\bar{c}_{k}(z)+\delta c_{k}(t)=C_{0}\left[\bar{v}_{f i}+\Omega(z-\bar{\lambda})\right]+\ll v_{g j} \gg+C_{0} \varepsilon e^{s t} \Lambda_{1}(s)
$$

where $\Lambda_{1}(s)$ is a transfer function. The solution for mixture density becomes 


$$
\frac{\bar{\rho}_{\mathrm{m}}(\mathrm{z})}{\rho_{\mathrm{f}}}=\frac{\left(\mathrm{C}_{0}-1\right) \overline{\mathrm{c}}_{\mathrm{k}}(\mathrm{z})+\overline{\mathrm{c}}_{\mathrm{k}}(\bar{\lambda})}{\mathrm{C}_{0} \overline{\mathrm{c}}_{\mathrm{k}}(\mathrm{z})}
$$

and

$$
\delta \rho_{\mathrm{m}}(\mathrm{z}, \mathrm{t})=\rho_{\mathrm{f}} \varepsilon \mathrm{e}^{\mathrm{st}} \Lambda_{2}(\mathrm{z}, \mathrm{s})
$$

where $\Lambda_{2}(z, s)$ is a transfer function. Similarly, the solution for the mixture velocity can be obtained as

$$
\frac{\overline{\mathrm{v}}_{\mathrm{m}}(\mathrm{z})}{\overline{\mathrm{v}}_{\mathrm{f}}}=\frac{\mathrm{C}_{0} \overline{\mathrm{c}}_{\mathrm{k}}(\mathrm{z})}{\left(\mathrm{C}_{0}-1\right) \overline{\mathrm{c}}_{\mathrm{k}}(\mathrm{z})+\overline{\mathrm{c}}_{\mathrm{k}}(\lambda \mathrm{bar})}
$$

and

$$
\delta \mathrm{v}_{\mathrm{m}}(\mathrm{z}, \mathrm{t})=\varepsilon \mathrm{e}^{\mathrm{st}} \Lambda_{3}(\mathrm{z}, \mathrm{s})
$$

where $\Lambda_{3}(\mathrm{z}, \mathrm{s})$ is a transfer function. The detailed expressions for these transfer functions can be found in [16].

After solving for the kinematics of the fluid, the velocity field and the density variation are known, and the pressure drop can be calculated by integrating the momentum equation. By considering the heated section with the inlet and exit flow restrictions, the steady channel pressure drop becomes

$$
\begin{aligned}
& \Delta \overline{\mathrm{p}}_{\mathrm{ext}}=\mathrm{k}_{\mathrm{i}} \rho_{\mathrm{f}} \overline{\mathrm{v}}_{\mathrm{f}}^{2}+\rho_{\mathrm{f}} \overline{\mathrm{v}}_{\mathrm{fi}}{ }^{2}\left[\frac{\mathrm{C}_{0} \overline{\mathrm{c}}_{\mathrm{k}}(1)}{\left(\mathrm{C}_{0}-1\right) \overline{\mathrm{c}}_{\mathrm{l}}(1)+\overline{\mathrm{c}}_{\mathrm{k}}(\bar{\lambda})}-1\right] \\
& +\rho_{\mathrm{f}}\left[g_{0} \mathrm{l}_{\mathrm{i}}+\mathrm{g} \bar{\lambda}+\mathrm{g} \int_{\bar{\lambda}} \frac{\left(\mathrm{C}_{0}-1\right) \overline{\mathrm{c}}_{\mathrm{k}}(\mathrm{z})+\overline{\mathrm{c}}_{\mathrm{k}}(\bar{\lambda})}{\mathrm{C}_{0} \overline{\mathrm{c}}_{\mathrm{k}}(\mathrm{z})} \mathrm{dz}+\frac{\mathrm{g}_{\mathrm{e}}}{\mathrm{Cr}^{*}} \mathrm{l}_{\mathrm{e}}\right]+\rho_{\mathrm{f}} \overline{\mathrm{v}}_{\mathrm{fi}}{ }^{2}\left[\frac{\mathrm{f}_{0} \mathrm{l}_{\mathrm{i}}}{2 \mathrm{D}_{0}}\left(\frac{\mathrm{A}_{\mathrm{c}}}{\mathrm{A}_{0}}\right)^{2}+\frac{\mathrm{f}_{\mathrm{s}} \bar{\lambda}}{2 \mathrm{D}}+\right. \\
& \left.\int_{\bar{\lambda}}^{1} \frac{f_{m}}{2 D} \frac{C_{0} \bar{c}_{k}(z)}{\left(C_{0}-1\right) \bar{c}_{k}(z)+\bar{c}_{k}(\bar{\lambda})} d z+\frac{\bar{f}_{m e}}{2 D_{e}} \frac{C_{0} \bar{c}_{k}(l)}{\left(C_{0}-1\right) \bar{c}_{k}(1)+\bar{c}_{k}(\bar{\lambda})}\left(\frac{A_{c}}{A_{e}}\right)^{2} l_{e}\right]+ \\
& \rho_{\mathrm{g}} \mathrm{Cr}^{*}\left(\mathrm{Cr}^{*}-1\right)\left[\left(\mathrm{C}_{0}-1\right)^{2}\left[\overline{\mathrm{v}}_{\mathrm{f}}+\Omega(1-\bar{\lambda})\right]^{2}+\right. \\
& \left.2\left(\mathrm{C}_{0}-1\right)\left[\bar{v}_{\mathrm{fi}}+\Omega(1-\bar{\lambda})\right] \ll v_{\mathrm{gj}} \gg+\ll v_{\mathrm{gj}} \gg^{2}\right]+\mathrm{k}_{\mathrm{e}} \rho_{\mathrm{f}} \overline{\mathrm{v}}_{\mathrm{fi}}{ }^{2} \frac{\mathrm{C}_{0} \mathrm{c}_{\mathrm{k}}(1)}{\left(\mathrm{C}_{0}-1\right) \overline{\mathrm{c}}_{\mathrm{k}}(\mathrm{l})+\overline{\mathrm{c}}_{\mathrm{k}}(\bar{\lambda})}
\end{aligned}
$$

where $\mathrm{Cr}^{*}=\overline{\mathrm{c}}_{\mathbf{k}}(1) / \mathrm{c}_{\mathrm{k}}(\bar{\lambda})$.

The first term is the inlet orifice term, the second is the convective acceleration term, the third 
(inside the rectangular braces) is the gravity term, the fourth (inside the rectangular braces) is the friction term, the fifth (inside the rectangular braces) is the drift stress term, and the sixth is the exit orifice term.

A simplifying assumption is that $\rho_{\mathrm{m}}-\rho_{\mathrm{g}}=\rho_{\mathrm{m}}$ in the drift pressure drop term. The two phase friction factor model used is $f_{m}=C_{m} f_{s}$. The value of the multiplier $C_{m}$ depends upon inlet subcooling, inlet velocity, flow regime and system pressure [35]. For the conditions considered in the present work, $\mathrm{C}_{\mathrm{m}}=1.5$ is a good approximation which gives pressure drops comparable to the Martinelli-Nelson correlation with a maximum error of about $18 \%$.

Here the first order solution is given as a form of functional relationship between the perturbation of the system pressure drop and of the incoming fluid velocity:

$$
\delta \Delta \mathrm{p}_{\text {ext }}(\mathrm{s}, \mathrm{t})=\mathrm{Q}(\mathrm{s}) \delta \mathrm{v}(\mathrm{s}, \mathrm{t})
$$

where $\mathrm{Q}(\mathrm{s})$ is the characteristic transfer function. According to control theory, the asymptotic stability of the system is determined from the nature of roots of the characteristic equation $Q(s)=0$. For stability against flow excursion, it can be seen from equation (6) that the system will be stable against flow excursion if

$$
\lim _{s \rightarrow 0} Q(s)>0 .
$$

\subsubsection{Important Similarity Parameters}

The characteristic equation is nondimensionalized by choosing the length scale as the heated length, time scale as the reciprocal of the characteristic frequency of phase change, and the cross sectional area of the heated section as the area scale. The following independent basic parameters governing the system dynamics are obtained : The Froude number

$$
\mathrm{N}_{\mathrm{Fr}}=\frac{\overline{\mathrm{v}}_{\mathrm{f}}{ }^{2}}{\mathrm{gl}} \text {. }
$$

The liquid Reynolds number

$$
\mathrm{N}_{\text {Res }}=\frac{\rho_{\mathrm{f}} \overline{\mathrm{v}}_{\mathrm{f}} \mathrm{D}}{\mu_{\mathrm{f}}} .
$$

The subcooling number, which takes into account the time lag effects in the heated liquid region due to the subcooling of liquid entering the heated duct.

$$
\mathrm{N}_{\mathrm{sub}}=\tau_{12}^{*}=\frac{\Delta \mathrm{i}_{\text {sub }}}{\Delta \mathrm{i}_{\mathrm{fg}}} \frac{\Delta \rho}{\rho_{\mathrm{g}}} .
$$

The phase change number, which scales the change of phase due to the heat transfer to the 
system. It decides the time lag in the heated mixture region.

$$
N_{p c h}=\frac{1}{v_{f i}^{*}}=\frac{q^{\prime \prime} 0 \xi 1}{A_{c} \bar{v}_{f i} \Delta i_{f g}} \frac{\Delta p}{\rho_{g} \rho_{f}}=\frac{\Omega l}{\bar{v}_{f i}}=\frac{\Gamma_{g} 1}{\bar{v}_{f i}} \frac{\Delta p}{\rho_{g} \rho_{f}} .
$$

The drift number, which accounts for the diffusion effects due to the relative motion of fluids. It characterizes the flow pattern.

$$
\mathrm{N}_{\mathrm{d}}=\mathrm{v}_{\mathrm{gj}}^{*}=\mathrm{v}_{\mathrm{f}}^{*}+\left(\mathrm{z}^{*}-\lambda^{*}\right)+\ll \mathrm{v}_{\mathrm{gj}} \gg \Omega 1 .
$$

The density number, which scales the system pressure.

$$
\mathrm{N}_{\rho}=\rho_{\mathrm{g}}^{*}=\frac{\rho_{\mathrm{g}}}{\rho_{\mathrm{f}}} .
$$

Hence, the dimensionless characteristic equation can be expressed in terms of various similarity parameters as

$$
Q^{*}=f\left(k_{i}, k_{e}, N_{F r}, N_{R e s}, N_{\text {sub }}, N_{p c h}, N_{d}, N_{\rho}, s^{*}\right)=0
$$

To present the stability boundaries in a two dimensional plane, two representative parameters as the coordinates, are required. For constant system pressure, inlet velocity, given fluid and geometry, the Froude number, the Reynolds number, the drift number and the density ratio are fixed. Hence, the subcooling and the phase change numbers are useful as the coordinates of the stability plane. Operational domain in the stability plane is bounded by the physical restriction on heat flux and subcooling. For positive subcooling, if $\Delta \mathrm{i}_{\mathrm{s}}$ denotes the maximum possible subcooling, then

$$
0 \leq \mathrm{N}_{\text {sub }} \leq \frac{\Delta \mathrm{i}_{\mathrm{s}}}{\Delta \mathrm{i}_{\mathrm{fg}}} \frac{\Delta \rho}{\rho_{\mathrm{g}}} .
$$

For boiling in the channel, without superheating,

$$
N_{p c h}-\frac{\Delta \rho}{\rho_{\mathrm{g}}}<\mathrm{N}_{\text {sub }}<\mathrm{N}_{\mathrm{pch}} .
$$

For constant exit quality,

$$
\mathrm{N}_{\mathrm{sub}}=\mathrm{N}_{\mathrm{pch}}-\mathrm{x}_{\mathrm{e}} \frac{\Delta \rho}{\rho_{\mathrm{g}}} .
$$

The dimensionless length of the boiling region is given by

$$
\lambda^{*}=\frac{\lambda}{1}=\frac{\mathrm{N}_{\mathrm{sub}}}{\mathrm{N}_{\mathrm{pch}}} .
$$

Equations (41), (42), (43) and (44) represent the basic characteristics in the stability plane. Figure 2 shows the stability plane with these basic characteristics. 
A simple stability criterion was obtained by considering only the inlet and outlet orifice pressure drops. This gives a trend of the results, which is useful as a qualitative basis for the system under consideration. A equation was obtained representing the stability boundary in terms of the coordinates of the stability plane, as [36]

$$
N_{p c h}=\frac{\left(A-B N_{\text {sub. }}\right)\left(C-D N_{\text {sub. }}\right)}{\left(E-\mathrm{FN}_{\text {sub. }}\right)}
$$

Here A, B, C, D, E and F are constants given by

$$
\begin{aligned}
& A=k_{e}{ }^{\prime}\left(\frac{c_{\mathrm{k}}^{*}(\lambda)}{c_{k}^{*}(1)}-1\right), \quad B=k_{e}{ }^{\prime} \frac{c_{k}^{*}(\lambda)}{c_{k}^{*}(1)} \\
& \mathrm{C}=\mathrm{Cr}^{*}\left(2 \mathrm{Cr}^{*}\left(\mathrm{C}_{0}-1\right)+1\right), \mathrm{D}=2 \mathrm{Cr}^{* 2}\left(\mathrm{C}_{0}-1\right) \\
& E=2\left[k_{\mathrm{i}}{ }^{\prime} \mathrm{c}_{\mathrm{k}}^{*}(1)+\mathrm{k}_{\mathrm{e}}{ }^{\prime} \mathrm{Cr}^{*}\left[\mathrm{c}_{\mathrm{k}}^{*}(\lambda)+\left(1-\frac{\mathrm{c}_{\mathrm{k}}^{*}(\lambda)}{\mathrm{c}_{\mathrm{k}}^{*}(1)}\right) \mathrm{Cr}^{*}\left(\mathrm{C}_{0}-1+\frac{\ll \mathrm{v}_{\mathrm{gj}} \gg}{\Omega l}\right)\right]\right] \\
& \mathrm{F}=\mathrm{k}_{\mathrm{e}}{ }^{\prime} \mathrm{Cr}^{*}\left[\mathrm{c}_{\mathrm{k}}^{*}(\lambda)+\left(1-\frac{\mathrm{c}_{\mathrm{k}}^{*}(\lambda)}{\mathrm{c}_{\mathrm{k}}^{*}(1)}\right) \mathrm{Cr}^{*}\left(\mathrm{C}_{0}-1+\frac{\ll \mathrm{v}_{\mathrm{gj}} \gg}{\Omega \mathrm{l}}\right)\right]
\end{aligned}
$$

Two computer codes, have been developed to carry out the numerical analysis. One code determines the neutral stability curves, and the other tests chosen points for stability. The parametric equations describing the neutral stability curve are obtained by separating the real and imaginary parts of the shifted characteristic equation. The limiting value $w \rightarrow 0$ makes the imaginary part zero, thus the initial value of the real part decides the excursive stability boundary. The stability plane is bounded by the finite domain for its coordinates. A nodal mesh can be created by constant subcooling and quality lines. The crossover frequencies can be found by interpolation. These are substituted into the real part of the shifted characteristic equation and for non zero values of the real part, the stability test is carried out. When the real part is zero, the point lies on the stability boundary. The excursive stability boundary is also added. The stability boundaries are constructed by covering the entire mesh. The test of stability at any point is carried out by applying the stability test criterion. The real and imaginary parts of the shifted characteristic equation are calculated, the result is plotted in the $s^{*}$ plane, and the stability test criterion is applied.

The input data for the computer code have been obtained from Westinghouse Savannah River Company and Babcock and Wilcox Research and Development Center at Alliance, Ohio. The data consist of reactor geometry and operating conditions. The following modifications are needed in the model:

1. The inlet unheated section consists of many sections of different hydraulic diameters and loss coefficients due to area expansion or reduction. So, the model for inlet 
unheated section is used for each section individually, and then the results are summed up for all the unheated section.

2. The exit loss in the form of area reduction or expansion does not occur at the exit of the heated assembly. So the exit orifice pressure drop term has to be modified by evaluating it at the proper location.

The solution to the characteristic equations as described in the method of analysis have been obtained. The parametric equations describing the neutral stability curve and the stability test criterion have been obtained. The details of the analysis are given in [15]. The initial results of the analysis indicate the existence of first order and higher order instabilities in the transient operating conditions. The effect of the fluid inlet subcooling has a stabilizing effect on the system except at very low subcooling. At low flow rate the instability is easily encountered. Also the instabilities are encountered at low system pressure and high heat flux.

\subsubsection{Analytical Results}

\subsubsection{Density Wave Instability}

Figure 3 show the stability boundaries for flow excursions and density wave oscillations. Figure 3(b) also shows two higher order solutions. But when the system crosses the stability boundary, it goes into oscillations that are likely to damage the system. Hence, the first stability boundary is the most important. Higher order solutions are not important and will not be presented in the following figures. From figure 3, it is important to note that flow excursions are important for low subcooling, whereas density wave oscillations are predominant for high subcooling.

Figures 4 to 7 describe the effects of various operational parameters on the stability of the system. It is important to note that density wave oscillations occur at low exit qualities. Figure 4 describe the effect of inlet velocity (represented by the Reynolds number) on the stability of the system. An increase in the inlet velocity reduces the effects of both the gravitational force and the relative velocity. The kinematic effects of change in the inlet velocity are largely reflected in the ordinate itself. Since the friction factor is not a very strong function of the Reynolds number for turbulent flow, if the inertial, frictional and orifice pressure drops dominate the fluid dynamics, then the change in inlet velocity is significantly reflected in the phase change number. All the curves in figure 4 almost overlap, and hence it can be concluded that the effects of velocity are taken into account by the phase change number.

Figures 5 and 6 describe the effect of inlet and exit throttling on the stability of the system. Increased inlet throttling tends to stabilize the system, whereas increased exit throttling tends to destabilize the system. This is because the inlet pressure drop is in phase with the inlet velocity. The exit pressure drop is in phase with the mixture velocity, but the 
mixture velocity is not in phase with the inlet velocity due to the time lag in wave propagation.

Figure 7(a) describes the effect of system pressure on the stability of the system. The system pressure mainly affects the exit quality, and hence, in terms of the exit quality, the system pressure significantly stabilizes the flow. However, in terms of the phase change number, there are no appreciable effects of the system pressure. Figure $7(\mathrm{~b})$ shows a comparison of the simple stability criterion (given by equation 45 ) and the stability boundary for density wave oscillations. It does not predict the curve for very small subcooling. Except for that, it predicts the curve within 10\% error. For very small subcooling, the stability boundary curve itself has a large change in the phase number compared to the subcooling number. Hence, the numerical data points are difficult to obtain accurately. Also, for low subcooling, the effect of subcooled boiling may have a significant influence on the system stability. Subcooled boiling may dominate the entire heated region. In that case, phase change proceeds further than the case of thermal equilibrium and the value of phase change number increases.

\subsubsection{Flow Excursion and Critical Heat Flux}

By equating the internal pressure drop to the external driving head, the inlet flow can be calculated as a function of the heat flux. A sample calculation is performed and is illustrated with the help of figure 8 . Figure 8 shows the internal pressure drop as a function of inlet flow for various values of heat flux while the subcooling is held constant. The horizontal line represents the external driving head. Two limiting cases of all vapor and all liquid conditions at the exit are also shown. The $S$ curves connecting these two limits are the internal pressure drop versus inlet flow curves calculated from the steady pressure drop expressions for regions A, B, C and D. The intersection of these curves with the available pressure drop (horizontal line) represent possible operating conditions. The operation is stable if the intersection occurs in that portion of the $S$ curve that has a positive slope [36]. It follows that all operational points with a negative slope are exclusively unstable and therefore cannot be sustained under steady state conditions.

Figure 9 show all the possible solutions in terms of inlet velocity and heat flux. For certain values of heat flux, the solution for inlet velocity is multivalued. Hence, for these conditions the operational conditions depend on past history. The region from $C^{\prime}$ to $C$ is the most important for reactor safety. It shows if the reactor can be recovered from the high quality mode. A parametric study for external driving head reveals that when the external driving head drops below 1.2 times the value of the hydrostatic head, the system cannot be recovered from the high quality mode, even by reducing the heat flux to zero. Enthalpy burnout is certain, if the heat flux is not reduced to a value less that $5 \%$ of the full power. Figure 8 also indicate the exit quality values at excursion points. The possibility of system recovery can be judged by these values. 


\subsubsection{Flooding and Flow Regime Transition}

Flooding and churn-turbulent to annular flow regime transition are two important static instabilities that can result in the occurrence of critical heat flux at low flow [5]. Hence, it is worthwhile to predict these instabilities for given operating conditions. Critical Heat Flux due to Flooding occurs when the bottom of the subassembly is blocked. The net flow through the system is zero because the vapor prevents any downward flow of liquid. The flooding correlation expressed in terms of heat flux, [5] is

$$
\mathrm{q}^{\prime \prime}=\frac{\mathrm{A}}{\mathrm{A}_{\mathrm{h}}}\left(\frac{1}{\mathrm{C}_{0}}-0.11\right) \Delta \mathrm{i}_{\mathrm{fg}} \sqrt{\rho_{\mathrm{g}} \Delta \rho \mathrm{gD}}
$$

where, $\mathrm{A}$ is the flow area and $\mathrm{A}_{\mathrm{h}}$ is the heated area. Or, in terms of stability plane parameters,

$$
N_{p c h}=\left(\frac{1}{C_{0}}-0.11\right) \frac{\Delta \rho}{\rho_{g} \rho_{f} \bar{v}_{f i}} \sqrt{\rho_{g} \Delta \rho g D} .
$$

Critical Heat Flux due to the flow regime transition from churn- turbulent to annular flow occurs at low flow and low pressure conditions [5], due to the dryout of the film which cannot be wetted by the liquid slug. The churn-turbulent to annular flow regime transition, expressed in terms of heat flux [8], is

$$
\mathrm{q}^{\prime \prime}=\frac{\mathrm{A}}{\mathrm{A}_{\mathrm{h}}}\left[\Delta \mathrm{i}_{\mathrm{sub}} \rho_{\mathrm{f}} \overline{\mathrm{v}}_{\mathrm{ff}}+\left(\frac{1}{\mathrm{C}_{0}}-0.11\right) \Delta \mathrm{i}_{\mathrm{fg}} \sqrt{\rho_{\mathrm{g}} \Delta \rho \mathrm{gD}}\right] .
$$

Or, in terms of stability plane parameters,

$$
\mathrm{N}_{\mathrm{pch}}=\mathrm{N}_{\mathrm{sub}}+\left(\frac{1}{\mathrm{C}_{0}}-0.11\right) \frac{\Delta \rho}{\rho_{\mathrm{g}} \rho_{\mathrm{f}} \overline{\mathrm{v}}_{\mathrm{fi}}} \sqrt{\rho_{\mathrm{g}} \Delta \rho \mathrm{gD}} .
$$

Consider a hypothetical operation curve for the reactor. Figures 10 and 11 are plots of the operation curve in the stability plane along with flow excursions and density wave oscillations boundaries and flooding and churn- turbulent flow regime transition respectively. The results give a quantitative basis to predict which instability is encountered first under the given operating conditions. Since the operation curve is hypothetical, the results are not exact. But the important point is that if a correct operation curve is available, the analysis will predict the behavior of the system.

\subsection{Experimental Study}

\subsubsection{Design Considerations}

A scaling study for simulating the heavy water reactor by Freon 113 was carried out using the previously developed thermal hydraulic similarity laws $[17,18]$ as well as several low flow CHF criteria [1-3]. Based on this study the experimental loop design has been carried 
out. In Table 2 and 3 the comparison between parameters of the model and the prototype system are given. The model geometry, working fluid and the operating conditions were chosen with consideration to the cost effectiveness and scaling. The simulated loop correctly scales the phase change, subcooling and friction numbers. These insure that the dynamical phenomena due to the void propagation, enthalpy waves and pressure drop are simulated.

The CHF at low flow and low pressure condition is very complicated phenomena influenced by both the loop dynamical characteristics and local conditions. In order to simulate the CHF conditions, several existing CHF correlations have been examined using the nondimensional parameters developed by Mishima and Ishii [1-3]. The results of the location of CHF in these parameter domain are shown in figures 12 and 13 for the case of the prototype (Savannah River Reactors) and one for the simulation loop. Although, the exact locations of CHF are not identical, the general behaviors are very similar between these systems. Therefore, it is expected that the similar CHF mechanisms can be encountered in the Purdue simulation loop. The velocity relations between the model and the prototype as well as the heat flux relations are shown in figures 14 and 15. It can be seen that the velocity is reduced by a factor of three. The heat flux necessary to reach CHF is reduced by a factor of 2.5 in the simulation loop.

\subsubsection{Experimental Facility}

An experimental test facility was constructed to study the critical heat flux (CHF) phenomenon at low flow and low pressure conditions for vertical flow of Freon-113, as the test fluid. The annular geometry of the test section is designed to simulate the SRS (Savannah River Site) reactor Mark 22 assembly flow conditions as discussed in the design considerations. The test loop has a provision for both the down flow and up-flow experiments. The schematics of the experimental facility is shown in figure 16. Central to the test facility, which consists mainly of delivery and recovery systems of the test fluid, Freon-113, in addition to various instrumentations to monitor and record the data, is the test section. It consists of a vertical transparent glass tube and a cartridge type heater located inside the glass tube with annular space for fluid flow. Use is made of the transparent test section to investigate the hydrodynamic aspects of the critical heat flux phenomenon in addition to the conventional heat transfer studies.

A detailed description of the test facility is given below:

\section{a. Test section}

The cartridge heater at the center of the test section is $2.17 \mathrm{~m}$ long, $1.2 \mathrm{~cm}$ OD with a maximum power of $6.72 \mathrm{KW}$. The heated length of the heater is $1.88 \mathrm{~m}$ long which is equal to the length of the beaded glass tube that makes the outer wall of the annular space of the test section with $1.9 \mathrm{~cm}$ ID. The annular gap is $0.35 \mathrm{~cm}$ wide which is equivalent to the hydraulic 
radius of the annular test section. The beaded glass tube is fused at both ends with 1 inch conical connectors for assembling with the rest of the loop. Sixteen $0.21 \mathrm{~mm}$ OD K-type Chromel-Alumel thermocouples are spot welded on the heater surface to monitor and record the surface temperature of the heater during the experimental runs. The thermocouples are covered with high-temperature thermally conductive cement to help fixing them to the heater surface. The thermocouples are equally spaced near the center of the heater but are more closely spaced near the two ends since dry patches are expected more frequently near the outlet. The locations of the sixteen thermocouples are shown in figure 17. The azimuthal location of each thermocouple differs from the rest of the thermocouples with respect to the heater surface, in order to get the CHF location as closely as possible. The azimuthal locations of the thermocouples are not shown, however, in figure 17.

Four spacer-rings are used to center the heater in the test section. Use is made also of the spacer-rings to guide the thermocouple wires away from the heater surface such that the wires extend along the glass wall. Eight thermocouples extend from the top of the test section and the remaining eight extend from the bottom. Two Teflon flanges are attached at both ends of the test section. Each flange has three side holes; two for thermocouple lead wires and one serves as pressure tap connection.

The upper and and lower plenums are made of 2 inch Pyrex crosses. The connections to the test section and the delivery and recovery lines are made via 2 to 1 inch Pyrex reducers. The test section is equipped with two flow resistance devices made of hard Teflon in the shape of a tapered plug as can be seen in figure 17. A male and a female threads are adopted in making the traversing mechanism of the flow restriction devices which produces various degrees of flow restriction by reducing/opening the flow area. The lower plenum is mounted on a steel flange which, in turn, is mounted on the main loop structure. Both the upper and the lower steel flanges have three holes, $3 / 8$ inch NPT in size, for the flow restriction device traversing mechanism, the main heater, and a pressure tap connection.

\section{b. Freon delivery and recovery system}

A $2 \mathrm{HP}$ centrifugal pump, capable of delivering $145 \mathrm{gpm}$ maximum flow rate and $67 \mathrm{ft}$ of maximum head, is used to supply Freon to the test section. The pump is installed at the lowest point of the test loop and a draining valve is attached to it. A by-pass line with a ball valve is connected to the inlet and outlet of the pump to regulate the flow rate to the test section. Downstream of the pump a preheater is installed to control the Freon temperature entering the test section. The $2 \mathrm{KW}$ galvanized steel preheater can increase the Freon temperature, flowing at $30 \mathrm{~cm} / \mathrm{sec}$ in a 1 inch diameter tube, by $10 \mathrm{C}$. Downstream of the preheater the system branches into two: upflow and downflow branches. To direct the flow in either direction a set of two valves (two sets are available) is closed which will force the Freon to follow, say, in the upward direction in the test section. The test section outlet, for both up and down flow cases, is connected to the inlet of a condenser which consists of 
double sets of coils submerged in a water bath. The outer set has 22 coils with $43 \mathrm{~cm}$ OD and $32.4 \mathrm{~cm} \mathrm{ID}$, and the inner set has 15 coils with $31 \mathrm{~cm}$ OD and $28 \mathrm{~cm} \mathrm{ID.} \mathrm{The} \mathrm{outlet} \mathrm{of} \mathrm{the}$ condenser is connected to a subcooler which controls the Freon subcooling, if needed, required for the experimental runs. The subcooler consists of a chest-type freezer with a bath of Ethylene Glycol in which a set of 17 coils with $43 \mathrm{~cm}$ OD and $32.4 \mathrm{~cm}$ ID is submerged. If no subcooling is desired, the Freon emerging from the condenser could be directed to by-pass the subcooler to the pump inlet.

A 1 inch $\mathbb{D}$ by-pass tube is connected to the test section. The flow through the by-pass line is controlled by a ball valve and is measured by a turbine flow meter. Ten tubular bandtype heaters of $495 \mathrm{~W}$ power each are mounted on the by-pass line and are used to match the temperature conditions of the flow inside the by-pass line with the temperature conditions inside the test section. The by-pass line isolates the flow disturbances and/or instabilities generated in the loop from the test section instabilities.

The test loop is supplemented with a 15 gallon, galvanized steel degassing tank located at the highest point of the test section. Two immersion heaters of $600 \mathrm{~W}$ power each are screwed at the bottom of the degassing tank which is equipped with a level gauge to monitor the Freon level inside the degassing tank. A condenser is attached to the degassing tank that utilizes water to cool a set of 28 coils with $6.35 \mathrm{~cm}$ OD and $5 \mathrm{~cm}$ ID. The degassing tank along with the heaters and the condenser could be used to regulate the pressure in the loop resembling a pressurizer in a reactor.

The loop has four relief valves that are connected to the test section lower plenum, the test section upper plenum, positive pressure line of the degassing tank, and to the negative pressure line of the degassing tank with cracking pressures of $210 \mathrm{kPa}(30 \mathrm{psi}), 210 \mathrm{kPa}(30 \mathrm{psi})$, $21 \mathrm{kPa}(3 \mathrm{psi})$, and $-6.89 \mathrm{kPa}(-1 \mathrm{psi})$ respectively. The outlets of the relief lines are connected to a dump tank which, in turn, is connected to the atmosphere. The dump tank is equipped with a $6.89 \mathrm{kPa}(1 \mathrm{psi})$ cracking pressure relief valve.

Two solenoid valves are mounted on the outlet of the preheater and the inlet to the condenser to isolate the test section from the rest of the loop in case of an accident or unanticipated breakage of the test section. The Freon circulating through the loop is regularly filtered using a 25 micrometer pleated paper filter cartridge to trap any impurities or dirt that might exist in the Freon stream. The test section assembly is encased in a box of transparent, anti-shattering Lexan sheets to provide protection for personnel and instrumentations against and breakage of the test section.

\section{c. Instrumentation}

The parameters that are monitored and recorded in this experiment are: temperature, pressure, flow rate, degree of flow restriction, and heaters' power. Data are measured and recorded via MetraByte's DAS-8PGA/EXP-16 data acquisition system, whereas Labtech 
Notebook software is used to manage and analyze the collected data. The DAS-8PGAVEXP16 system contains the original eight analog input channels in the DAS-8PGA box, in addition to two EXP-16 multiplexer boxes with sixteen analog input channels in each box, variable gain setup switches, and cold junction sensing and compensation circuitry for direct temperature measurement using thermocouples. The sampling rate for all channels is $1 \mathrm{~Hz}$ and the duration of continuous sampling is 10 minutes.

Description of the instrumentation is detailed in the subsections below:

i) The test section heater surface temperature is measured using sixteen $0.21 \mathrm{~mm}$ OD K-type Chromel-Alumel thermocouples that are spot-welded on the heater surface and are covered with high temperature thermally conductive cement. An ice box is installed to serve as a reference point for the heater thermocouples. If CHF occurs in a heat flux controlled experiment, the wall temperature rises sharply and may result in a burnout of the heater if the power is not tripped immediately. To avoid such a drastic deterioration in the surface temperature, a feedback control circuit is built with a solid state relay that cuts the power off the heater if the surface temperature exceeds $150 \mathrm{C}$ at any point on the heater surface. The trip circuit will also cut the power off the heater if any of the thermocouples fails to function properly. The sixteen thermocouples are connected to the EXP-16 multiplexer box number 1 which has a set gain of 1000 . The power to the heater could also be cut off manually using an on-off switch located on the electronic circuit box. Figure 17 shows the locations of the heater thermocouples. The power trip circuit was calibrated to trip the heater at a temperature of $150 \mathrm{C}$ for each thermocouple using a known temperature source.

ii) The temperature of the test fluid is monitored in several locations around the loop in order to establish the temperature conditions designated for the specific experimental run. The fluid temperature measurements are made with K-type Chromel-Alumel thermocouples of 1/16 inch diameter, at nine locations in the test loop. the thermocouples are directly connected to EXP-16 multiplexer box number 0 set to a gain of 50 and taking advantage of the cold junction sensing and compensation circuitry. The code name and location of each thermocouple is given below:

1. FT1 Test section inlet fluid temperature (upflow case)

2. FT2 Test section outlet fluid temperature (upflow case)

3. FT3 Degassing tank fluid temperature

4. FT4 Condenser outlet fluid temperature

5. FT5 Subcooler outlet fluid temperature

6. FT6 Preheater inlet fluid temperature

7. FT7 Preheater outlet fluid temperature

8. FT8 By-pass line outlet temperature (upflow case)

9. FT9 By-pass line inlet temperature (upflow case) 
All thermocouples were individually checked against malfunctioning and/or wrong connection. The thermocouples used are made of 304 SS sheathed and ungrounded.

iii) Two turbine flow meters are installed in the loop to measure the flow rate of Freon at two locations. Information given below contain location, purpose, and range of each flow meter:

1. Main flow meter: located near the inlet to the preheater and is used to measure the flow rate in the loop with range of $0.75-7.5 \mathrm{gpm}$.

2. By-pass flow meter: located on the test section by-pass line and is used to measure the flow rate in the by-pass line with range of 0.75-7.5gpm.

Both turbine flow meters were calibrated by manufacturer. The calibration curve for the turbine flow meters is shown in figure 18. The output signals of the turbine flow meters are directed to the DAS-8PGA box (with set gain of 1). Independent DC power supply is provided for each flow meter with an input voltage of $12 \mathrm{VDC}$.

iv) Pressure measurements are made at five locations in the test loop. Three differential diaphragm-type pressure transducers are used to measure the pressure drop across the lower plenum, the test section and the upper plenum with ranges of $14 \mathrm{kPa}, 35 \mathrm{kPa}$ psi, and $35 \mathrm{kPa}$ psi, respectively. Mating connectors are used to connect the pressure transducers to the carrier demodulator which is used to condition the pressure signals and hence to send them to DAS8PGA data acquisition box (with set gain of 1). The three differential pressure transducers are calibrated using hydrostatic head of water column. The calibration curves of the three pressure transducers are shown in figure 19.

The remaining two pressure measurements are made with absolute pressure gauges. The system pressure is measured at the lower plenum using a pressure gauge with range of 0 $1400 \mathrm{kPa}(0-200 \mathrm{psi})$, whereas the degassing tank pressure is measured using a gauge with a range of $0-210 \mathrm{kPa}(0-30 \mathrm{psi})$. Both pressure gauges are fixed at the main control panel of the test loop.

v) Control panel: The powers of the main heater, the preheater, the by-pass heaters and the degassing tank heaters are monitored using voltage and current meters which are fixed to the control panel. The power of each heater can be varied using a power variac connected to each heater. The control panel also has two on-off switches for control of solenoid valves, system and degassing tank pressure gauges, turbine flow meters output voltage, and power switches for the heaters and the pump.

The photograph of the CHF experimental facility is shown in figure 20 .

\subsubsection{Experimental Results}


A set of preliminary experiment were designed and performed to test the performance of the various instrumentations in the test loop. After assuring the adequacy of the different components of the test loop, such as the flow meters, the pressure transducers, the heater thermocouples, a second set of experiments were carried out investigating the hydrodynamic behavior of the test fluid under boiling conditions. The first attempt was to study the effect of increasing the heat flux on the system while maintaining the rest of parameters constant. It is expected that, with minimal flow restriction at the inlet to the test section and substantial restriction at the exit of the test section, the flow instability will occur with increasing heat flux. Hence the experiment was performed with constant inlet flow rate to the test section of $35 \mathrm{~cm} / \mathrm{sec}$, no inlet flow restriction, substantial outlet flow restriction, and constant inlet subcooling.

The bypass line to the test section is kept open such that when the system reaches the instability, the reduction in fluid flow in the test section will be compensated by increasing the flow rate in the bypass line in order to maintain steady operating conditions. The heater power was increased from $1.0 \mathrm{KW}$ to $3.5 \mathrm{KW}$ with an increment of $0.5 \mathrm{KW}$ for each run. The results of one test run is summarized below. Figure 21 shows the flow rate into the test section versus time for the range of heater power used. Notice the fluctuation in the flow rate into the test section which is caused by the boiling process. At higher heater power values the boiling becomes very violent and chugging becomes dominant, which is clearly indicated by the large amplitude of the oscillation in the flow rate signal. Figure 22 shows the mean flow rate into the test section versus the heater power. It is clear that the flow rate falls from the mean value of $35 \mathrm{~cm} / \mathrm{sec}$ to a much lower value at heater powers in access of $2.5 \mathrm{KW}$, which indicates the occurrence of the flow instability. The phenomena of chugging could be explained as follows: When boiling takes place in a closed channel, or loop, at relatively high rates, the vapor generated expands in the loop and causes the inlet fluid to decelerate. After the vapor has condensed, the pressure in the loop will drop and hence will cause the fluid to accelerate in the test section causing further rapid boiling which will again produces large amount of vapor, and so on.

Figure 23 shows the inlet subcooling to the test section for three different values of heater power. Notice that the subcooling decreases with time. This was caused by the continuous running of the experiment. If constant subcooling is desired then time should be allowed between individual runs. Figure 24 shows the temperature of the two-phase mixture coming out of the test section for the same runs reported in the previous figure.

Figure 25 shows the pressure drop across the test section for two values of heater power. Notice the decrease in the mean pressure drop when boiling boiling occurs. This is mainly due to increase in the void fraction in the test section.

The photographs of the boiling in the test section are shown in figures 26-28 for different heater power. At heater power of $1.5 \mathrm{~kW}$ (figure 26) we observe a subcooled boiling. This is 
also evident from the outlet fluid temperature (figure 24). At heater power of $2.5 \mathrm{~kW}$ (figure 27 ) the we observe saturated boiling. At heater power of $3.5 \mathrm{~kW}$ (figure 28 ) there is vigorous boiling with large amount of vapor produced. The vapor bubbles coalesce and the flow regime is almost churn-turbulent. This region shows the occurrence of instability as seen from the mass flow rate.

Various experiments were conducted to study the hydrodynamically induced instabilities in downflow and CHF for the system by varying system parameters such as inlet subcooling, flow rate, system power, inlet and exit restrictions. The important observations are stated below.

With the increase in heater power, at constant inlet flow rate and subcooling, subcooled boiling starts at the last $30 \mathrm{~cm}$ of the test section. With further increase in power, the bubbles grow and start to detach from the heater surface and flow down the stream to the exit of the test section. the increase in void generation will cause bubbles to coalesce into one, or several, small cap bubbles at the exit of the test section. Beyond certain void fraction level in the test section, the flow will start to decelerate in the test section and accelerate in the bypass line. At this point the, bubbles along the length of the test section will grow rapidly in size and the test section will undergo rapid transition to a low quality state followed by flow reversal. The ensuing flow pattern is of natural circulation between the test section and the bypass line, superimposed on the forced flow into the bypass from the pump. The bypass flow rate signal shows a higher flow rate than that of the main pump. This instability is the flow excursion instability. The physical observation of the system clearly shows the transition from a low quality state to a high quality state, indicating the flow excursion instability.

The raw data obtained from the data acquisition system is collected and analyzed to obtain the instabilities. Figure 29a shows the heater surface temperature at the inlet and exit section for Run\#9 $\left(k_{i}=0\right)$. Figure $29 \mathrm{~b}$ shows the same information for Run\#46 $\left(k_{i}=22\right)$.Notice the temperature increase at both the inlet and outlet. The increase at the inlet, due to flow reversal, is more pronounced due to the low inlet temperature (high subcooling). Also notice that the heater surface temperature for the case of higher inlet restriction was much higher indicating a more violent excursion, which was physically observed. Also notice that the system reached CHF during Run\#46. Figures 30a and 30b show the main and bypass flow rates for Run\#9 and Run\#46, respectively. When the bypass flow rate exceeded the main flow rate, in Run\#9, this indicated that the flow excursion was followed by flow reversal. Flow reversal did not take place in Run\#46. The violent vaporization of the freon in the test section prevented the bypass liquid from entering the test section which remained voided until the control circuit tripped the heater power following CHF.

Data on the inlet velocity into the test section, the inlet subcooling, the inlet and exit flow restriction, and the heater power are properly collected for each run and the subcooling number and phase change number were consequently calculated. The instability boundary is 
shown in figure 31 for the case of zero inlet and exit restrictions. At high subcooling, the instability boundary lies to the left of the zero quality line where as at low subcooling, the boundary crosses the zero quality line to the region of positive stability. At high subcooling, the instability boundary lies further to the left of the zero quality line for high inlet restriction in comparison with zero inlet restriction. Also it is clear that subcooled boiling plays an important role in two phase instabilities for downward flow situation. 


\section{POST CHF IN INVERTED FLOW}

Inverted annular flow, which consists of a liquid core surrounded by a vapor annulus, as shown in figure 32 , is of considerable importance in the areas of confined, low quality film boiling applications such as LWR accident analysis. While many analytical and experimental heat transfer studies for this flow situation have been carried out, the relevant hydrodynamics of the post-CHF flow field received less attention. A more thorough understanding of the hydrodynamics of the post-CHF flow is necessary in order to adequately assess post-CHF heat transfer due to the coupled thermo-hydraulic nature of confined flow film boiling phenomena. Consequently, the determination and characterization of the various two-phase flow regimes both before and after $\mathrm{CHF}$ become important in determining heat transfer (as well and mass and momentum transfer).

\subsection{State of the Arts Review}

Most of the research on the post-CHF region dealt mainly with heat transfer. Excellent reviews of the widespread literature were provided by Jordan[19] and Clemments and Clover[20]. A subsequent review by Kalinin et al.[21] considered both free and forced convective film boiling in great detail. Complete tabulations as well as extensive graphical comparisons of the various predictive equations for heat transfer were given. However, because heat transfer is significantly influenced by the regime of film boiling, some of the disagreement among the various correlation's are not so readily explained due to insufficient understanding of the complex hydrodynamics of the postCHF region[8].

Groeneveld and Gardiner [37] have provided a review which is restricted to post dryout under forced convection in confined flows. Essentially, three flow regime types have been observed. First, is an inverted annular flow regime. For this regime, a continuous liquid core is surrounded by a continuous vapor blanket for confined forced flows. In some cases entrained liquid droplets have been observed in the vapor annulus. Overall the flow regime seems to exist in void fraction ranges from 0 to 0.3 . Next, is an inverted slug flow and/or inverted churn flow. This flow regime is described as an intermediate regime which exists when the void fraction is moderate $(\alpha>0.3)$ and the liquid flow rate is low, also slug flow is inhibited by subcooling. The final flow regime is a dispersed droplet flow regime. When the liquid of the first two flow regimes finally breaks up, the liquid flow makes the transition to the dispersed droplet regime. This break up is due to interfacial instabilities and has been examined as a liquid jet disintegrating in a vapor continuum.

Collier [38] examined the "state of the art" in post dryout heat transfer with particular emphasis on water cooled reactor applications. He classified the literature on post-dryout correlation's into three types:

(a) Correlation's which are purely empirical and which make no assumptions as to the mechanisms about the heat transfer. These correlation's attempt to put the heat transfer coefficient in terms of independent system variables. 
(b) Correlation's which account for departure from thermodynamic equilibrium. These correlation's try to model the vapor quality and temperature coupled with single phase calculations for the heated wall temperature.

(c) Mechanistic (semi-theoretical) models based on the hydrodynamic and heat transfer processes which occur in the modeled system.

Mayinger and Langner's [39] work concentrates on the forced convective heat transfer in post dryout for the dispersed droplet flow regime. Furthermore, the review was limited to work conducted between 1975 and 1978. The authors point out that both the experimental data and predictive capabilities for the 3 flow regimes are not equivalent. For the Dispersed phase flow regime both experimental and theoretical understanding was adequate (although the need for some experimental work in low flow was suggested); however, for both the inverted annular and inverted slug flow regimes, very little work had been conducted in either the heat transfer or hydrodynamic visualization work. In addition to a lack of data, the results of the data available showed a general lack of agreement.

Visual and high-speed motion picture observations of film boiling in channels have been reported by a number of researchers. For upward flow of liquid nitrogen in a vertical tube, Laverty and Rohsenow[22] obtained two distinct flow regimes: an inverted annular flow with liquid in the center and vapor in the annulus occurred at the beginning of the heated section, followed by a dispersed region of ligaments/droplets of liquids at greater tube lengths. In a subsequent study, Forslund and Rohsenow[23] confirmed the large departure from equilibrium in dispersed flow film boiling. A detailed review of visual studies in the post-CHF region was reported by Denten and Ishii[8]. A detailed experimental study of inverted annular flow for the adiabatic and diabatic cases were reported by Ishii and co-workers[7,24,25]. The disintegration of the liquid core into droplets was found to be due to two different mechanisms: wave instabilities at the interface and roll-wave entrainment. Correlation's for core shape, breakup mechanisms and dispersed core drop size were developed for the adiabatic case, by extending the results of free jet instability, roll-wave entrainment and churn turbulent droplet stability studies. The diabatic study reported the presence of four well-defined flow regimes in the post-CHF region; namely, inverted annular, agitated, inverted slug/churn and dispersed flow regimes. The axial extent of each flow regime, as well as the transition from one regime to another, was found to depend markedly on the relative velocity between the gas and the liquid, in agreement with the observation of Laverty and Rohsenow[22]. Correlation's were developed for the axial extent of flow regimes reported above.

A number of computer codes and analytical/empirical models have been developed for predictions of void fractions, wall temperatures and heat fluxes in the post-CHF region[11,26]. A review of the numerous analytical and empirical methods for annular and slug flow film boiling was carried out by Groeneveld[27], while Chen[28], in his review, examined phenomenological questions relevant to our understanding of the transport mechanisms in the post-CHF heat transfer. Yadigaroglu and Bensalem[29] presented a critical and thorough review of the various approaches that are used for modeling of interfacial mass generation in two-phase flows, including a detailed discussion of the 
mechanistic models for inverted annular and dispersed flow film boiling. More recently, Nelson and Unal[30] developed a heat transfer model for the post-CHF region based on flow transition criteria.

Ishii and Denten[8,31] extended the studies, reported by Ishii and coworkers $[7,24,25]$, to investigate the axial extent and flow regime transition in an idealized inverted annular flow geometry where a two-phase liquid core is injected into the heated test section surrounded by a gas annulus. They correlated the axial extent of the agitated flow regime in the post-CHF region in terms of the two-phase liquid jet Capillary number, $C a=\frac{\mu_{f} j_{J}}{\sigma}$ and the jet theoretical void fraction. Their correlation is given by:

$$
L / D=595 \sqrt{C a}\left(1-\frac{\alpha_{J}}{0.854}\right)^{1.22}
$$

The brief review presented above indicates that more effort has been recently put into the study of hydrodynamics of the post-CHF region. However, it is evident that there is a need for an experimental data base, to be used for validation of heat transfer models, on the hydrodynamics of the post-CHF region in a transient reflooding case. This paper attempts to address the case of low pressure, low flow, transient bottom reflooding experiment, explain the hydrodynamic characteristics of the flow field downstream of a moving quench front, and develop a flow transition criterion for the agitated regime in the post-CHF region. Babelli [33], continued this work, by examining the quench front propagation velocity. The results of this work concluded that the propagation velocity was wall conduction dominated and independent of either inlet velocity or subcooling; however, below a minimum inlet velocity, the rewetting front could not exist. Furthermore, only as the inlet velocity became large were isolated quench spots observed. In trying to extend the void fraction correction factor it was noted that the ability to calculate the void fraction presented exceptional difficulty for this series of studies.

\subsubsection{Experimental Apparatus 4 \\ 3.2. Experimental Apparatus and Procedures}

The overall test apparatus is shown, as a schematic, in figure 33. The specific components of the apparatus include: the test section, used for the hydrodynamic studies; the heat transfer system; the Freon delivery and recovery system and the gas delivery system. System variables measured are differential pressure across the test section; liquid and vapor inlet velocity; fluid subcooling (delivery temperature) and heating fluid temperature and void fraction. All system variables are obtained with fast data acquisition which is computer controlled. The gas delivery system was not used in the quench front analysis, and it was used in the flow regime studies; but is used in the inverted annular studies.

\subsubsection{Test Section}

The test section configuration is shown in figure 34 and it consists of two concentric quartz tubes which act as a parallel tube and concurrent flow heat exchanger. The heat transfer 
fluid flows through the external annuli and the Freon flows through the internal annuli. The dimension of the outer tube are $31 \times 35 \mathrm{~mm} \mathrm{ID} / \mathrm{OD}$ and the dimensions of the inner tube are 15 $\mathrm{x} 18 \mathrm{~mm} \mathrm{ID} / \mathrm{OD}$. At one end of the test section is a $150 \mathrm{~mm}$ section before the heating jacket, this acts as an unheated entrance length for tests involving nozzle injection of fluid. In the case of the quench front analysis, it was not used. The heated portion of the test section is $100 \mathrm{~cm}$ long. Quartz was choose over Pyrex, due to it's superior thermal mechanical properties (strain point :- $1070 \mathrm{C})$ and extremely low expansion coefficient $\left(5.5 \times 10^{-7} \mathrm{~cm} / \mathrm{cm} / \mathrm{C}\right)[42]$.

All test section connectors are (Pyrex style) one inch conical end connectors and are also made of fuzed quartz. The heat transfer delivery system is connected with a series of buttflanges, flow alignment blocks and silicon rubber gaskets. The Freon delivery system is connected using Pyrex four bolt bead-connectors and asbestos/teflon gaskets. The test section is installed vertical with the Freon/gas inlets at the top of the test section and the two-phase exit, to the dump tank at the bottom.

Inverted annular flow was attained in the test section by a two step process. First, the heat transfer fluid temperature must be raised to a temperature above the film boiling temperature of the working fluid, then the subcooled Freon is injected to the test section. Prior to this, the experimental flow rate of the test run must be established.

\subsubsection{Heat Transfer Delivery System}

The heat transfer fluid used for these experimental studies is Dow Corning's Syltherm 800 , because it met essential criteria for the visualization study. First, the fluid is transparent (amber in color), it has a very low viscosity for an oil and is commonly used in the food technology applications since it is not hazardous if ingested and is non-toxic. The last item is important in the case of accidents, spills and vaporization of leaking fluid.

The delivery system consisted of a degassing and storage tank, centrifugal delivery pump, two $8.1 \mathrm{~kW}$ electrical heaters and two $1.8 \mathrm{~kW}$ external jacket heaters, a throttle valve and assorted delivery and isolation valves and a flow meter. The system is capable of delivering the heat transfer fluid at a volumetric flow rate of $20 \mathrm{gpm}$. Constant operating temperature is monitored by a controller thermostat with an over temperature cut off. Inlet delivery temperatures were all less than $\pm 0.5 \mathrm{C}$ during the acquisition of data. The degassing and storage tank has both gas inlet and outlets so that a nitrogen atmosphere is present during operation. This prevents the fluid from oxidizing at high temperatures. The delivery pump was originally designed with water cooling for the shaft seal; however this developed a leak in it during a previous series of tests, which resulted in contamination of the heat transfer oil. This cooling system was replaced with a Coolant system consisting of a Syltherm/water heat exchanger in order to eliminate the possibility of contamination of the heat transfer fluid. Furthermore, the oil by-pass line was modified to include a high capacity filtering system. This was used

periodically after data acquisition sessions in order to filter any impurities which might degrade the visual quality through the heat transfer fluid. The system is shown in figure 35 .

\subsubsection{Freon Delivery and Recovery System}


Freon, Trichlorotrifluroethane or R-113, was the test fluid used for all of the experiments performed in this work. Freon was chosen because it is a reasonable simulant to water, but with distinct advantages. First, it has a lower film boiling temperature and lower vapor pressure than water, which makes the experiment easier to perform technically. Furthermore, it is one of the less reactive and hazardous of the freon class of fluids.

The delivery system consists of a delivery tank, small particle fluid filter, cutoff and throttle valve, electric flow cutoff and flow meter. The recovery system consists of a dump tank, recirculation pump, and pre-cooler, shown in figure 36.

The delivery tank is operated by pressurizing the system with nitrogen, usually between 20 to 50 psig and has an internal coil heater for increasing the temperature. Furthermore, it has a bypass line through the recirculation pump in order to pass the fluid through the pre-cooler. By judiciously using the heater and pre-cooler simultaneously, almost any value of subcooling can be achieved. During some of the pre-testing, a bit of gasket material was displaced and destroyed the flow meter bearing. To prevent this from happening again, on line pre-filtering of the Freon was added to the delivery system. This consists of a 0.3 micron filter and housing. The electric flow cutoff is used in conjunction with the flow valve to allow presetting of the flow rate and instantaneous flow control.

Due to the sky-rocketing cost of Freon, thanks to the beloved Green Peace, the dump tank was modified to allow for closed flow operation. This was done to ensure that no freon was lost due to venting of the system. The pre-cooler was a 25 cu.ft. chest freezer with dual ethylene glycol heat exchanger.

\subsubsection{Pressure Measurement}

Pressure taps were drilled into the test section connecting flanges of both the inlet and outlet. The inlet $(+)$ and outlet $(-)$ were connected to a validine pressure transducer in a differential displacement mode. The transducer was calibrated in situ using the test section filled with 10 varying levels of fluid. The calculated pressure, based on the static head of the fluid column, was plotted against the transducer voltage in order to provide the calibration conversion and correlation. The data is shown in figure 37. Since the system is vertical, care was taken before each acquisition series to ensure the pressure taps and transducer lines were full of fluid and free of vapor bubbles. Furthermore, repeatability of the calibration was tested by applying draining and refilling the test section and checking the voltage measurement against the static head. Repeatability of the series of 5 tests was less than $\pm 0.3 \%$.

\subsubsection{Liquid Velocity Measurement}

The volumetric flow rate of the Freon was measured with a Cox 1523 turbine flow meter. This is a high precision flow meter which has a voltage to flow rate calibration certified to $< \pm 0.5 \%$ of the designed flow range for the life of the device. Furthermore, the device calibration was previously examined [40]. In these validation experiments, a series of weigh 
versus time measurements were preformed over the range of meter. The results for these tests verified repeatability of less than $1 \%$. Flow rate readout is measured and displayed by a Cox 1050 digital flow rate indicator which is also connected, in analog mode, to the A/D conversion board.

\subsubsection{Temperature Measurement}

All temperature measurements are acquired with K-type thermocouples with cold junction compensators. The system is calibrated by the manufacture with an accuracy of \pm 0.2 $\%$. This test has 6 temperature measurements for the heat transfer oil inlet, heat transfer oil outlet ( two ), Test section inlet and outlet and the delivery tank for subcooling measurements. Five of these are connected to a fast data acquisition system with computer control. The sixth thermocouple, for the heat transfer oil outlet, is connected to the thermostat controller.

\subsubsection{Data Acquisition System}

Two significant improvements over previous experiments were desired. First, was the ability to examine data for the transient conditions of the fluid flow during the quench front propagation analysis. Second, was the ability to coordinate both the video filming and the transient data obtained. This was accomplished by combining both computer controlled analog/digital data acquisition along with time display video. The need for both of became apparent during some of the pre-test experiments which were performed, because a persistent oscillating phenomena was observed and it was more dynamic than reports from other vertical down flow experiments. This was amplified by the fact that during this type of oscillations, the still photography could not distinguish flow direction.

A Strawberry Tree Inc, model ACJR, analog/digital (AD) board was used for the data acquisition. The system hardware features included: 8 differential analog inputs, 9 to 12 bit programmable resolution, internal cold box compensation, individual and programmable channel gain. An internal driver and output conversion program was written in FORTRAN to allow for easy file management of the data obtained. The computer control of the data acquisition was performed with an IBM-PC.

The video system consisted of a Sony CCD-FX710 video camera recorder with onscreen elapse time display and audio recording. In order to synchronize the video record and the data acquisition, the following methodology was employed. Once the experimental study was ready to proceed, the video system was started. Next, the data acquisition sequence was started, and then the flow initiated simultaneously with an audio record of the event. By shifting the time scale of the quench front coming into view on the data log acquired during the run, a sequential match of the velocity propagation data and the test time history was both possible and accurate to \pm 1 second.

\subsubsection{Experimental Procedures}

\subsubsection{Test Runs}


For this research, two types of experiments are proposed to be performed. Both are designed to investigate the hydrodynamics for vertical downflow. The first set of experiments, which have been completed, concentrate on transient quench front propagation analysis. The second set of experiments concentrate on the flow regime visualization for the steady state post dryout. Detailed procedures for performing both preparatory and data acquisition test series have been previously published [41]. With only minor modifications, these procedures also apply to the current tests, and only a brief outline of the task requirements are provided:

1. Prepare $275 \mathrm{lbs}$ of Freon prior to the experimental test run. This includes both transferring the liquid to the delivery tank and degassing it.

2. Check all instrumentation, data acquisition and safety systems in order to ensure that they operate properly, and within prescribed limits.

3. Initiate the pump seal coolant for recirculation pump for the heat transfer system. Also energize all of the circulation heaters. Be sure the temperature controller maximum temperature set point is at the desired temperature. Wait until the heat transfer system has reached equilibrium.

4. Get the delivery fluid subcooling at the desired value for the test run. As previously pointed out, the subcooling can be changed by using the pre-heater to increase fluid temperature or by using the cooler to decrease the fluid temperature.

5. Cool the dump tank to a low temperature. This is used to remove the latent heat of the two-phase mixture.

6. Purge the Freon line so that the desired delivery temperature can be achieved.

7. Execute the data acquisition plan.

Overall 21 quench front propagation data series have been acquired. On a planed experimental series the outlined procedure would be followed by using a checklist. In each case a series would continue until the volume of prepared Freon was gone.

In previous tests [42], it was noted that at high subcooling (freon temperatures below $10 \mathrm{C}$ ) it was difficult to maintain a fixed delivery temperature. To avoid this problem that data range was ignored. For this data series, additional insulation was added which solved part of the problem. In addition to this, before each data sequence, the delivery line would be purged while setting the inlet velocity. By doing this, the entire line was cooled and with the added insulation the delivery temperature could be maintained over the entire subcooling range. In the case of adiabatic test in which the inlet thermocouple temperature and delivery tank thermocouple temperature were compared, less than $1 \mathrm{C}$, at most, was ever observed.

\subsubsection{Safety Precautions}


In addition to the purely economic concerns associated with any accidents or misuse of the test facility, there are numerous potential human hazard. During normal operation, the facility can operate the heat transfer fluid as high as $320 \mathrm{C}(608 \mathrm{~F})$. This presents the problem of severe burns. Further more, although the heat transfer fluid is not an ingestion hazard, long term exposure to the vapor can produce raspatory difficulties. In the case of Freon, the vapors are a severe asphyxiation problem, because like Argon they have a higher density than air. Also, prolonged exposure to Freon vapors may produce cardiac problems. During the operation of any testing in which the heat transfer temperatures are high, vapor explosions may occur if the inner wall of the test section were to break. Also, during operation the rupture of the outer wall presents the potential problem of spraying large quantities of extremely hot oil in the vicinity of the test section. Finally, the use the gamma densitometer presents a potential radiation hazard and care must be taken to keep personal exposure as low as reasonably achievable (ALARA).

In order to prevent personal exposure to the potential heat hazards during the operation of the facility, both heavy insulation of the piping and structure exists. In addition to this, heat shielding has been erected in order to protect personal. In order to minimize vapor inhalation a high capacity blower has been installed in the room. This system is capable of removing the volume of air in the room in under $3 \mathrm{~min}$. During all tests involving heat transfer, the blower is left on. Furthermore, this safety procedure is applied during operations in which Freon transfer occurs. Freon-113 is naturally odorless, however the manufacturer has provided an inert scent so that Freon vapors can be detected easily. In all cases, whenever vapors can be smelled, the blower was turned on.

Due to the special requirements associated with using a radiation source both a license and specific radiation training were obtained. Furthermore, facility modification and handling procedures were initiated. Shielding design specifications and requirements were established for obtaining the license. These were used and applied in designing the gamma densitometer. Finally it should be noted that general care was taken during all aspects of testing to ensure personal and equipment safety.

\subsubsection{Closed Loop Operation}

During the course of this test development, the use and cost of all halogens and especially Freons have become both more scrutinized and restricted. Furthermore, the cost of Freon-113 has increased significantly (by a factor of 5!). This created tremendous budget problems and made even the natural losses due to evaporation more costly. In order to eliminate the problem, a set of test modifications were performed. Principally, the freon recirculation was modified so that continuous subcooling could be performed during the test. In doing this, it was demonstrated that complete recondensation of the vapor could be performed. During all testing the dump tank pressure is monitored and in the event that the tank pressure increases by more than 2 psig, a relief vent is opened. During all of testing performed to date, this procedure has not needed to be implemented.

\subsection{Experimental Observations}




\subsubsection{Rewetting Front Experimental Results \\ 3.3.1.1 Method of Investigation}

The experimental investigations of this chapter concentrated on the hydrodynamic visualization of the rewetting front. The focus of this work was to apply still photography and motion picture (using SH video technology) methods in order to examine the flow characteristics of the test section, and to coordinating the motion picture studies with the flow parameters data acquisition. The archival data on the rewetting front experiment represents approximately 9 hours of flow visualizations using video technology, over 100 sets of photographs and over 10 Mega-bytes of flow data.

The purpose of this data is to provide preliminary knowledge about the rewetting mechanisms involved in co-current down-flow and to provide a basis for developing a strategy for future work. This data has been compared to rewetting results for vertical up flow. The cocurrent down-flow data is more complicated than the up-flow data and some of the mechanisms observed in the visualizations will be discussed below.

\subsubsection{Preliminary Results \\ 3.3.1.2.1 Mechanisms Study}

Mechanisms observed from the film series of this research include (1) transient, periodic and partial flooding of the heated test section; (2) a strong oscillation phenomena; (3) a precursory wetting of the dry-out region beyond the quench front, (4) a condensable volume influence on the flow and (5) rivulet wetting. All of these mechanisms are unique to the downflow system.

\section{Flooding phenomena}

In steady state flooding experiments involving both adiabatic and reflux condensation, sustained prevention of liquid penetration and dryout occur. However, for this work, a more complicated scenario has been observed. When the fluid initially enters the heated region of the test section, the fluid can only penetrate 10 to $20 \mathrm{~mm}$ before the local film boiling generates enough vapor to initiate flooding, but the flooding prevents additional fluid from entering the heated section. Once all of the remaining fluid has been converted to vapor, then more fluid enters the heated test section. This is a transient type of flooding, since the vaporization of the fluid occurs at a faster rate than the fluid is entering the heated test section. This occurs generally at onset of liquid injection with low flow rate and when the fluid is near saturation.

If the inlet liquid velocity or subcooling are increased, then the flooding begins to take on a more periodic characteristic. In this situation, the vapor generation term has both an evaporation and condensation component. While the local mean temperature is close to saturation, the evaporation component is dominant and flooding occurs. But, the violent action of the boiling creates strong mixing and the mean temperature becomes more subcooled as lower temperature liquid is mixed into the heated test section. This results in a reduction of the net vapor generation and flooding can not be maintained and liquid issues back down the test 
section. This in turn increases the evaporation and a cyclic or periodic type of flooding situation is observed.

When the inlet liquid velocity or subcooling are still further increased, then an unusual situation has been observed in which the liquid is "partially" flooded which results in a restricted fluid flow. In this situation, the vapor generated by evaporation seems to take on both a counter current and co-current directions with respect to the fluid flow. The vapor generated before the dryout location is driven by the buoyancy force in a counter current direction upward towards the upper plenum. But the vapor generated at or near the dryout point seems to flow in the co-current direction. The vapor flowing in the counter current direction effectively impedes the liquid flow rate. This can be clearly seen by the accumulation of liquid in the upper plenum which also increases the inlet pressure. The vapor flowing in the counter current direction creates an effective annular blanket around the heated wall and the fluid flows in a restricted vapor annulus about the centerline creating ligaments of fluid which are isolated from the heated wall.

This "partial" wetting or restricted flow phenomena has an enormous consequence on the heat transfer in a reactor situation. For example, if only inlet flow monitoring is available, then the actual cooling of the system would be over estimated in an accident scenario, since not all of the coolant flows down the tube. Furthermore, since the fluid seems to be preferentially restricted from wall contact by the vapor blanket, the heat transfer is reduced depending on the ligament size and the time for breakup and droplet entrainment into the vapor blanket.

\section{Oscillation phenomena}

One of the most unexpected and most violent phenomena observed in the vertical down flow experiments is a steady state oscillation of the fluid in the test section. Visually, a typical scenario is as follows: Initially, there is a large quantity of vapor generated, and it is forced into the upper plenum while simultaneously subcooled fluid enters the upper plenum. A highly agitated mixing of the liquid and vapor takes place, followed by a nearly complete condensation of the vapor. The near quiescent fluid rushes down the test section; however, within 60 to $80 \mathrm{~cm}$ down the test section a large quantity of the liquid-vapor mixture completely changes direction and the liquid-vapor mixture in the test section traverses back into the upper plenum with a violent force acting against gravity. Figures 38-41 show typical temperature and pressure oscillations observed for two extremes of the inlet velocity and subcooling conditions.

Both the amplitude and frequency of the resulting pressure pulse are a function of inlet fluid velocity and subcooling and in general they seem to increase as these parameters increase. This phenomena has been observed in almost all of the experiments performed. Only when the liquid flow rate and subcooling are both low dose the phenomena cease.

\section{Precursory cooling}

Previous studies of vertical up-flow indicated that precursory cooling down stream from the quench front was only of minor consequence and in general did not influence the quench front propagation rate. Physically, this is due to the fact that gravity tends to keep the 
entrained fluid droplets from residing down stream of the propagation of the fluid front. Thus, the amount of entrained fluid transported ahead of the wetting front is inhibited. However, in the case of co-current down flow, gravity entrained fluid transported ahead of the quench front is enhanced. Furthermore since the quench front initially propagates at only $1 / 3$ the rate of upflow, the deposited fluid has a longer time scale to actively increase the amount of quench spots. Visually, the amount of quench spots increase with increasing distance down the test tube. This would qualitatively explain the increase in propagation velocity of the quench front down the test section.

\section{Condensable volume influences}

In general, the upper plenum represents a capacity of the system to condense the vapor which traverses counter current to the direction of the fluid flow. The effectiveness of the condensation or latent heat removal of the upper plenum depends on both the amount of subcooling of the incoming fluid and the quantity of fluid residing in the plenum. If the condensation rate exceeds the generation rate in the heated test section then flooding can be temporarily or permanently stopped. This in turn can have an effect on the frequency and force of the oscillation phenomena. As the condensable volume increases so does the period of oscillation.

Associated with the size of the condensable volume is capacity for venting the vapor. As the venting capability increases, the pressurization needed to overcome the flooding is effectively removed and the period of oscillation again increases.

\section{Rivulet wetting}

When the liquid flow rate is low and the fluid subcooling is large then the heated region of the test section can experience a rivulet wetting instead of a rewetting front propagation. In this situation, there seems to be an insufficient volume of coolant to allow for a full quench front to propagate from the inlet, but there is enough subcooling of the liquid to maintain single or even multiple rivulets approximately 5 to $10 \mathrm{~mm}$ in width. These filaments of liquid can slowly grow in length down the test section in time. Rivulets of up to $70 \mathrm{~cm}$ long have been observed over a period of 300 seconds. Physically, the portion of the rivulet up-stream from the dryout location seem to effectively cool the wall locally and allow for a path of subcooled fluid to come from the upper plenum to the dryout location.

\subsection{Quench Front Propagation Analysis}

In order to provide a quantitative comparison between the up-flow results of Babelli [33] and the down-flow results were compared. Examples of the co-current down-flow results are shown in figures 42 and 43.

\section{Overall comparison of up-flow and down-flow}

The axial distance versus time comparisons of the quench fronts between the up-flow and down-flow data show a definite difference in the local and average velocities of the quench front. For the up-flow data, the quench front velocity was seen to be constant and relatively independent of both the inlet flow rate and the subcooling. And so the local and average 
velocities of the quench front were identical at a steady value of $1.05 \mathrm{~cm} / \mathrm{sec}$. These results are shown in figures 44 and 45 . The conclusions of this study indicated that the quench front advance was dominated by axial heat conduction in the heated surface.

For the down-flow data, two distinct regions can be seen. The first region lasts for approximately $20 \mathrm{~cm}$ down the test section. In this region the propagation front is constant and relatively independent of both flow rate and subcooling; however the average velocity of the quench front are only $0.51 \mathrm{~cm} / \mathrm{sec}$ which is less than half the up-flow velocity. The second region continues past the $20 \mathrm{~cm}$ mark in which the quench front accelerates to local velocities as high as $5.5 \mathrm{~cm} / \mathrm{sec}$. Essentially, for the first region, there appears to be additional mechanism(s) which inhibits the quench front velocity; where as in the second region, there appears to be additional mechanism(s) which increase the quench front velocity. Overall, the average quench front velocity is lower for the down-flow data.

\section{Hypothesis}

At this point, it is conjectured that the flooding phenomena may be the mechanism involved in inhibiting the quench front velocity in the initial region, while the oscillation and precursory cooling phenomena may be the mechanisms involved in accelerating the quench front in the second region. It should be noted that although these conjectures are qualitatively supported by the visualization studies, at present there is no existing analysis to validate these conclusions. Figure 46 shows an example of an inhibited or stalled quench front due to flooding. In this series, the quench front completely stalled at about the $15 \mathrm{~cm}$ mark and for nearly 60 seconds the test section experienced flooding. Figure 47 shows an example of an accelerated quench front in which strong precursory cooling and flow oscillation were present near the $20 \mathrm{~cm}$ mark.

\subsubsection{Conclusions}

Both the observed physical mechanism and overall performance of the down-flow study have shown that the system response of the two phase flow is significantly more complicated than that of either the adiabatic down-flow or heated up-flow studies previously preformed. In general both the data acquisition and the overall data base need to be expanded in order to be able to separate some of these mechanism and obtain both modeling approaches and constitutive relations to either confirm or extend the visualization work completed to date.

\subsubsection{Inverted Annular Experimental Results}

A preliminary study indicated that four types of experimental series could be performed which would clearly extend the knowledge of post dryout downflow. Furthermore, the data acquisition would have to be obtained in six stages of effort which would include: (1) an adiabatic test series; (2) a heat transfer test series; (3) a break-up length fluctuation test series; (4) a void fraction test series at the flow field inlet; (5) a void fraction test series at the flow field outlet; (6) a drift flux test series. 
Even though each of these experimental series can be executed with the design modifications, two economic factors limited the parametric range of each study performed. One limitation of the current apparatus is the condensing capability of the freon dump tank. The current sub-cooler is simply a house-hold use chest freezer which can only take the dump tank to half the subcooling attained in previous experiments. This severely limits both the time it takes for the heat exchange system to recover from an experimental series, and it also severely limits the amount of time an experimental series can run. Both of these limits decrease the total amount of data which can be taken.

A second economic factor which limited the parametric range of the studies was subcooling volume of the freon R-113. Again it must be noted that in previous tests, the dump tank was allowed to maintain a condensation volume which is about twice the current system's volume. This significantly decreased the latent heat removal ability of this system.

A third economic factor which limited the parametric range of the studies was the loss of freon experienced in the gas injection test with heat transfer. Essentially, this represents an adverse heat transfer problem which is impossible to over come with the available equipment. The problem is that when ever a non-condensable gas such as nitrogen is present it acts as an insulation layer which severely reduces the heat transfer coefficient. This in turn requires larger condensation lengths which can not be achieved with the current system.

In order to combat this problem, three actions were taken. First, a large water cooled pre-condenser was installed prior to the dump tank to remove all latent heat prior to dump tank discharge. The system increased the condensation length fifty feet. In addition to this, a re-flux condenser was installed at the dump tank exit in order to help condense out the freon vapor during the combined gas-liquid tests. The third action taken was to operate the tests involving gas injection in a pseudo-closed manner. The procedure in this case was to leave the dump tank closed until it reached two psi-gauge. Then the experimental series was halted, the re-flux condenser was given time to remove as much freon vapor as possible, then the remaining nitrogen-freon vapor was discharged. This extensively reduced the freon loss; however, in spite of these precautions and extreme experimental care, an average of 5 pound of freon per data set was lost.

\subsubsection{Adiabatic Results}

\subsection{Experimental Test Matrix}

The purpose for this experimental series was to simulate the hydrodynamic behavior of inverted annular flow in a similar manner to previous work [32,40,43-45]; however, the data of this thesis provides an extension of the water studies since freon R-113 was the fluid used. Also, the boundary condition differences between the water studies [43] and this study were investigated. And in conjunction with the boundary condition study, an evaluation of the statistical fluctuation of the time series data was also performed. Another purpose for this experimental series was to provide a "same basis" comparison of adiabatic and heat transfer data. This is essential in order to eliminate all mechanism differences except wall super heat and jet subcooling. 
Determination of the test matrix for this research was based on the results of previous test data, the parameters which could be altered experimentally, and the functional dependence of the break-up length. The break-up length can be written:

$$
L_{B}=L_{B}\left(V_{j}, V_{G}, \rho_{j}, \rho_{G}, \sigma, \mu_{j}, \mu_{G}, \delta, \alpha\right) \text {, }
$$

where $V_{j}$ and $V_{G}$ are the jet and gas velocities; $r_{j}$ and $r_{G}$ are the jet and gas densities; $s$ is the surface tension; $m_{j}$ and $m_{G}$ are the respective viscosities; $d$ is the initial disturbance and $a$ is the void fraction. In the list of variables presented in equation (55), it was apparent that additional data for the fluid properties, void fraction and the initial disturbance were most appropriate. Thus, the test matrix of table 4 was established and the data was acquired and analyzed. For this data series the nitrogen gas velocity ranged from 0 to $14 \mathrm{~m} / \mathrm{sec}$ and the R-113 velocity ranged from 1 to $3 \mathrm{~m} / \mathrm{sec}$.

For each hydrodynamic flow condition, one to three minuets of VHS-video filming was performed to acquire both flow regime and break-up length data, and the entire length of the test section was filmed in $20 \mathrm{~cm}$ segments. Also, the flow field parameters were recorded by the data acquisition system simultaneous with the filming; and the estimated average and fluctuating gas parameters were recorded by hand. The video recording of the break-up was analyzed on a frame by frame basis, for a filming rate of 30 frames/second, and a time series data base for each flow condition was obtained. An example of a typical time series for the break-up length is shown in figure 48. Each flow parameter and the break-up length were time averaged for every individual run, and a mean and a standard deviation were calculated. For the diabatic data this procedure was not always able to be used, as discussed in section 3.3.2.2.1.

\subsection{Adiabatic Flow Regime Criteria Modifications}

From an erudite point of view, the development of a flow regime criteria is some what arbitrary and qualitative, especially for visualization work. This view was expressed by De Jarlais and he noted some of the systematic problems encountered in trying to develop criteria for defining break-up length [43]. In this work, the fundamental definitions of the three basic types of flow regimes encountered have remained the same as previously defined and include the sinuous, sinuous-varicose, varicose, and roll-wave entrainment flow regimes. However, the criteria for establishing the break-up length for these flow regimes had to be changed. The reason for this is as follows: for all flow regimes except the sinuous type, De Jarlais included wall wetting in the break-up criteria, which provided a reliable visual technique for defining break-up length, since wall wetting is easy to identify visually. This was provided as a criteria even if the interface clearly disintegrated down stream of the wall wet location.

In this work, wall wetting was ignored for this adiabatic study for two reasons. First, although wall wetting is a necessary criteria when data is acquired by direct visual or photographic observation it can be ignored in the VHS filming since many "photographs" can be acquired in a very short time relative to still-photography. Furthermore, and more importantly it is not a realistic criteria for the post dryout regime since by definition the wall 
cam not be wet. In addition to this, even if temporary wall contact does occur, the VHS filming technique can not distinguish it. Thus, the decision was made to ignore the wall wetting for the adiabatic case in order to allow for a consistent criteria in both the adiabatic and heat transfer studies of this work. It does, however create a minor bias between the adiabatic results in this work as compared to the previous adiabatic study.

In this study, three break-up mechanisms were observed, which are similar in characteristic to the mechanisms seen in the free jet studies and by De Jarlais' work, and they included:

Varicose Break-Up-this regime was characterized by symmetric wave on the jet core which result in alternating locations of jet expansion and contraction. When the wave form has been provided with sufficient time for the wave amplitude to reach $1 / 2$ of the extended jet diameter then the waves forms cause droplets with diameters on the order of the most dangerous wave length.

Simuous Break-Up- this regime was characterized by an asymmetric wave form which both distorts and displaces the liquid jet with respect to the jet's axial line of symmetry. It is distinguished by a sin-wave or snake-like shape and the mechanistic cause of this regime is the aerodynamic forces exerted by the pressure of the vapor on the liquid jet. The sinuous-varicose break-up is a superposition of both break-up mechanisms on the jet.

Roll-Wave Entrainment Break-Up- this regime occurs at higher vapor Reynolds number flows of the sinuous break-up regime. At the crest of a sinuous wave, the decrease in pressure results in an increase in velocity until the entrainment criteria is exceeded and droplets are entrained into the vapor. In many cases this occurred very early in the flow development. In this study, similar ligament formations were seen as in previous studies; however, the droplet formations which have been observed using still photography could not be observed with the VHS filming because of the slow filming rate.

The additional flow regimes visualized for the diabatic study will be discussed in section 3.3.2.2.

\subsection{Analysis of Adiabatic Break-up Length Results}

For the adiabatic series of this thesis, the exit pressure boundary was not open to the atmosphere, and all of the data for the test matrix was acquired, analyzed and extensively compared to the open boundary work [43]. Analysis of the break-up data included investigating: (a) the error analysis of the filming method; (b) comparisons of time series breakup length data; (c) comparisons of initial disturbance data; (d) the break-up lengths dependence on gas velocity; (e) pressure fluctuation data; (f) velocity fluctuation analysis.

From the literature it was apparent that there exists concern over the break-up length fluctuation and the ability to quantify the actual mean deviation of data [43,46-49]; however, this is not usually done because in the past it has been prohibitively expensive and excessively time consuming. In view of this problem, and in light of the (relative) ease that the VHS filming can be performed, an error analysis was performed similar to the statistical method used by 
Wilmarth [50]. In this method, the long term mean fluctuation was examined (via numerical simulation) as a function of sample size in order to determine how large a sample space was required in order to obtain a convergent mean value.

Wilmarth's work was extended in order to provide a more rigorous convergence criteria and was then applied to the jet break-up data acquired for this research. For the jet data both a "stable" or convergent mean value and a "stable" or convergent sample-deviation were necessary so that reliable plots of these quantities could be provided. The rational for such a criteria can be justified by application of the law of large number. Although both the mean:

$$
\bar{X}=\frac{1}{N} \sum_{i=1}^{N} X_{i},
$$

And the absolute mean deviation of the sample space:

$$
s_{M D .}=\frac{1}{N} \sum_{i=1}^{N}\left|X_{i}-\bar{X}\right|
$$

are guaranteed to converge to the actual values as $N \rightarrow \infty$, the convergence rates are not necessarily the same. Thus, the convergence rate of both quantities must be investigated in order to determine which rate is the most restrictive in term quantifying the minimum sample space needed. A typical example of the sequence of events for this type of analysis are provide in figures 49 to 51 . For the break-up length data of time series F7.1, both the mean and deviation are plotted as a function of sample space size. From the figures two typical trends were noted. First, the mean value in this example (and for virtually all the data sets) usually converged prior to the variance, and so the stability of the absolute mean deviation became the restrictive criteria for the minimum sample space instead of the mean value used in Wilmarth's research. Secondly, the mean value almost always converged by 30 samples, indicating that when only mean value information is necessary, the VHS filming method is far superior to the still photography method by virtue of the smaller sample size and by virtue of the much faster data acquisition and reduction time.

The investigation of a minimum sample space criteria was also conducted as a function of gas velocity. A plot of break-up lengths for an extended range of gas velocities is provided in figure 52 along with the mean and absolute deviation calculations provided in figures 53 and 54 respectively. Surprisingly, even though the instantaneous fluctuation of the data seems to be qualitatively different as gas velocity increases, the convergence of the mean seem to be relatively independent of velocity. Again, the absolute mean deviation seems to control the minimum sample space criteria, which was determined to be $N \geq 60$.

With the sample space criteria firmly established, then both the stable mean and standard deviation of the jet break-up data were plotted as a function of inlet gas velocity. A typical set of jet break-up length data for the freon R-113 jet is shown in figure 55. These results indicate that at low gas velocities, $V_{g}$, (within the standard error of the experiment) a relatively constant value of break-up length results. But at some point, once the aerodynamic influences of the gas become important, then the break-up length monotonically decreases as 
gas velocity increases. Furthermore, as the break-up length decreases, the standard error decreases. This indicates a more vigorous and stable disturbance on the vapor-jet interface. This can be justified on a semi-quantitative basis by examining the initial disturbance written in Fourier series form:

$$
\delta(z, t)=\delta_{o} \exp (b t+K z)
$$

where $\delta_{o}$ is the initial disturbance, $\mathrm{b}$ is the growth rate of the disturbance, $\mathrm{K}$ is the wave number and $z$ is the position of the disturbance. As the turbulence amplitude and frequency increases at some fixed position, say the jet outlet, then the break-up length will occur in a shorter distance. Furthermore, as the wave number increases so does the frequency which also decreases the break-up length. The smaller standard error can be accounted for by considering both the frequency spectrum of a turbulent flow and the aerodynamic forces. Klebanoff [51,52] and Kovaznay et.al. have investigated the turbulence phenomena. Their results indicate that near an interface, such as the liquid vapor interface at the vapor jet injection site, the frequency of the turbulence eddies increase and the spectral variation decreases. This would result in a smaller variation in the jet break-up length. Also, as the vapor velocity increases, the pressure gradient and interfacial shear act against the cohesion influence of surface tension, which results in an earlier break-up of the jet.

The adiabatic data of this study was also extensively compared to the adiabatic work of De Jarlais. A direct comparison of similar jet velocity data under similar experimental conditions are presented in figure 56 . When plotted to scale, it becomes immediately evident that both the overall magnitude of the break-up length and the general trend of the data compare very well to De Jarlais data, although for the data of this thesis the break-up length seems to decrease some what faster at the high end of the velocity abscissa. This curve also shows that the overall break-up mechanisms of the free jet and confined jet works are consistent over variation in gas velocity, gas density, liquid density and Ohnesorge number. From the figure it is obvious that two mechanisms exist and that the a clear transition takes place on the order of $2-3 \mathrm{~m} / \mathrm{s}$ since the power of velocity dependence changes from zero to about one. Furthermore, the liquid velocity dependence can be clearly seen in the gas independent region since the breakup length increases with liquid velocity.

One systematic difference between this adiabatic study and the previous study [43] is in the global pressure response. When the exit pressure boundary remained open to the atmosphere, the magnitude of a typical pressure reading was considerably lower than the results obtained in this research. Furthermore, the fluctuation of De Jarlais' data was less than $1 / 10$ the average value of the current study. In figure 57 the differential pressure data for two extreme gas flow velocities is plotted. From the figure, three important points can be made. First, the overall magnitude of the pressure reading for this study was a factor of 5 to 7 greater than the pressure reading of the previous study. Also, for the closed boundary experiment, the magnitude of the differential pressure changed by $25 \%$ over the range of velocities investigated in the study. Finally, the pressure fluctuation of this study became both intermittent and larger as the gas velocity increased. 
This pressure fluctuation affect is particularly difficult to analyze since it is both stochastic and global. The combined problems of the fluctuation being both intermittent and stochastic makes it unlikely that a deterministic representation of the pressure field can be realized. The reason for this is run time. In order to characterize both the amplitude and burst frequency, very long run times would be necessary; however, these long run times are prohibited due to the loss of freon involved. The results of the data available can be qualitatively used to explain the small increase in break-up length for the high velocity data relative to the open boundary study. Initially, the fluctuation of the pressure field can be viewed as an equivalent fluctuation in the velocity field by making an approximate Bernoulli analysis. This is done by assuming that the inertia of the liquid jet is much greater than the gas core and then neglecting any compressibility affects on the gas density. This allows the pressure field to be written as:

$$
\Delta P_{d i f}-1 / 2 \rho_{G} \Delta V_{G}^{2}
$$

where the gas density is on the order of one. Thus, the influence of pressure fluctuation could be converted to a velocity fluctuation which is on the order of 5 to $10 \%$. This increased fluctuation in the interfacial shear would tend to slightly enhance the break-up of the jet.

\subsection{Mechanistic Model Development}

Since the results for the adiabatic work were qualitatively similar to [43] a similar nondimensional data model was examined. From the data in figure 56 it was apparent that the data could be separated into two distinct regions. The first, was a constant gas velocity region which had a jet velocity dependence. The second was a gas velocity dependent region.

In the first region, the free jet data results can be used to qualify scaling criteria, since the results are fairly similar. The results of Weber, Middleman and others [53-56] show that the jet break-up has a functional form:

$$
\frac{L B}{D_{j}} \propto R e_{j}^{N} \sqrt{W e_{j}} .
$$

This form assumed a varicose and laminar jet and relinquishes the surface disturbance term to a fitting coefficient. This, is a reasonable procedure from an experimental point of view, since it is nearly impossible to accurately measure the initial disturbance, let alone provide a relationship between it and the jet break-up length. The correlation form could also be written in terms of a modified capillary number similar to Ishii and Denten [57].

For the region where the gas core begins to induce an aerodynamic influence a drag relation similar to the inception criteria for film flow can be applied in analogy $[58,59]$. For the jet, it is assumed that beyond some criteria point the drag force on the jet interface becomes significant, thus, the drag force acting on the perturbed region of the jet would be proportional to the relative velocity:

$$
F_{d} \propto \rho_{G} V_{G, r e l}^{2} .
$$


Also, as the liquid jet increases in diameter, for a fixed confinement diameter, the interfacial shear term is modified by virtue of the velocity profile modification which occurs. Thus there is a diameter ration influence which must be accounted for. Since the diameter ratio is related to the void fraction, this is the variable of choice. Again, from the free jet data, where the drag induced asymmetric waves occurred, most correlations appear in the form of a relative gas Weber number. These two influences were combined in to one term which included both the drag and the void fraction affects. This resulted in the formulation:

$$
\frac{L_{B}}{D_{j}} \propto\left(W_{G, r e l} / \alpha^{2}\right)^{M},
$$

and would be applicable beyond the transition criteria. The data of this study was examined for the transition criteria based on a relative gas Weber number and it was determined that:

$$
W e_{G, r e l} / \alpha^{2}=1.63 \text {, }
$$

which was very close to the criterion developed by De Jarlais [43] and Iciek [48,49].

With this in mind, it was decided to evaluate the data of this work against the previous adiabatic data in order to determine how closely the data is correlated. In figure 58 the adiabatic data was plotted for the liquid jet modified break-up length as a function of the modified gas Weber number. Essentially, there is good agreement between the results. Two observation should be noted. First, the data seem to be slightly high as compared to De Jarlais' results however the results are still within the standard error of his data. Furthermore, at extremely high velocities, the break-up length of this work begins to decrease at a faster rate. This phenomena would be worth examining as a continuation study at a future date; however it would be more appropriate to use a closed boundary water system because the current experimental apparatus can not afford the freon loss associated with high gas Weber number flow.

\subsubsection{Diabatic Results}

\subsection{Experimental Test Matrix}

The purpose of the diabatic experimental series was to simulate hydrodynamic behavior coupled with liquid and wall boundary thermodynamic influences. This represents experimental work which has not previously been acquired, and this work provides an additional extension to both the water studies and the results of section 3.3.2.1. Furthermore, this work also provides a resource for comparison between the upflow results of Ishii and others $[60,62]$.

Determination of the test matrix was based on three needs which included variation of the thermodynamic influences especially wall superheat and liquid jet subcooling, the desire to develop an explanation for the shorter break-up length data observed in the up flow studies $[33,34]$ and provide a controlled geometry experiment where the oscillation phenomena of section 3.3.1 could be eliminated. For the thermodynamic influences, a parametric study was limited to only a variation of the fluid subcooling and wall superheat was kept fixed. One 
reason for doing this was to reduce the number of experiments necessary to complete the test matrix. Another reason is that over the range of post-CHF temperatures the heat transfer loop can operate at, the wall super heat is more difficult to accurately control than the liquid subcooling. Furthermore it is a more important experimental parameter since in an actual reactor inlet subcooling is measured and the wall superheat is not. The thermodynamic similarity between the upflow studies and this work was maintained by examining three subcooling temperature ranges for the study and furthermore by providing similar inlet fluid flux conditions. These criteria were used to develop the test matrix shown in table 5.

The overall filming procedure for the adiabatic experiments was not acceptable for much of the diabatic experimental series. This was due to an optical problem. During filming, the maximum range of the test section that could be visualized and the break-up interface clearly identified was $25 \mathrm{~cm}$. Thus, four viewing regions were necessary in order to acquire data from the full extent of the test section $100 \mathrm{~cm}$ long. Now for all of the adiabatic data, the maximum deviation of the break-up data never exceeded $15 \mathrm{~cm}$; however, for the diabatic data series, maximum deviation could be as high as $35 \mathrm{~cm}$. For these cases a fundamental problem existed in terms of the data acquisition: how does one accurately determine the mean value of the time series when all of the time series is not captured by the viewing region? An example of the data series acquired from the $\mathrm{H} 68$ test is presented in figure 59, and an example of the statistical analysis is presented in table 6 .

This problem of determining the actual break-up length is additionally aggravated by the fact that it is possible for the jet to simultaneously break-up in multiple location. Hence, it can be unclear if a the break-up viewed in a lower viewing window (such as the $45-70 \mathrm{~cm}$ view of figure 59) is truly the first break-up location or if it is one of the multiple locations which occurred in the upper viewing window (which is the $60-85 \mathrm{~cm}$ view of figure 59). Mathematically, this is a problem of statistical inference when one of the dependent variables is a function of the another dependent variable. This can be seen by considering the data of figure 59. Let the break-up data of the $60-85 \mathrm{~cm}$ view be referred to as $\mathrm{L}_{\mathrm{B} 1}(\mathrm{t})$ and the break-up data of the $45-70 \mathrm{~cm}$ view be referred to as $L_{B 2}\left(L_{B 1}(t), t\right)$. This means that the probability of an event (eg. the break-up length) in the lower view field is conditional based on the weather the break-up occurred in the upper view field. Physically, what we want to do is subtract out the dependence of $L_{B 2}$ on $L_{B 1}$. However, the experimental problem with doing this task is that we do not know how often (eg. the frequency) this event occurs. Thus, we are forced to make a formal guess as to the frequency of the event even though we have no experimental basis for the formulation. Essentially, the only way to obtain this information is to simultaneously film both regions and determine the frequency in which multiply viewed break-up's occur.

In this research the total probability of the jet break-up occurring in both view windows is:

$$
\mathrm{P}\left(L_{B, \text { total }}\right)=\mathrm{P}\left(L_{B 1}\right)+\mathrm{P}\left(L_{B 2}\right)-\mathrm{P}\left(L_{B 1} \cap L_{B 2}\right),
$$

where $L_{B, \text { total }}$ is the total break-up events which occur. This can be put into a sample space estimate of the mean value for $\mathrm{L}_{\mathrm{B} \text {,total }}$ by assuming that the break-up events in each window are mutually exclusive. Thus, the mean value can be written: 


$$
\bar{L}_{B, \text { total }}=f_{1} \bar{L}_{B 1}+f_{2} \bar{L}_{B 2}-f_{1} f_{2} \bar{L}_{B 1} \text {, }
$$

where $f$ represents the sample frequency of the view field. An example of the analysis for the lowest subcooling cases are provided in table 7 .

\subsection{Analysis of Diabatic Break-up Length}

For the diabatic series, all of the data for the test matrix was acquired, analyzed and extensively compared to the previous adiabatic research [43-45], the previous diabatic up-flow research [60-62] and the current adiabatic research. Analysis of the diabatic break-up length included: (a) the error analysis of the filming method; (b) the pressure fluctuation influence; (c) the flow field error analysis; (d) the comparison of diabatic and adiabatic data and; (e) comparison to the up-flow data.

Within the literature examined to date, the actual break-up length fluctuation of diabatic data has never been a statistical evaluated, and so one of the tasks of this research was to develop a methodology and sample space criteria similar to the results developed for the adiabatic data. In section 3.3.2.1.3 it was experimentally determined that the criteria for the adiabatic data acquisition was:

$$
N \geq 60 \text {, }
$$

where $\mathrm{N}$ is the size of the sample space. In the case of the diabatic data, as shown in figure 59 , it is possible to collect fewer "hits" in the sample space since the sample frequency is less than one. And the only true measure of the statistical convergence is the convergence of the actual break-up events visualized. Furthermore, from equation 65 it is necessary that the total breakup length converge. This can only be assured by guaranteeing that the data series is piece wise convergent for each individual viewing range. In view of this, one can modify the adiabatic criteria of equation 66 to be:

$$
f_{k} N_{k} \geq 60
$$

where $\mathrm{f}$ is the sample frequency of the viewing window and $\mathrm{N}$ is the total size of the sample space. The index $k=1$ or 2 , refers to the first of second viewing range respectively. This sampling criteria forced the size of the filming sample space to be on the order of 120 to 240 samples (at $1 / 30 \mathrm{sec}$ per sample) for most of the diabatic data obtained in this work. The application of this criteria unfortunately increased by as much as a factor of four the amount of raw data necessary to develop each data point; however, even at this significant increase in raw data acquisition, this technique is still faster and more reliable than the still photography method.

For the adiabatic data the pressure response was determined to be the cause for decreasing the break-up length as the modified gas Weber number, $\mathrm{We}_{\mathrm{grel}}$, increases beyond the roll wave criteria; however due to the intermittent nature of the fluctuation, the influence was measurable but small. This phenomena drastically changes for the diabatic data which is shown in figure 60. For the diabatic data two consistent trends were observed. First, the pressure fluctuation is strongly dependent on both the inlet liquid flux and subcooling: 


$$
\Delta P_{\text {diff }}=\Delta P_{\text {diff }}\left(J_{L}, \Delta T_{\text {sub }}\right)
$$

As the liquid flux increased at a fixed subcooling, both the magnitude of the pressure signal and the magnitude of the pressure fluctuation increased. Physically, this is due to the increased vaporization of the freon in the heated channel: this mechanism is non-intuitive, since it is the opposite of what happens in pre-CHF flows. In inverted annular flow, the liquid jet is insulated from the wall heat transfer by the vapor blanket until after break-up occurs. After break-up occurs, then entrainment and deposition rates govern the wall impingement which causes vaporization. Thus, as the jet velocity increases the jet break-up length decreases and this effectively provides a longer path for droplet impingement to occur. Subcooling has less of an influence on the net vaporization; however, it does control re-condensation of the vapor which can result in large pressure variations. Figures 57 and 60 can be compared in order to show the order of magnitude difference between the adiabatic and diabatic situations.

In the case of the low liquid flux high, subcooling diabatic flow the pressure signal is similar in magnitude and pressure fluctuation to the adiabatic case and thus the axial extent should be about the same order of magnitude. As the pressure fluctuation increases the results should be to increase the relative velocity (and it's fluctuation) at the interface. This increase in interfacial shear will cause the jet to disintegrate sooner which should decrease the break-up length. Furthermore, the more violent global perturbation on the jet inter face will also provide for a broader spectrum of the initial disturbances which will increase the deviation of the breakup fluctuation. The pressure fluctuations for the diabatic data can be nearly $100 \%$ in the high liquid flux and low subcooling cases. For the system pressure instrumentation, the validine pressure transducer was only rated for \pm 5 Psid, and so it can be seen from the figure that the pressure well exceeded the diaphragm limitation an could potentially damage the device. Furthermore, the instantaneous pressure fluctuations can be estimated to be on the order of 40 psi static equivalent. Since the test section is only rated for $50 \mathrm{psi}$, this violent pressure swing represented a potential safety problem. Thus, the low subcooling tests were restricted.

The results of the flow field error analysis is presented in figure 61. Here we can draw three conclusions about the diabatic data. First, the qualitative discussion concerning the pressure fluctuation is representative of the actual data. Thus the decrease in the subcooling results in a decrease in diabatic break-up length. Next, the standard error of the break-up length increases as the subcooling decreases. This can be interpreted from the pressure fluctuation analysis and is due to the increased perturbation of the liquid interface. The increase in the error in the Reynolds number is also due to the pressure fluctuation. From the data, as the subcooling decreased and the pressure fluctuation increased, the back pressure in the test section resulted in changing the liquid jet velocity as much as $50 \%$. This results in a proportional degradation of the jet Reynolds number uncertainty. It must be noted that in this case the uncertainty is caused by the phenomena and is not a error in the conventional instrumentation sense.

The jet break-up length was also compared to the adiabatic correlation, and those results are shown in figure 62 . Here the dimensionless break-up length modified by the liquid jet parameters is plotted as a function of modified Weber number. Although the functional form seems to be correct, the subcooling is an influence which must be accounted for in order to 
reduce the data into a single line an be dimensionless. From these results it is also apparent that the adiabatic correlation is fairly accurate for much of the subcooling range. But as the pressure influence increases the mechanism is not accounted for by the present theory.

These results have also been compared to the up-flow data of Ishii and co-workers. In this research, it was noted that the quotient of the jet Weber and Reynolds is equivalent to the Capillary number and so the data was formulated as a function of that parameter. An example of these results are provided in figure 63. With some manipulation it can be shown that the jet break-up for the upflow is less than 1/10 the axial extent of the concurrent downflow. The results are even more severe when the data of this research is compared to the data of Babelli. Currently, within the literature there is no theoretical explanation to account for the difference between these flow situations.

\subsection{Diabatic Dimensionless Break-up Length Results}

The methodology applied to the development of a dimensionless break-up length was to build on the mechanistic model of Ishii, De Jarlais and Co-workers [43-45,58-62], and then to provide an extension of the adiabatic results for the post dryout diabatic flow fields. The principle reasoning for this is that the overall response of the heat transfer data shown in figure 62 is qualitatively similar to the adiabatic data however there is also a clear thermodynamic affect which decreases the break-up length. This result has not currently been quantified in the literature.

The order of magnitude of the subcooling affect can be more clearly quantified by observing the raw data of break-up length as a dependent variable of the subcooling as an independent variable. This is shown in figure 64. This shows a proportionality which is approximately second order:

$$
L_{B} \propto \Delta T_{s u b}^{2}
$$

Furthermore, if a formal regression analysis of the raw data, as shown by the dotted line, is performed then the power is quantified as 2.03 . In addition to this, the overall fit of the data to the regression analysis is $R=90$, which nominally adequate. The one shortcoming of this result is that while it is clearly a natural variable for developing a dimensionless result it precludes us from developing an encompassing model for both the adiabatic and diabatic data simultaneously. However, if the result is framed in the context of an actual reactor problem, the this is acceptable since inverted annular flow can not exist in a truly adiabatic flow field.

In order to provide a mechanistic development of the thermodynamic influence in terms of a dimensionless property of the flow field we note that the vaporization seems to be the dominant factor involved in decreasing the break-up length. Thus, it is postulated or assumed that a dimensionless break-up length should be a function of the hydrodynamic or momentum influences as provided by the adiabatic study and a yet undetermined thermodynamic influence, $T^{*}$ : 


$$
L_{B}^{*}=L_{B}^{*}\left(R e_{j}, W e_{j}, W e_{G}^{*}, r e l, T^{*}\right)
$$

where $\mathrm{L}^{*}$ is the dimensionless break-up length, Re and We are the Reynolds and Weber numbers respectively with the subscript $\mathrm{j}$ indicating a jet property, and $\mathrm{We}_{\mathrm{G}, \mathrm{xte}}$ is the void fraction modified gas Weber number. Next, it is also assumed that the principle mechanisms are due to subcooling and due to heat transfer available for vaporization. This implies that there would be a heat transfer influence on the order of the temperature difference between the wall and the fluid. Thus we would write the dimensionless variable as a ratio of these two affects. Furthermore, we require them to be functionally correct with respect to the results of figure 64 . First, we require the break-up length to decrease as the subcooling approaches zero, or $L^{*} \rightarrow 0$ as $T^{*} \rightarrow 0$. Furthermore, as heat transfer to the liquid increases the break-up length must again approach zero. This requires the affect to be inversely proportional to the break-up length. Thus were formally assume the dimensionless form:

$$
T^{*}=\frac{T_{\text {sat }}-T_{F}}{T_{\text {wall }}-T_{\text {sat }}},
$$

where $T_{\text {sat }}$ is the saturation temperature of the fluid, $T_{\text {wall }}$ is the system wall temperature and $T_{f}$ is the fluid temperature. This form of dimensionless or normalized temperature meets the physical restrictions determined from the diabatic data.

By constructing a correlation form, from equations 70 and 71 , we obtain the general functional form:

$$
L_{B}^{*}=K\left(R e_{j}\right)^{m}\left(W e_{j}\right)^{n}\left(W e_{G, r e l}^{*}\right)^{p}\left(T^{*}\right)^{q},
$$

where $L_{B}^{*}$ is the break-up length normalized by the jet diameter; $K$ is the fitting coefficient; $R e_{j}$, $\mathrm{We}_{\mathrm{j}}$ are the jet Reynolds and Weber numbers respectively; and $\mathrm{We}_{\mathrm{G}, \mathrm{rel}}$ is the void fraction normalized gas Weber number. Also, $\mathrm{m}, \mathrm{n}, \mathrm{p}, \mathrm{q}$ are power coefficients which must be determined experimentally. In order to simplify this correlative process it is noted that the functional change of the momentum processes seems to be similar to the adiabatic data. Thus, we assume the coefficients $\mathrm{m}, \mathrm{n}$ and $\mathrm{p}$ as developed in De Jarlais work. Furthermore, we can then develop values for $\mathrm{K}$ and $\mathrm{q}$ from the diabatic data directly by applying regression analysis techniques. When this is done, the value of $\mathrm{K}$ is $3.0 \mathrm{e} 5$ and the value of $\mathrm{q}$ is 2.029 . Thus we can write the final form of the dimensionless axial extent or break-up length as:

$$
L_{B}^{*}=30000\left(R e_{j}\right)^{-0.53}\left(W_{j}\right)^{0.5}\left(W e_{G, r e l}^{*}\right)^{-0.645}\left(T^{*}\right)^{2.029} .
$$

The correlation was applied to the diabatic data series and was plotted as a function of the fluid variables versus the gas variables. This result is shown in figure 65 . From the figure it can be seen that the data reduces fairly well. However, a restrictions is implicit in the correlation because of the difficulty in changing the liquid subcooling. Thus, caution should be observed in applying the correlation beyond the reliable subcooling range of the data base which is $5 C \leq \Delta \mathrm{T}_{\text {sub }} \leq 35 C$. 


\section{CONCLUSIONS}

For a low pressure system with downflow, typical of heavy water isotope production reactors and other research reactors, the occurrence of the critical heat flux under a loss-of-flow or loss-of-coolant accident is significantly affected by various flow instabilities and hydro-dynamic transitions. A detailed stability analysis for downflow systems has been carried out by using the one-dimensional drift flux and small perturbation method. The stability boundary for the flow excursion as well as for the density wave instability has been obtained from the D-partition method. The results are presented in the stability plane.

Experimental data were obtained for flow excursion instability under low flow and low pressure conditions for downflow in an annular geometry. Flow excursion was the dominant instability mode for the downflow conditions and density wave was not observed for low flow restriction, in agreement with the predictions of Nair et. al. [63]. Subcooled boiling is important in downflow instabilities as can be seen for the experimental data for low subcooling. The boundaries were shown to lie at the region of negative quality for both cases of inlet flow restriction. The analytical model can be improved by modeling subcooled boiling.

The quench front propagation research completed to date includes the design, construction and development of the data acquisition series for the investigation of vertical down-flow. In this research a new method for extending the full extent visualization data acquisition was successfully developed and implemented on an experimental post dryout loop. Mechanisms observed include: (a) transient periodic and partial periodic flooding of the heated test section; (b) a strong oscillation phenomena (c) a precursory wetting of the dry-out region beyond the quench front; (d) a condensable volume effect on the flow field which seems to initiate the oscillation phenomena and (e) rivulet wetting of the wall at low liquid fluxes.

The rewetting front study provided a number of important conclusions as to the difference between concurrent up-flow and down-flow. One conclusion is that the rewetting front propagation speed is significantly inhibited by the flooding phenomena which essentially reduces the net fluid flux into the heated channel. In the comparison between previous full extent visualization research and this research, downflow rewetting occurs at $1 / 2$ the speed of the equivalent upflow condition. Another conclusion is that there appears to be a chaotic phenomena referred to as "stalling" in this research. As part of future work, significant effort should be put into investigating this to quantify the reason for the phenomena. This is important since the amount of time the stalling can occur is significant compared to the total rewetting time. A third conclusion is that the precursory cooling is significantly greater than for up flow. Although this results in accelerating the propagation speed of the rewetting front, it does not compensate for the reduction in propagation speed due to flooding.

The most significant development for this work is the coordination of the flow-field data with the visualization data. This effectively eliminates some of the principle concerns with the visualization research as being limited to a qualitative research tool. By coordinating both 
the visualization data and the flow field data, the actual system state and flow regime are known simultaneously. This is essential for developing concrete explanations of the phenomena observed. The next step for future work would to apply this technique to simple heat transfer situations, such as pre-CHF boiling, in order to demonstrate the applicability of this work to a broader class of problems.

In the inverted annular research, an extensive set of experimental tests and the data acquisition was obtained in six stages which included: (1) an adiabatic test series; (2) a heat transfer test series; (3) a break-up length fluctuation test series; (4) a void fraction test series at the flow field inlet; (5) a void fraction test series at the flow field outlet and; (6) a drift flux test series.

For the adiabatic series, the work of Ishii and Co-workers was extended in several significant ways. First, accurate void fraction data acquisition was provided along with the determination of break-up length, and this was performed for the closed atmosphere exit boundary condition. In addition to this, complete time series data acquisition of the flow field variables were obtained. The influence of pressure fluctuation on the break-up length for high flow rates was observed, analyzed and was shown to decrease the break-up length. Furthermore, the data results were examined on a mechanistic level and the results obtained in this work were shown to be in good agreement with the previous results of De Jarlais.

For the heat transfer series, this work represents the only post dryout visualization study for concurrent downflow with heat transfer. The results provide a mechanistic means for evaluating heat transfer influences on the break-up length as a function of fluid subcooling. The most significant problem for the diabatic case break-up length are the global system changes, such as pressure fluctuation, on the local perturbations which cause instabilities. This results in a modification of the break-up length which causes transition from inverted annular to inverted slug flow sooner than predicted by previous studies.

The break-up length fluctuation series represents the only instantaneous time fluctuation data ever acquired for the confined jet problem. This allowed one to obtain an accurate statistical evaluation of the break-up length, which was not currently feasible, and it also allowed one to provide an accurate evaluations of the break-up frequency and flow regimes of the jet. Furthermore, it should be noted that this method makes the entire process of data acquisition and analysis much faster, cheaper and more accurate than the photographic method previously used. As part of future work, these results could be extended to the evaluation of free jet research in order to quantify the statistical fluctuation and break-up frequency for fuel injection systems and other liquid injection applications.

For the void fraction series, the optimization criteria for the densitometer was modified in order to provide accurate results in the presence of heat transfer. Furthermore, the void fraction accuracy in the extremely high void fraction regimes was validated in a real fluid system. In the future, this nozzle injection technique could be similarly applied in an adiabatic study in order to validate the large void fraction values which were not attainable in chapter 3 . For the drift flux series, this data is unique and represents the only research, to date, in which 
the drift flux model has been extended to the inverted annular flow regime along with the constitutive relations necessary for application to fluid systems. In the future, much work will be required in order to get data such as entrainment and deposition rates so that realistic models for inverted flow can be applied to the rewetting front research. 


\section{ACKNOWLEDGMENTS}

This research was supported by the Westinghouse Savannah River Site through the Department of Energy - Office of Energy Research - Nuclear Engineering Research Grant Program. The authors would like to express their sincere appreciation to Dr. Courtney Apperson of SRS, Drs. David Woodall and T.J. Dolan of INEL and the staff of DOE and SRS. 


\section{REFERENCES}

1. D. B. Collins, M. Gacesa and C. B. Parsons, "Study of onset of prematureheat transfer crisis during hydrodynamic instability in a full scale reactor channel", ASME Paper No.71HT-11 (1971).

2. W. H. Lowdermilk, C. D. Lanzo and B. L. Siegel, "Investigation of boiling burnout and flowinstability of water flowing in tubes", NACA-TN 4382 (1958).

3. K. Mishima and M. Ishii, "Critical heat flux experiments under low flow conditions in a vertical annulus," NUREG/CD-2647, ANL-82-6 (1982).

4. K. Mishima and M. Ishii, "Experimental study on natural convection boiling burnout in an annulus," Proc. Intl. Heat Transfer Conf., Vol. 4 pp. 309-314, Munich (1982).

5. K. Mishima, "Boiling burnout at low flow rate and low pressure conditions", Ph.D. Thesis, Kyoto University, Research Reactor Institute (1984).

6. S. W. Webb and J. C. Chen, "A two-region vapor generation rate model for convective film boiling", Intl. Workshop on Fundamental Aspects of Post Dryout Heat Transfer, Salt Lake City, Utah, April 1-4, NUREG/CR-0060 (1984).

7. N. T. Obot and M. Ishii, "Two-phase flow regime transition criteria in post-dryout region based on flow visualization," Intl. J. Heat Mass Transfer, 31, 2559-2570 (1988).

8. J. G. Denten and M. Ishii, "Flow visualization study of post critical heat flux region for inverted bubbly, slug and annular flow regimes," NUREG/CR-5171, ANL-88-27 (1988).

9. D. A. Barnard, F. R. Dell and R. A. Stinchcombe, "Dryout at low mass velocity for an upward boiling flow of refrigerant 113 in a vertical tube,"AERE-R7726 (1973).

10. P. Griffith, C. T. Avedisian and J. P. Walkush, "Counterflow critical heat flux", AICHE Symposium series, No. 174, vol. 74, 149 (1980).

11. G. F. Hewitt, H. A. Kearsey, P. M. C. Lacey and D. J. Pulling, "Burnout and nucleation in climbing film flow", Int. J. Heat Mass Transfer, 8, 793 (1965).

12. J. A. Boure, A. E. Bergles and L. S. Tong, "Review of two-phase flow instability", ASME Paper No. 71-HT-42 (1971).

13. M. Ishii, "Study of flow instabilities in two-phase mixtures," ANL-76-23 (1976). 
14. M. Ishii and H. Fauske, "Boiling and dryout behavior in a liquid metal fast breeder reactor subassembly bundle under low heat flux and low flow conditions, "Nucl. Sci. Eng, 84, 131-146 (1983).

15. M. Ledinegg, "Instability of flow during natural and forced convection",Die Warme, 61, 891-898 (1938), Translation USAEC-tr-1861.

16. S. Lele, "Stability analysis of downflow for Westinghouse Savannah River Site reactor", M.S. Thesis, Purdue University, School of Nuclear Engineering, (1992).

17. M. Ishii and I. Kataoka, "Scaling laws for thermal hydraulic system under single-phase and two-phase natural circulation," Nucl. Eng. Design., 81, 41-425 (1984).

18. G. Kocamustafaogullari and M. Ishii, "Scaling of two-phase flow transient using reduced pressure system and simulant Fluid," Nucl. Eng. Design., 104, 121-132 (1987).

19. D.P. Jordan, "Film transition boiling", Adv. Heat Transfer, 5, 55-128(1968).

20. L.D. Clemments and C.P. Clover, "Natural convection film boiling heat transfer", Ind. Eng. Chem., 62(9), 26-46 (1970).

21. E.K. Kalinin, I.I. Berlin and V.V. Kostyuk, "Film boiling heat transfer",Adv. Heat Transfer, 11, 51-197 (1975).

22. W.F. Laverty and W.M. Rohsenow, "Film boiling of saturated nitrogen flowing in a vertical tube", ASME J. Heat Transfer, 89, 90-98 (1967).

23. R.P. Forslund and W.M. Rohsenow, "Dispersed flow film boiling", ASME J. Heat Transfer, 90, 399-407 (1968).

24. M. Ishii and G. De Jarlais, "Flow regime transition and interfacial characteristics of inverted annular flow", Nucl. Eng. Des., 95, 171-184 (1986).

25. M. Ishii and G. De Jarlais, "Flow visualization study of inverted annular flow of post dryout heat transfer region", Nucl. Eng. Des., 99, 171-184 (1986).

26. I. Vojtek, "Investigation of dispersed flow heat transfer using different computer codes and heat transfer correlation", Pro. 1st Int. Workshop on Fundamental Aspects of Postdryout Heat Transfer, NUREG/CP-0060, Salt Lake City, Utah, 2-4 April (1984).

27. D.C. Groeneveld, "Inverted annular and low quality film boiling: a state-of-the-art report", Keynote Paper, Pro. 1st Int. Workshop on Fundamental Aspects of Post-dryout Heat Transfer, NUREG/CP-0060, Salt Lake City, Utah, 2-4 April (1984). 
28. J.C. Chen, "Review of post-dryout heat transfer in dispersed two-phase flow", Keynote Paper, Pro. 1st Int. Workshop on Fundamental Aspects of Post-dryout Heat Transfer, NUREG/CP-0060, Salt Lake City, Utah, 2-4 April (1984).

29. G. Yadigaroglu and A. Bensalem, "Interfacial mass generation rate modeling in nonequilibrium two-phase flow", Pro. 1st Int. Workshop on Fundamental Aspects of Postdryout Heat Transfer, NUREG/CP-0060, Salt Lake City, Utah, 2-4 April (1984).

30. R. Nelson and C. Unal, "A phenomenological model of the thermal hydraulics of convective boiling during the quenching of hot rod bundles, Part I: Thermal Hydraulics Model," Los Alamos National Laboratory Report LA-UR-91-209, 1991.

31. M. Ishii and J.P. Denten, "Two-phase flow characteristic of inverted bubbly, slug and annular flow in post-critical heat flux region", Nucl. Eng. Des., 121, 349-366 (1990).

32. G. De Jarlais and M. Ishii, "Inverted annular flow experimental study", Argonne National Laboratory Report ANL-85-31, NUREG/CR-4277 (1985).

33. I. Babelli, "Flow visualization study of post-critical heat flux in inverted flow",M.S. Thesis, Purdue University, School of Nuclear Engineering, (1992).

34. I. Babelli, S.T. Revankar and M. Ishii, "Flow Visualization Study of Post-Critical Heat Flux in Inverted Flow," Nucl. Eng. Des. 146, 15-24, 1994.

35. M. Ishii, Thermally Induced Flow Instabilities in Two-Phase Mixtures in Thermal Equilibrium, PhD Thesis, Georgia Institute of Technology, (1971).

36. E. P. Serov, The operation of once-through boilers in variable regimes, Technical Report 11, Turdy, Moscow Energ. Inst., (1953).

37. D.C. Groenveld and S.R.M. Gardiner "Post CHF Heat Transfer Under Forced Convective Conditions," Proc. Symposium on the Thermal and Hydraulic Aspects of Nuclear Reactor Safety, $A S M E, 1,43-73,1977$.

38. J.G. Collier "Post-Dryout Heat Transfer - A Review of the Current Position," Proceedings of NATO Advanced Study Institute, Istanbul, Turkey, Vol 2, 769-813, 1976.

39.F. Mayinger and H. Langner, "Post-Dryout Heat Transfer," Proceedings from 6th International Heat Transfer Conference, Toronto, Vol. 6, 181-198, 1978.

40. G. De Jarlais, M. Ishii and J. Linehan "Hydrodynamic Stability of Inverted Annular Flow in an Adiabatic Simulation," ASME J. Heat Transfer 108, 84-92, 1986 
41. G. De Jarlais, "Inverted Annular Run Experimental Facility: Operation and Maintenance Manual," Argonne National Laboratory, (no number assigned), (no date available).

42. CRC Handbook of Chemistry and Physics, 48-th edition, 1968-1969, section E55.

43. G. De Jarlais, "An Experimental Study of Inverted Annular Flow Hydrodynamics Utilizing an Adiabatic Simulation," Argonne National Laboratory Report, ANL-83-44, NUREG/CR$3339,1983$.

44. G. De Jarlais and M. Ishii, "Hydrodynamics of Adiabatic Inverted Annular Flow - An Experimental Study," 3rd Multi-Phase Flow and Heat Transfer Symposium, Miami Beach, FL, Vol. 1, 317-331, 1984.

45. M. Ishii and G. De Jarlais "Flow Regime Transition and Interfacial Characteristics of Inverted Annular Flow," Nucl. Eng. Des. 95, 171-184, 1986.

46. R.M. Christiansen and A.N. Hixson, "Break-up Length of a Liquid Jet in a Denser liquid," Ind. Eng. Chem. 49, pg. 1017, (1957).

47. T.F. Chen and J.R. Davis, "Disintegration of a Turbulent Water Jet," Proc. ASCE, Hyd. Div. 90, Pg. 175, (1964).

48. J. Iciek, "The Hydrodynamics of a Free, Liquid Jet and their Influence on Direct Contact Heat Transfer -I," Int. J. Multiphase Flow 8, 239-249, 1982.

49. J. Iciek, "The Hydrodynamics of a Free, Liquid Jet and their Influence on Direct Contact Heat Transfer -II," Int. J. Multiphase Flow 8, 251-260, 1982.

50. T. L. Wilmarth, "A Study of Two-Phase Flow Characteristics in Narrow Channels," MSNE Thesis, Purdue University, (1993).

51. P.S. Klebanoff, "Characteristics of Turbulence in a Boundary Layer with Zero Pressure Gradient," NACA Report No. 1247, (1955).

52. P.S. Klebanoff, K.D. Tidstrom, "Mechanisms by Which a Two-Dimensional Roughness Element Induces Boundary Layer Transition," Phys. Fluids 15, 1173-1188, (1972).

53. R.P. Grant and S. Middleman, "Newtonian Jet Stability," A.I.Ch.E Journal 12, 669-678, 1966.

54. R.W. Fenn and S Middleman, "Newtonian Jet Stability: The Role of Air Resistance," A.I.Ch.E Journal 15, 379-383, 1969. 
55. R.E. Phinney, "Stability of a Laminar Viscous Jet - The Influence of the Initial Disturbance Level," A.I.Ch.E Journal 18, 432-434, 1972.

56. R.E. Phinney, "Break-up of a Turbulent Liquid Jet in a Low-Pressure Atmosphere," A.I.Ch.E Journal 21, 996-999, 1975.

57 M. Ishii and J.P. Denten, "Flow Regime Transition and Interfacial Characteristics of Inverted Annular Flow," Nucl. Eng. Des. 99, 171-184, (1986).

58. M. Ishii and M.A. Grolmes, "Inception Criteria for Droplet Entrainment in Two-Phase Concurrent Film Flow," A.I.Ch.E. Journal 21, 308-318, 1975.

59. G. Hestroni Ed., "Handbook of Multi-Phase Flow," Hemisphere Pub, 1983.

60. N.T. Obot and M. Ishii, "Two-Phase Flow Regime Transition Criteria in Post-Dryout Region Based on Flow Visualization Experiments," Argonne National Laboratory Report, ANL-87-27, NUREG/CR-4972, 1987.

61. N. T. Obot and M. Ishii, "Two-Phase Flow Regime Transition criteria in Post-Dryout Region Based on flow Visualization Experiments," Int. J. Heat Mass Transfer 31, 2559-2570, 1988

62. M. Ishii and J.P. Denten, "Two-Phase Characteristic of Inverted Bubbly, Slug and Annular Flow in Post-Critical Heat Flux Region," Nucl. Eng. Des. 121, 349-366, 1990.

63. S. Nair, S. Lele, M. Ishii and S. T. Revankar, "Analysis of Flow Instabilities and their role on Critical Heat Flux for two phase down flow and low pressure systems", submitted for publication. 


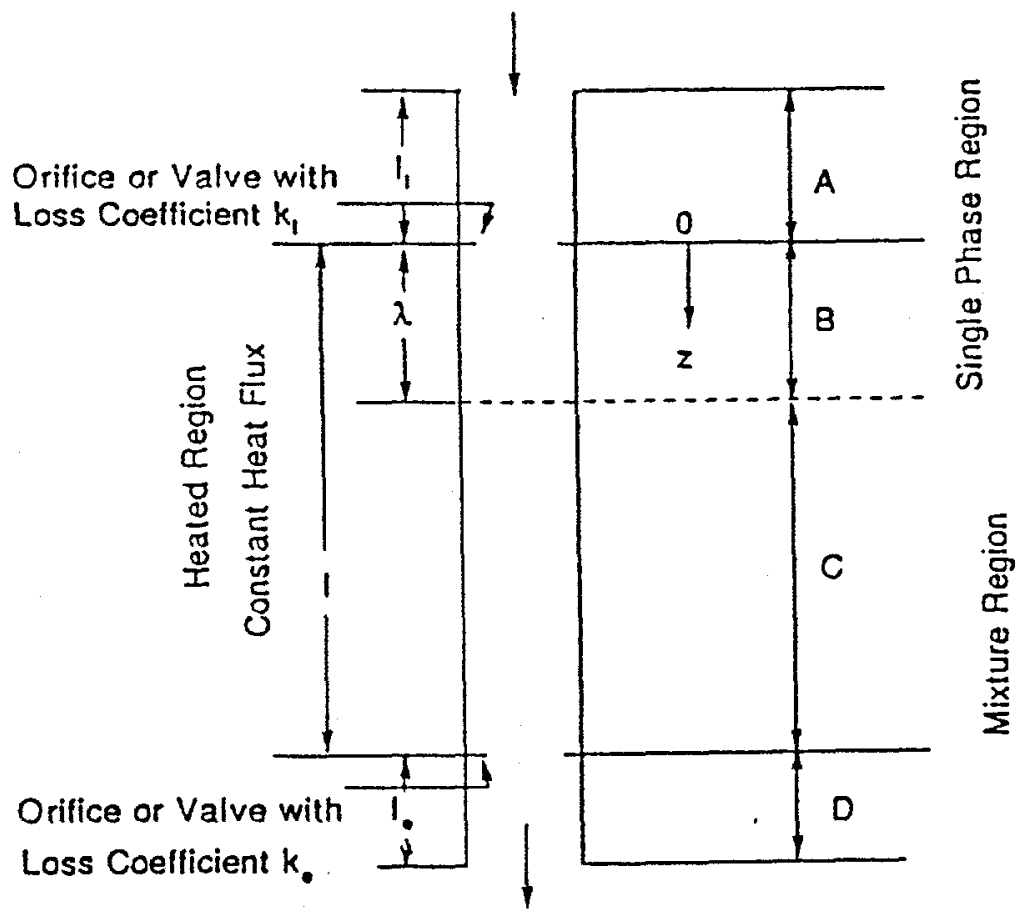

Fig.1. Schematic diagram of the System.

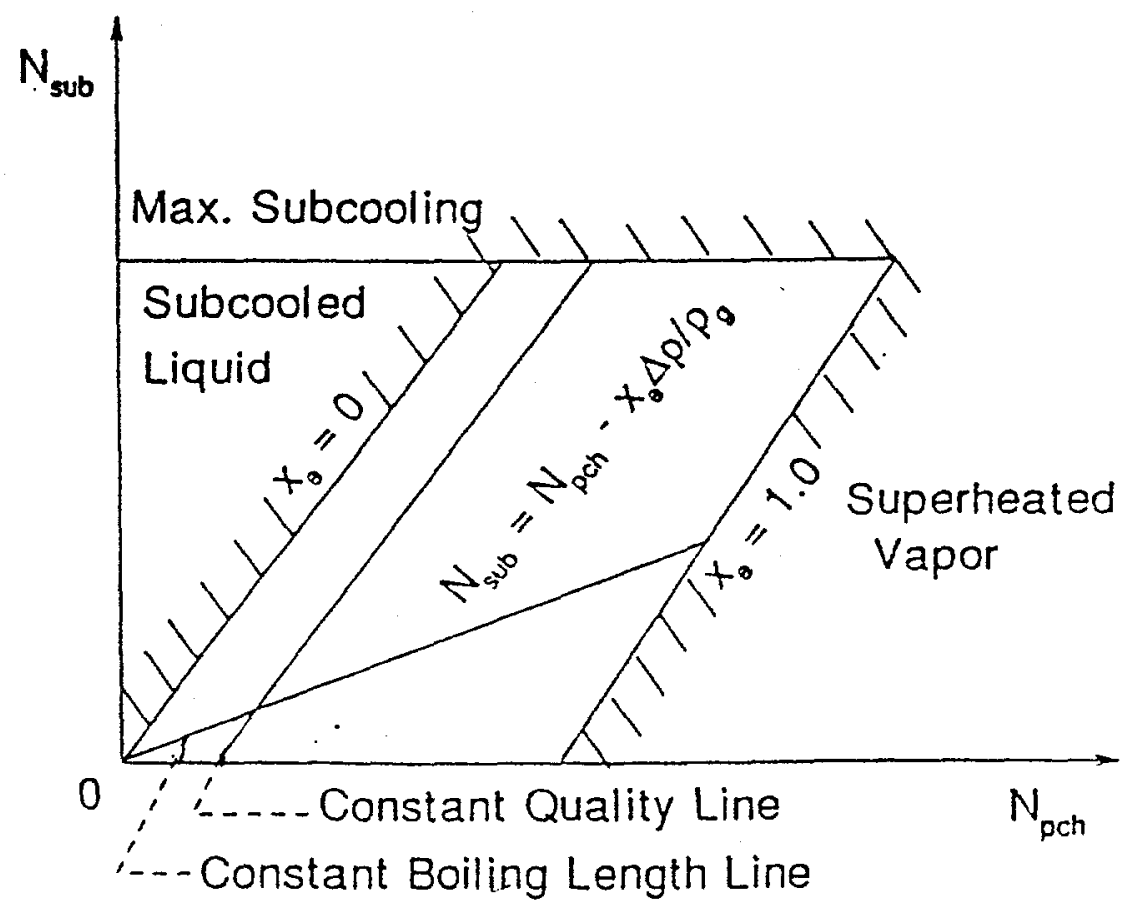

Fig.2. Stability plane with basic characteristics. 


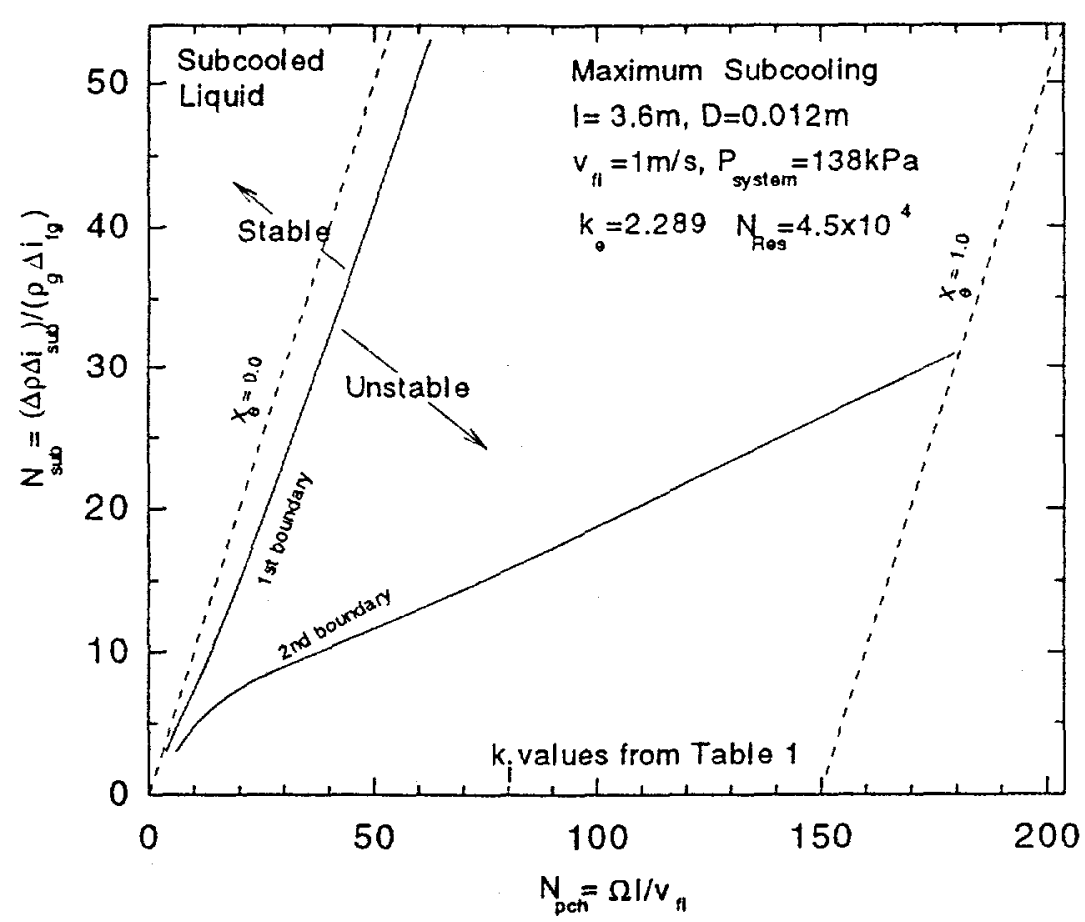

(a)

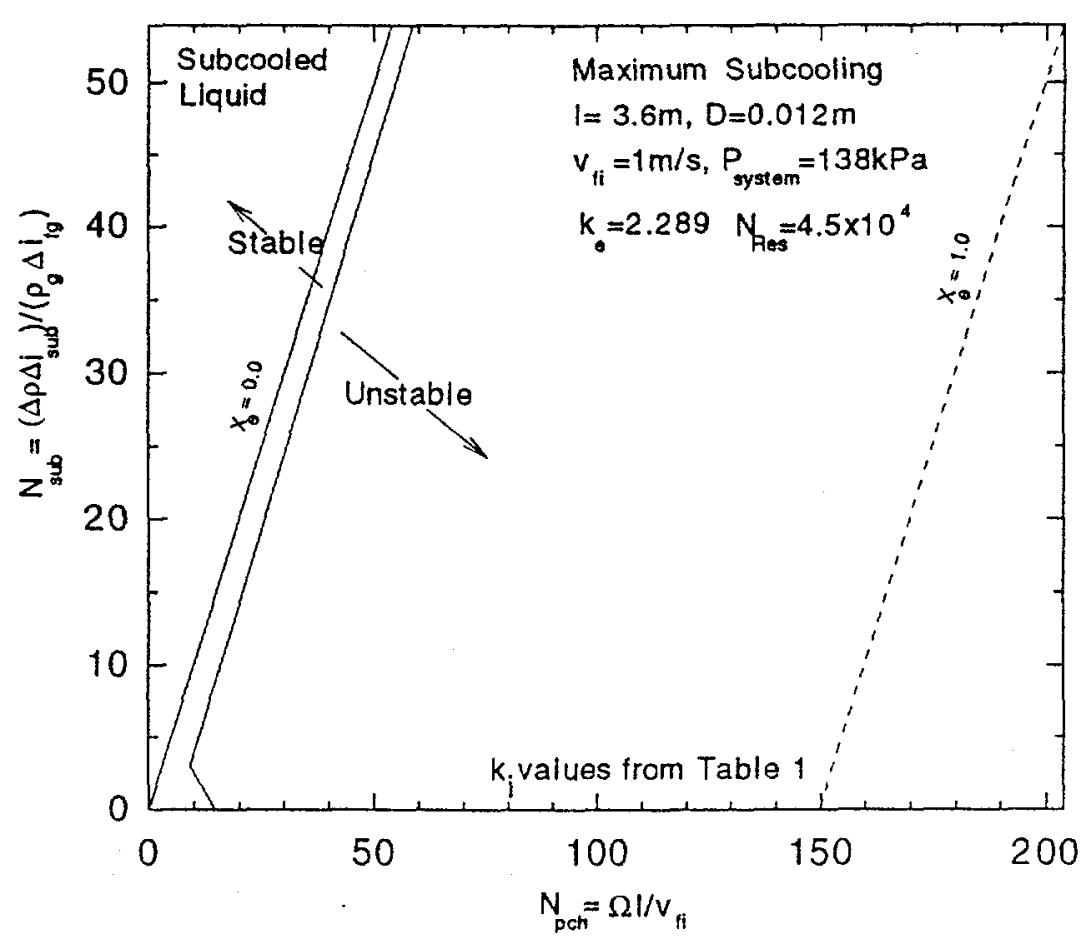

(b) 


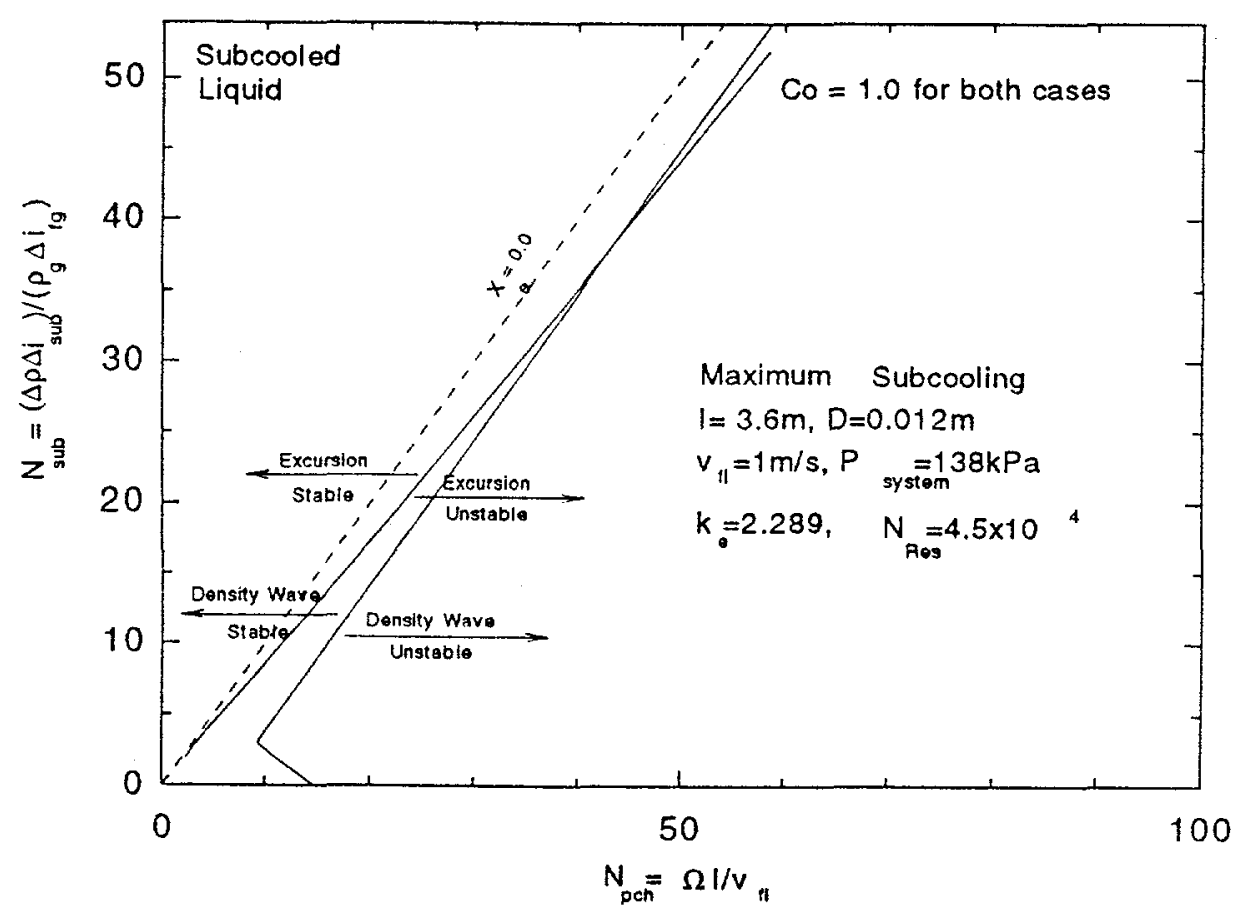

(c)

Fig.3. Stability boundary (a) for flow excursions, (b) for density wave oscillations, (c) both instabilities together. 


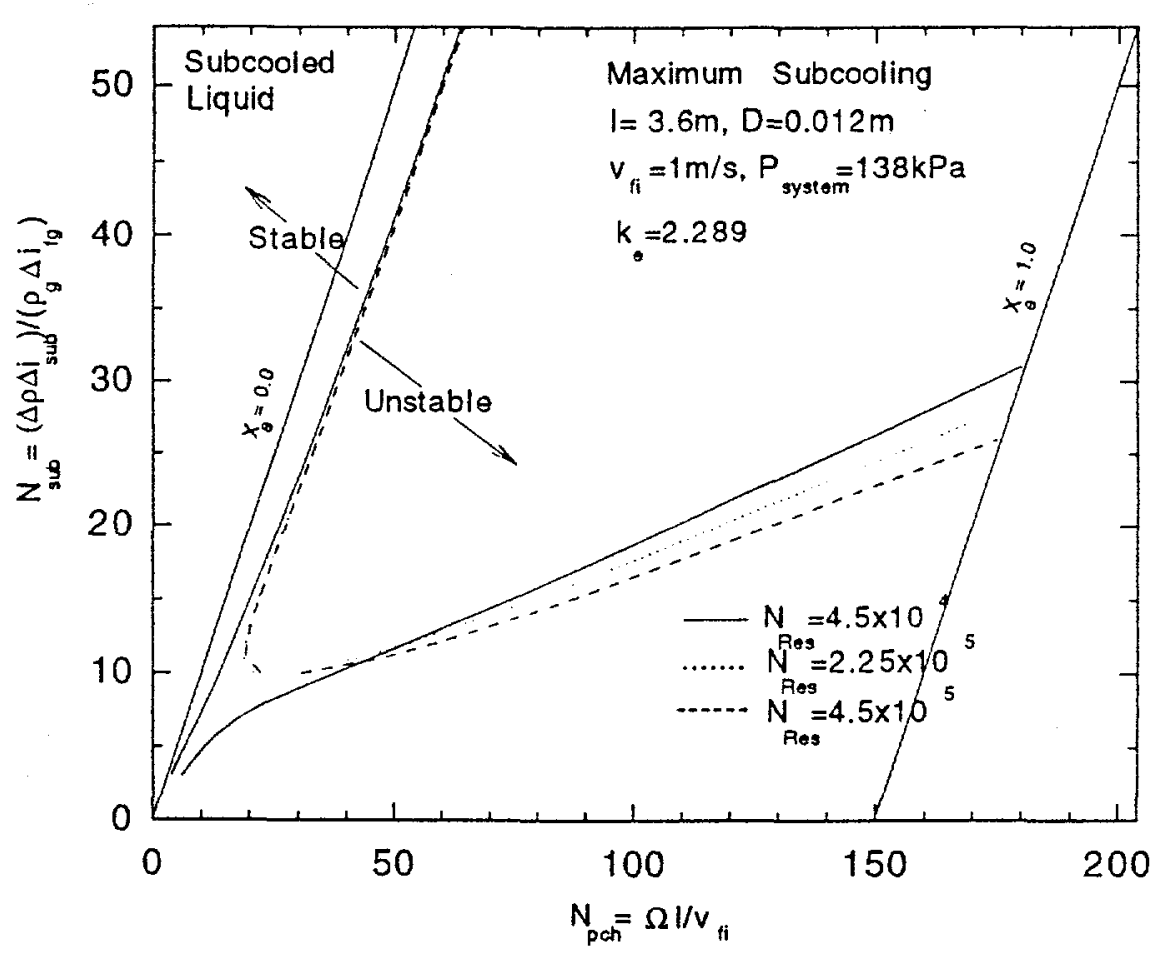

(a)

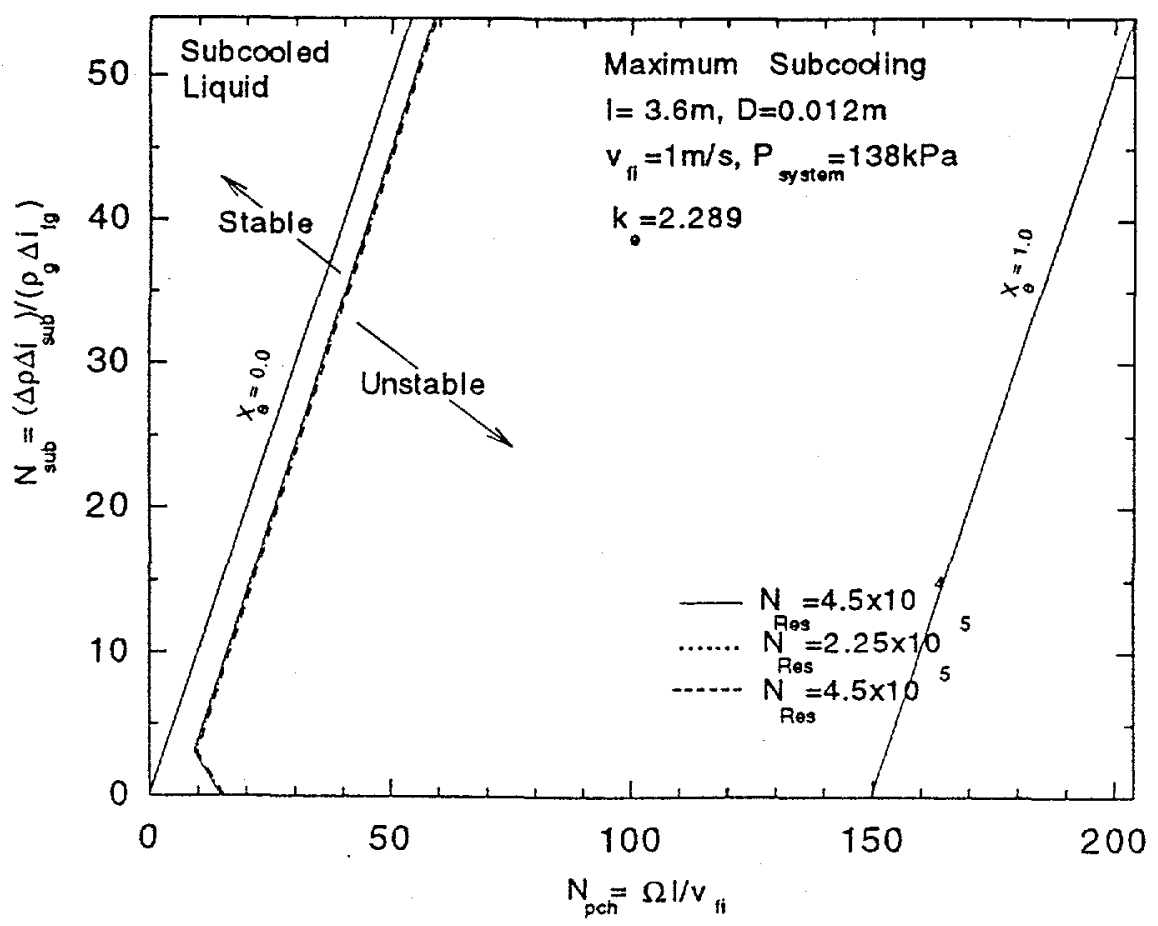

(b)

Fig.4. Effect of inlet velocity on the stability boundary (a) for flow excursions, (b) for density wave oscillations. 


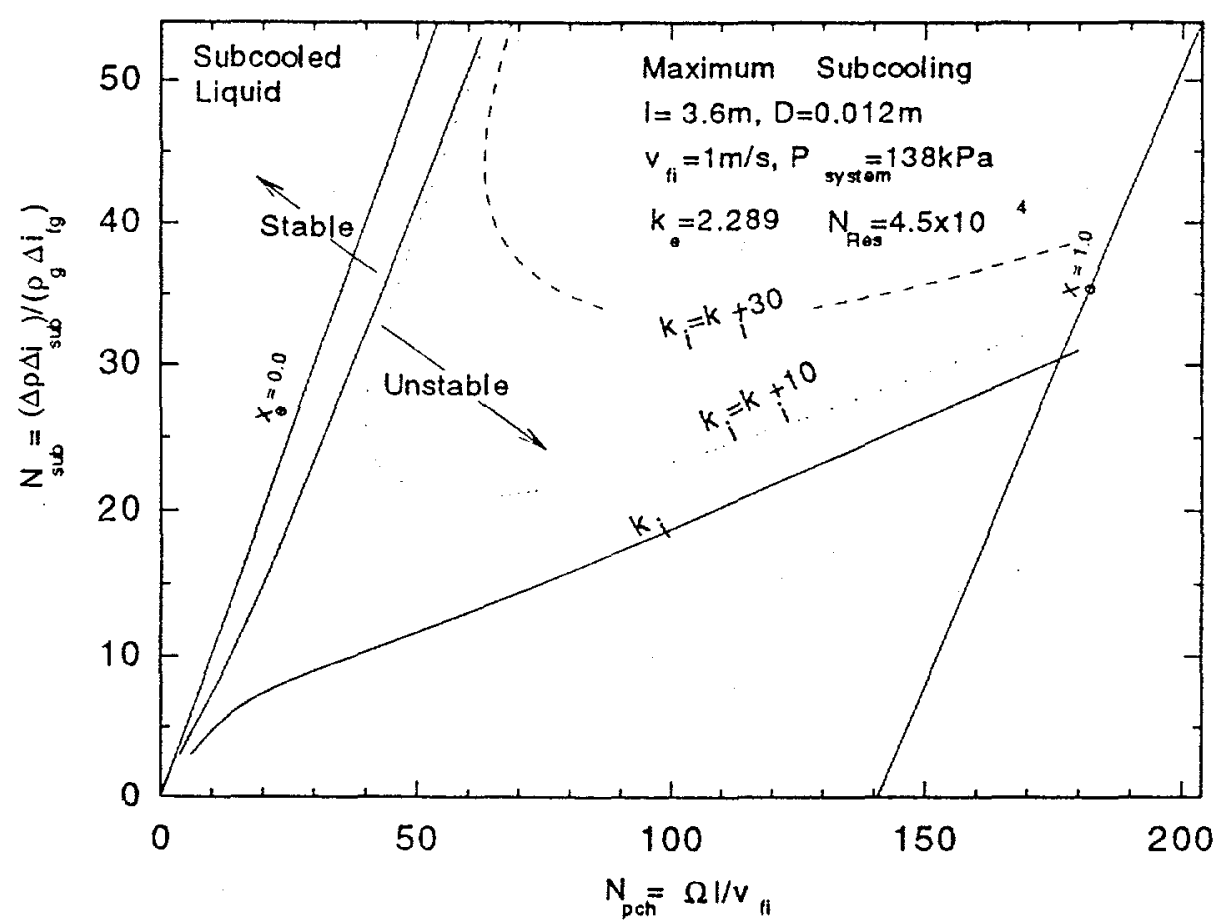

(a)

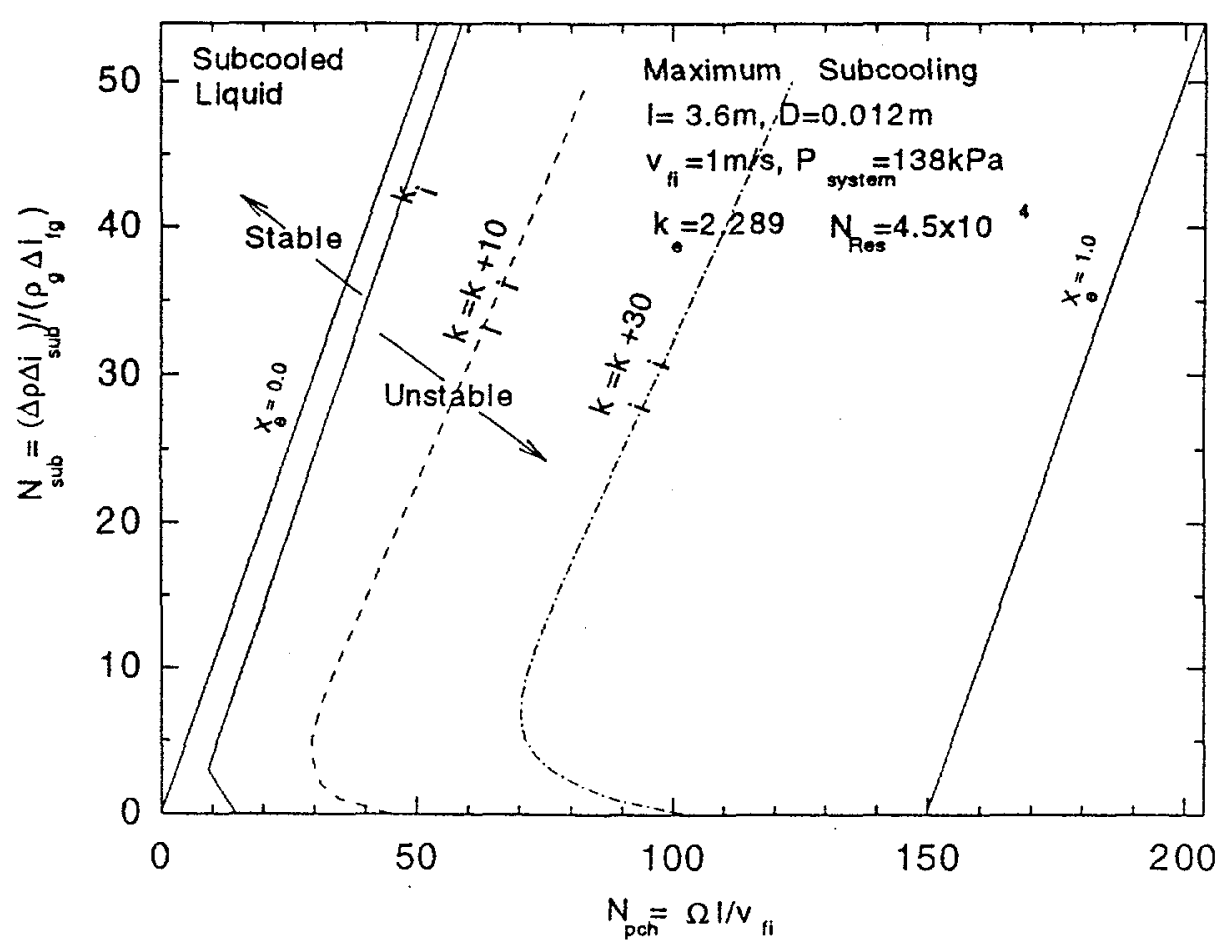

(b)

Fig.5. Effect of inlet throttling on the stability boundary (a) for flow excursions, (b) for density wave oscillations. 


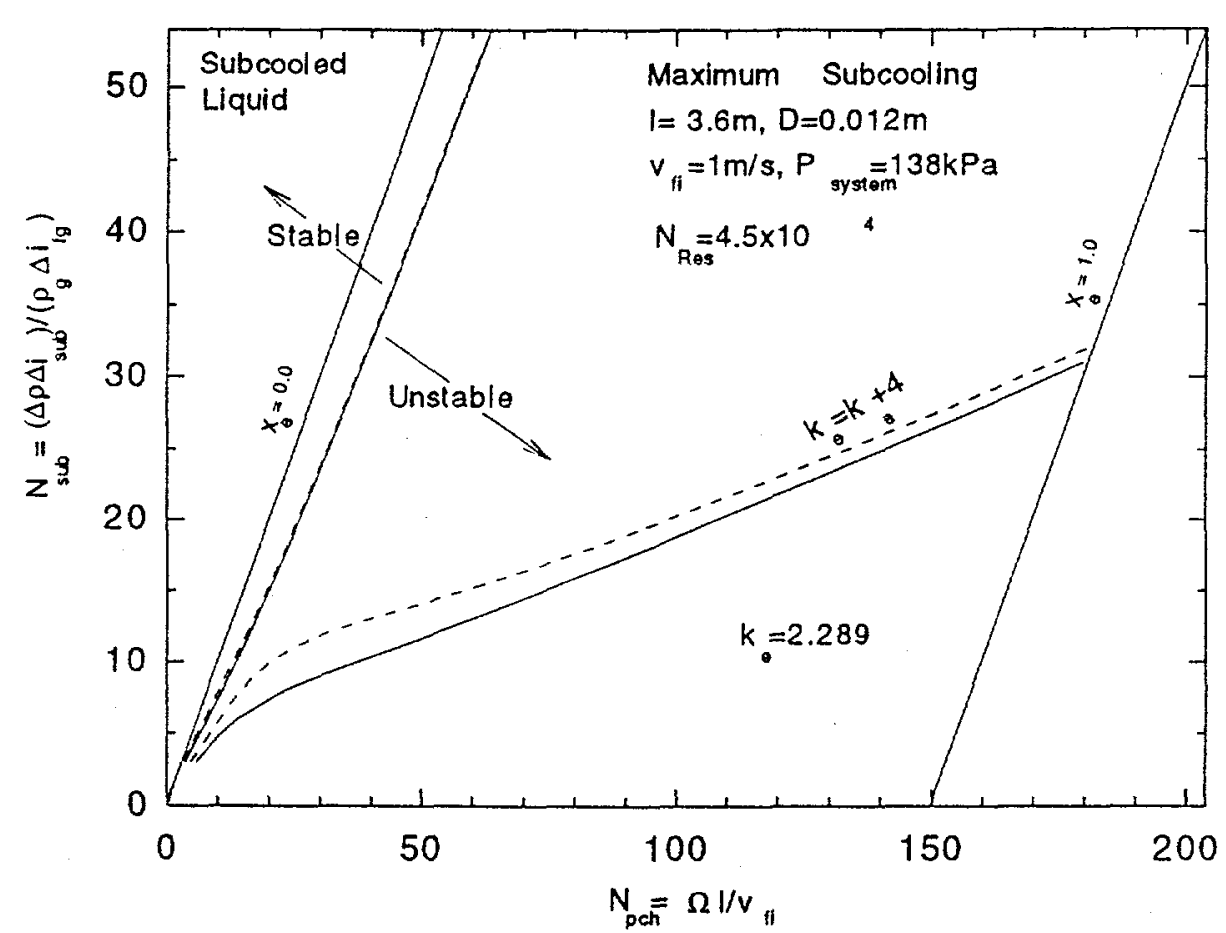

(a)

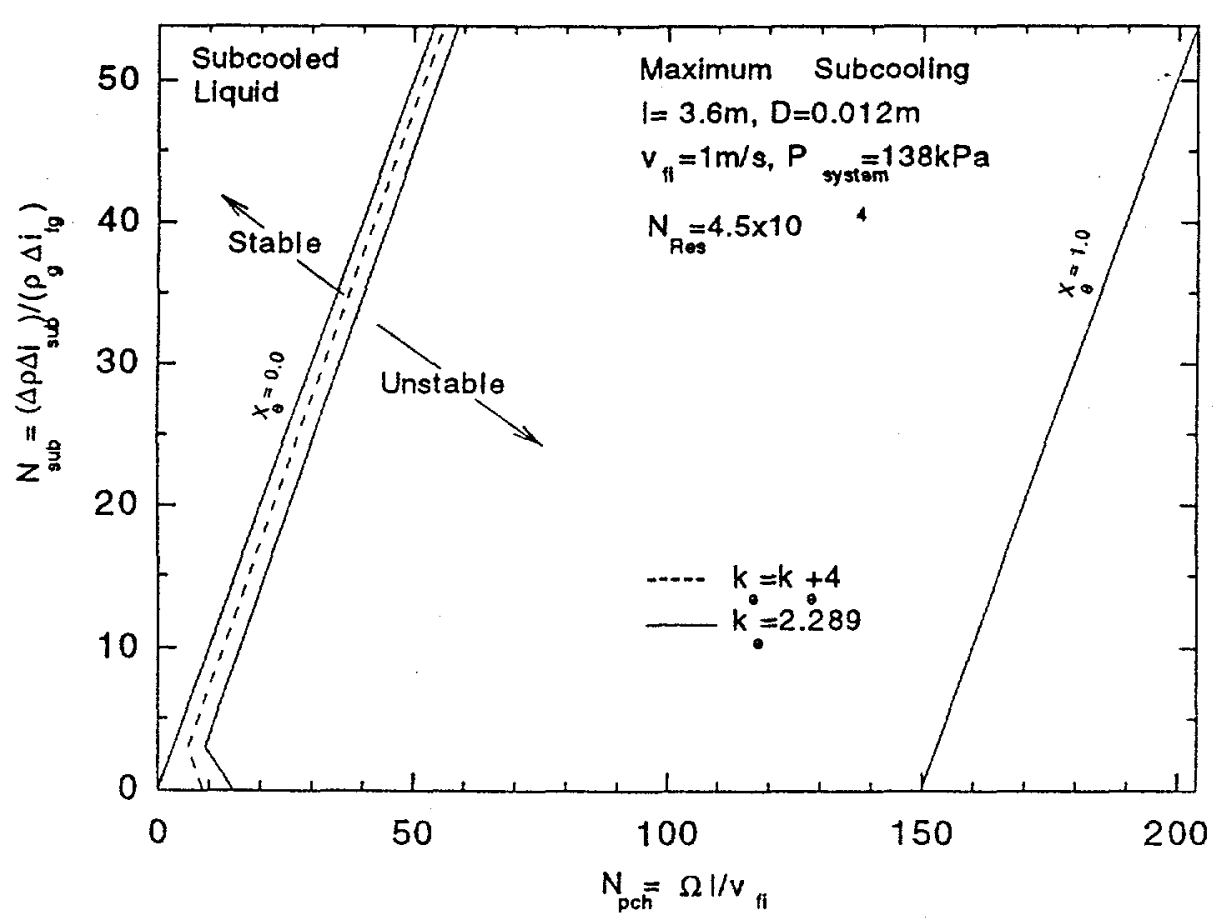

(b)

Fig.6. Effect of exit throttling on the stability boundary (a) for flow excursions, (b) for density wave oscillations. 


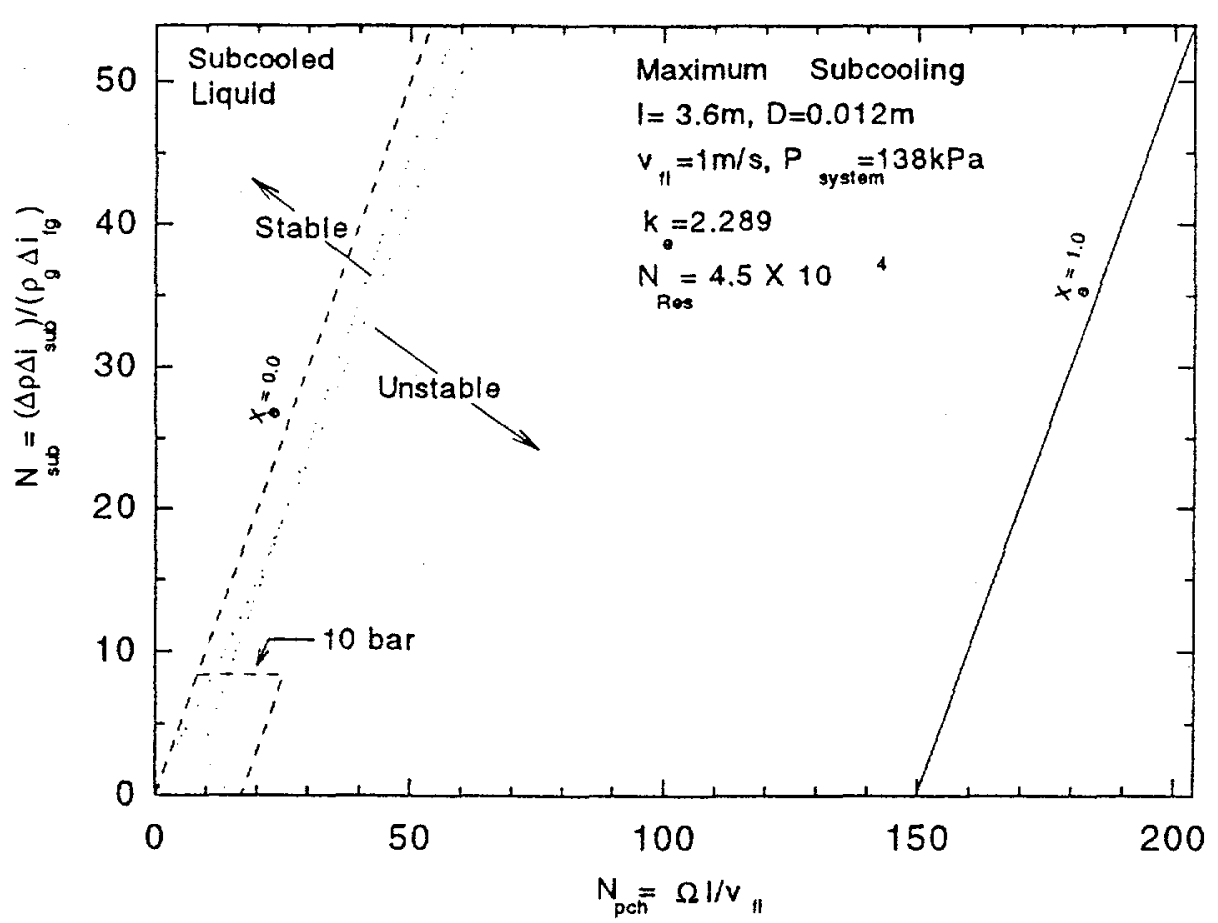

(a)

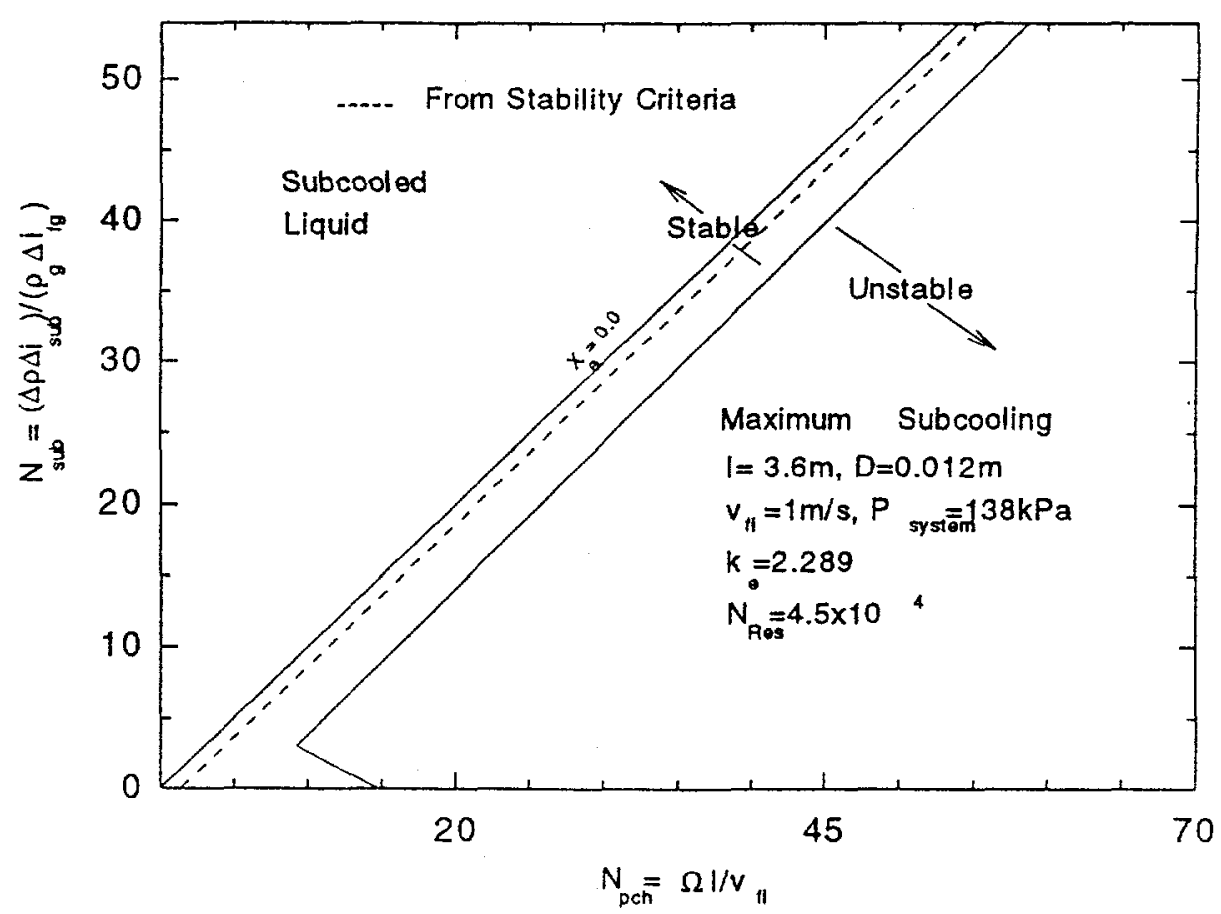

(b)

Fig.7. (a) Effect of system pressure on system stability, (b) simple stability criterion and stability boundary for density wave oscillation. 


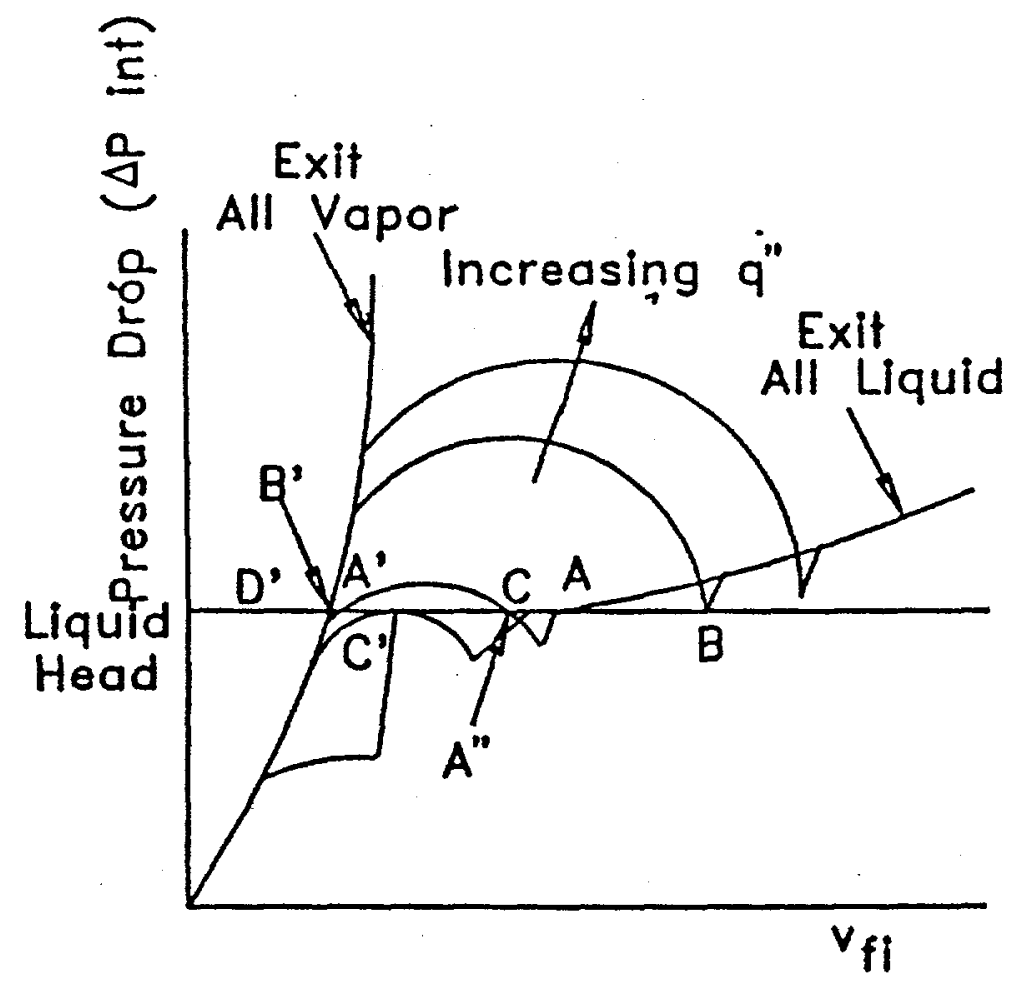

Fig.8. Internal pressure drop as a function of inlet flow. 


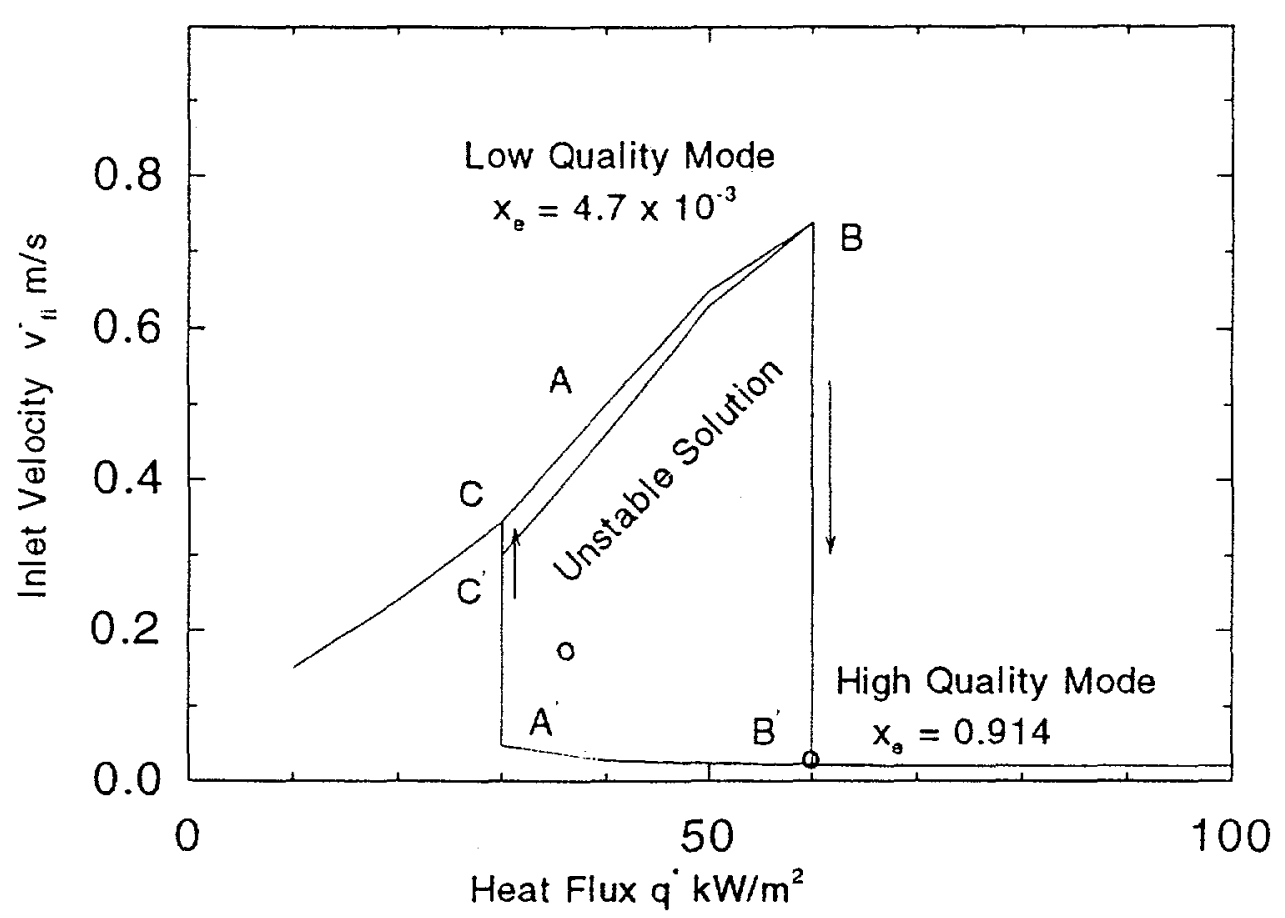

(a)

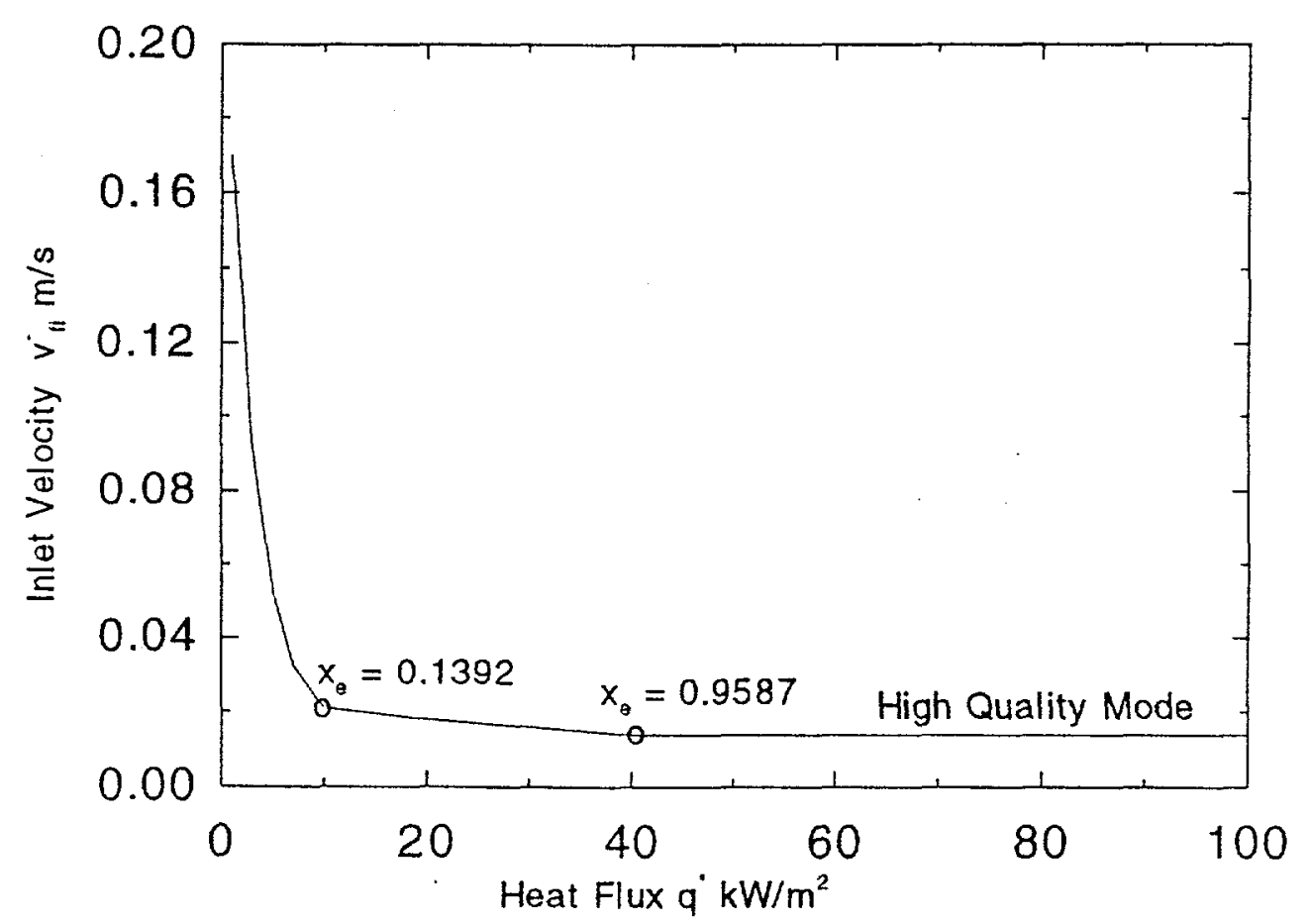

(b)

Fig.9. Inlet flow as a function of heat flux : (a) $\Delta p_{\text {ext }}=1.2 \times$ hydrostatic head, (b) $\Delta p_{\text {ext }}$ $=1.1 \times$ hydrostatic head. 


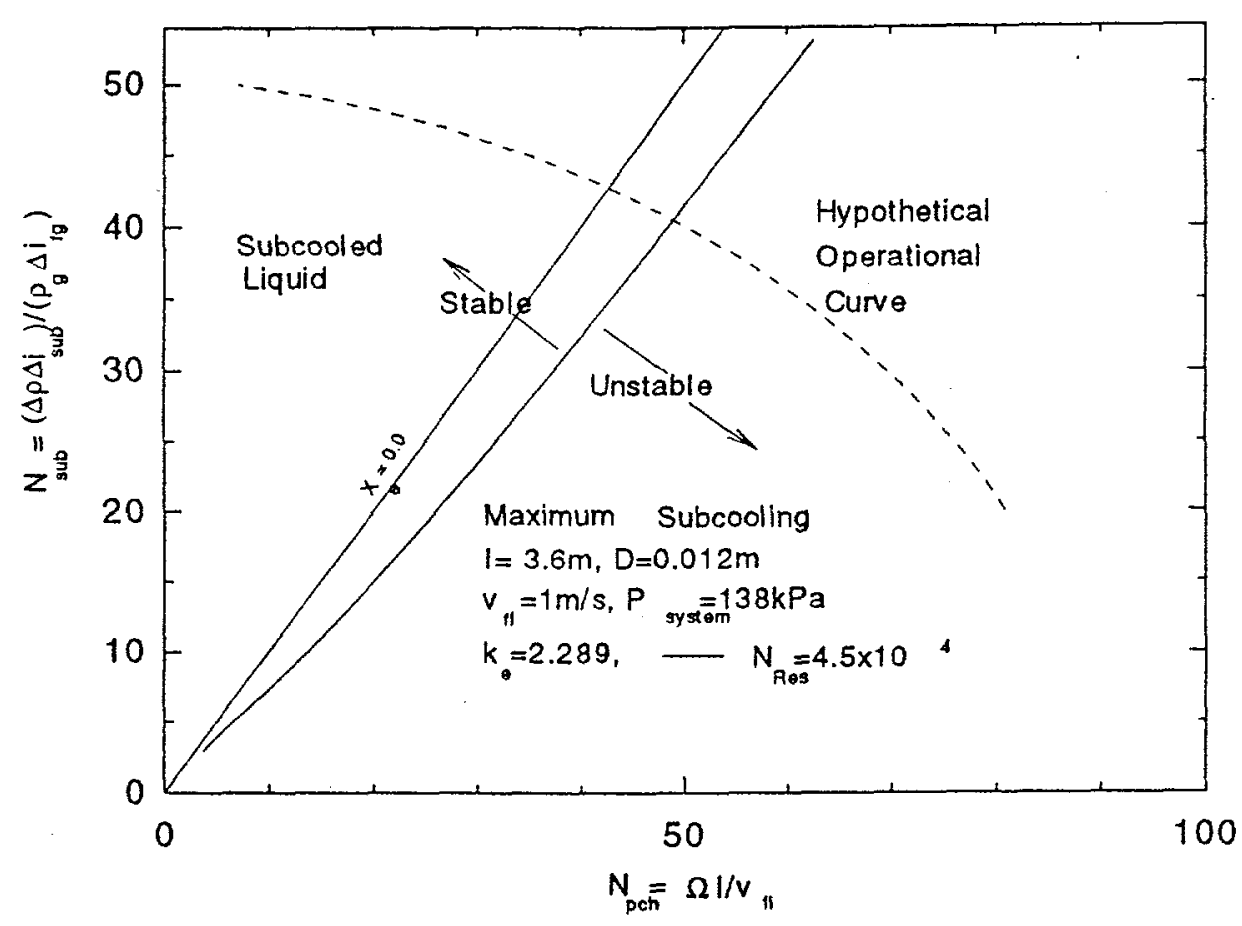

(a)

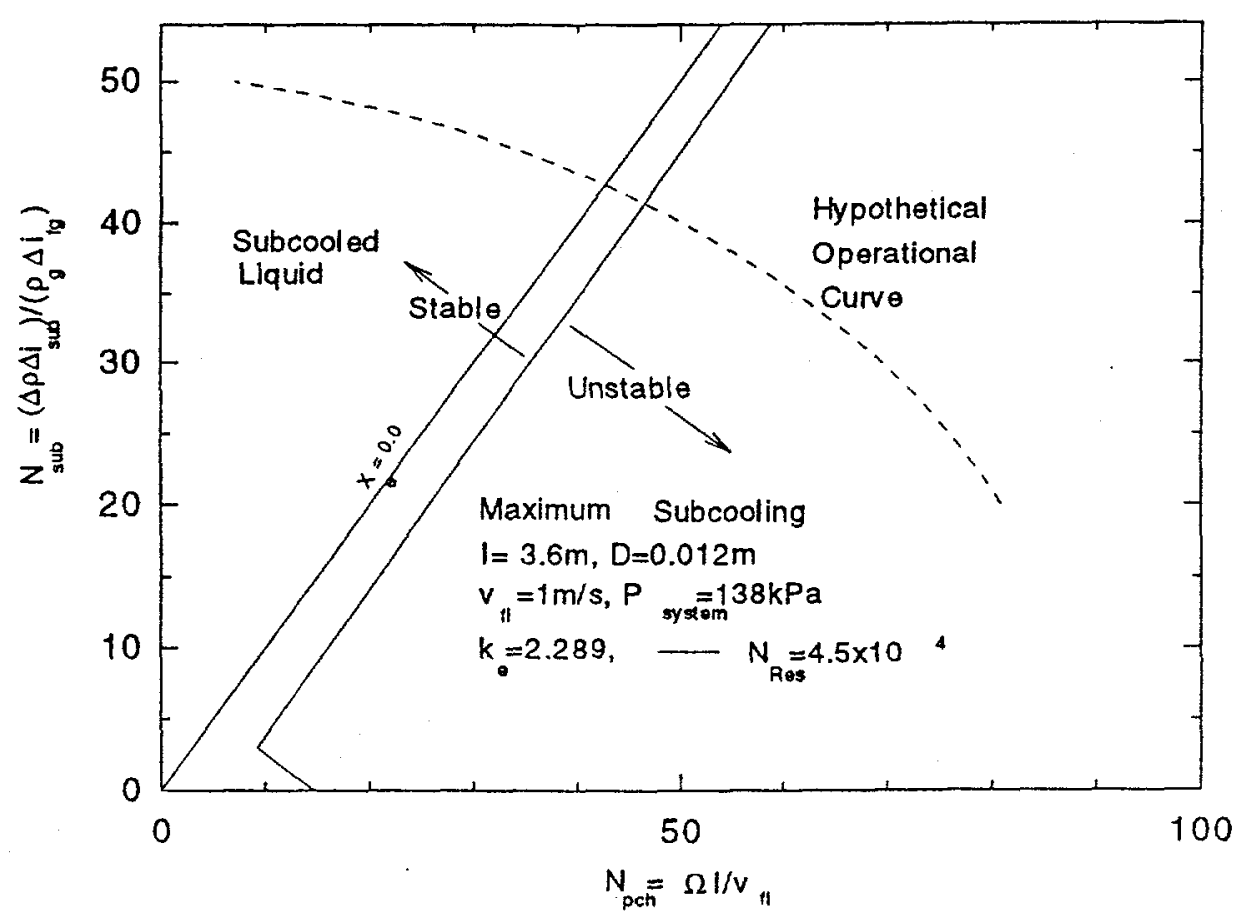

(b)

Fig.10. Hypothetical operation curve: (a) with flow excursion stability boundary, (b) with density wave oscillation stability boundary. 


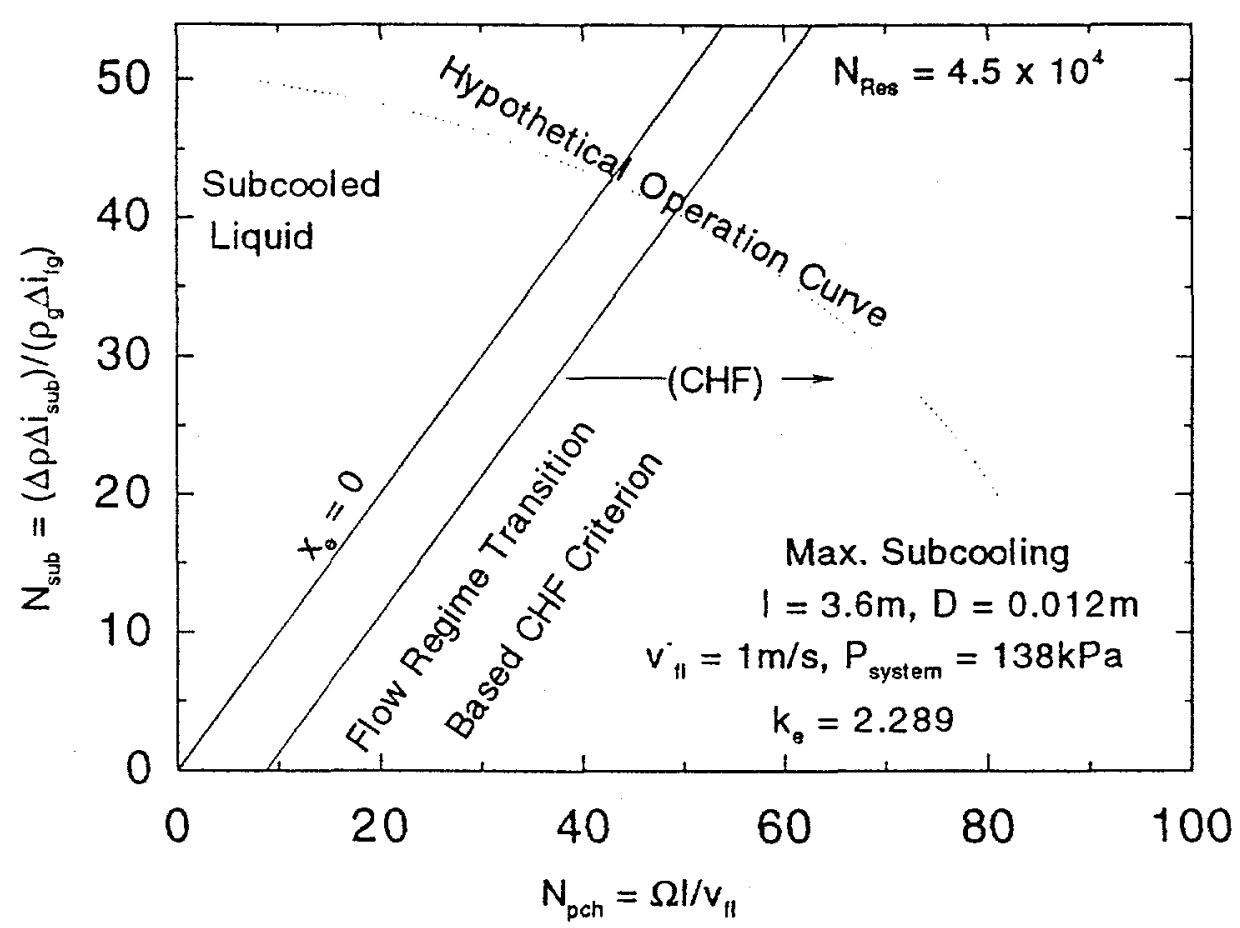

(a)

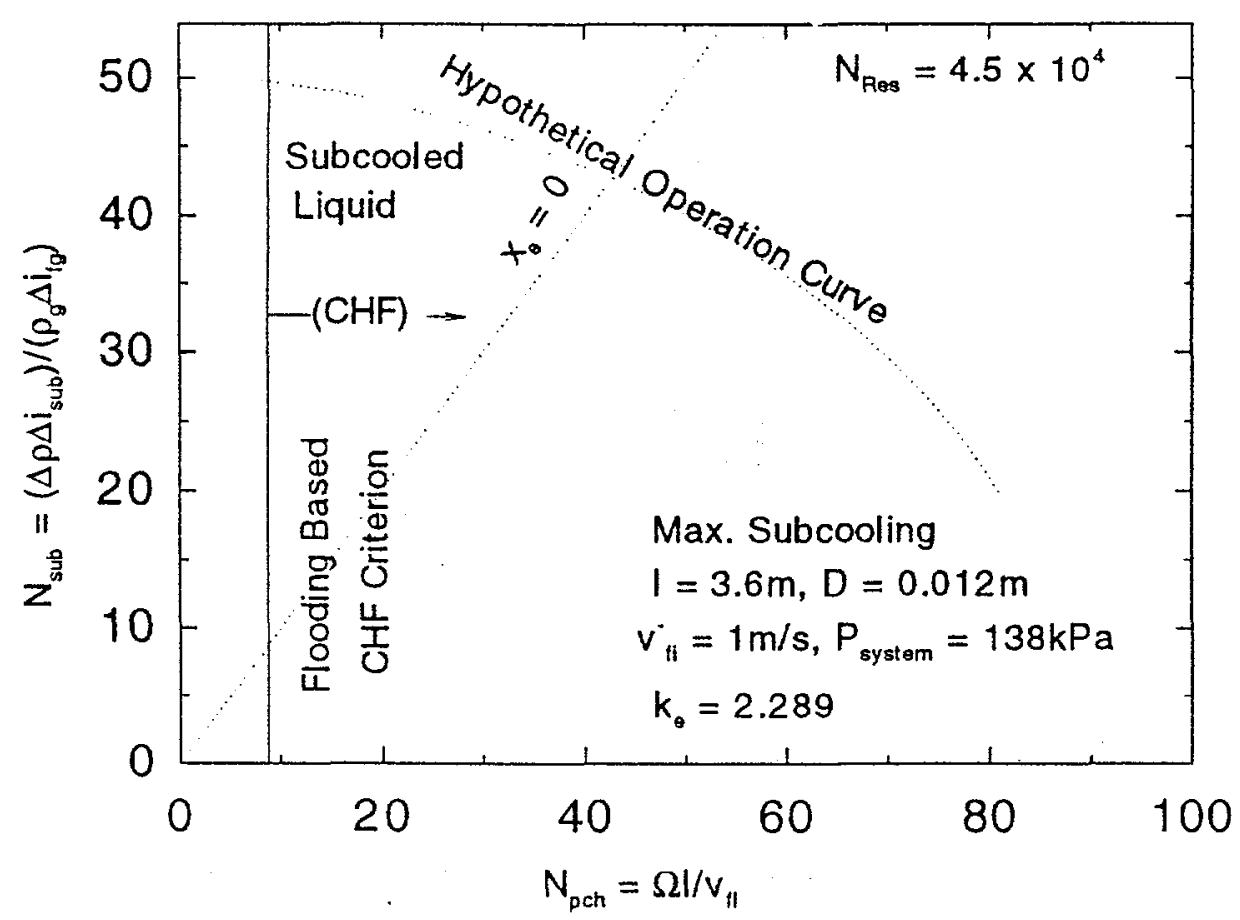

(b)

Fig. 11. Hypothetical operation curve: (a) churn-turbulent to annular flow regime transition based CHF criterion, (b) flooding based CHF criterion. 


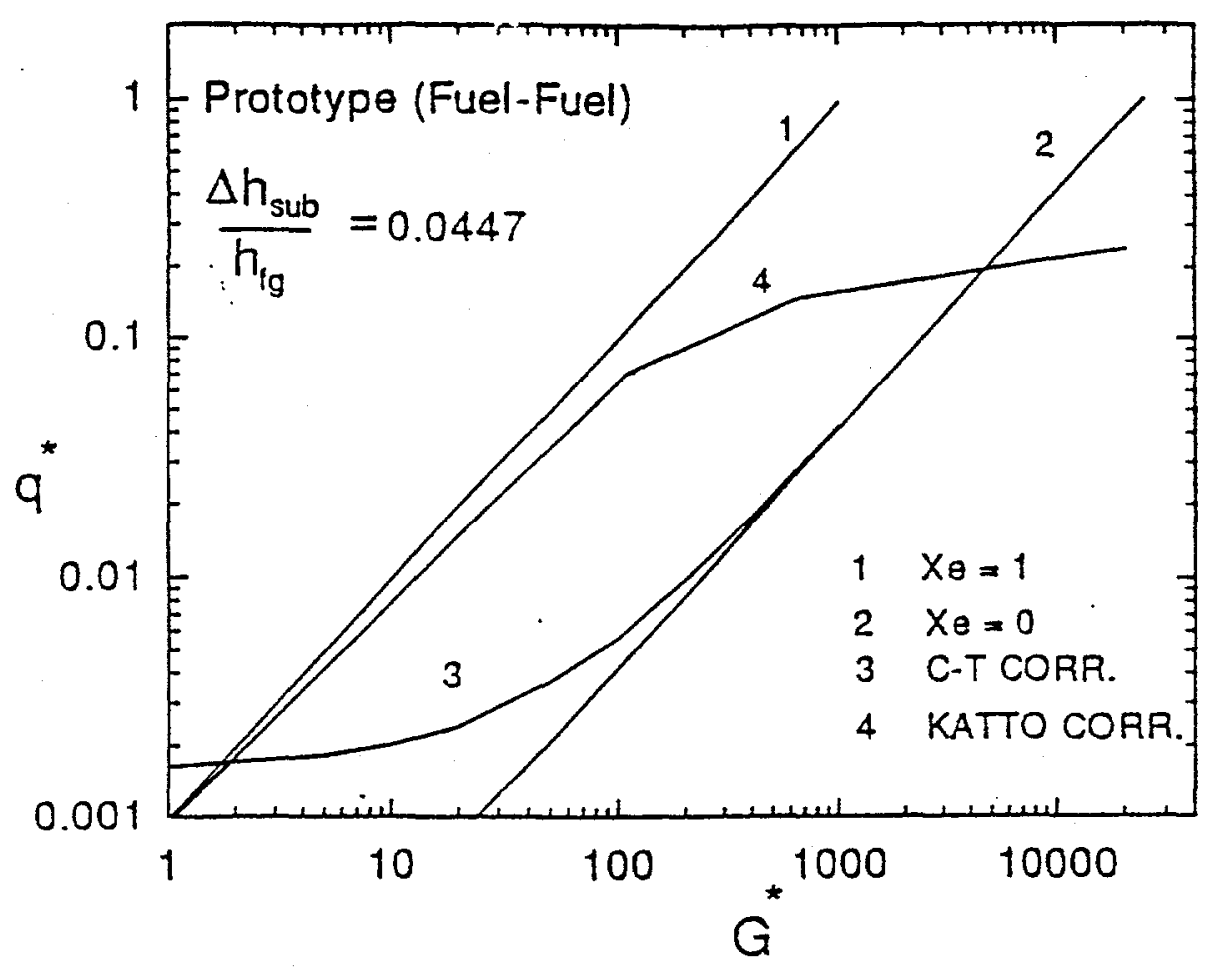

Fig. 12. CHF correlation's for prototype system.

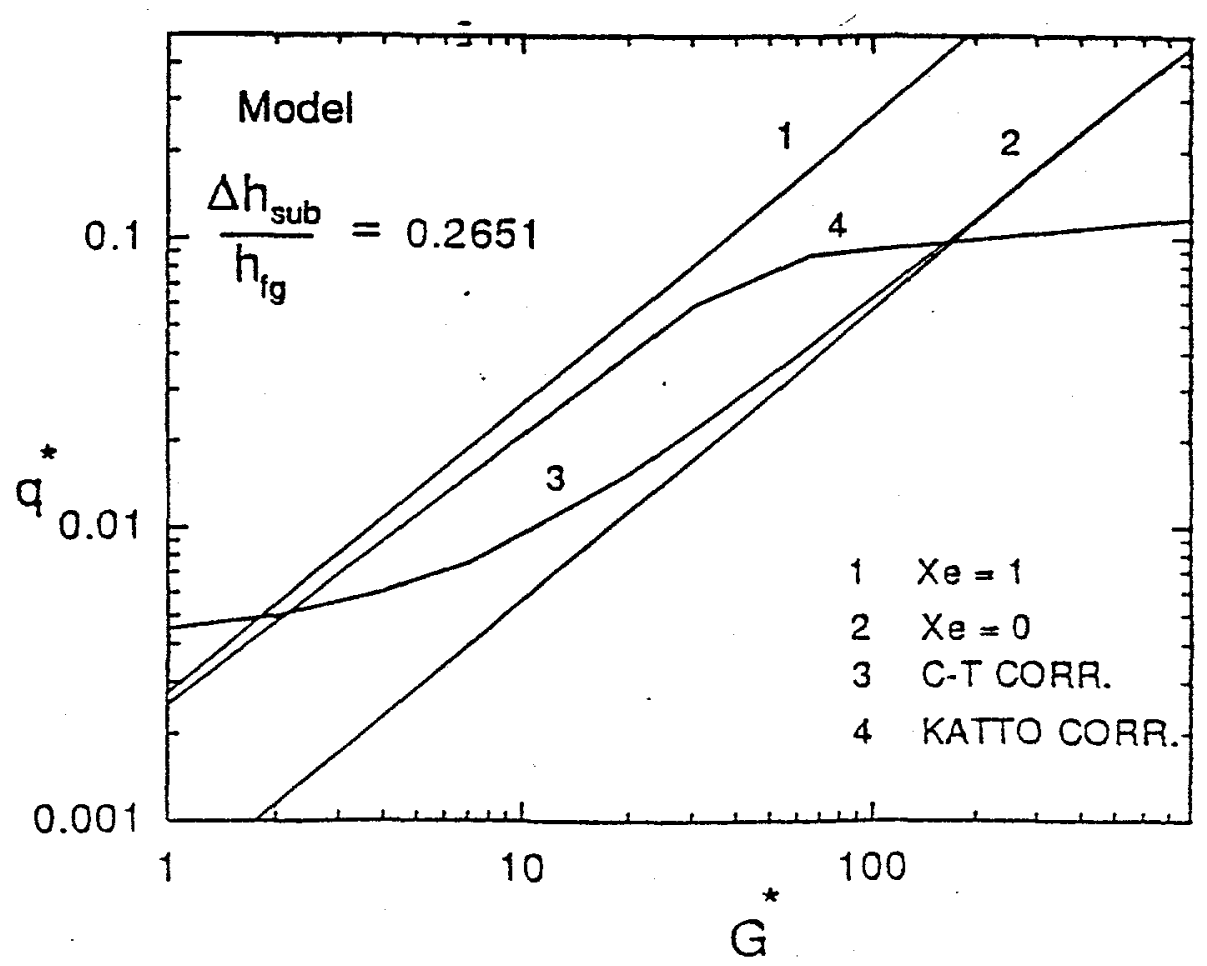

Fig.13. CHF correlation's for model system. 


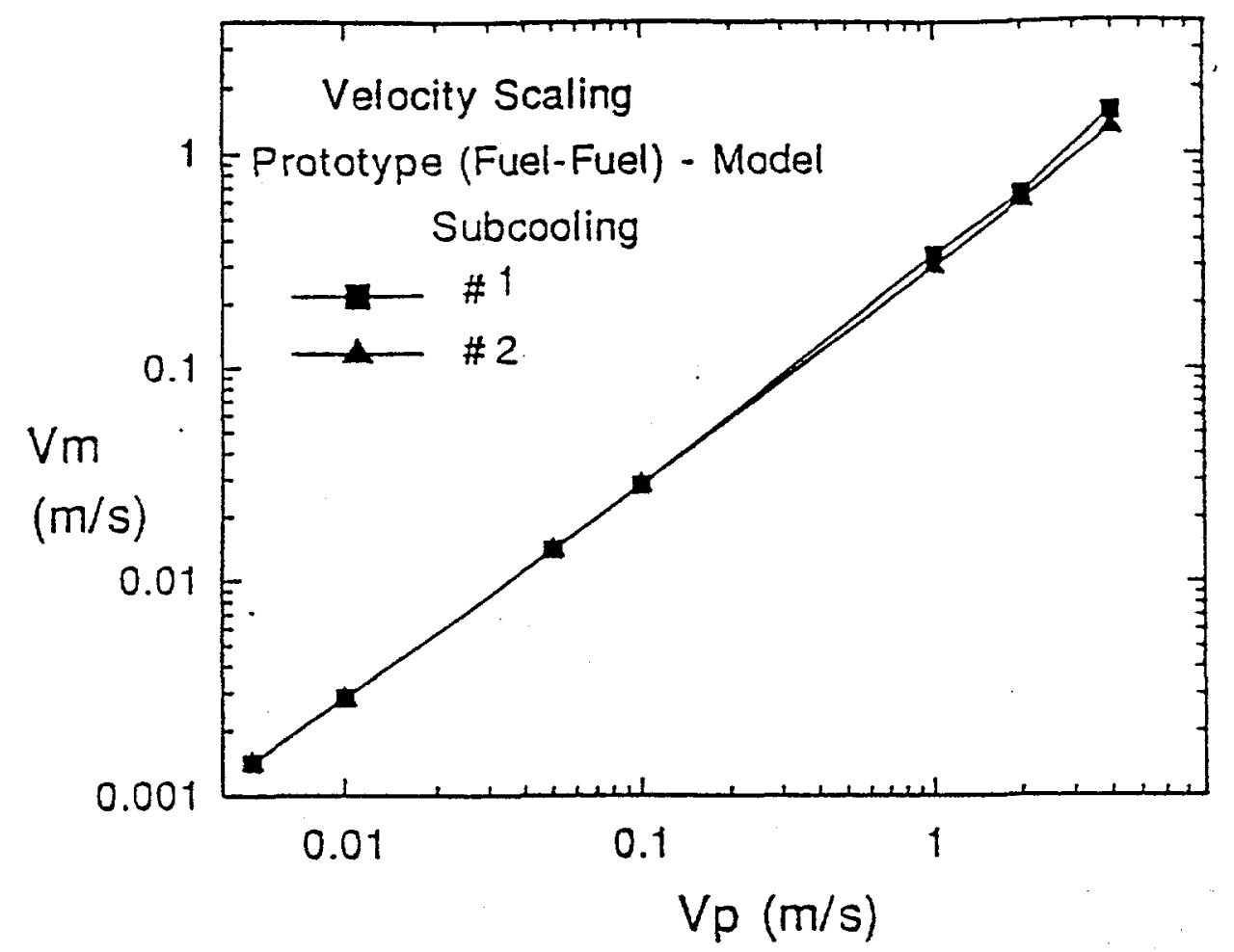

Fig. 14. The similarity scaling of velocity between prototype and model.

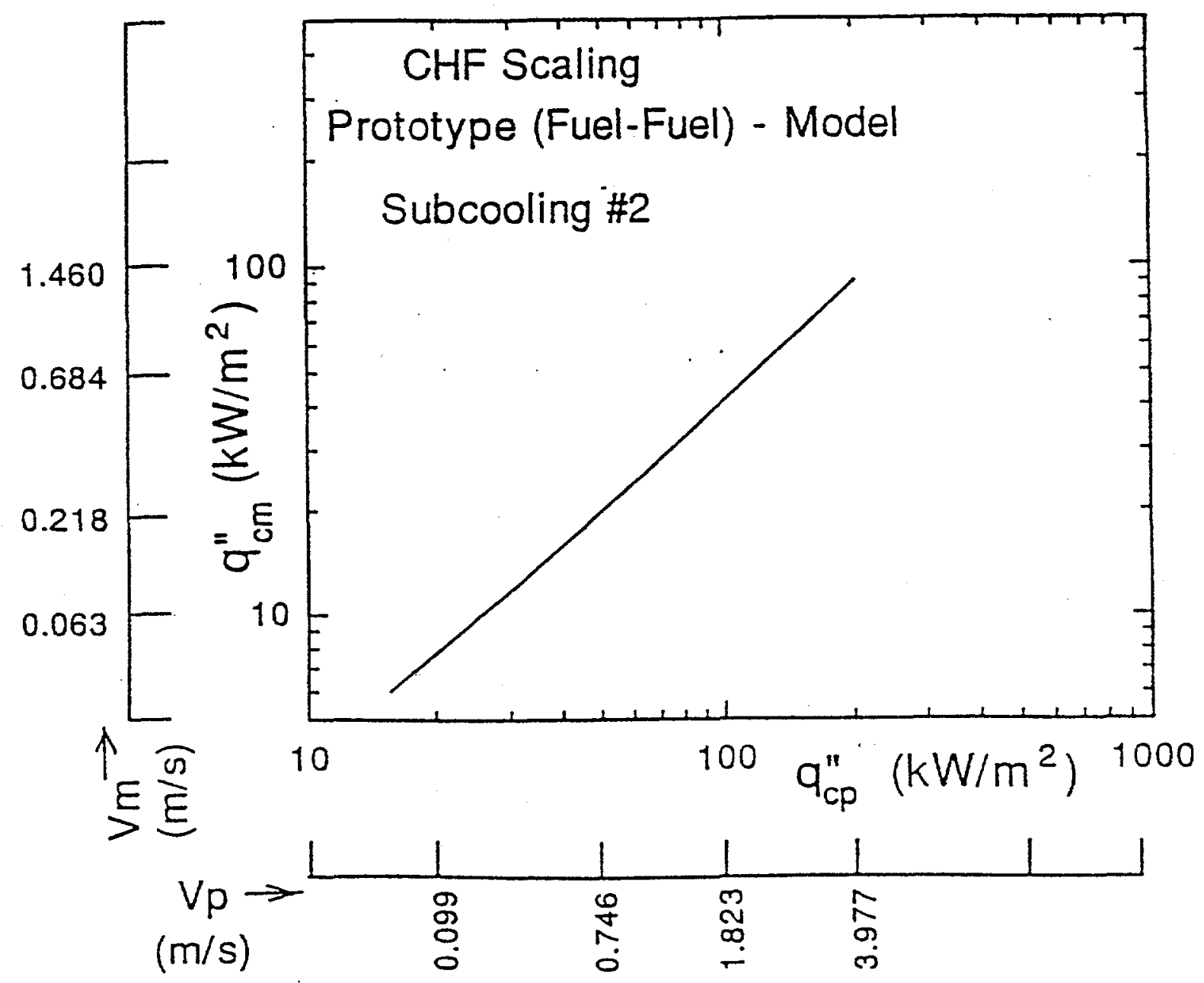

Fig. 15. The CHF scaling between the prototype and the model. 


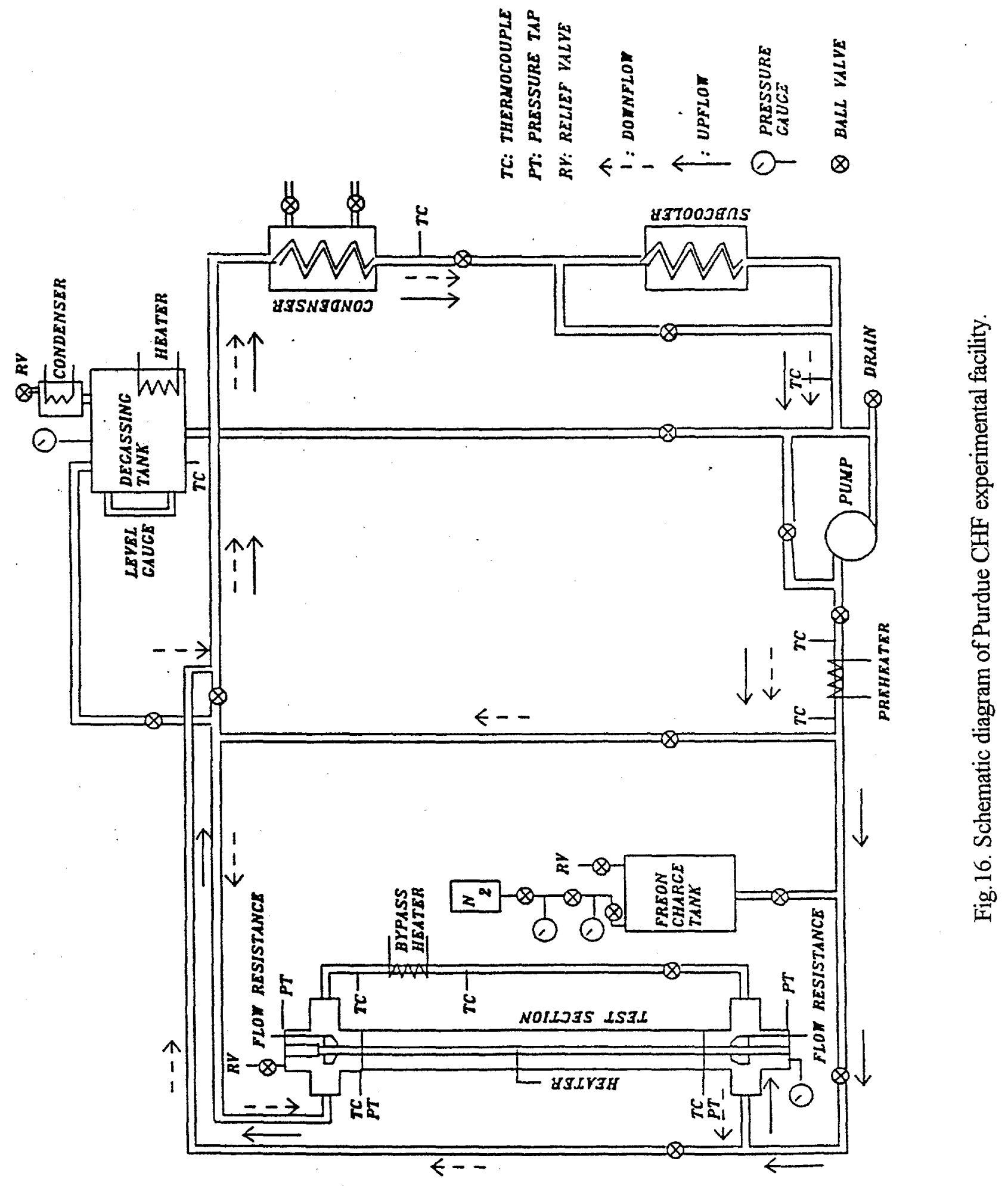




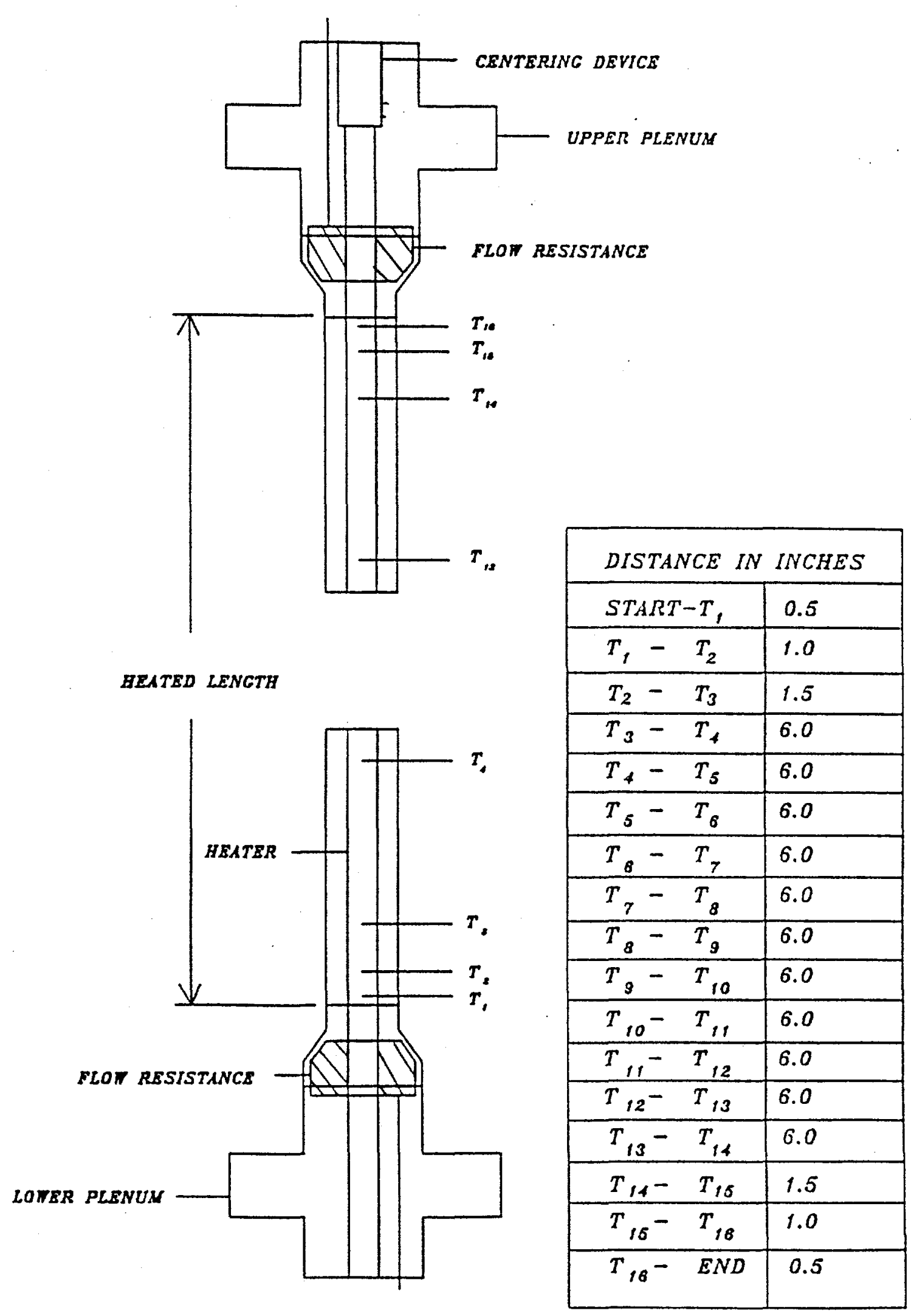

Fig. 17. Test section and location of the heater thermocouples. 


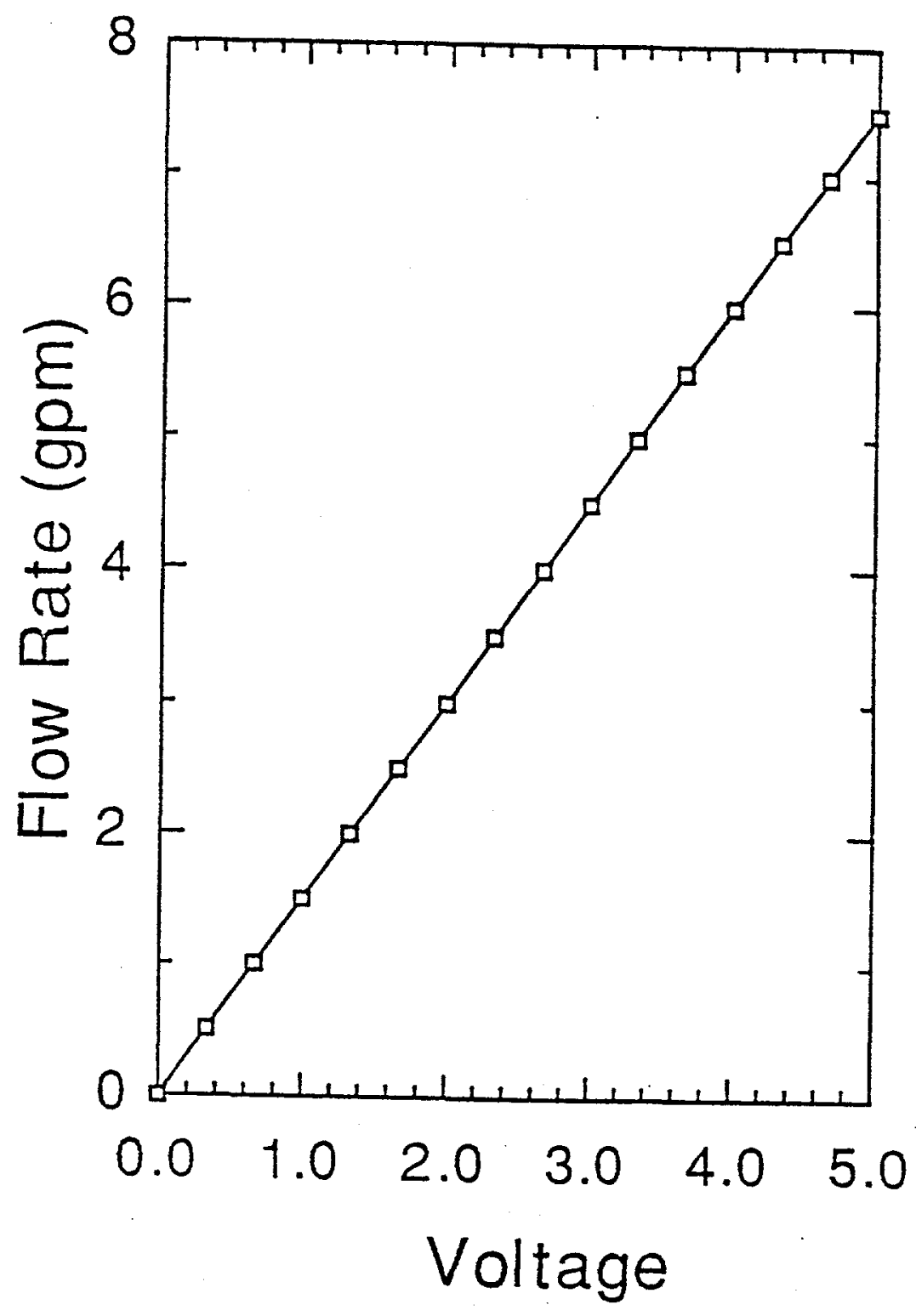

Fig. 18. Calibration curve for turbine flow meter. 

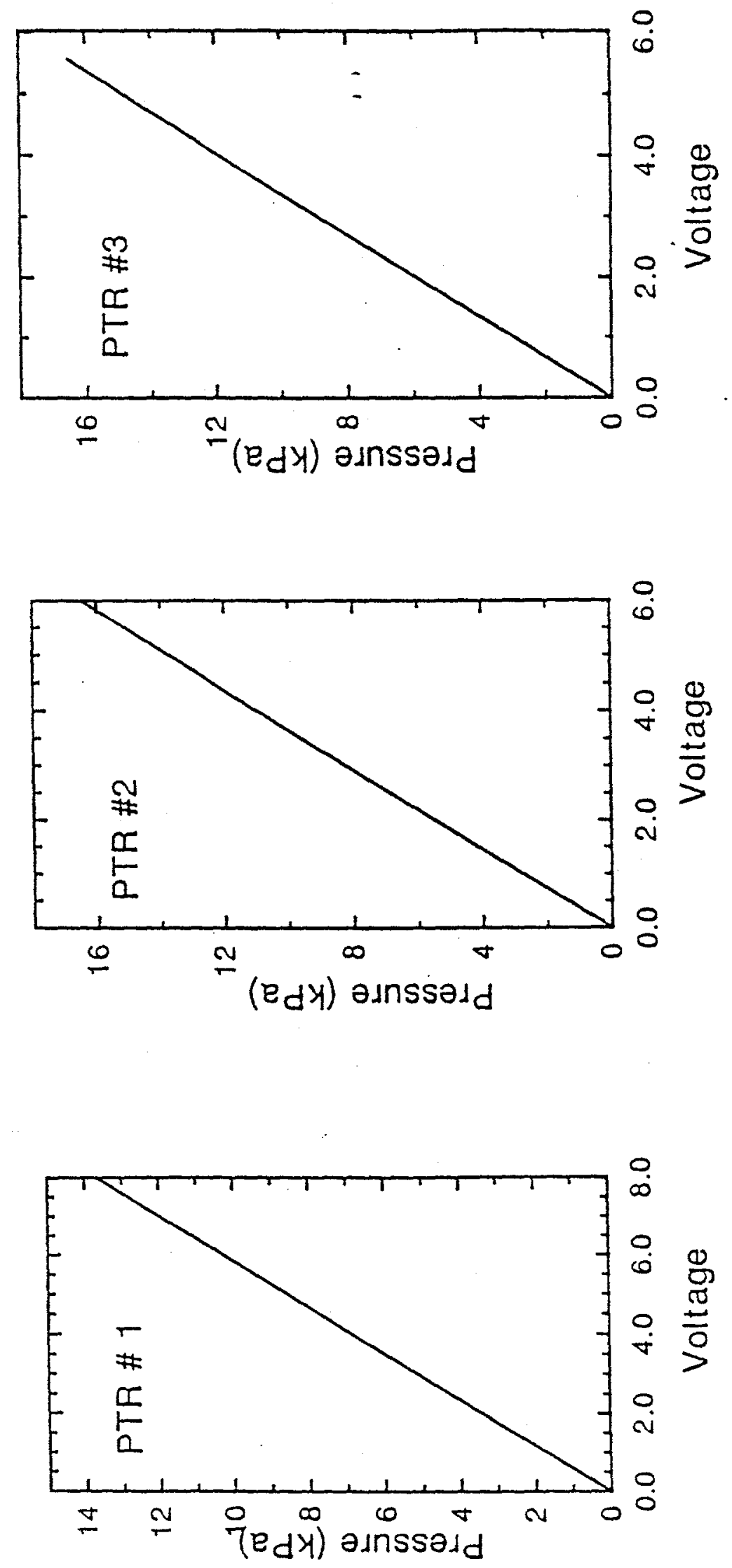


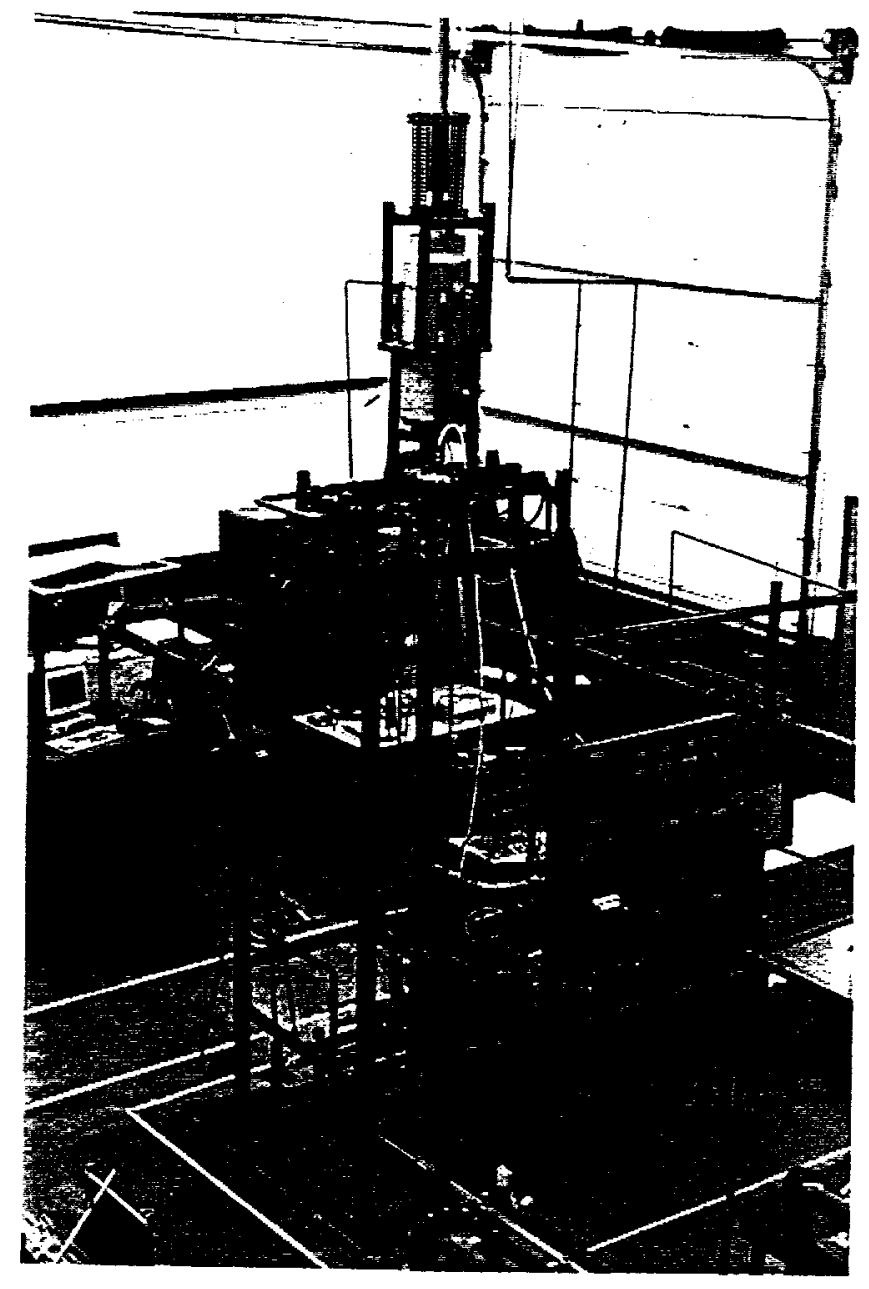

Fig.20. Photograph of Purdue CHF Experimental Facility. 


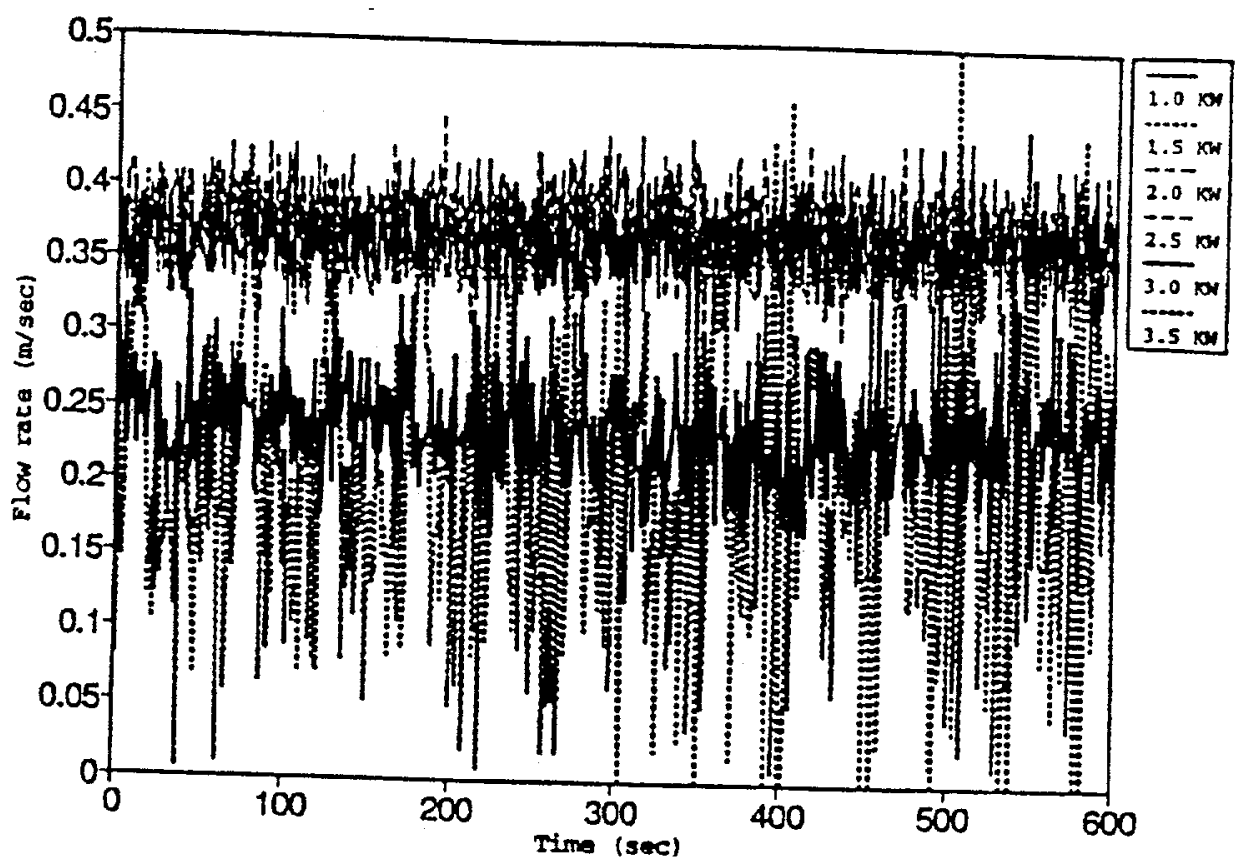

Fig.21. Test section flow rate vs. time for different heater powers.

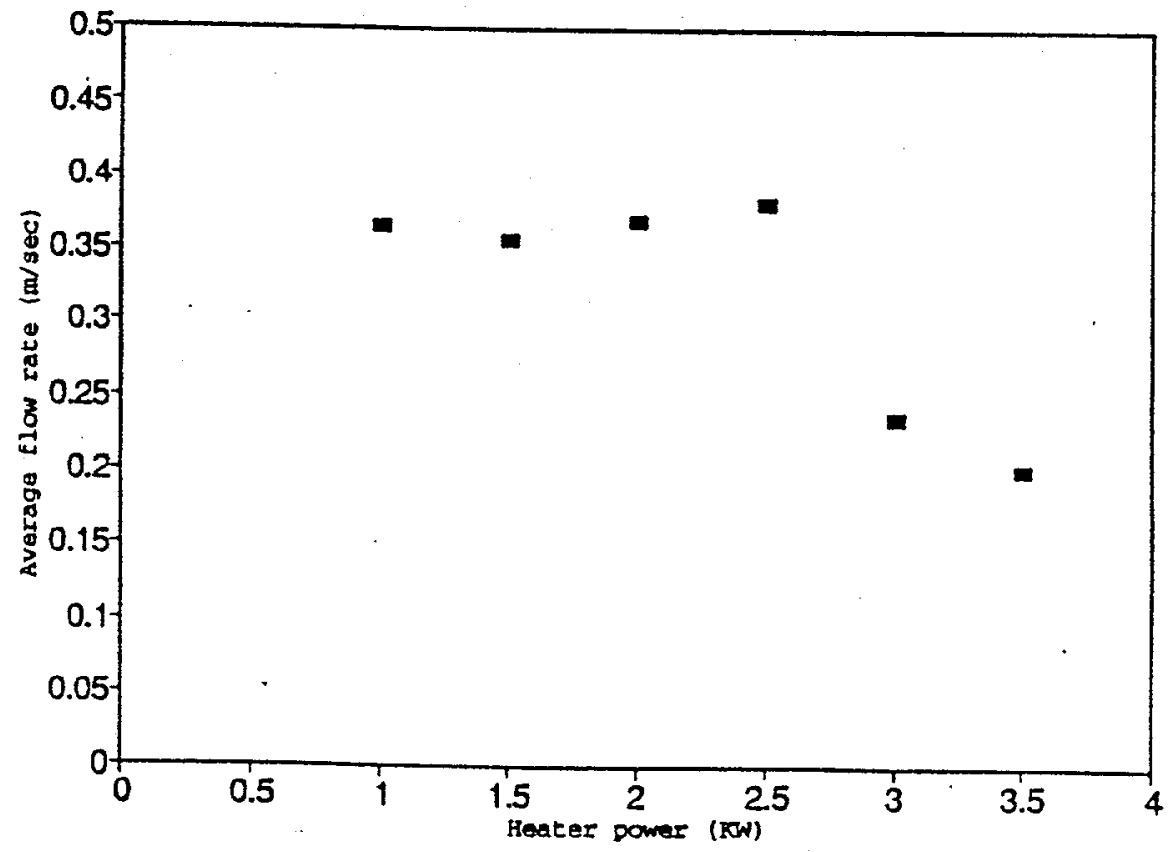

Fig.22. Test section mean flow rate vs. heater powers. 


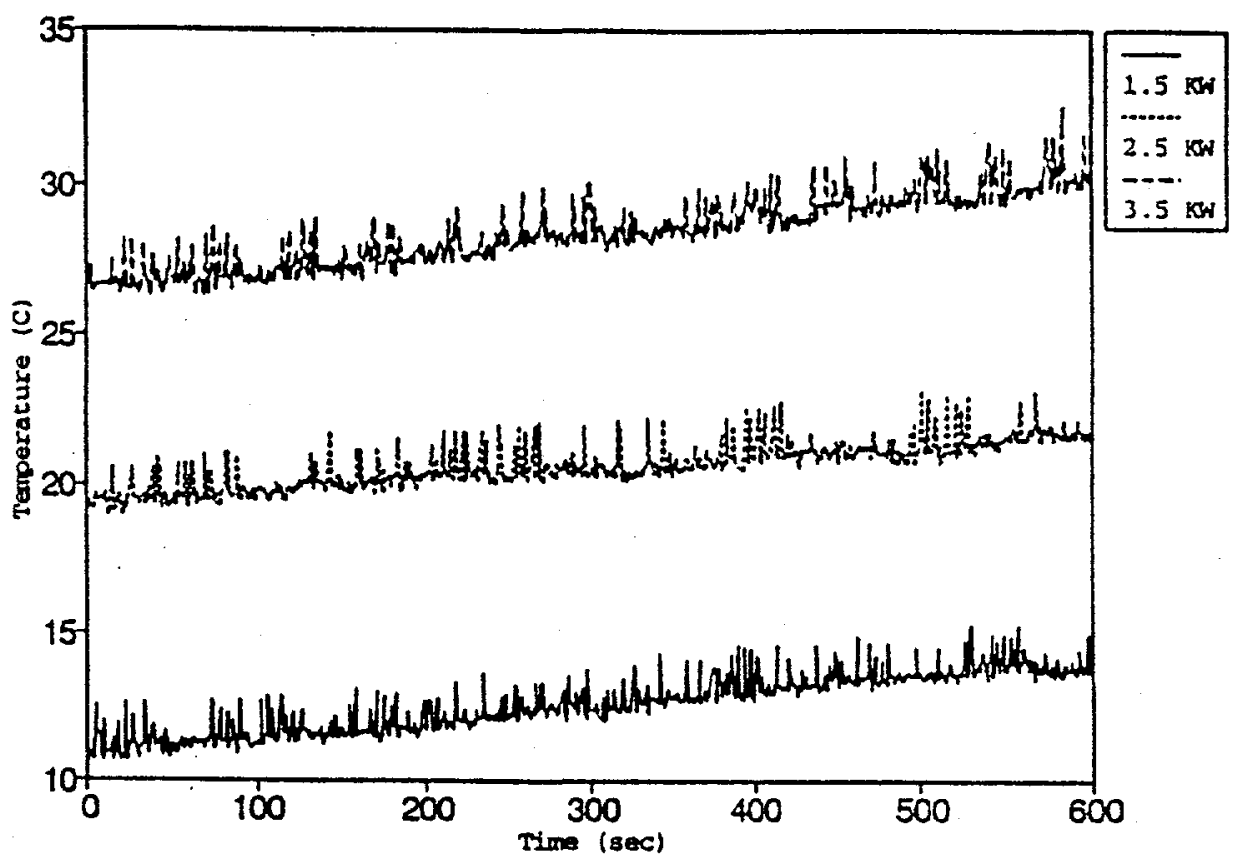

Fig.23. Inlet fluid temperature for different heater powers.

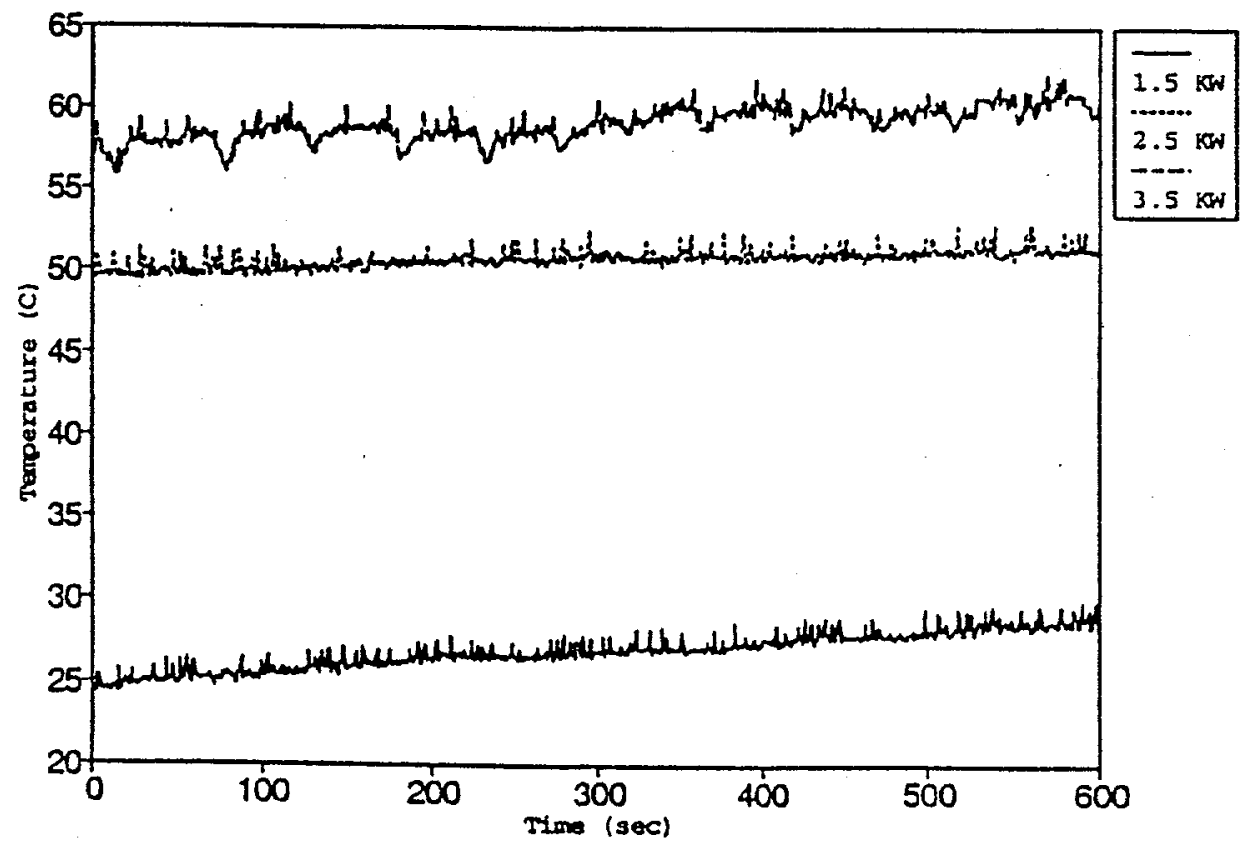

Fig.24. Outlet temperature of the fluid for different heater powers. 


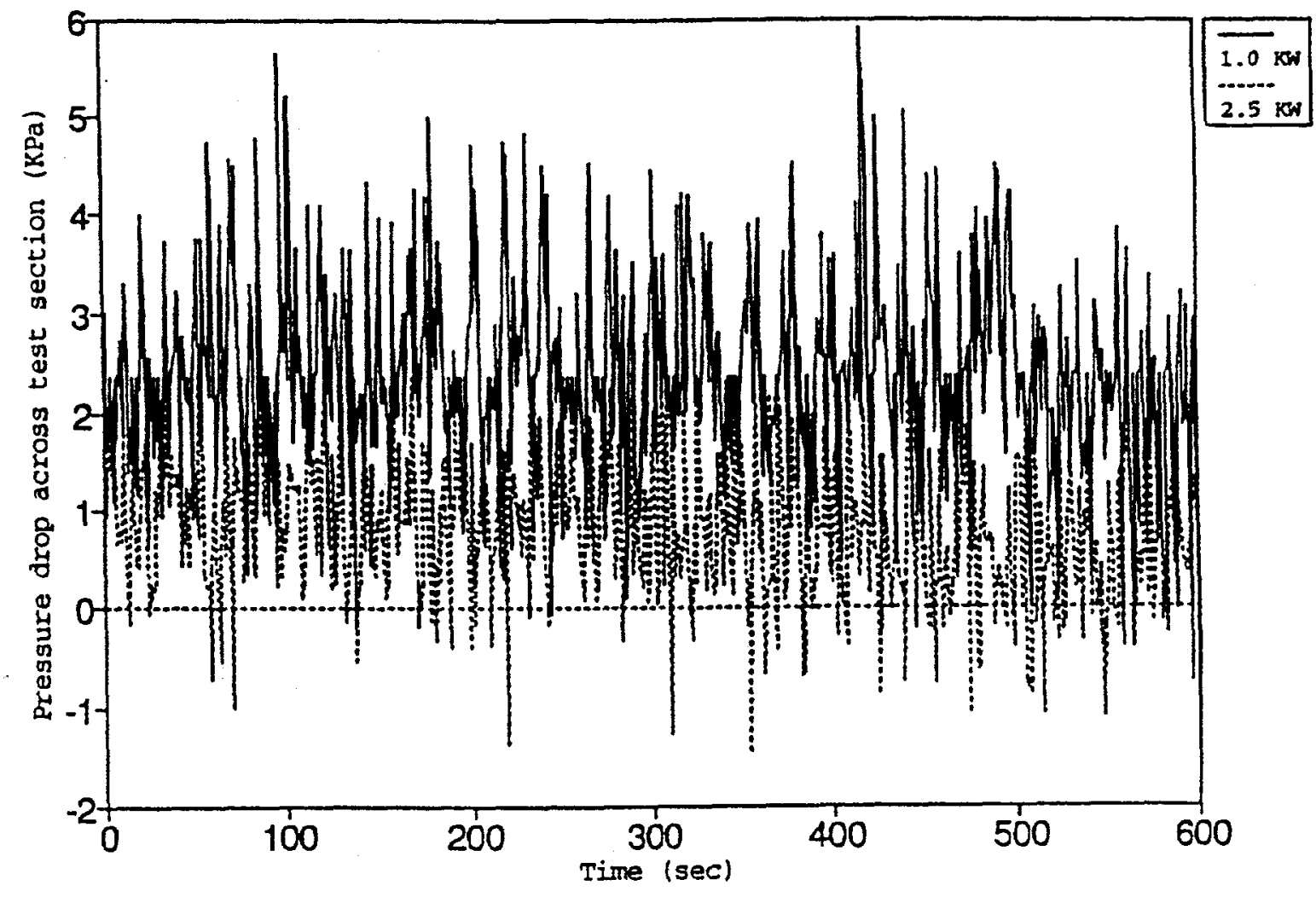

Fig.25. Pressure drop across the test section for different heater powers. 


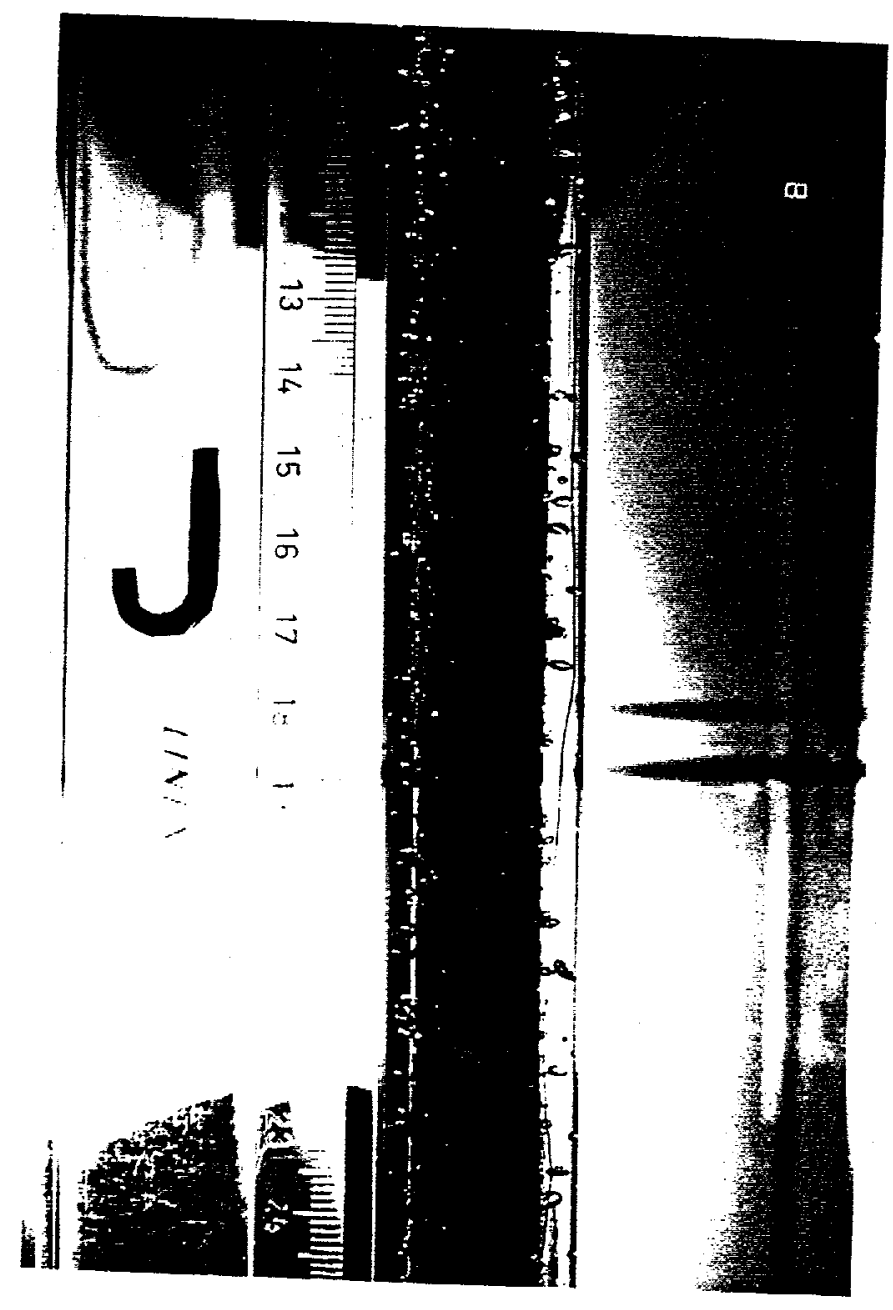

Fig.26. Photograph of the test section at liquid velocity of $35 \mathrm{~cm} / \mathrm{s}$, heater power of $1.5 \mathrm{~kW}$ and inlet subcooling $24 \mathrm{C}$. 


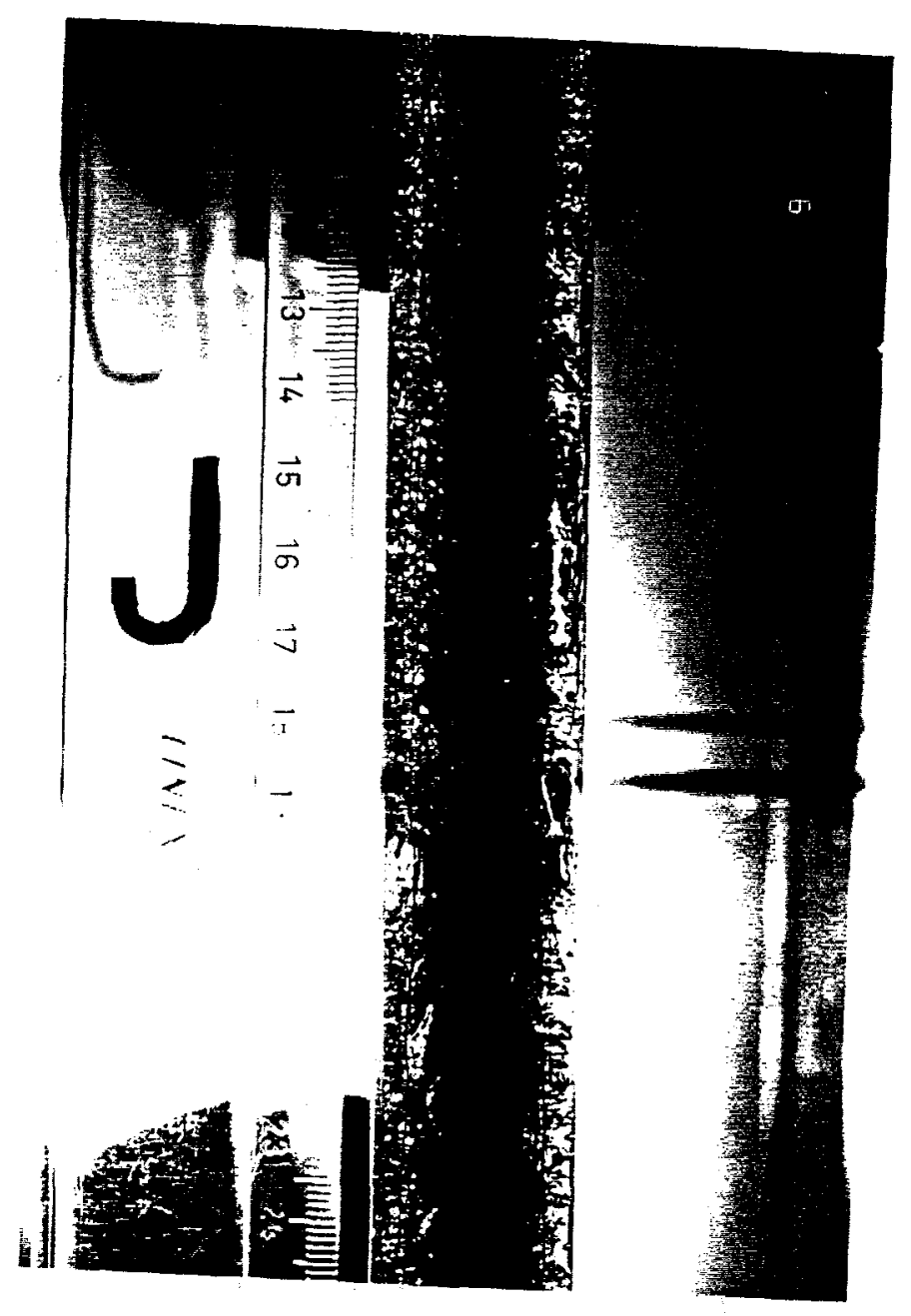

Fig.27. Photograph of the test section at liquid velocity of $25 \mathrm{~cm} / \mathrm{s}$, heater power of $2.5 \mathrm{~kW}$ and inlet subcooling $24 \mathrm{C}$. 


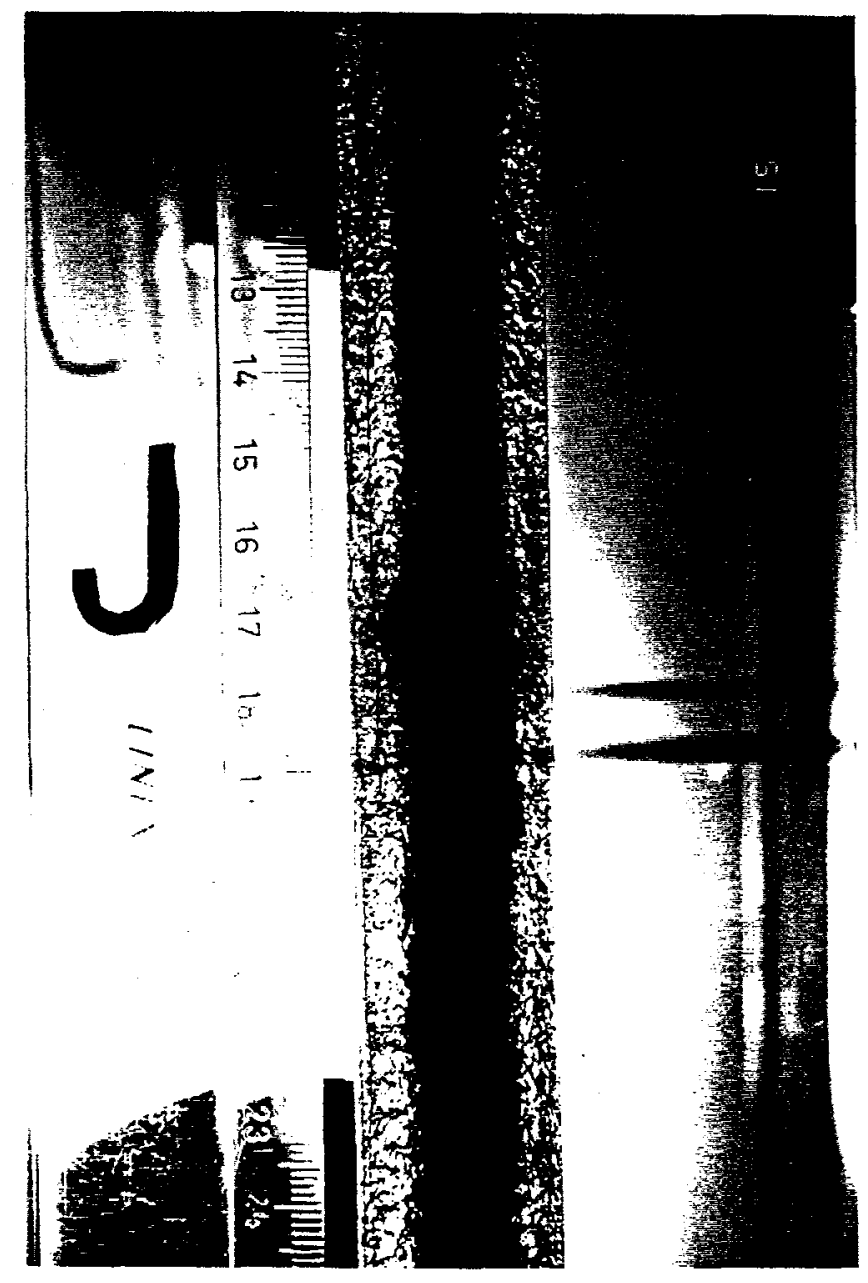

Fig.28. Photograph of the test section at liquid velocity of $20 \mathrm{~cm} / \mathrm{s}$, heater power of $35 \mathrm{~kW}$ and inlet subcooling $24 \mathrm{C}$. 

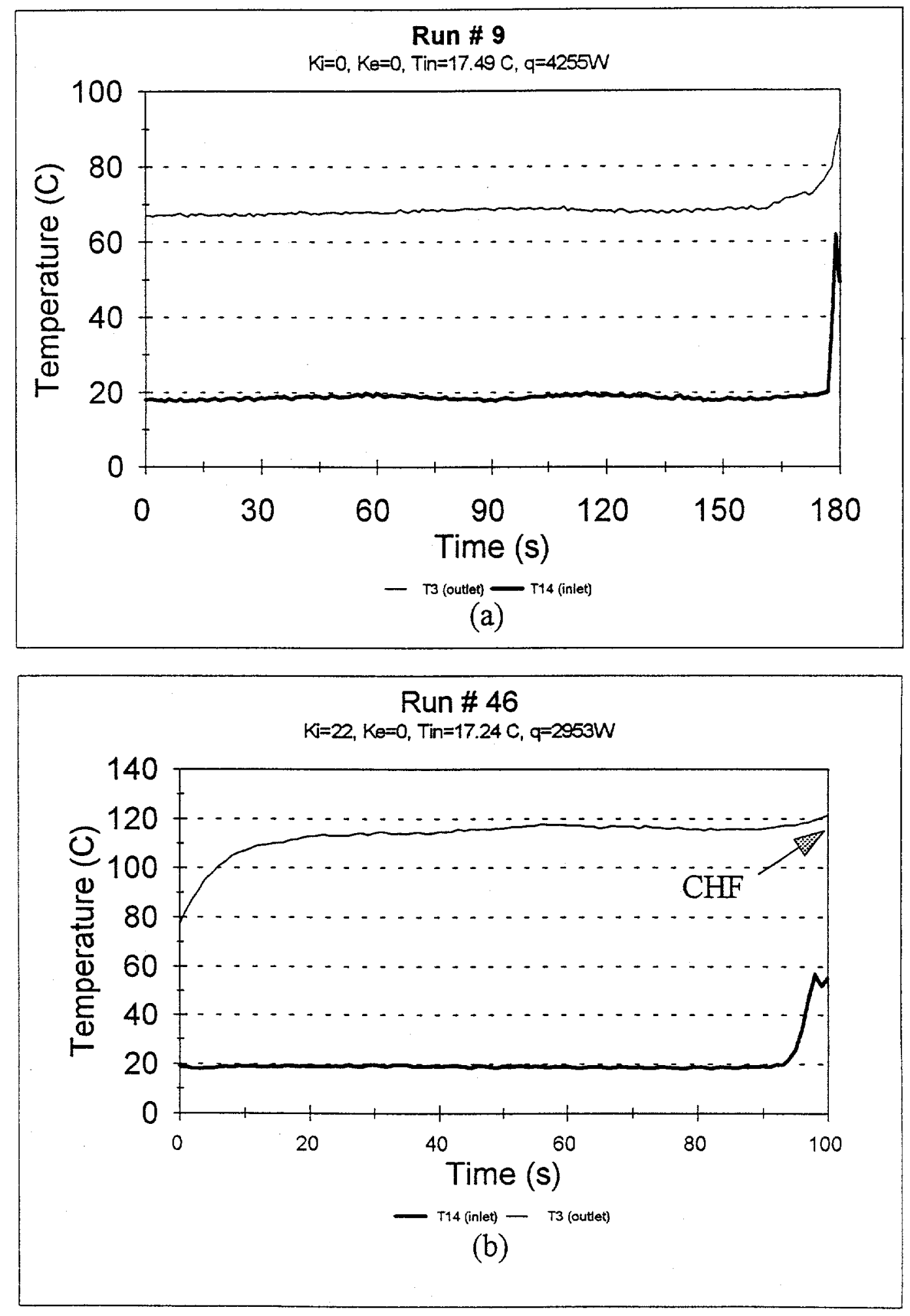

Fig.29. Heater surface temperature at inlet and exit : (a) for Run\#9 and (b) for Run\#46. 

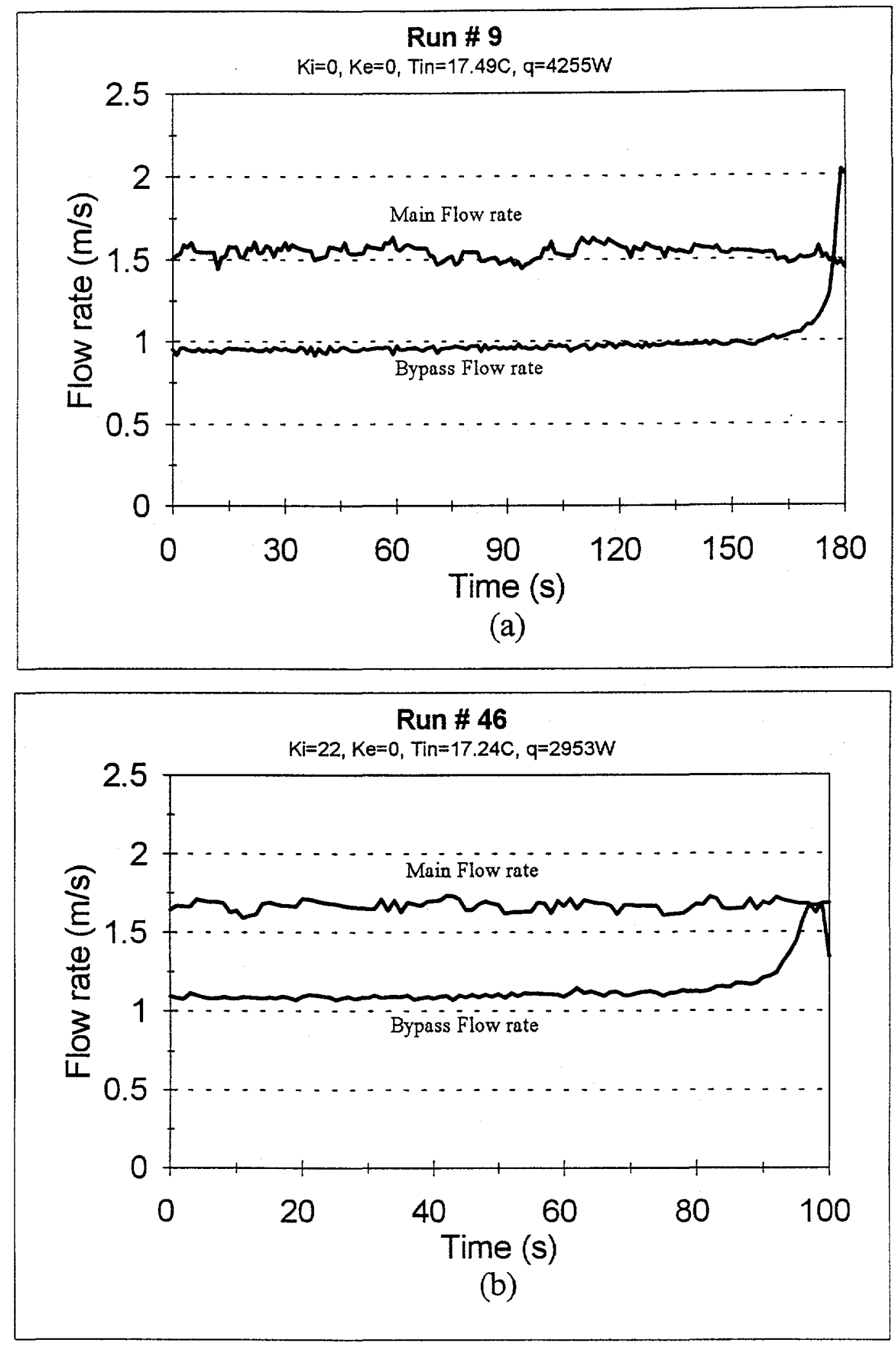

Fig.30. Main and Bypass flow rates : (a) for Run\#9 and (b) for Run\#46. 


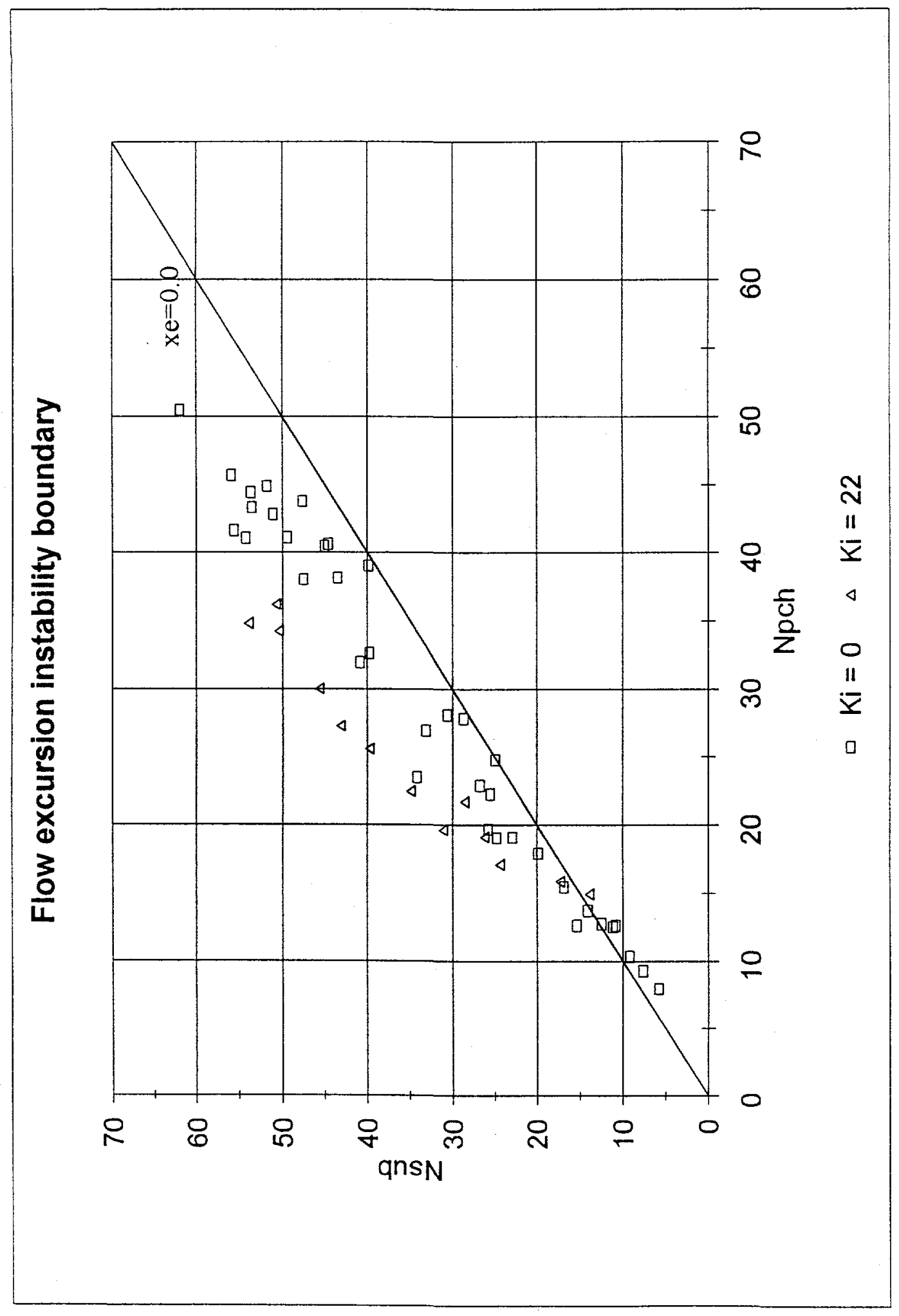

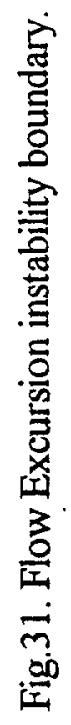




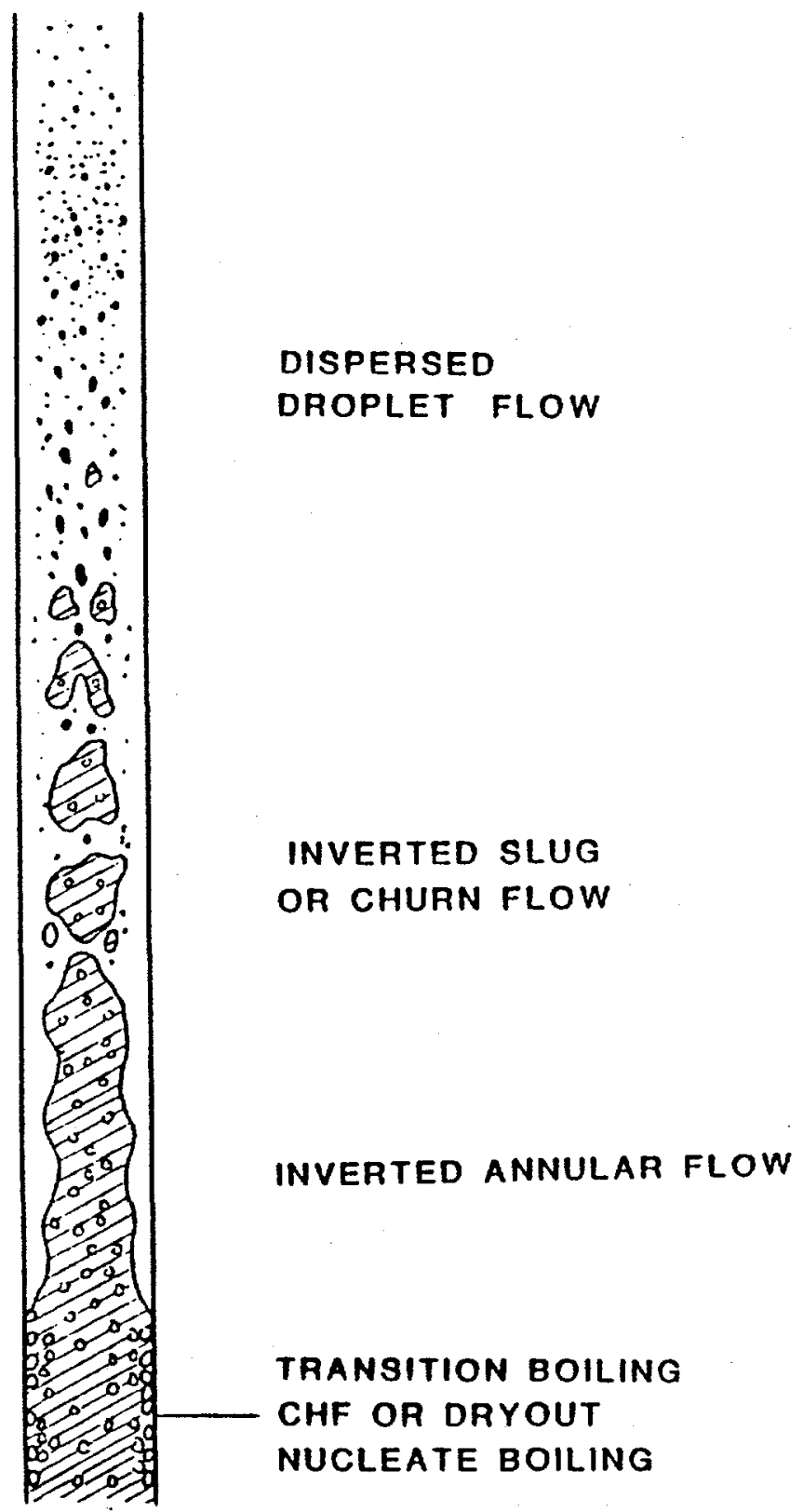

Figure 32 Illustration of flow regimes in the post dryout region. 


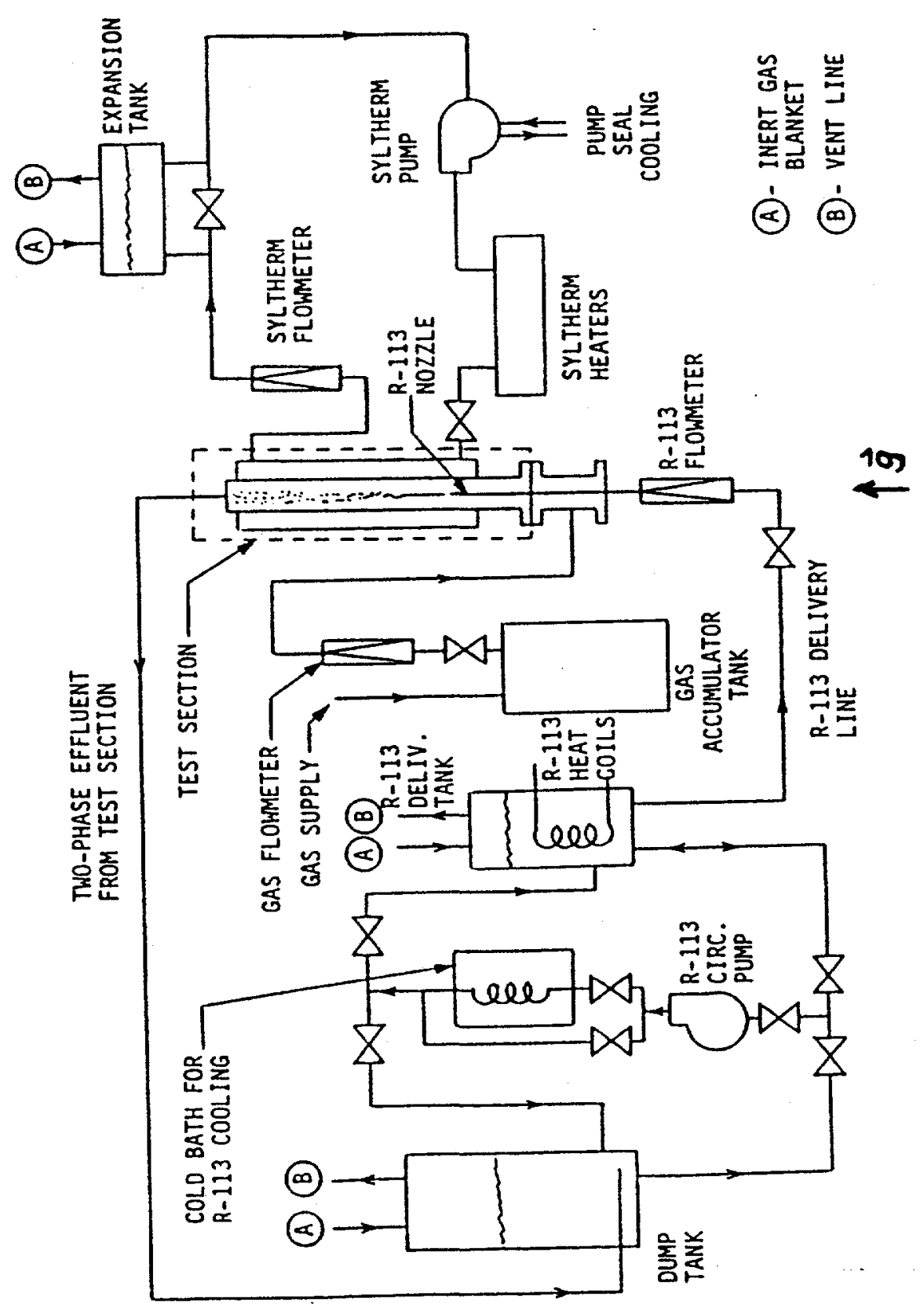

Figure 33. Schematic of overall test apparatus. 


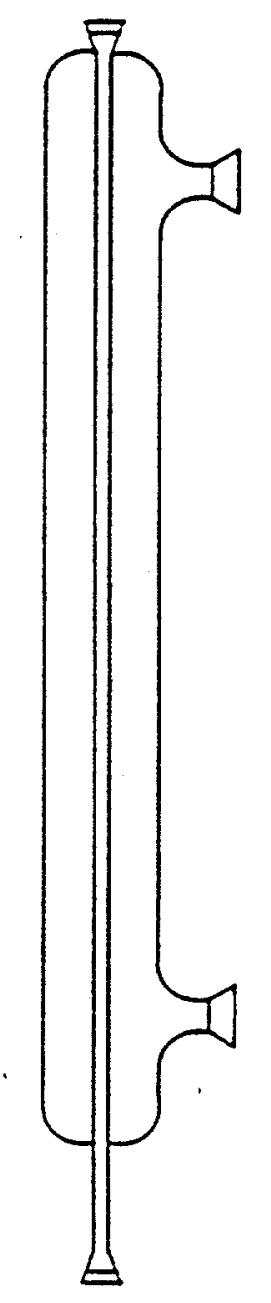

Figure 34 Quartz test section. 


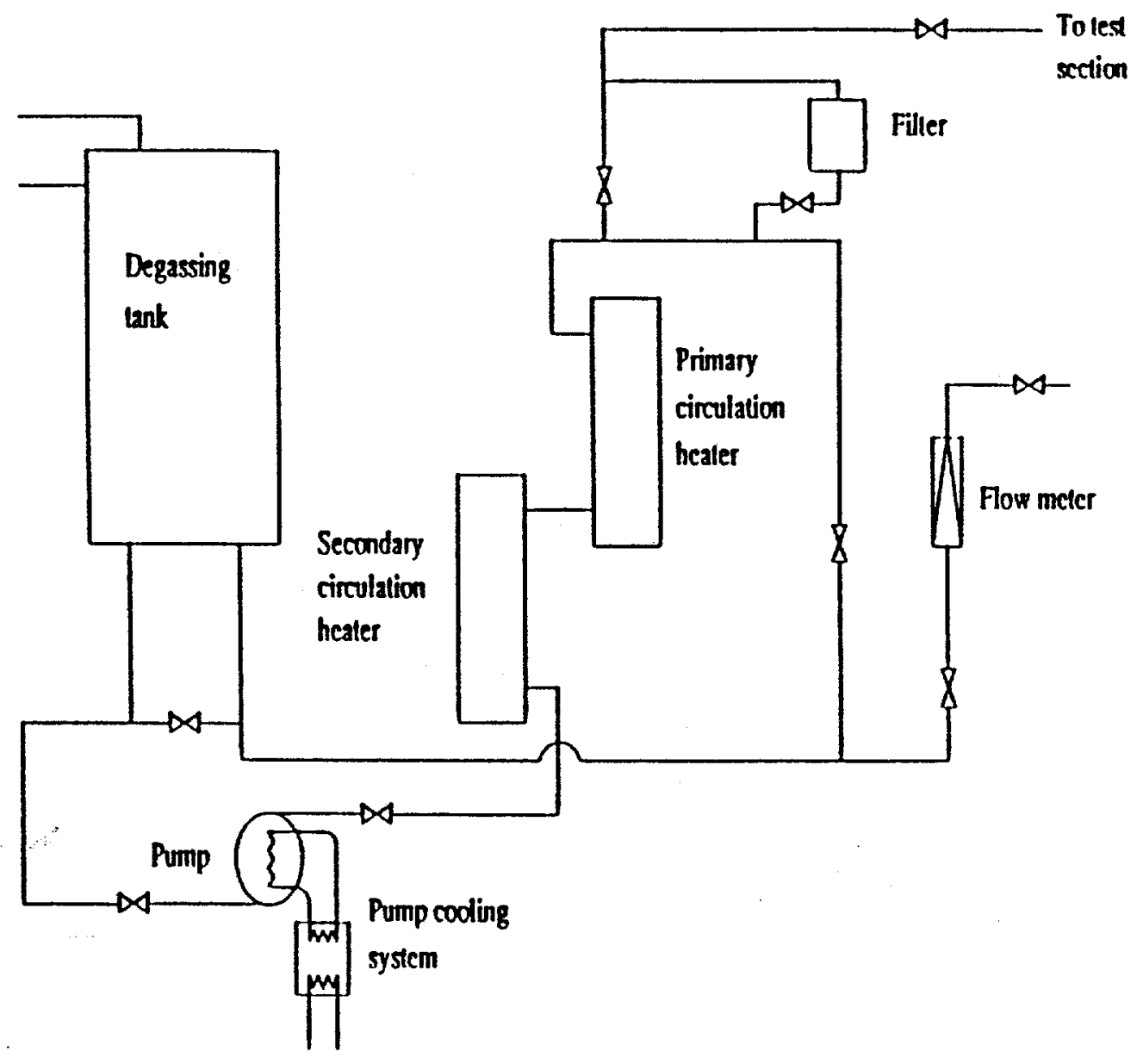

Figure 35 Heat transfer delivery system. 


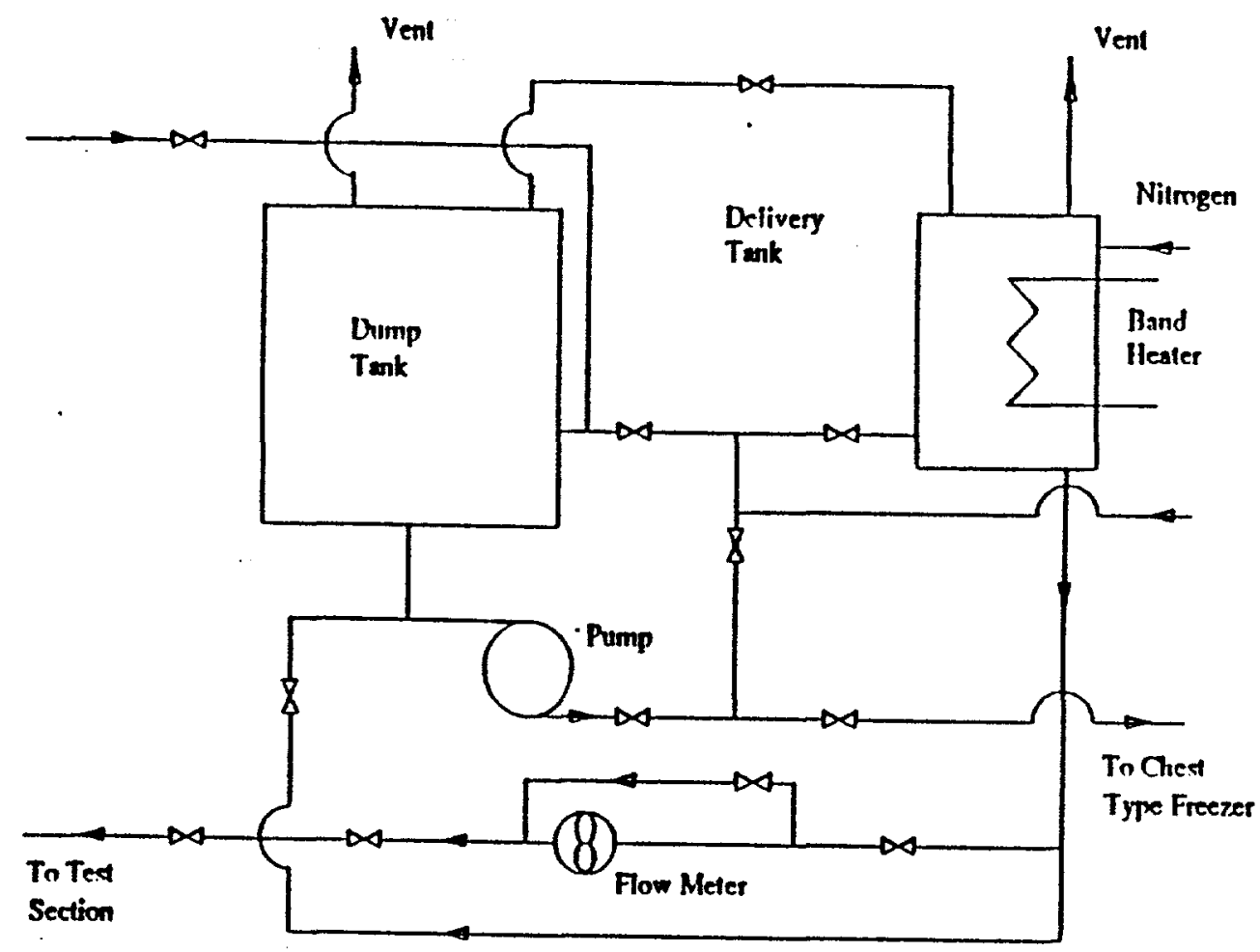

Figure 36 Freon delivery and recovery system. 
Pressure Transducer Calibration

(Freon Calibration of Test Section)

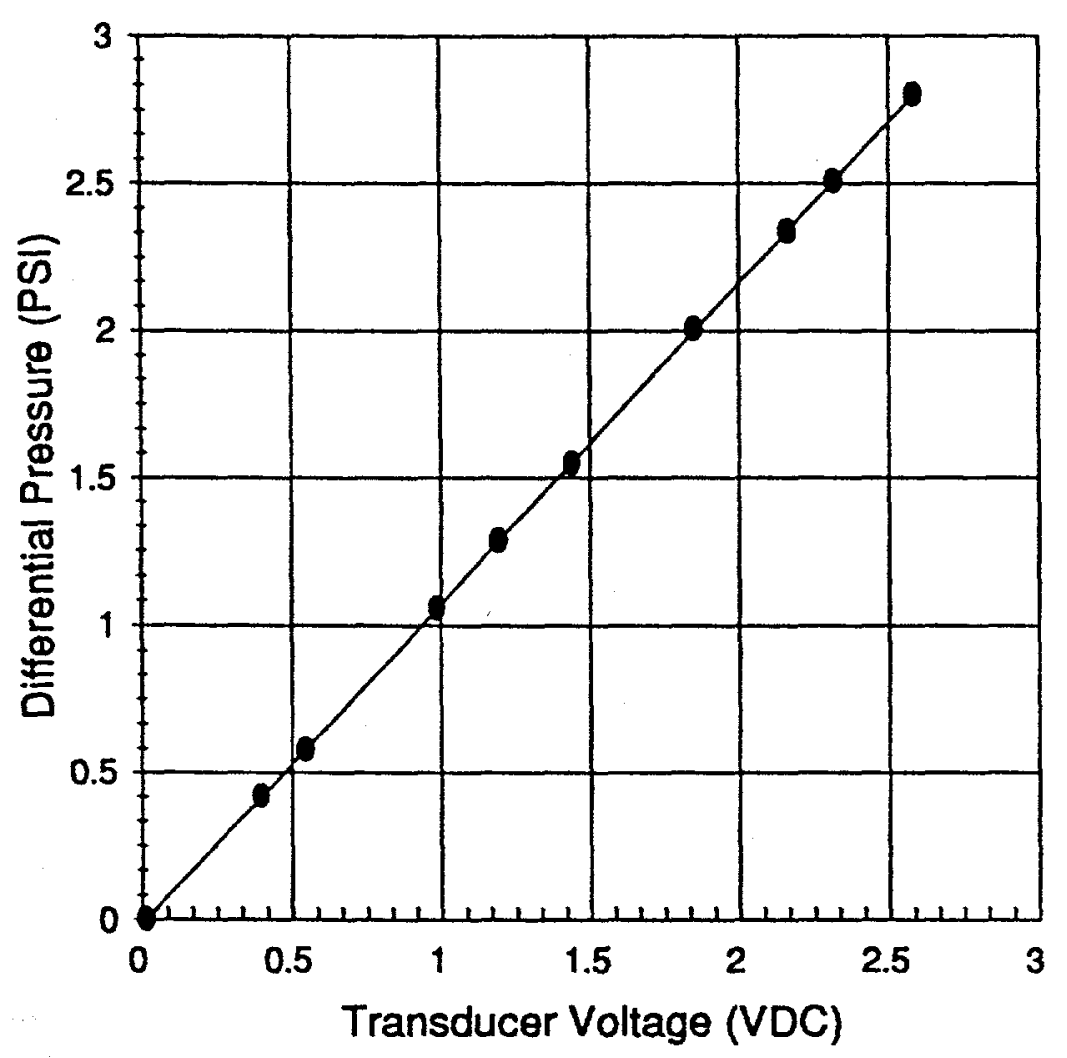

Moesured Data - Regression Analysis

Figure 37 Pressure transducer calibration. 


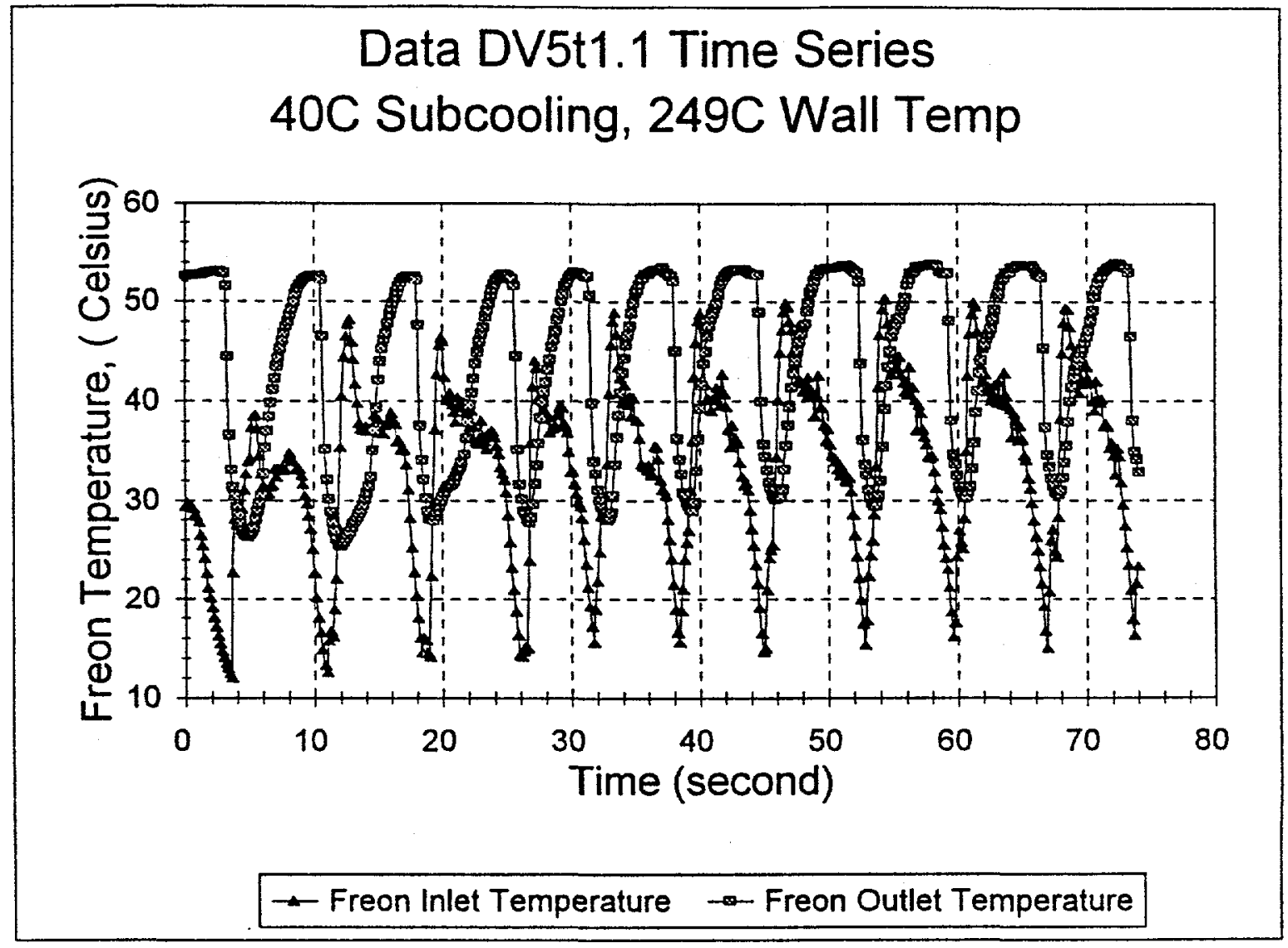

Figure 38 Temperature measurement during oscillation phenomena. 


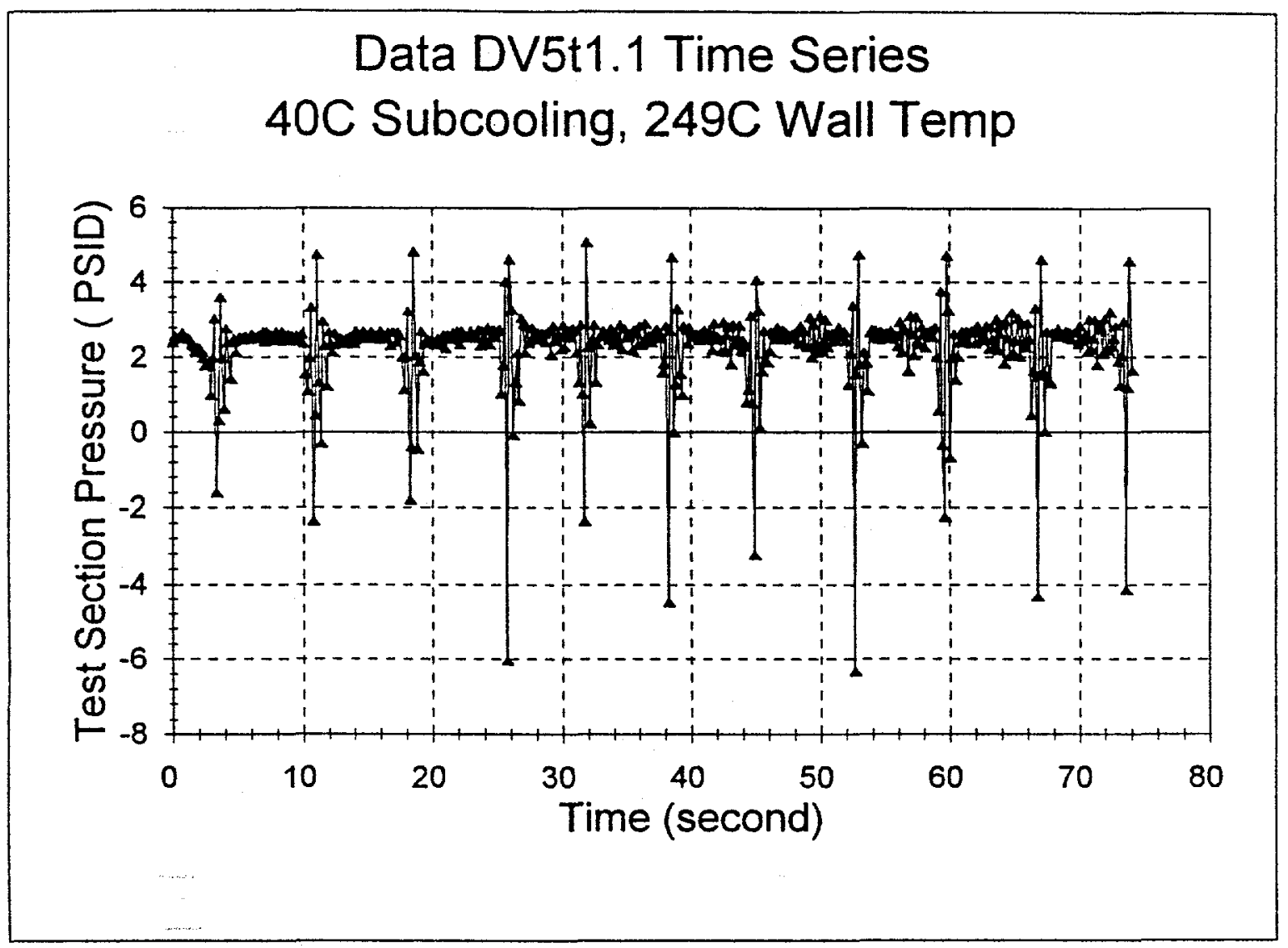

Figure 39 Pressure measurement during oscillation phenomena. 


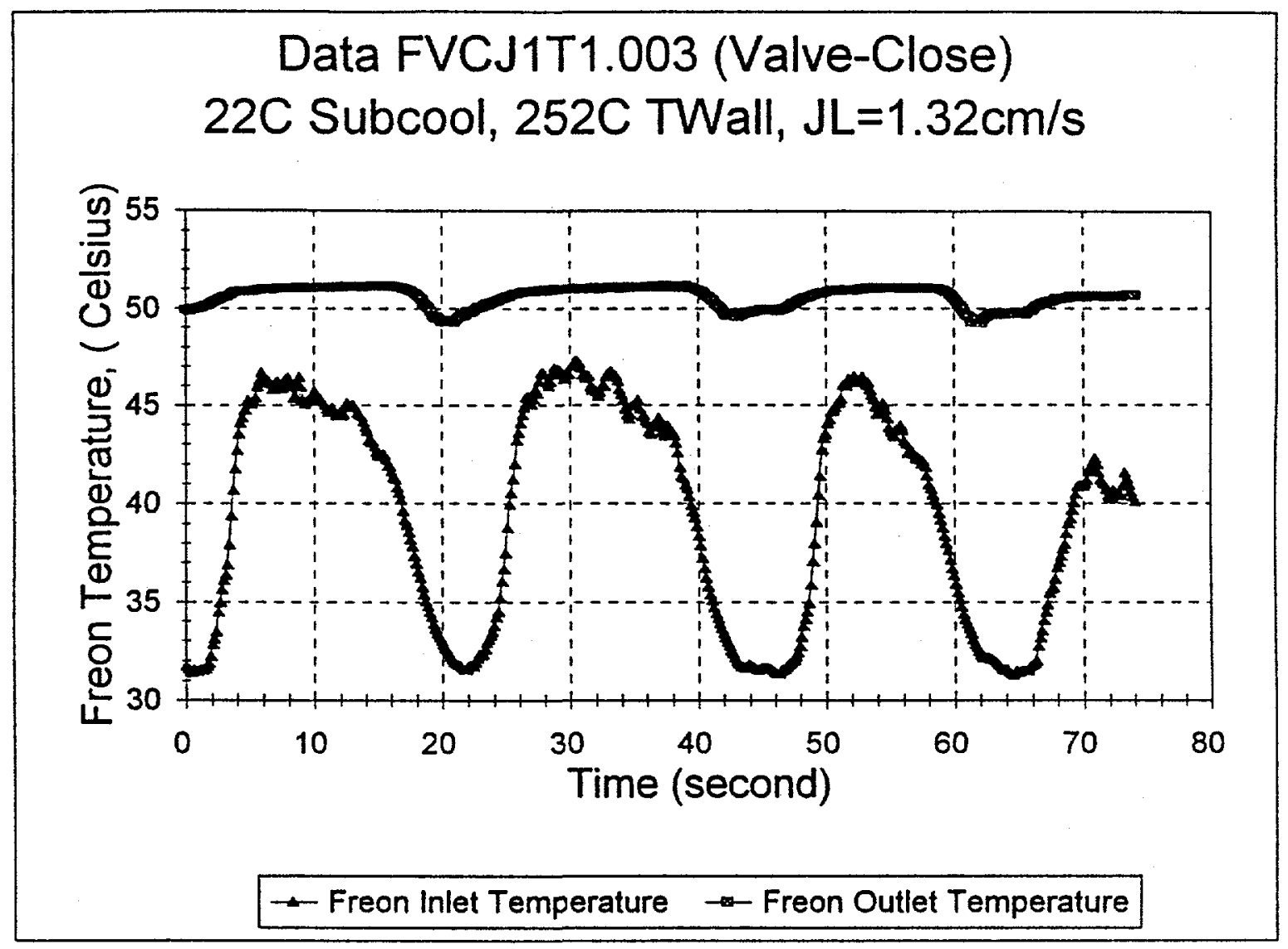

Figure 40 Temperature measurement during oscillation phenomena. 


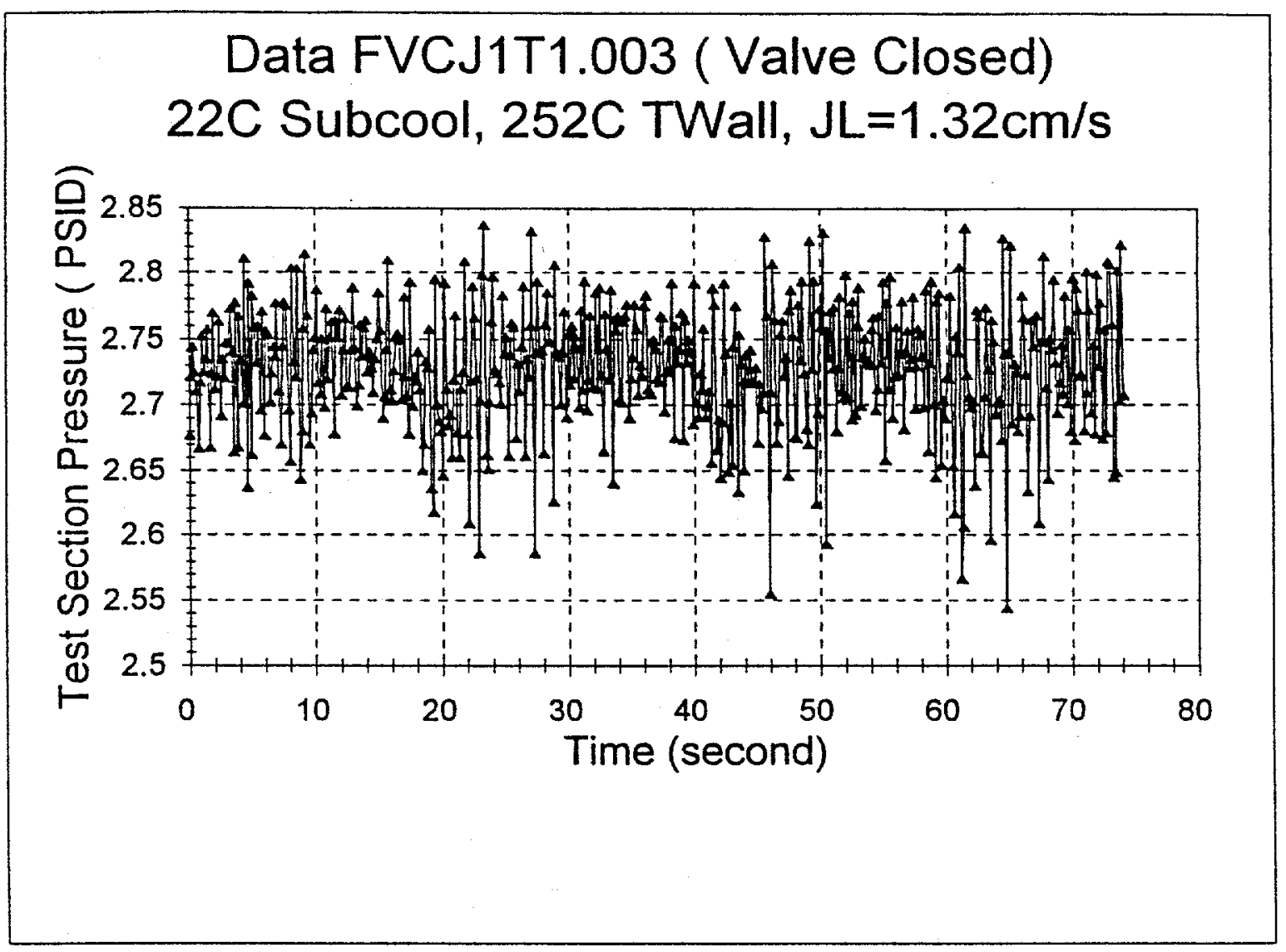

Figure 41 Pressure measurement during oscillation phenomena. 


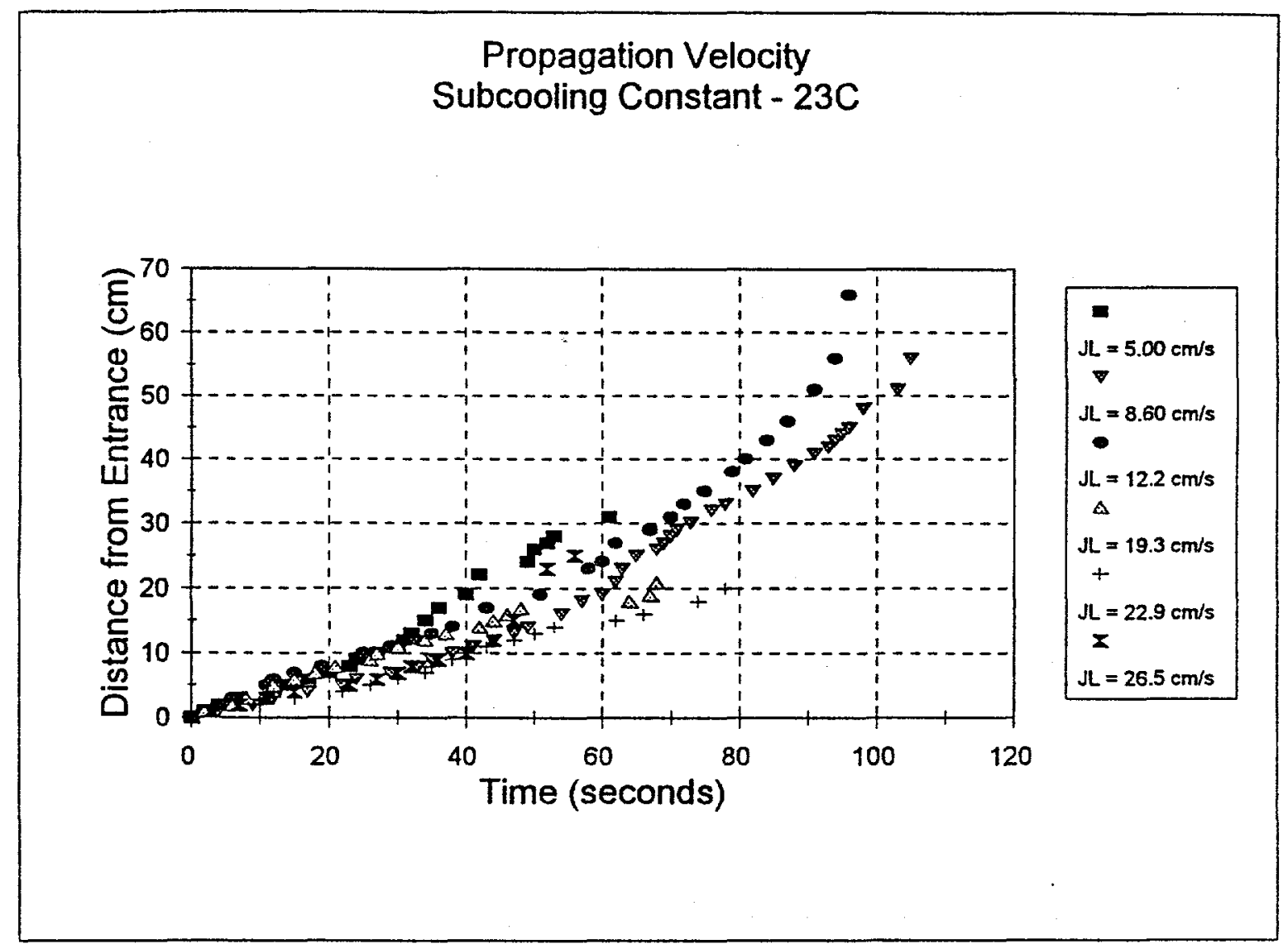

Figure 42 Quench front propagation data, $23 \mathrm{C}$ subcooling. 


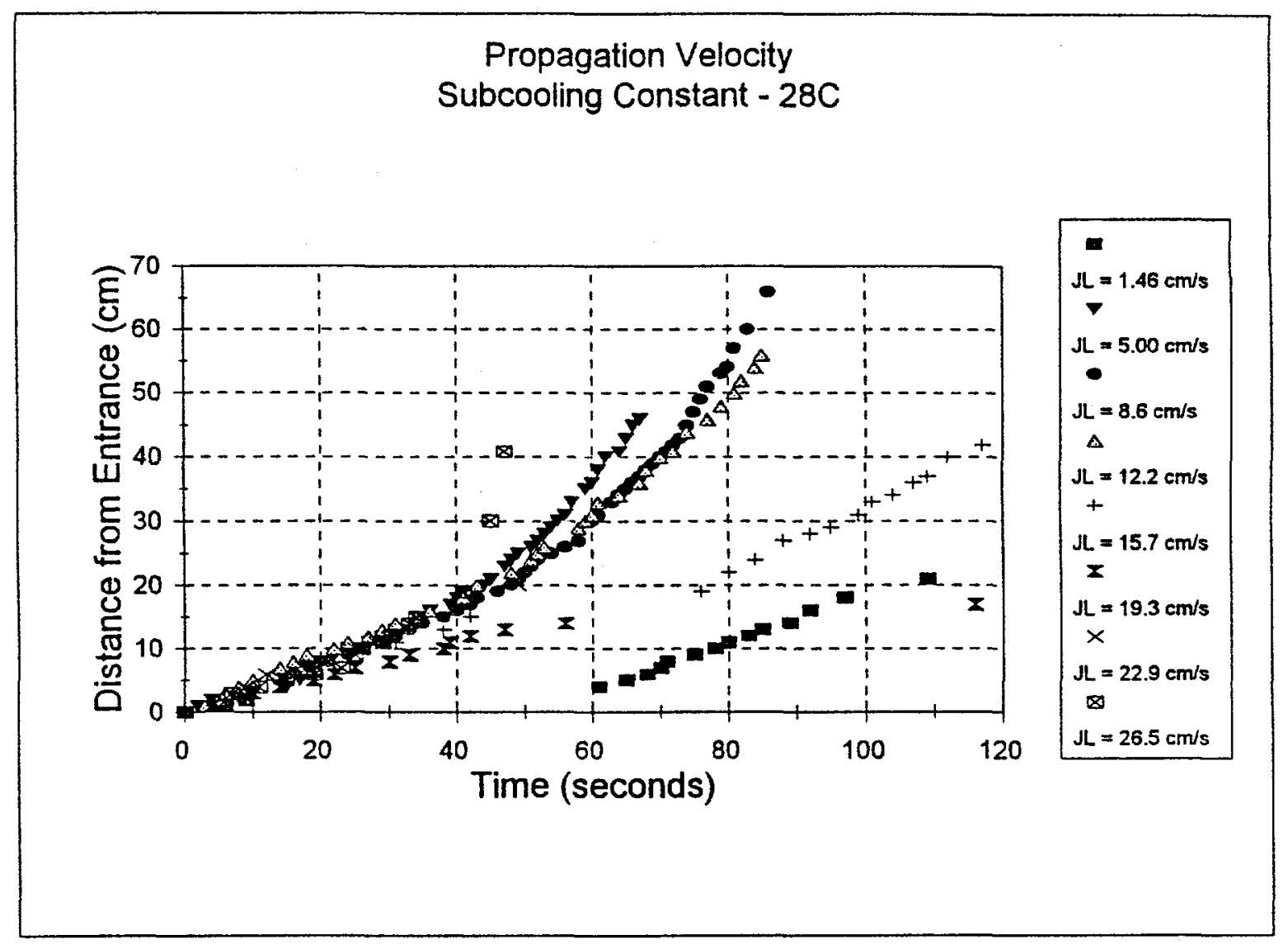

Figure 43 Quench front propagation data, $28 \mathrm{C}$ subcooling. 


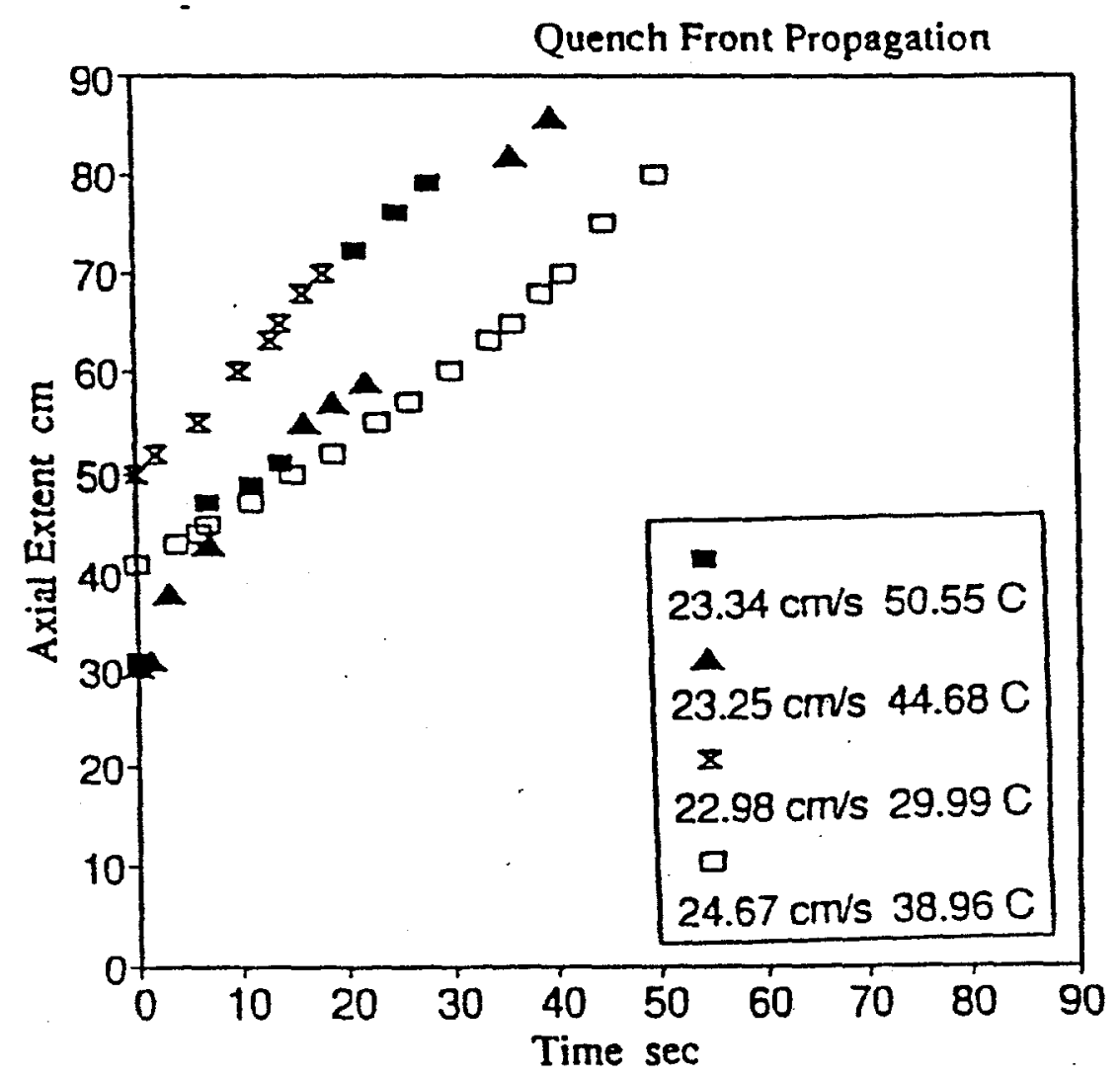

Figure 44 Vertical up-flow quench front propagation data 


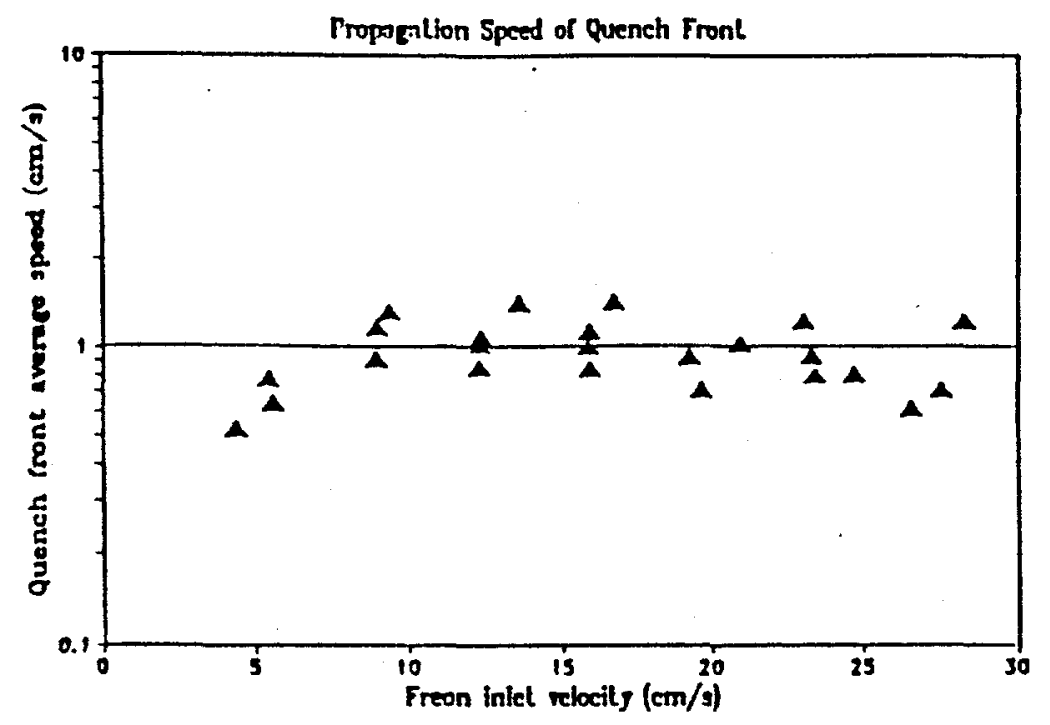

(a)

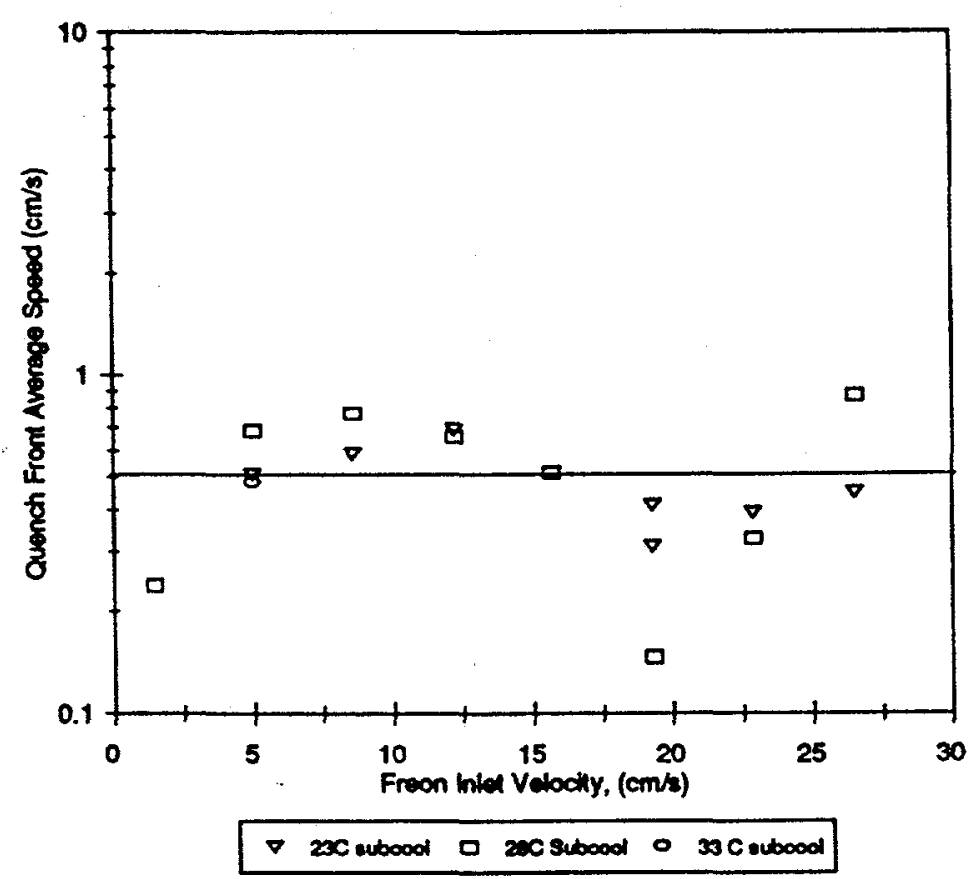

(b)

Figure 45 Quench front Average Propagation speed (a) up-flow (b) down-flow. 


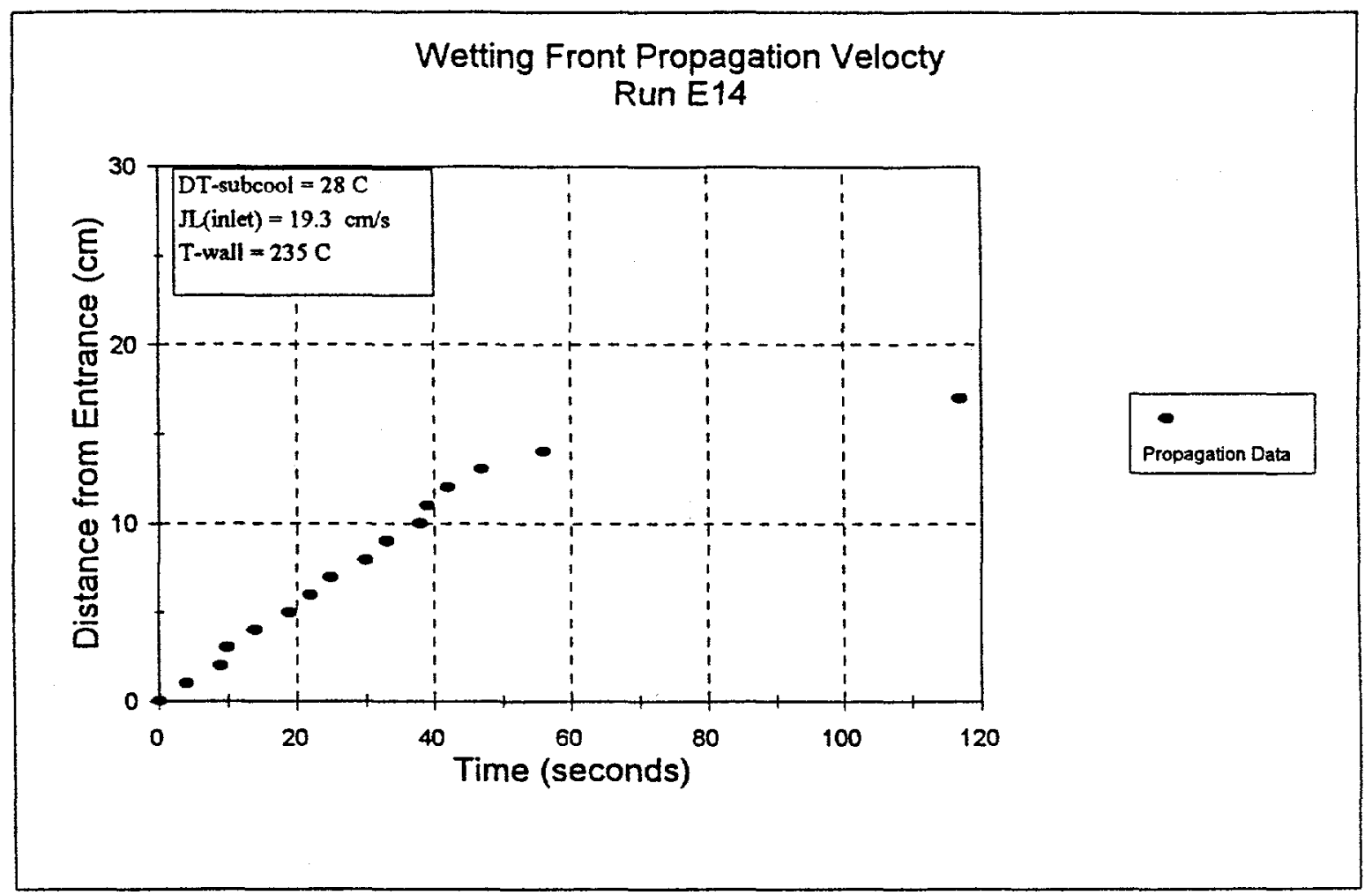

Figure 46 Example of an inhibited or stalled quench front. 


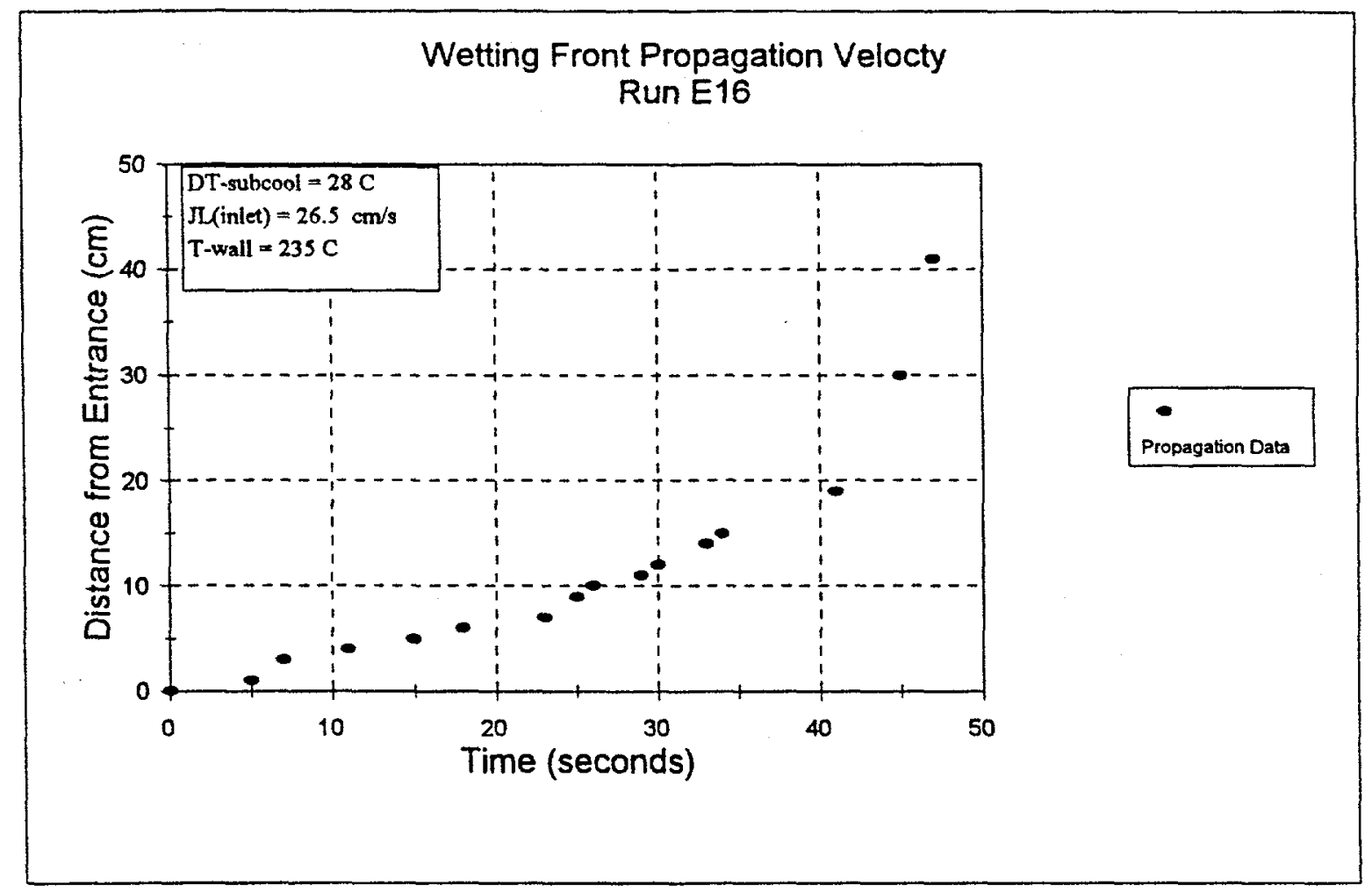

Figure 47 Example of an accelerated quench front. 


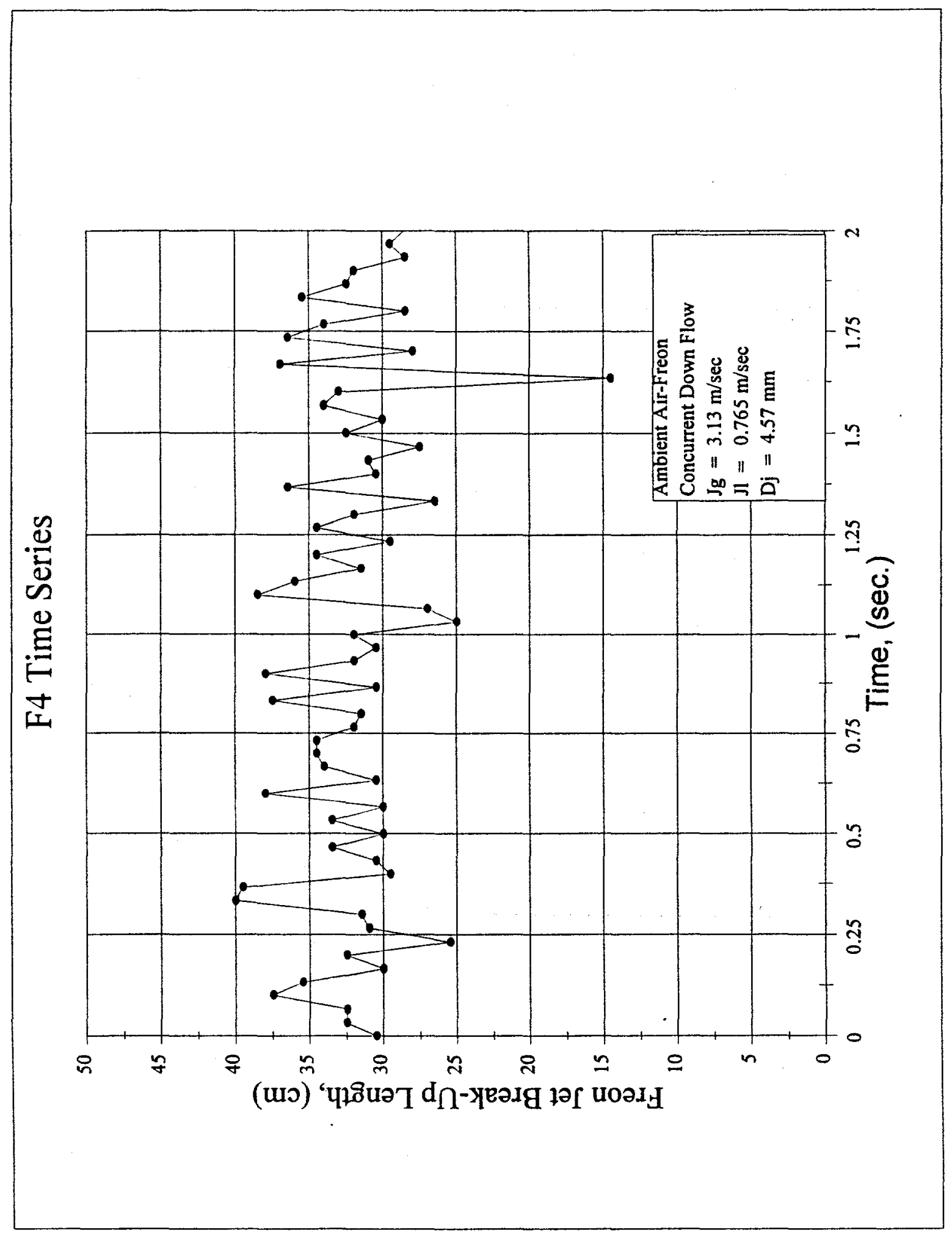

Figure 48 An example of a typical time series for the break-up length. 


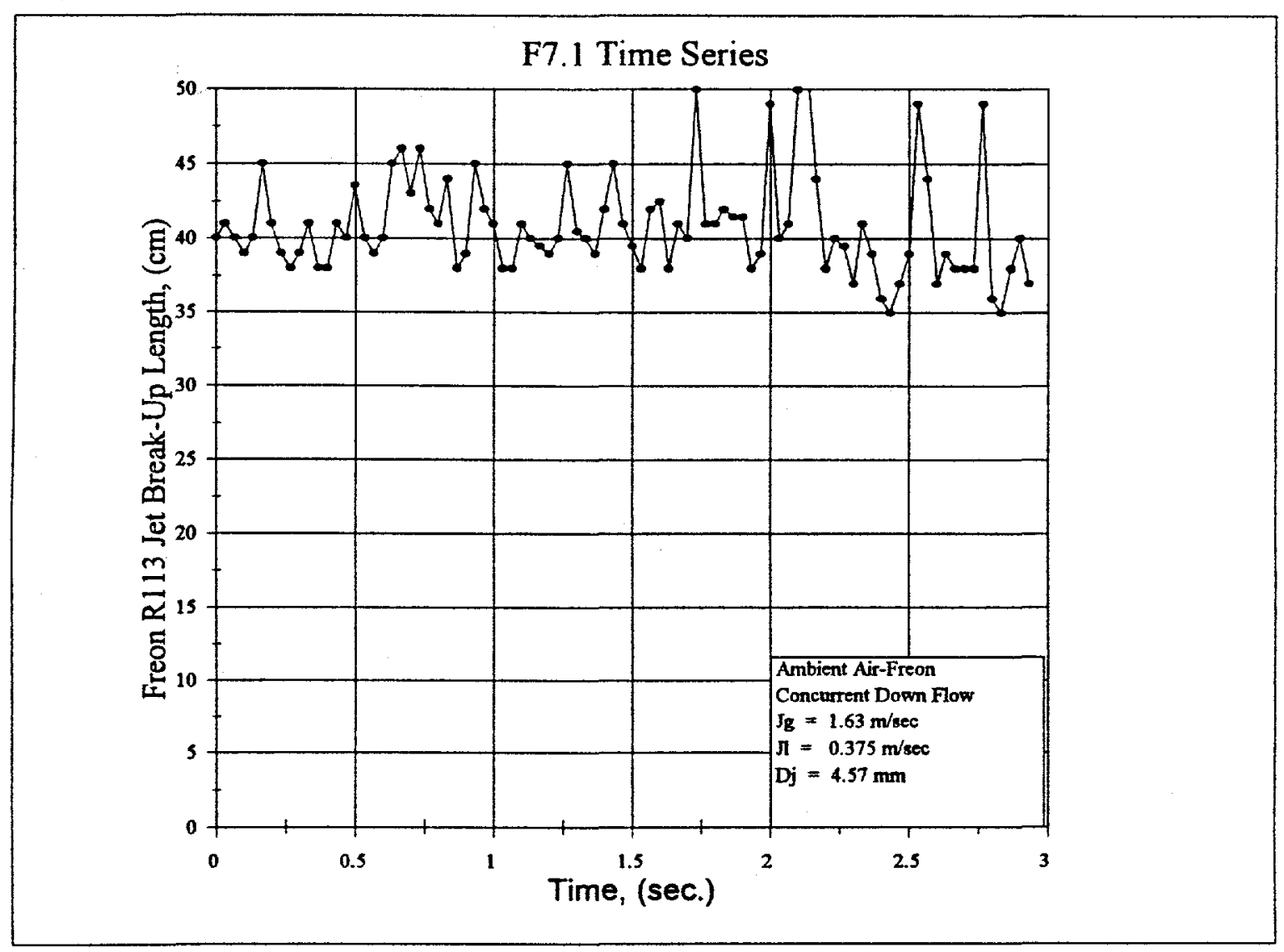

Figure 49 Break-up length data for time series F7.1. 


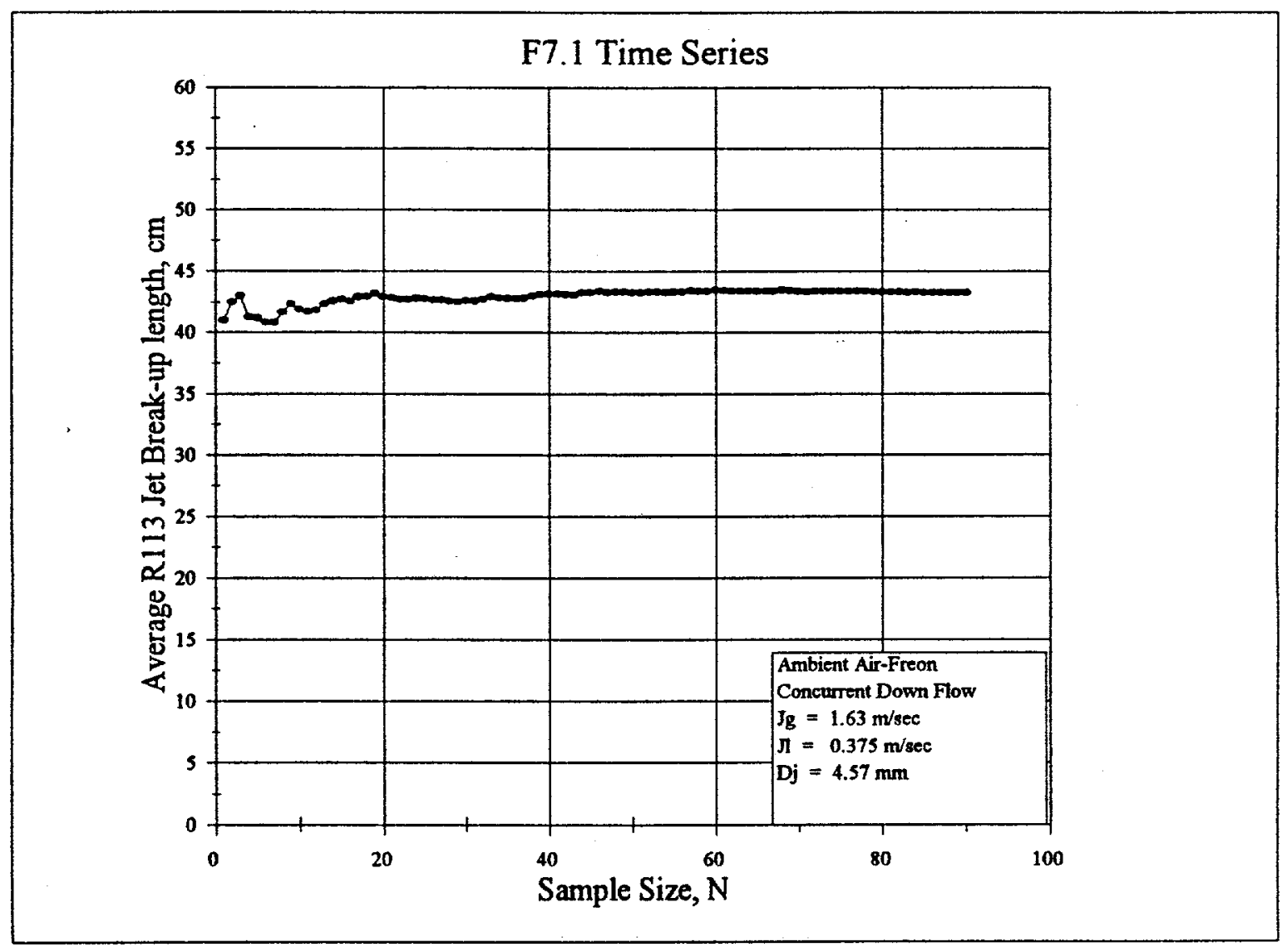

Figure 50 Average break-up length versus sample size for F7.1 data. 


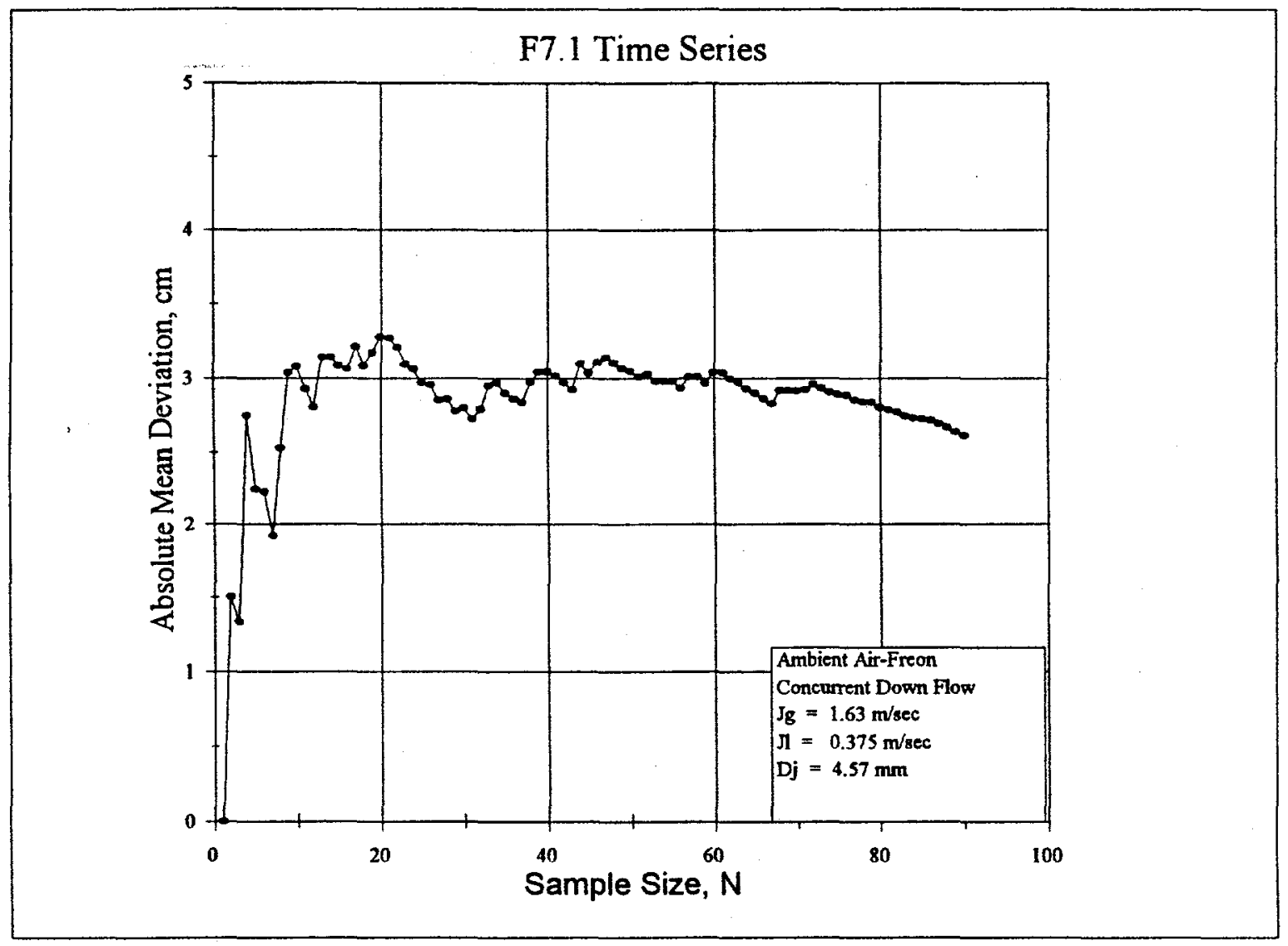

Figure 51 Absolute mean deviation of F7.1 data. 


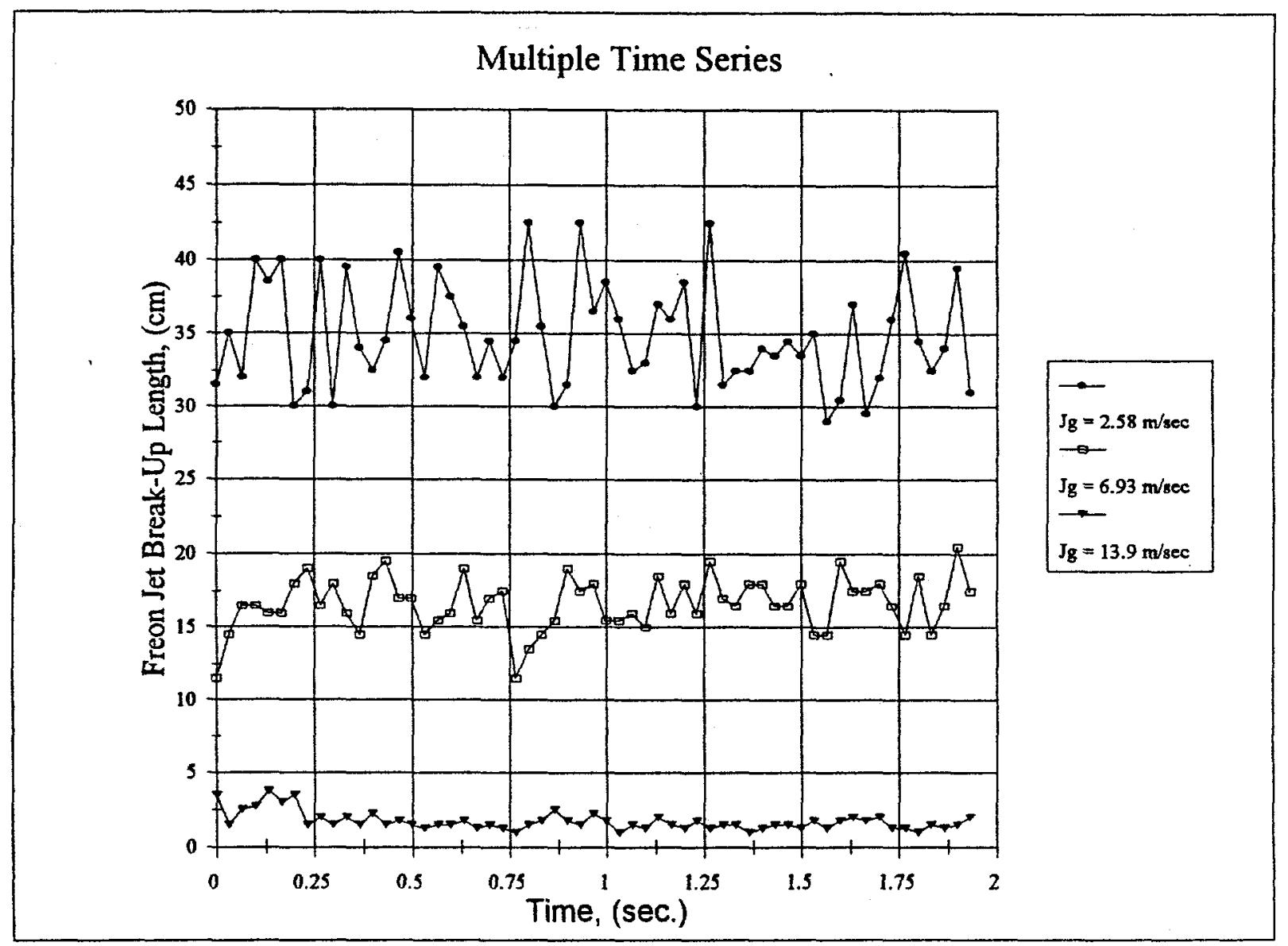

Figure 52 Comparison of break-up data for various gas velocities. 


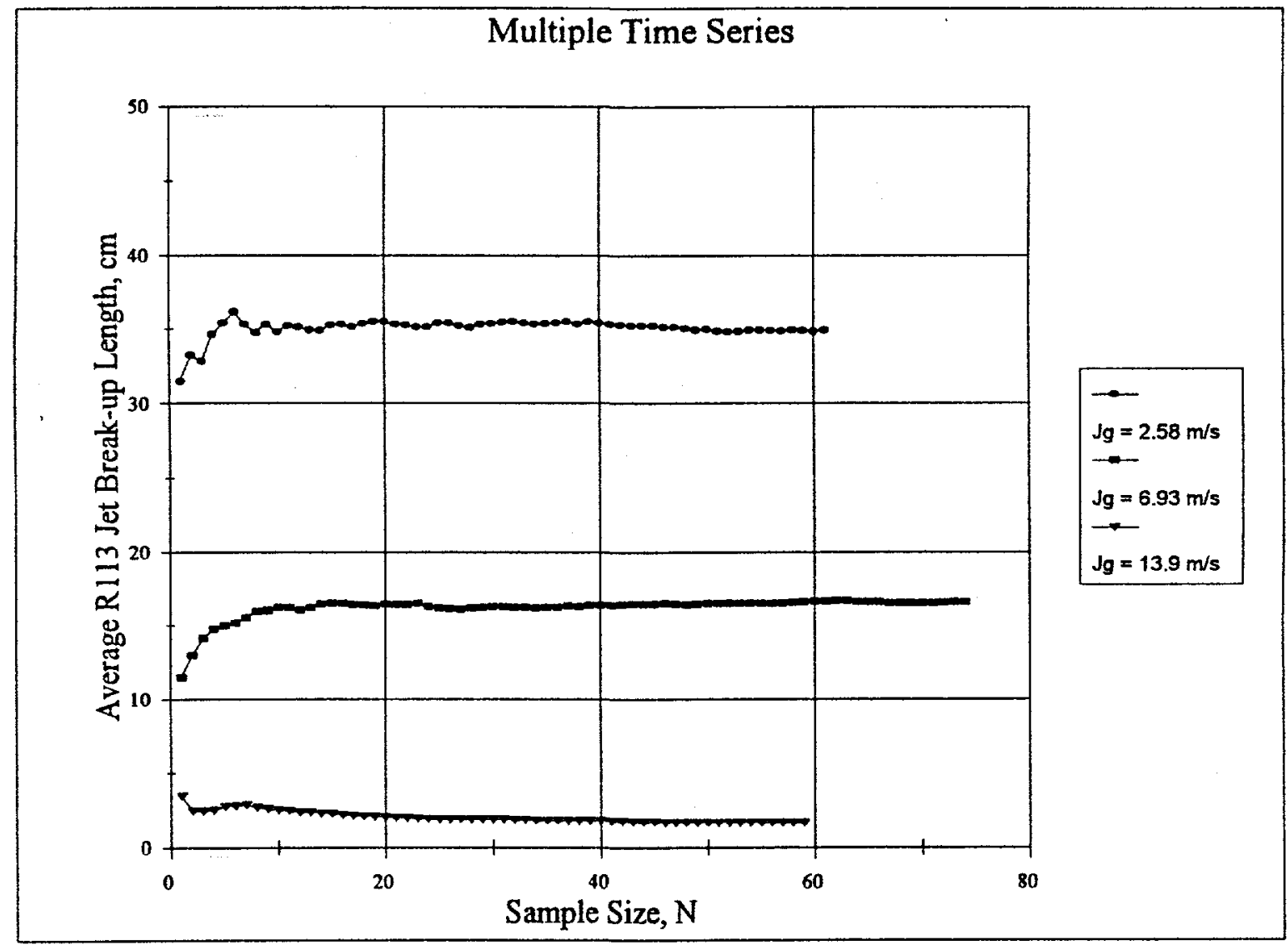

Figure 53 Comparison of average break-up data for various gas velocities. 


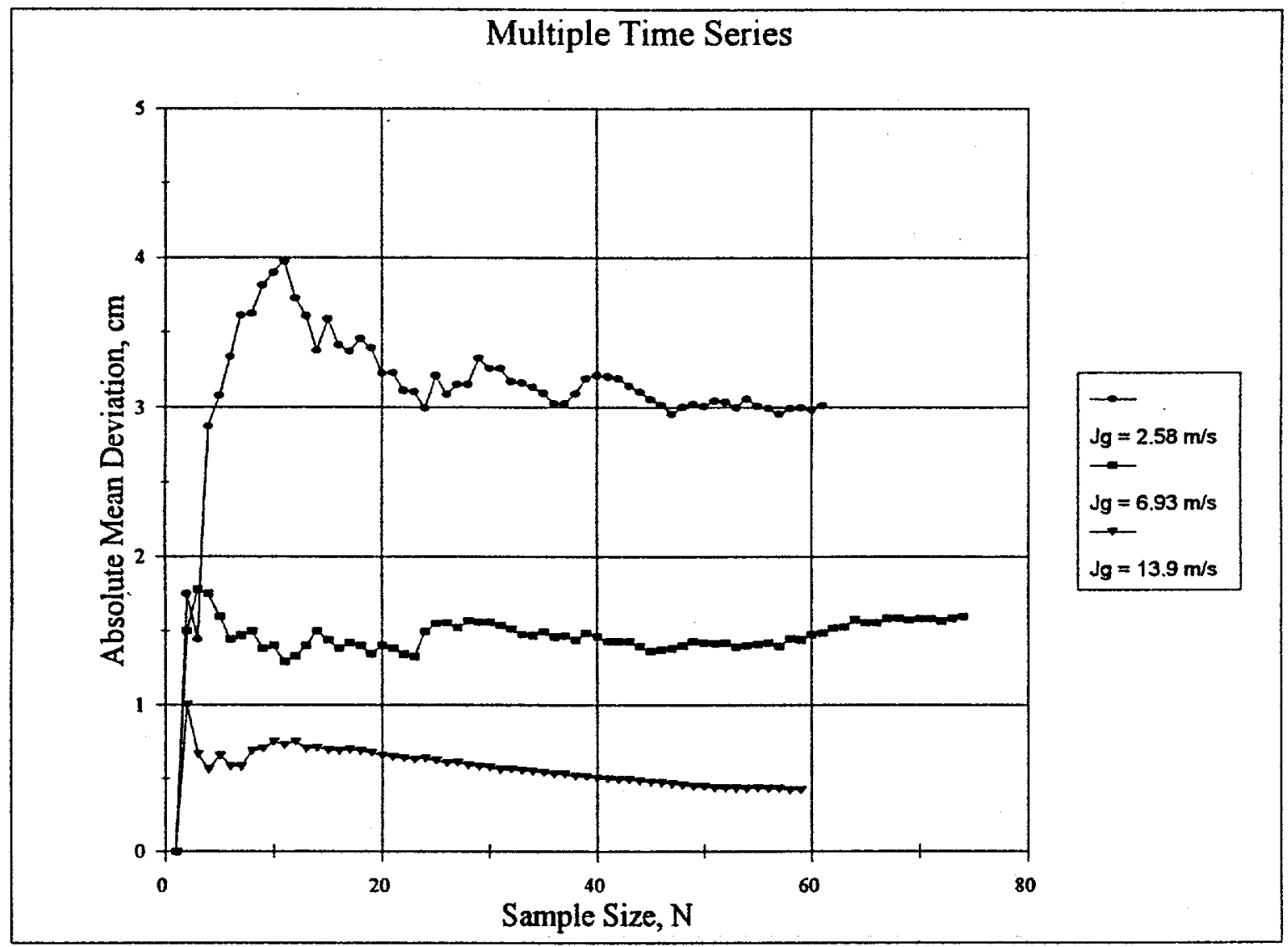

Figure 54 Comparison of absolute mean deviations for various gas velocities. 


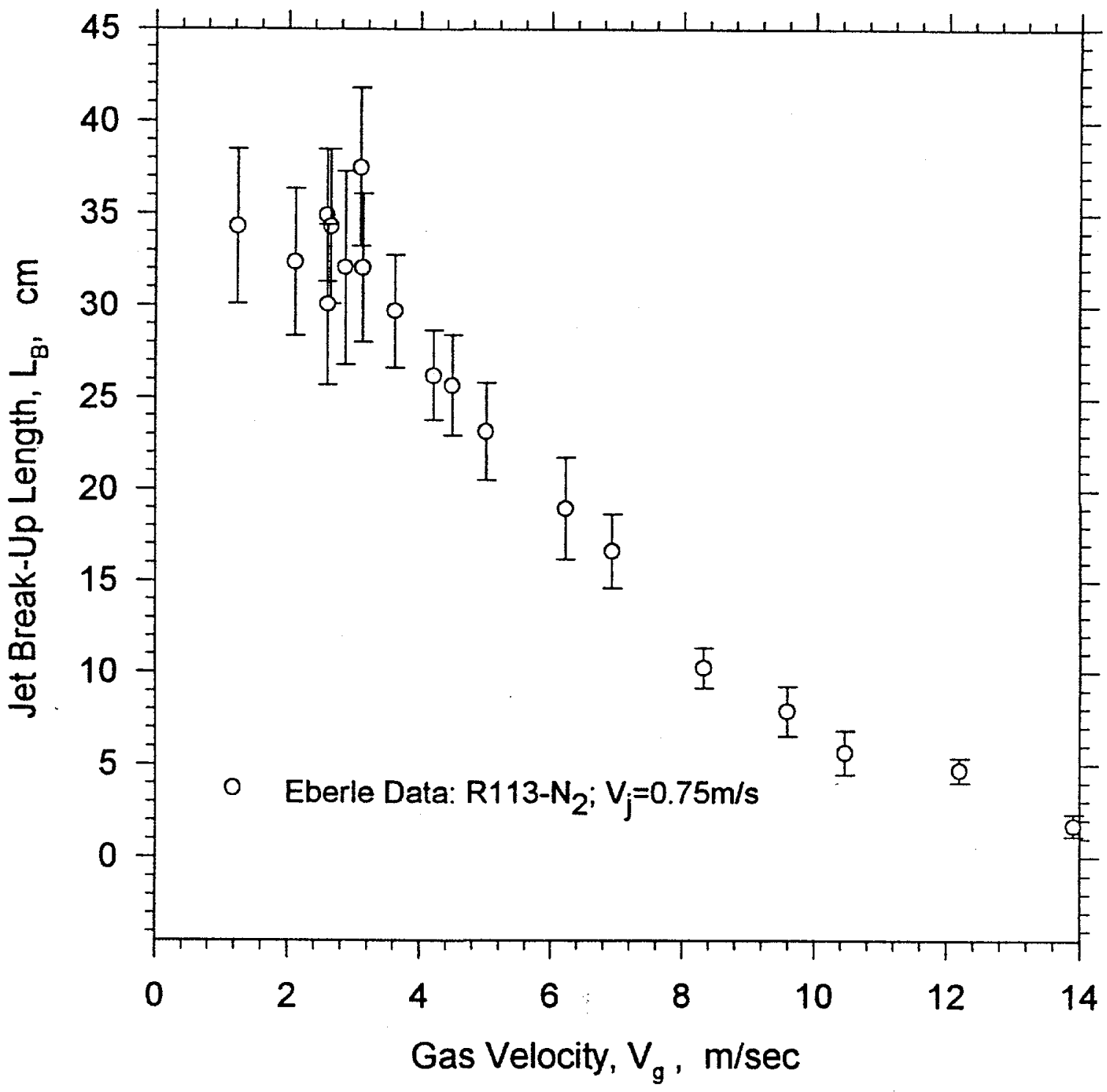

Figure 55 Adiabatic results of $\mathrm{L}_{\mathrm{b}}$ versus $\mathrm{v}_{\mathrm{g}}$ data including mean and standard error. 


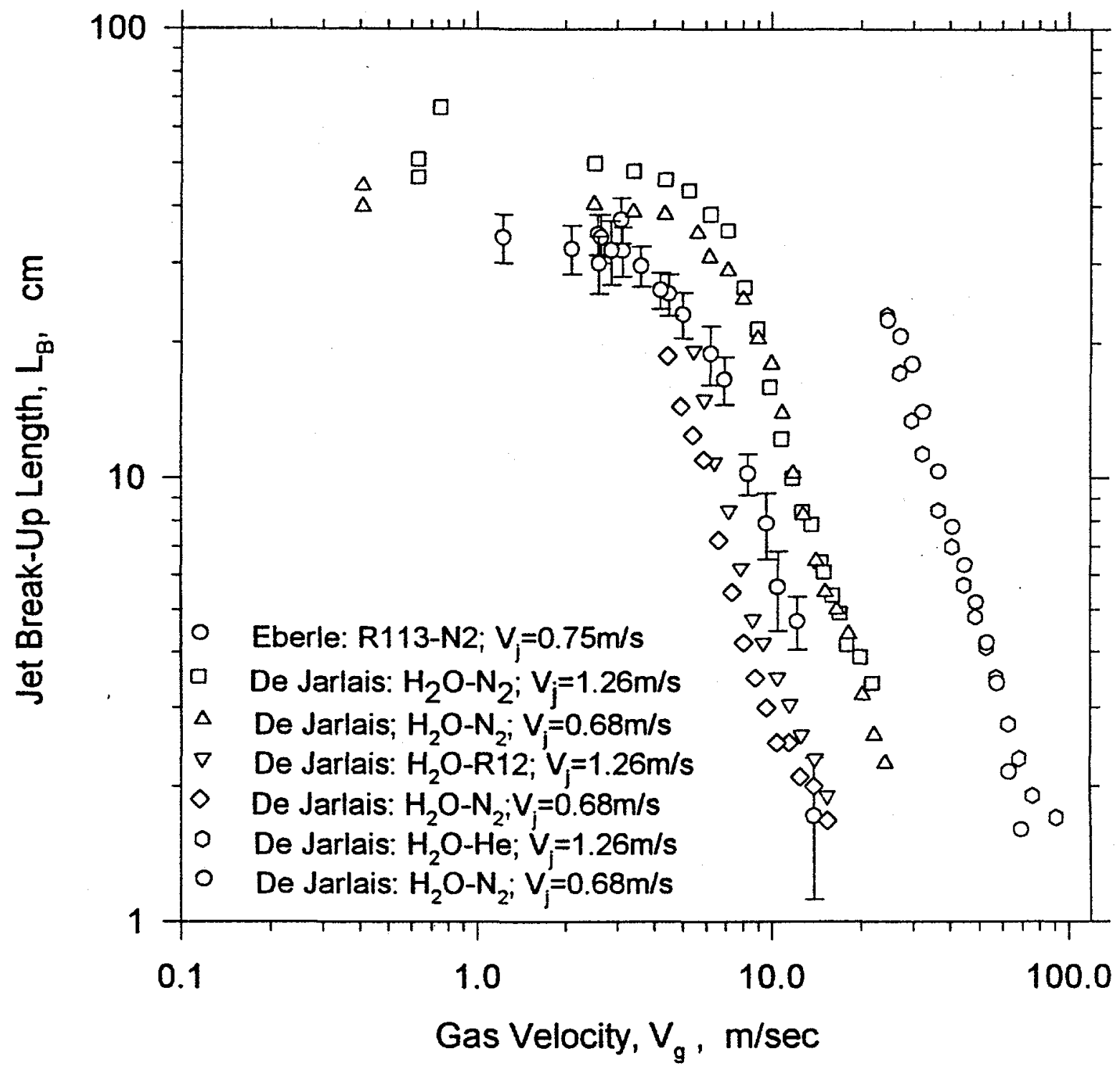

Figure 56 Comparison of Eberle and De Jarlais Adiabatic data. 


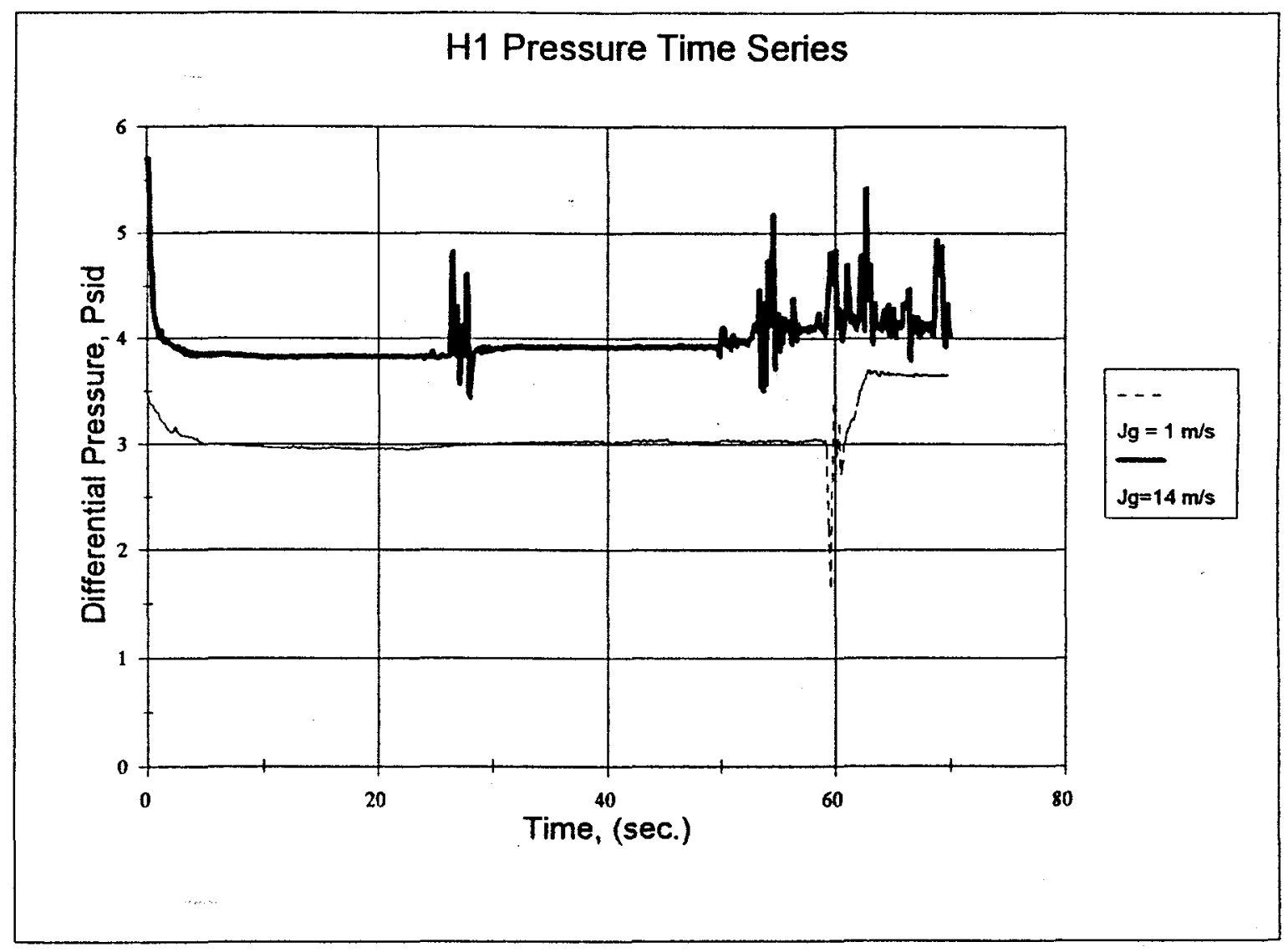

Figure 57 Comparison of adiabatic differential pressure time series. 


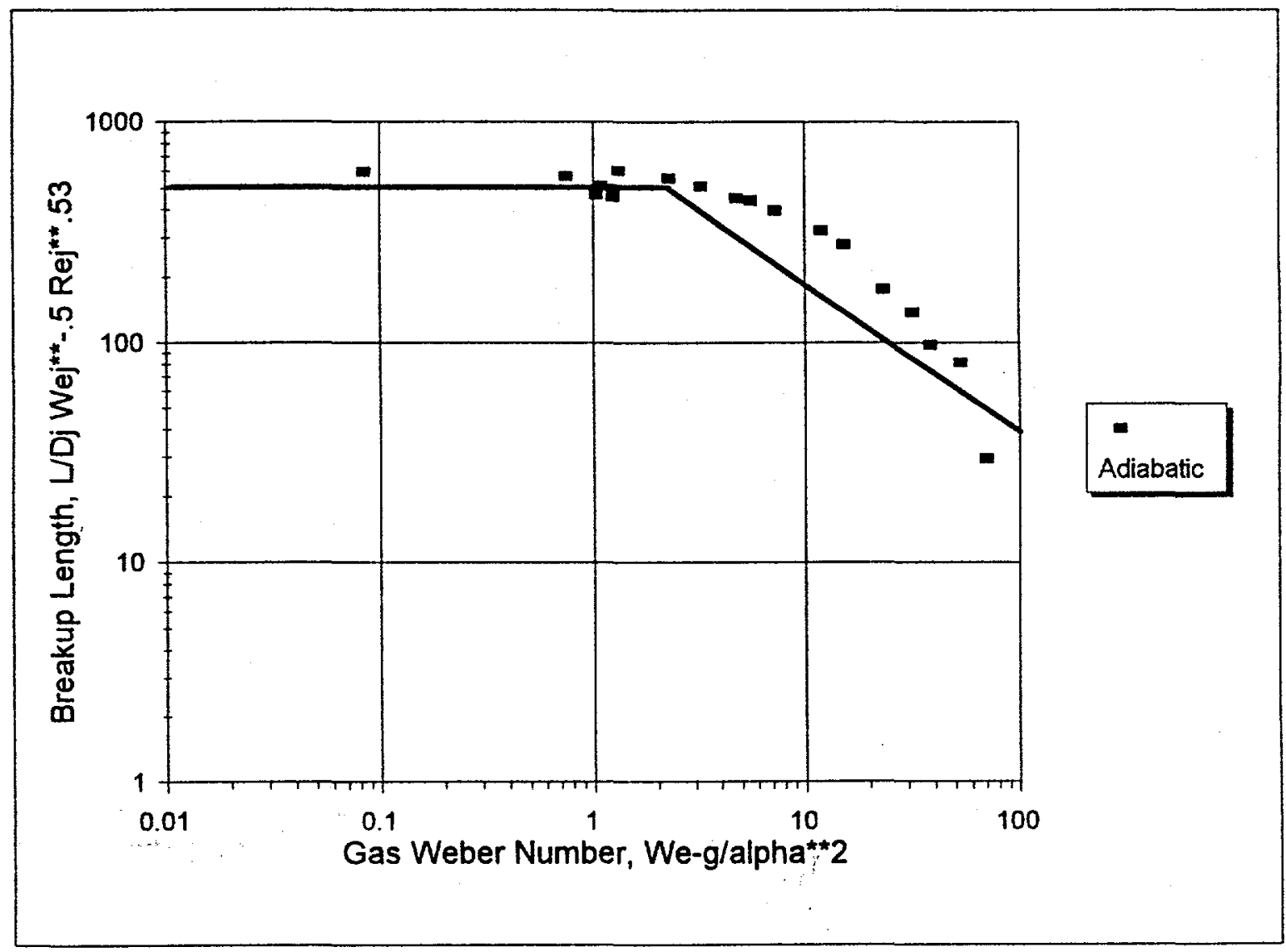

Figure 58 Dimensionless break-up length for Adiabatic data. 


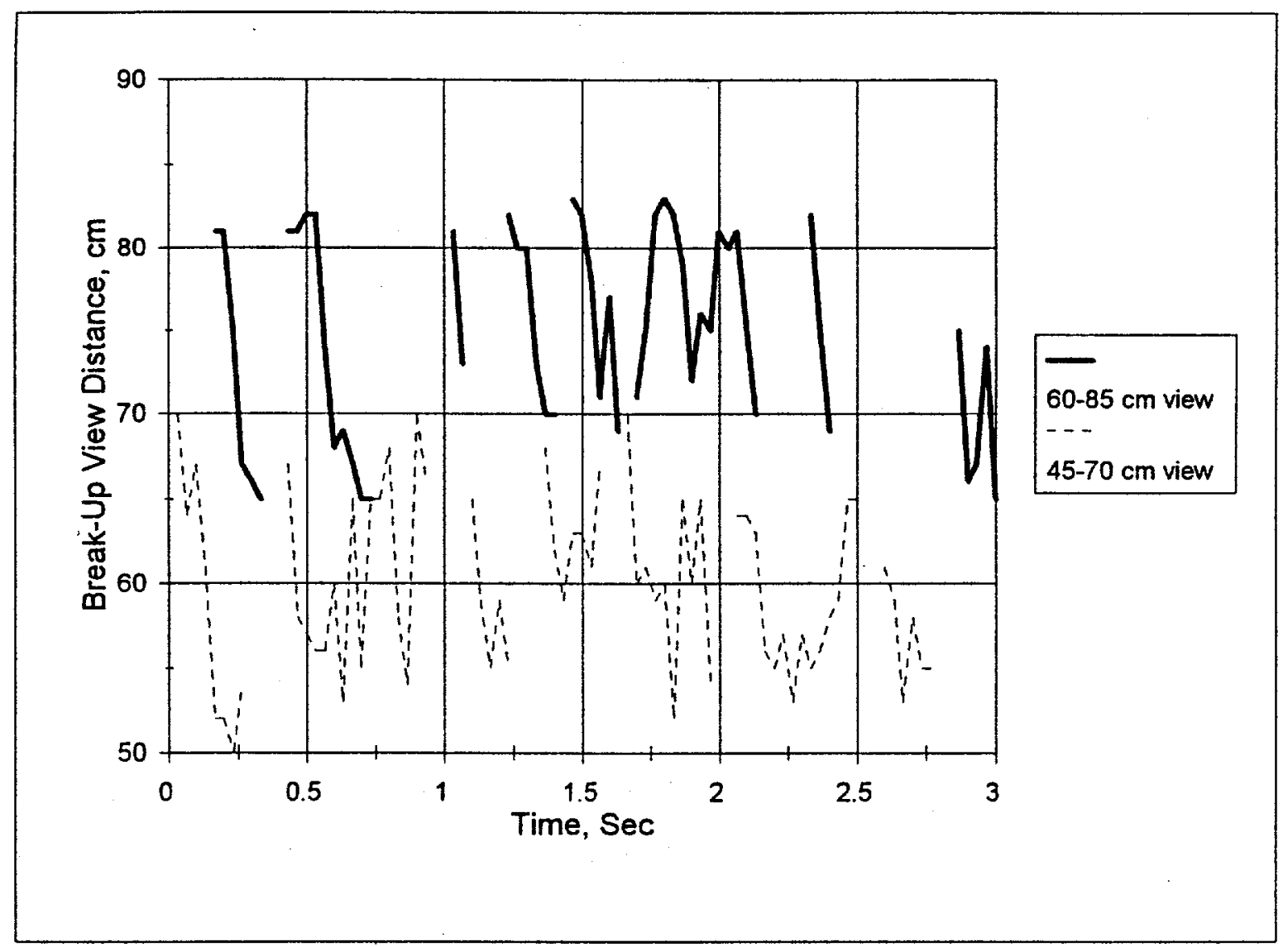

Figure 59 Two break-up filming view windows for $\mathrm{H} 69$ data series. 


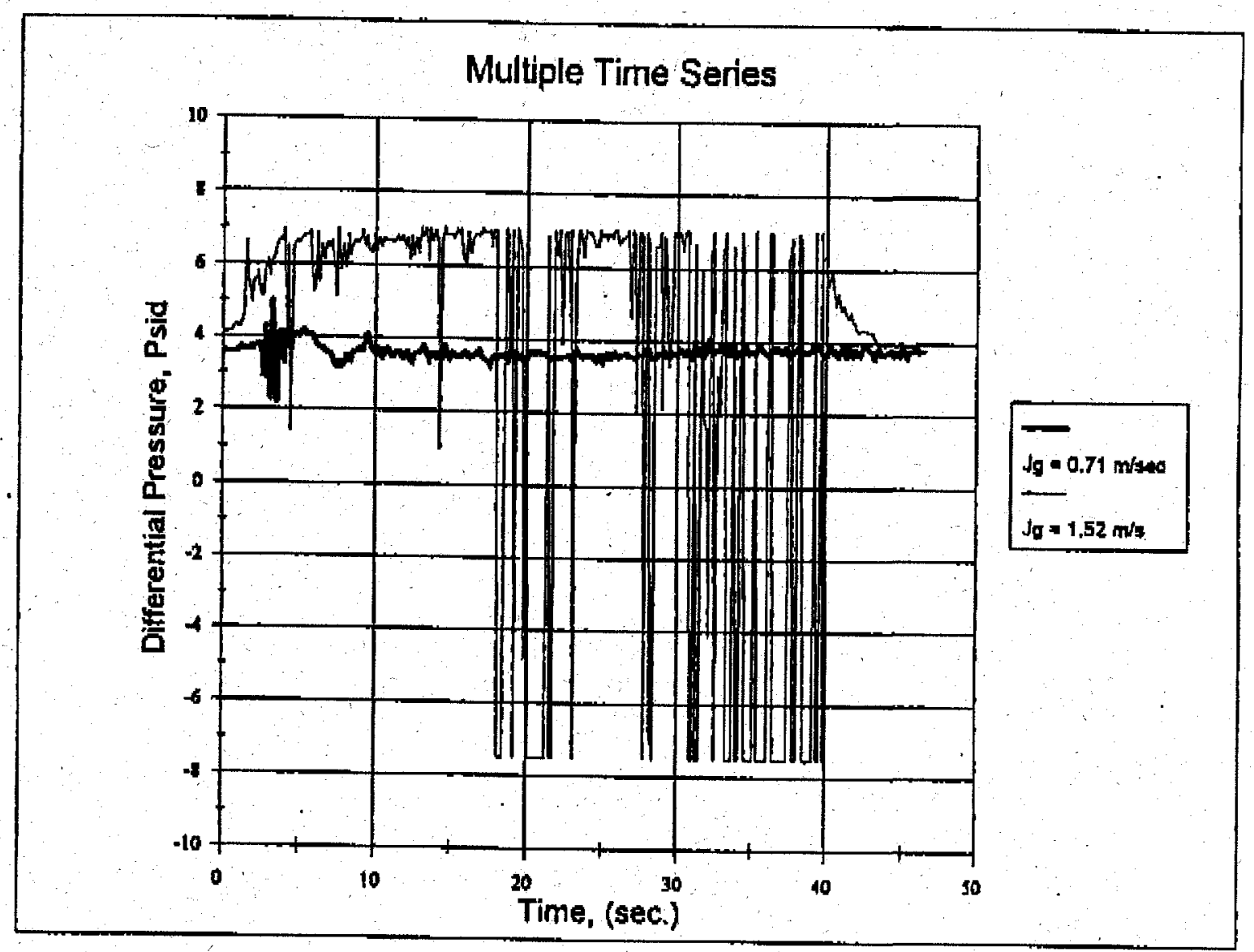

Figure 60 Comparison of diabatic differential pressure time series. 
Diabatic Data Error Analysis

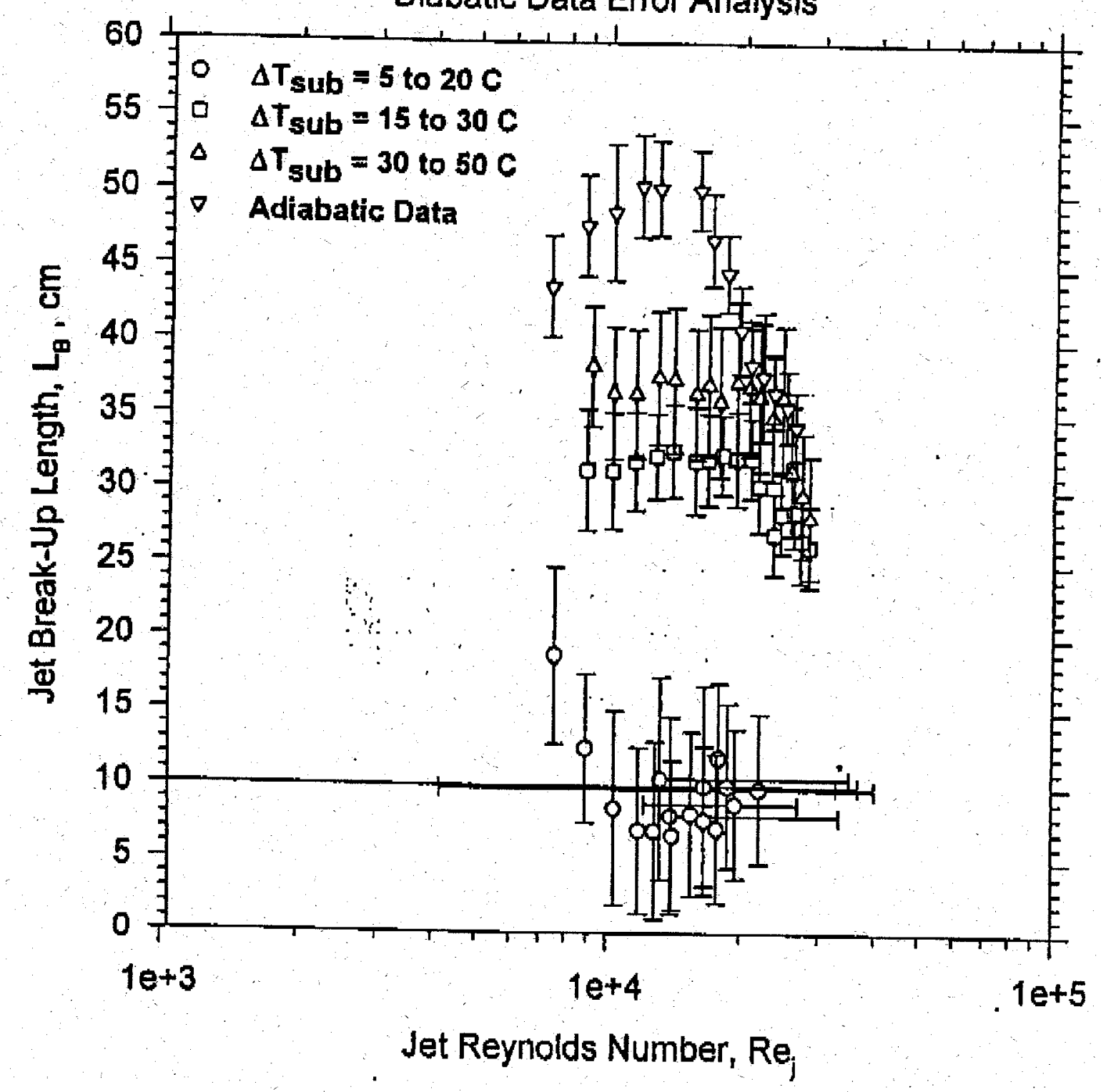

Figure 61 Diabatic error analysis results. 


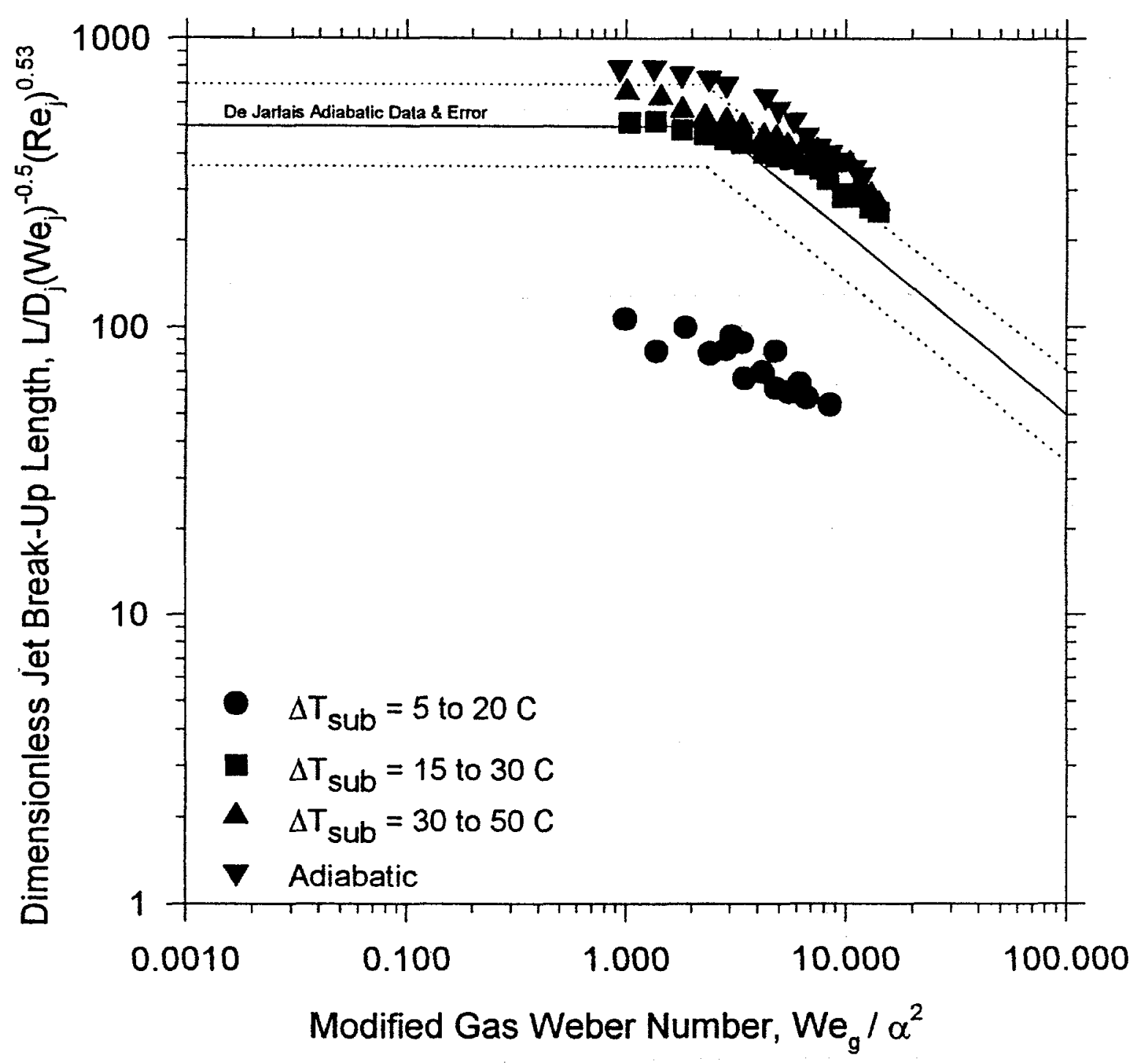

Figure 62 Adiabatic and diabatic data comparison. 


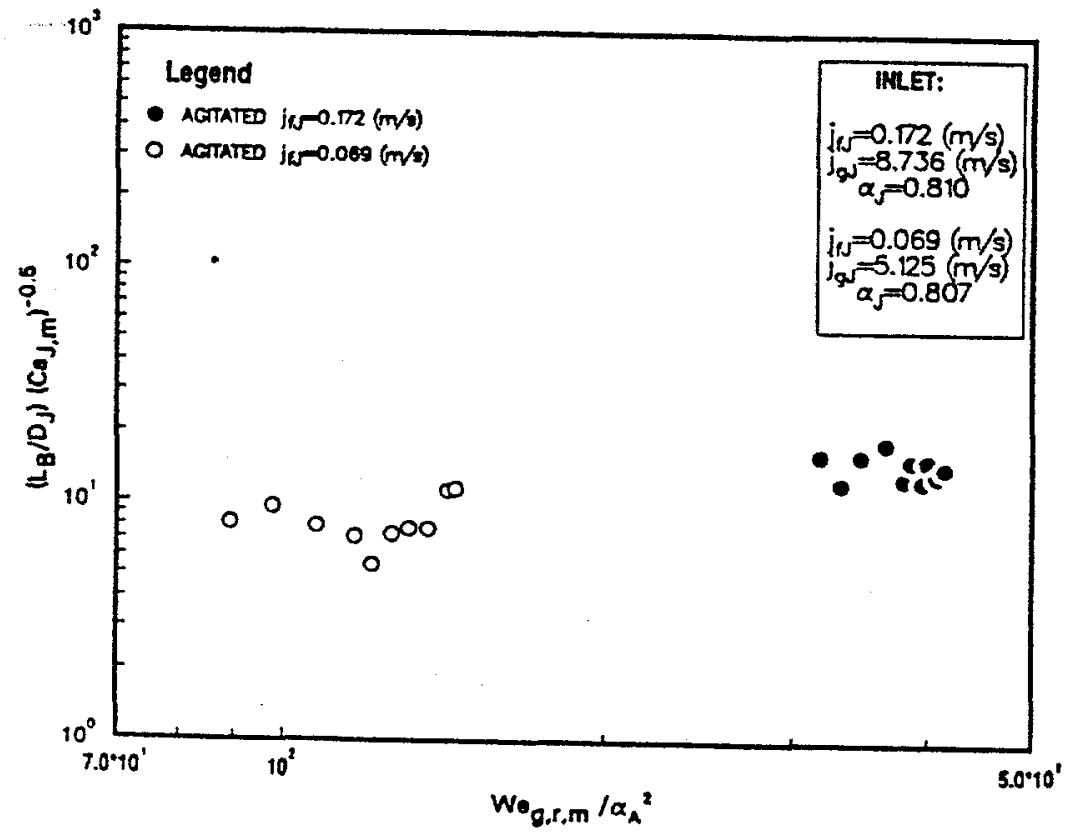

Figure 63 Denten et. al. axial extent data for upflow [23]. 


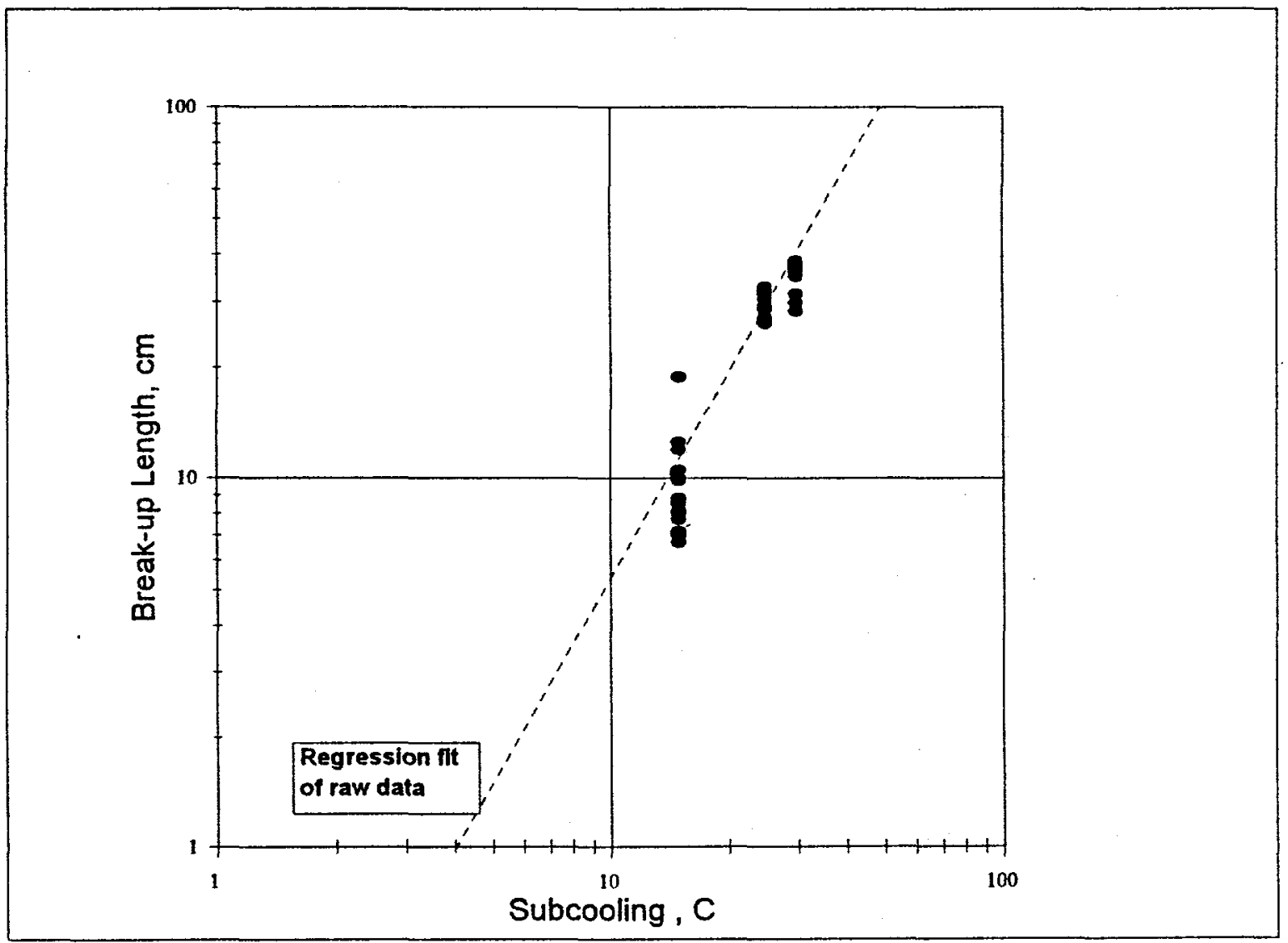

Figure 64 Diabatic break-up length as a function of subcooling. 


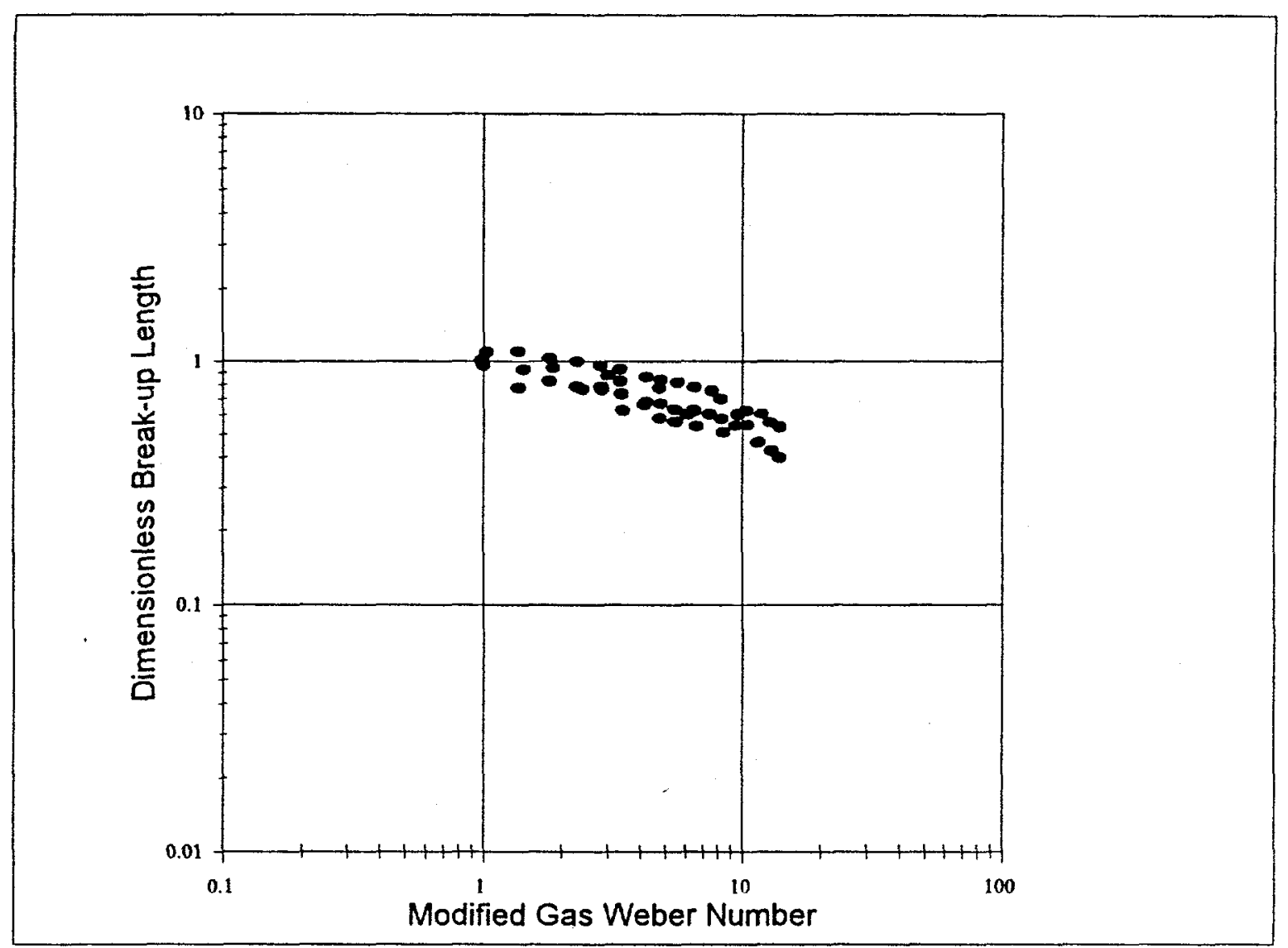

Figure 65 Dimensionless break-up length versus modified gas Weber number. 
Table 1: Geometry of the Inlet Unheated Sections

\begin{tabular}{|c||c|c|c|c|}
\hline $\mathrm{i}$ & $k_{i}$ & $L_{i}(\mathrm{~m})$ & $A_{i}\left(\mathrm{~m}^{2}\right)$ & $D_{i}(\mathrm{~m})$ \\
\hline \hline 1 & 0.61723 & 0.75565 & 0.00760852 & 0.098425 \\
\hline 2 & 0.02665 & 0.053848 & 0.00643083 & 0.0904875 \\
\hline 3 & 1.03949 & 0.130175 & 0.00541154 & 0.0830072 \\
\hline 4 & 0.02576 & 0.2272792 & 0.00456036 & 0.0762 \\
\hline 5 & 0.06721 & 0.1166812 & 0.00515027 & 0.0556042 \\
\hline 6 & 1.03591 & 0.2024062 & 0.0045296 & 0.0391647 \\
\hline 7 & 0.02222 & 0.4953 & 0.0040506 & 0.0354048 \\
\hline
\end{tabular}


Table 2: Parameters for prototype (Fuel-Target) and model

\begin{tabular}{|c|c|c|}
\hline & Prototype (Fuel - Target) & Model \\
\hline Geometry & Concentric Annulus & Annulus \\
\hline Heated Length $L_{H}(\mathrm{~m})$ & 3.6 & 1.83 \\
\hline Equivalent Diameter $D_{H}\langle\mathrm{~m}\rangle$ & $1.817 \times 10^{-2}$ & $1.587 \times 10^{-2}$ \\
\hline Heated Area $A_{B}\left(m^{2}\right)$ & 0.919 & $7.3 \times 10^{-2}$ \\
\hline Fluid & Water & Freon-113 \\
\hline Pressure (kPa) & 138 & 101 \\
\hline Velocity $(m)$ & $v_{p}-2$ & $v_{m}-1$ \\
\hline Subcooling $\frac{\Delta h_{s u b}}{h_{f g}}$ & $\begin{array}{cc}\# 1, & \# 2 \\
0.0447, & 0.0231\end{array}$ & $\begin{array}{cc}\# 1, & \# 2 \\
0.265, & 0.137\end{array}$ \\
\hline$C H F(C-T) q_{c}{ }^{\prime \prime}\left(\mathrm{kW} / \mathrm{m}^{2}\right)$ & $16 \cdot 257,16 \cdot 141$ & $6-131,6-70$ \\
\hline Power (kW) & - & 6 \\
\hline
\end{tabular}


Table 3 Parameters for prototype (Fuel-Fuel) and model

\begin{tabular}{|c|c|c|}
\hline & Prototype (Fuel - Fuel) & Model \\
\hline Geometry & Concentric Annulus & Annulus \\
\hline Heated Length $L_{B}(\mathrm{~m})$ & 3.6 & 1.83 \\
\hline Equivalent Diameter $D_{B}(\mathrm{~m})$ & $1.361 \times 10^{-2}$ & $1.587 \times 10^{-2}$ \\
\hline Heated Area $A_{B}\left(\mathrm{~m}^{2}\right)$ & 1.506 & $7.3 \times 10^{-2}$ \\
\hline Fluid & Water & Freon-113 \\
\hline Pressure (kPa) & 138 & 101 \\
\hline Velocity $(\mathrm{m})$ & $V_{p}-2$ & $V_{m}-1$ \\
\hline Subcooling $\frac{\Delta h_{s u b_{1}}}{h_{f \dot{ }}}$ & $\begin{array}{cc}\# 1, & \# 2 \\
0.0447, & 0.0231\end{array}$ & $\begin{array}{cl}\# 1, & \# 2 \\
0.265, & 0.137\end{array}$ \\
\hline$C H F(C \cdot T) q_{c} "\left(k W / m^{2}\right)$ & $15-195,15-108$ & $6-131,6-70$ \\
\hline Power (kW) & $\cdots$ & 6 \\
\hline
\end{tabular}




\begin{tabular}{|l|l|l|l|l|l||}
\hline $\begin{array}{l}\text { Data Test } \\
\text { Series }\end{array}$ & $\begin{array}{l}\text { Nozzle } \\
\text { I.D., cm }\end{array}$ & $\begin{array}{l}\text { Tube } \\
\text { I.D., cm }\end{array}$ & $\begin{array}{l}\text { Nozzle } \\
\text { Length, cm }\end{array}$ & $\begin{array}{l}\text { Initial Void } \\
\text { Fraction }\end{array}$ & $\begin{array}{l}\text { Gas } \\
\text { Species }\end{array}$ \\
\hline $\mathrm{f} 1-\mathrm{f} 20$ & .475 & 14 & 53 & .89 & $\mathrm{~N}_{2}$ \\
\hline $\mathrm{h} 1-\mathrm{h} 20$ & .475 & 18 & 53 & .93 & - \\
\hline $\mathrm{h} 1.1-\mathrm{h} 20.1$ & .475 & 18 & 52 & .93 & - \\
\hline h1.2-h15.2 & .475 & 18 & 52 & .93 & - \\
\hline $\mathrm{n} 1-\mathrm{n} 20$ & 1.27 & 18 & 54 & .50 & $\mathrm{~N}_{2}$ \\
\hline
\end{tabular}

Table 4 Test matrix for adiabatic study. 


\begin{tabular}{|l|l|l|}
\hline Data Test Series No. & $\begin{array}{l}\text { R-113 Subcooling, } \\
\Delta \mathrm{T}_{\text {sub }}{ }^{\circ} \mathrm{C}\end{array}$ & $\begin{array}{l}\text { Heated Wall } \\
\text { Temperature, }{ }^{\circ} \mathrm{C}\end{array}$ \\
\hline H1 - H15 & ADIABATIC & 21 \\
\hline H16 - H32 & 30 TO 50 & 241 \\
\hline H33 - H49 & 15 TO 30 & 241 \\
\hline H50 - H58 & 20 TO 30 & 241 \\
\hline H59 - H75 & 5 TO 20 & 241 \\
\hline
\end{tabular}

Table 5 Test matrix for diabatic study. 


\begin{tabular}{|c|c|c|c|c|}
\hline Time & $\begin{array}{l}\text { H68Data } \\
85-60 \mathrm{~cm} \\
\text { Number }\end{array}$ & $\begin{array}{l}85-60 \mathrm{~cm} \\
\text { indicator }\end{array}$ & $\begin{array}{l}70-45 \mathrm{~cm} \\
\text { number }\end{array}$ & $\begin{array}{l}70-45 \mathrm{~cm} \\
\text { indicator }\end{array}$ \\
\hline 0.033333 & & $\mathbf{L}$ & 70 & \\
\hline 0.066667 & & L & 64 & \\
\hline 0.1 & & L & 67 & \\
\hline 0.133333 & & $L$ & 61 & \\
\hline 0.166667 & 81 & & 52 & \\
\hline 0.2 & 81 & & 52 & \\
\hline 0.233333 & 75 & & 50 & \\
\hline 0.266667 & 67 & & 54 & \\
\hline 0.3 & 66 & & & $\mathrm{H}$ \\
\hline 0.333333 & 65 & & & $\mathrm{H}$ \\
\hline 0.366667 & & L & 61 & \\
\hline 0.4 & & $L$ & & $\mathrm{H}$ \\
\hline 0.433333 & 81 & & 67 & \\
\hline 0.466667 & 81 & & 58 & \\
\hline 0.5 & 82 & & 57 & \\
\hline 0.533333 & 82 & & 56 & \\
\hline 0.566667 & 74 & & 56 & \\
\hline 0.6 & 68 & & 60 & \\
\hline 0.633333 & 69 & & 53 & \\
\hline 0.666667 & 67 & & 65 & \\
\hline 0.7 & 65 & & 55 & \\
\hline 0.733333 & 65 & & 65 & \\
\hline 0.766667 & & $L$ & 65 & \\
\hline 0.8 & & $L$ & 68 & \\
\hline 0.833333 & & L & 58 & \\
\hline 0.866667 & & $L$ & 54 & \\
\hline 0.9 & & L & 70 & \\
\hline 0.933333 & & L & 66 & \\
\hline 0.966667 & & L & & $\mathrm{H}$ \\
\hline mean & 74.99254 & & 59.48864 & \\
\hline std dev & 6.090876 & & 4.954324 & \\
\hline mean $L$ & 9.507463 & & 25.01136 & \\
\hline data Pts & 53 & 67 & 88 & 32 \\
\hline Total Pts & 120 & 120 & 120 & 120 \\
\hline Freq & 0.441667 & 0.558333 & 0.733333 & 0.266667 \\
\hline File & $\begin{array}{l}\text { H68 Data } \\
85-60 \mathrm{~cm} \\
\text { Number }\end{array}$ & $\begin{array}{l}85-60 \mathrm{~cm} \\
\text { indicator }\end{array}$ & $\begin{array}{l}70-45 \mathrm{~cm} \\
\text { number }\end{array}$ & $\begin{array}{l}70-45 \mathrm{~cm} \\
\text { indicator }\end{array}$ \\
\hline
\end{tabular}

Table 6 Statistical analysis of a large break-up maximum deviation case. 


\begin{tabular}{|c|c|c|c|c|c|c|}
\hline $\begin{array}{l}\text { Data } \\
\text { Series }\end{array}$ & $\begin{array}{l}\mathrm{L}_{\mathrm{Bl}} \\
60-85 \mathrm{~cm}\end{array}$ & $\begin{array}{l}f_{1} \\
60-85 \mathrm{~cm}\end{array}$ & $\begin{array}{l}\mathrm{L}_{\mathrm{B} 2} \\
45-70 \mathrm{~cm}\end{array}$ & $\begin{array}{l}f_{2} \\
45-70 \mathrm{~cm}\end{array}$ & $\begin{array}{l}\mathrm{L}_{\mathrm{B}, \text { total }} \\
\mathrm{cm}\end{array}$ & $\begin{array}{l}\text { St. Error } \\
\mathrm{cm}\end{array}$ \\
\hline H59 & 11.1 & .30 & 26.2 & .84 & 18.8 & 6.0 \\
\hline $\mathrm{H} 60$ & 6.0 & .65 & 28.6 & .30 & 12.5 & 5.5 \\
\hline H61 & 6.0 & .60 & 24.7 & .67 & 8.5 & 6.5 \\
\hline H62 & 7.0 & 1 & - & - & 7.0 & 5.6 \\
\hline H63 & 7.1 & .74 & 18.5 & .38 & 7.0 & 6.0 \\
\hline H64 & 6.8 & .7 & 21.4 & .30 & 6.7 & 5.0 \\
\hline H65 & 7.7 & .63 & 19.7 & .45 & 8.1 & 5.5 \\
\hline H66 & 6.0 & .55 & 25.8 & 38 & 7.7 & 5.0 \\
\hline $\mathrm{H} 67$ & 7.6 & .83 & 22.6 & .22 & 7.1 & 5.0 \\
\hline H68 & 9.5 & .44 & 25.0 & .56 & 12.0 & 5.0 \\
\hline H69 & 9.7 & .67 & 22.0 & .33 & 8.8 & 5.0 \\
\hline
\end{tabular}

Table 7 Break-up length estimates of the large fluctuation visualization data. 